\title{
Perceptual Architecture;
}

Using virtual reality (VR) to define, implement and resolve optimum high density apartment living.

\section{Llewelyn Edmund Griffiths}

A Thesis submitted to the Victoria University of Wellington in fulfilment of the requirements for the degree of Masters of Architecture (Professional)

Victoria University of Wellington

Te Whare Wānanga o te Ūpoko o te Ika a Māui, 

This thesis was conducted under the supervision of

Dr. Antony Pelosi (Primary supervisor)

School of Architecture and Design

Victoria University of Wellington

Wellington, New Zealand

And

Dr. Steve Lamb (Secondary supervisor)

School of Architecture and Design

Victoria University of Wellington

Wellington, New Zealand 
$\begin{array}{ll}\text { ABSTRACT } & 4\end{array}$

INTRODUCTION

$\begin{array}{ll}\text { Research topics } & 6\end{array}$

Design methods $\quad 7$

Principle theorists 9

Scope of design $\quad 10$

Thesis overview 12

PROJECT REVIEW 13

Program overlap 14

High density living 16

High density in NZ 16

Informed architecture 17

Section summary 18

LITERATURE REVIEW 19

Implications of densification 19

Overcrowded stress $\quad 20$

Perception of space $\quad 21$

Virtual reality in design and research $\quad 22$

Section summary 23

METHODOLOGY $\quad 24$

Research overview 24

Techniques $\quad 25$

Methodology in the subject area $\quad 25$

Limitations $\quad 26$

Section summary 26

$\begin{array}{ll}\text { EXPERIMENT METHOD } & 27\end{array}$

Section summary 32

CONCEPT DESIGN

Optimising parameters 33

Perceptual overlap 34

Archiectural principles $\quad 34$

Precedents 36

Section summary $\quad 40$ 
PRELIMINARY DESIGN

$\begin{array}{ll}\text { Pre-evaluation } & 42\end{array}$

Primary and secondary zones $\quad 43$

Form exploration $\quad 45$

Form development $\quad 46$

Material evaluation $\quad 49$

Building iteration $\quad 50$

Building rational $\quad 51$

Facade development $\quad 52$

Confimration study $\quad 53$

Results $\quad 55$

Final preliminary design $\quad 57$

$\begin{array}{ll}\text { Reflection } & 60\end{array}$

Section summary $\quad 60$

DEVELOPED DESIGN 61

$\begin{array}{ll}\text { Precedents } & 61\end{array}$

Removing barriers $\quad 64$

Creating transparency $\quad 65$

Facade rational 66

Structure informing space $\quad 68$

$\begin{array}{ll}\text { Perceptual overlap } & 70\end{array}$

$\begin{array}{ll}\text { Extending width } & 72\end{array}$

$\begin{array}{ll}\text { Optimization of space } & 73\end{array}$

$\begin{array}{ll}\text { Section summary } & 75\end{array}$

$\begin{array}{ll}\text { FINAL DESIGN } & 76\end{array}$

$\begin{array}{ll}\text { CONCLUSION } & 98\end{array}$

Current research 98

$\begin{array}{lr}\text { Future research } & 99\end{array}$

Reflection 100

Acknowledgements 100

$\begin{array}{ll}\text { BIBLIOGRAPHY } & 101\end{array}$

$\begin{array}{ll}\text { Figure list } & 103\end{array}$

$\begin{array}{ll}\text { APPENDIX } & 106\end{array}$ 
In this thesis, perceived space is investigated in a high density architectural context. Understanding how to optimize the subjective space is an opportunity to provide perceptually informed high density architecture. The aims of this thesis are to (1) develop an understanding of the perceived space by establishing optimizable parameters of a volume, (2) form a research through design methodology utilizing virtual reality experimentation, and (3) to apply the research to provide perceptually informed architecture which increases the perceived spaciousness and size of a dwelling. Virtual Reality (VR) improves an understanding of the perceived space compared to conventional design technologies. Firstly, a virtual experiment defined the optimum high-density apartment parameters with the key variables of perceived spaciousness, liveability, and size. During the VR experiments it was discovered that ceiling height and average room width determined separate responses to the perceived space. These were, ceiling height altering the perceived size and average room width altering the perceived spaciousness. Secondly, a VR methodology was utilized to test and resolve the complex issue of perceived space which requires implementation of architectural principles. The defined optimum parameters of room height and width alongside the literature provided the architectural principles to produce optimum perceived spaciousness, size and liveability. The principles include, perceptual overlap, extending line of sight, and primary and secondary zones. Thirdly, design evaluation explored architectural interventions using VR to illustrate the subjective space. I draw on research in design, virtual reality and psychology to develop a methodology that can sufficiently resolve the issues presented by this thesis. The paper argues that to design high-density housing for occupants, architects must have an understanding of perceived space. This has the potential to be achieved with the adoption of my thesis methodology.

\section{Keywords}

Occupant well being, Virtual reality, Perception of space, Densification

All images that have been previously marked will be labelled with * in image caption 

"The next stage in design, which is where we are today, is correcting these problems by developing methods of designing for the needs and capabilities of people" (Norman and Stappers, 2016).

Without people as the primary focus in the design process, architecture will have a negative presence in the built environment (Evans, Wells et al. 2003). By taking people into consideration in the design process, architecture has the potential to create a built environment that adheres to people's needs. Current architecture has cultivated an attitude which leads to architects designing for architects. Therefore, issues surrounding people are not being addressed (Norman and Stappers, 2016). To have people orientated design the design must utilise an architectural method which can explore and incorporate user needs and experience. The built environment can have an immense impact on experience, behaviour and perception (Kopec 2006). Therefore, architects must understand the fundamentals of these qualities and incorporate them into a design methodology.

In this thesis I investigate whether perceptually informed architecture can increase the perceived size and spaciousness of high-density apartments. The thesis aims to (1) develop an understanding of the perceived space by establishing optimizing parameters of a volume, (2) form a research and design methodology through VR experimentation, and (3) to utilize the research to provide perceptually informed architecture. In order to do this I have developed a methodology which investigates how people perceive the built environment to inform design decisions in the design process. Specifically, this thesis will look at perceived space within a high density architectural context. Virtual experiments have defined volume parameters in terms of perceived size, liveability and size. These parameters were then implemented into architectural principles to inform the overall architecture through virtual experimentation and iteration. The design was then resolved through virtual visualisation to ensure a successful incorporation of the design principles towards a coherent architecture. The methodology of define, implement and resolve formulated an architecture considerate of people. This was achieved by controlling the perceived space to improve the living conditions within high density design.

The research will explore three main topics of densification, perceived space and virtual reality (VR). These three topics will situate the design research by establishing frameworks to achieve the thesis aims. All of these topics orientate themselves to the investigation of the high density architecture (Figure 1). Literary research has informed the development of my methodology which incorporates fundamental perception of space alongside VR experimentation to design perceptually informed architecture. 
Figure 1 - Scope of research*

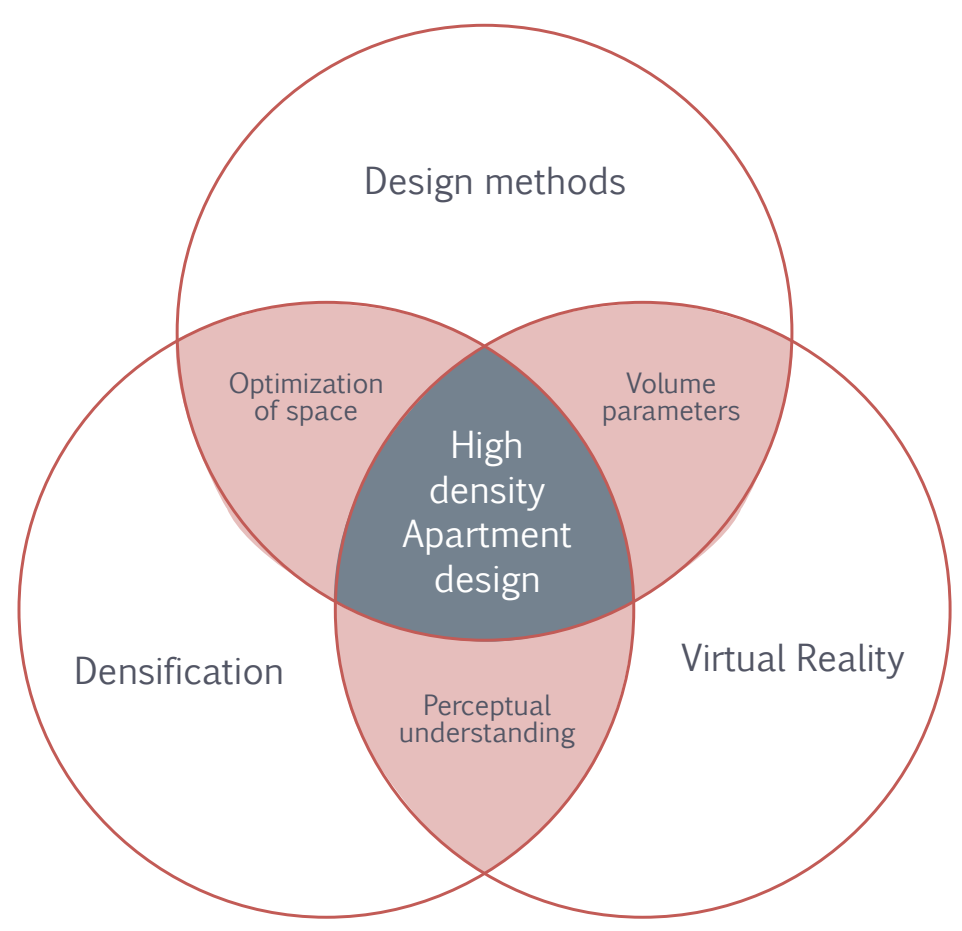

1.2 RESEARCH TOPICS

\subsubsection{DENSIFICATION}

\subsubsection{PERCEIVED SPACE}

Densified living is becoming an increasingly common lifestyle as cities become larger, denser and faster. Many sacrifice space in order to live in the city centre and this has the potential to cause issues in living conditions (kopec 2016). The majority of the time there is minimal room for objective space increase (e.g. square meterage) for apartments. An alternative approach must be taken to create more spacious and liveable apartments. In this thesis densification will be explored through a New Zealand context by confining to the current minimum floor plan requirements for apartments as set by Auckland city council.

It is unlikely that the objective size of high density architecture will increase, so to improve the spaciousness of a dwelling the perceived space must be altered (Stokols 1976). Improved spaciousness is required to generate better high density design which currently has the potential to affect occupant comfort and wellbeing (Solari and Mare, 2012). Overcrowded stress can cause psychological stress (Wells, Evans et al. 2016). Overcrowded stress through physical stimulation and behavioural constraint is largely associated with apartment living and is a serious issue which needs to be addressed (Cohen, Evans et al. 2013). It is known that poorly designed architecture can negatively affect an occupant yet it is not always due to the objective constraint but a lack of subjective understanding (kopec 2016). Without an understanding of the perceived space designers cannot begin to address the issues of densification. Through the understanding of the perceived space optimizing parameters can be established to design the improved living conditions in a high density setting. 


\subsubsection{VIRTUAL REALITY}

\subsection{DESIGN METHODS}
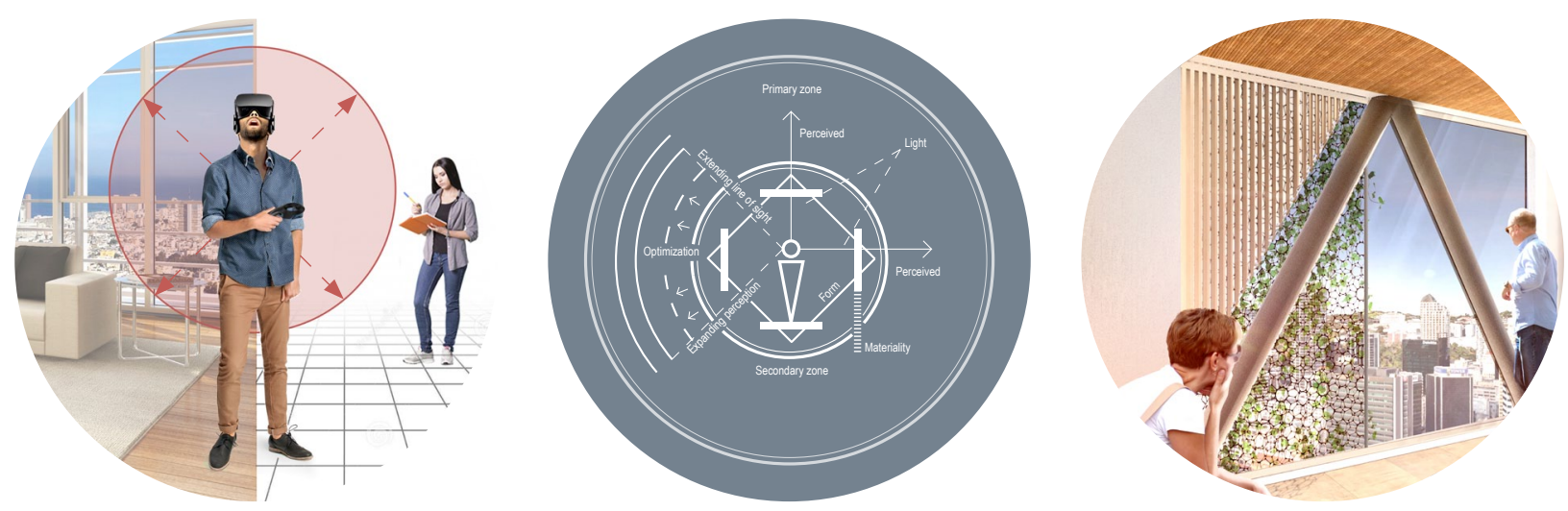
spatial parameters through
VR experimentation, to optimise space to improve spaciousness and liveability in high density design has been explored in this thesis. Perception of space is a complex response as it is a subjective view of an objective environment. It cannot be explored through traditional technologies. First person perspective is imperative to fully understand true spatial qualities (Bowman and Hodges 1999). To design with an understanding of this response an appropriate method or tool must be used (Portman, M., et al. 2015). Virtual reality forms a level of immersion as it puts the designer in a 1:1 scaled environment in a first person perspective (Schnabel and Kvan 2003). By taking a scientific approach the optimum measures to improve spatial responses in high density design can be established. The parameters could not be established to the same detail through another research medium (Maffei et al. 2016). The parameters are a crucial foundation to providing high density architecture which optimizes liveability, spaciousness and perceived size and further development would make more successful interventions.

The design research uses a methodology which can explore the perceived space. It aims to identify the needs and responses of people to incorporate and develop the architecture. VR is used to add additional design understanding alongside $2 \mathrm{D}$ drawings and $3 \mathrm{D}$ representations. This aids in the design process by experiencing 1:1 representation and becoming an active participant within the design (Stouffs et al. 2013). This is crucial to the design process when designing in response to perception of space, because it is the truest representation of architecture that we have (Maffei et al. 2016). The thesis methodology follows a structure of 'Define', 'Implement' and 'Resolve' which breaks down the question and issues to systematically investigate solutions.
Define

Define the perceived experiments to develop an understanding of the issue.

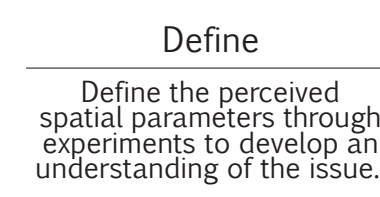

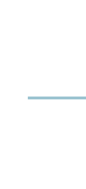

Implement

Implement the research into design principles and evaluate the design translation.

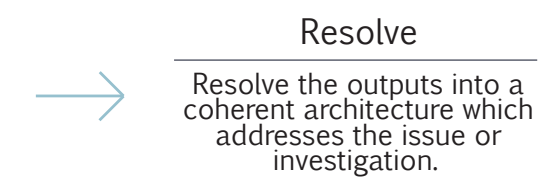

Figure 2 - Thesis components * 
Utilising virtual reality in a design process is slowly becoming more common in research and practice. Currently the primary use of VR in design is client or designer visualisation. However, in this thesis I want to focus on expanding the possible uses of VR. Both sections 'Define' and 'Implement' use a VR methodology to investigate the thesis question (Figure 3). This process aims to develop the use of VR in a design methodology to add understanding within the design process. Define as a research methodology is commonly found in research for other disciplines but not in architectural research. This thesis aims to integrate a systematic process in which to investigate fundamentals of perception to challenge the root of the issue and not just its symptoms. Together the methodological components aim to 'Define' the issue, 'Implement' the research into design solutions and then 'Resolve' a final deliverable.

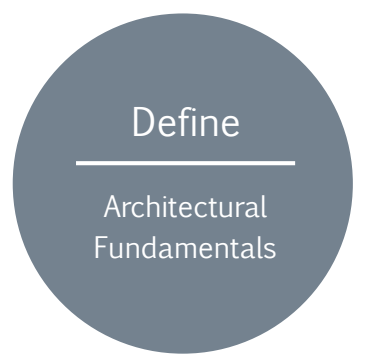

Utilising a Virtual Reality aided research method to establish an understanding of how people perceive space.

New methodology A developing process which is not traditionally used in architecture

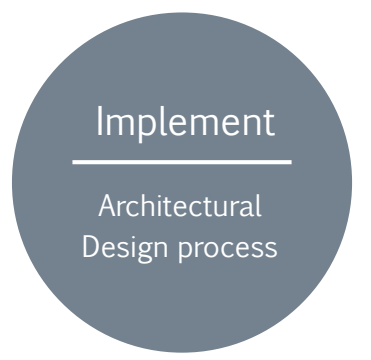

Virtually evaluating how design solutions have incorporated the research to provide architectural principles.

Developing design process

Using VR within the design process to add additional understanding

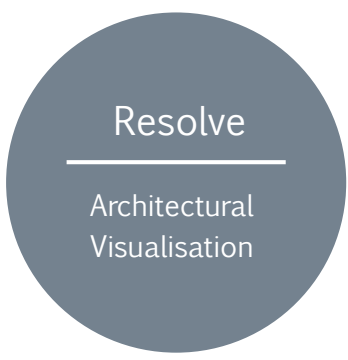

Using Virtual Reality to visualize the finished product, which offers a 1 to 1 representation of an architecture.

Current primary use

Client or designer visualisation towards the end of the design

Figure 3 - VR methodology *

\subsubsection{DEFINE}

The first section defines the fundamental understanding of the perceived space to break down the issues being explored. A scientific process to establish foundational parameters of perceived space establishes an understanding of the problem to be integrated into the design process. A defensible set of optimal design parameters have been established of the height and width of a volume. Volume width was found to affect perceived spaciousness and for ceiling height the perceived size. Typical architectural rule of thumb would suggest that ceiling height has a large effect on spaciousness, which was found not to be the case in these experiments. With this methodology optimising parameters could be found for a multitude of architectural questions and even develop further these current parameters. 
1.3.2 IMPLEMENT

\subsubsection{RESOLVE}

\subsection{PRINCIPAL THEORISTS}

The second section implements the parameters through virtual experimentation to establish architectural principles for design solutions. Components of the design are tested and evaluated in response to the perceived space to create effective solutions. Design questions are established to evaluate and develop the design in VR. Each evaluation session had a specific question or goal to aid in the development of an architecture design in response to the thesis aims. The architectural principles established were extending line of sight, primary and secondary zone, expanding perceived spaciousness and perceptual overlap.

The last section resolves the architecture to coordinate the architectural principles into a coherent final design. The quantitative research supports the qualitative design research, aiding in design decisions to produce the best solutions. VR visualization allows the entire scheme to be recognised and coordinate the multiple components of a design.

This paper contributes to ongoing discussions investigating human responses to densification. For example, the perception of small living environments (Kopec 2006), well-being in apartments, (Evans et al. 2003) and how form affects perception of space (Shemesh, Talmon et al. 2016). These researchers and their work aim to include the perception of space into the design process to improve architecture. Kopec (2006) and Evans et al. (2003) have expressed concerns with current high density housing. They explore key principles to create user informed spaces. This has influenced my process of formulating architectural principles to answer the thesis question.

One of the key contributors to the theory of this thesis is Design $X$ Collaborative. DesignX is an organisation which uses an evidence-based process for answering complex and serious issues, reformulating the role that design can play (Norman and Stappers 2016). Norman and Stappers (2016) from DesignX Collaborative, express that designing architecture for people in response to surface level issues, will not resolve the deeper design problems at hand. Architects need to, "concentrate on human needs, exploring issues in detail to find root causes, aiming to attack the fundamental problems" (Norman and Stappers 2016). This informed the thesis direction to explore the fundamentals of perception of space to incorporate into a methodology which considers human perception and response.

Hayward and Franklin (1974) research the perceived space to formulate an equation to calculate perceived enclosure. They conclude that the relationship between height of back wall $(H)$ / distance to back wall $(D)$ to perceived enclosure (E) are the key variables. This formed the equation $E=H / D$ to determine the perceived enclosure of a space. This equation sets a foundation to our understanding of perception of space and aided in the formulation of the thesis experiment. 


\subsection{INTRODUCTION}

\subsection{SCOPE OF DESIGN}

Three developed dwelling types of one, two and three bedrooms and supporting spaces of circulation and public areas within a high density residential building have been designed. The base of the building has been considered out of scope as this would typically be of retail, parking or office program which is not relevant to the thesis topic (Figure 4). My concepts were designed alongside the methodologies constructed during the research process. The design was an opportunity to test the methodologies of my thesis. The research and insight gained during this project, is transferable knowledge that could benefit future designers who aim to optimise people experience within architecture.

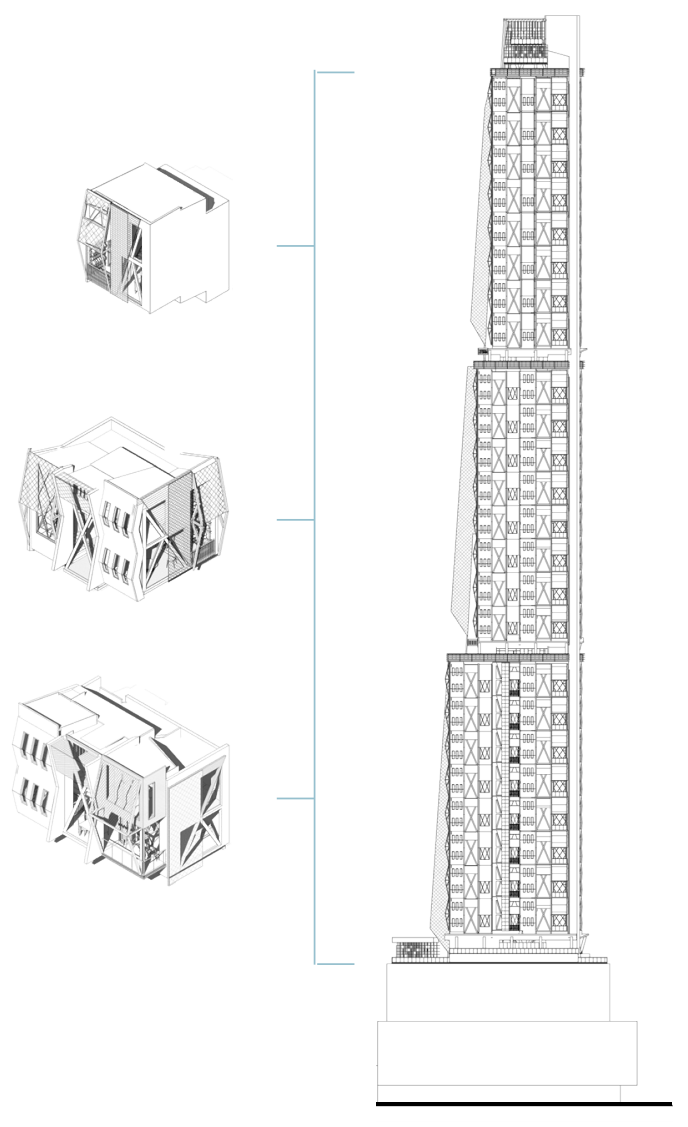

Elevation SE

$1: 2000$

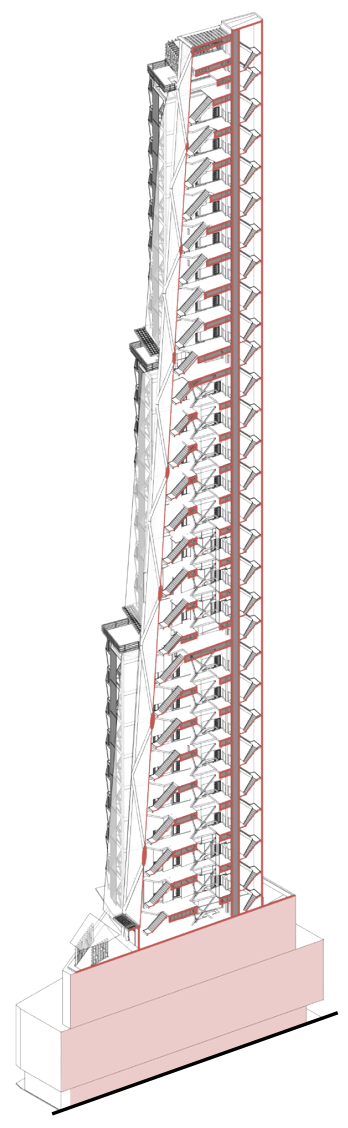

Building Section

$1: 2000$

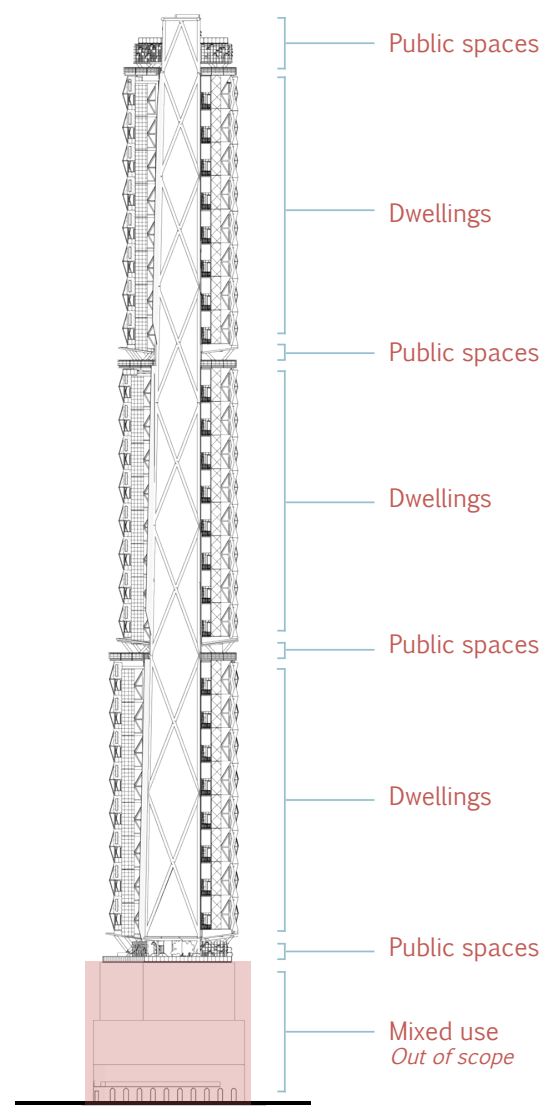

Elevation NE

$1: 2000$

Figure 4 - Scope of design * 

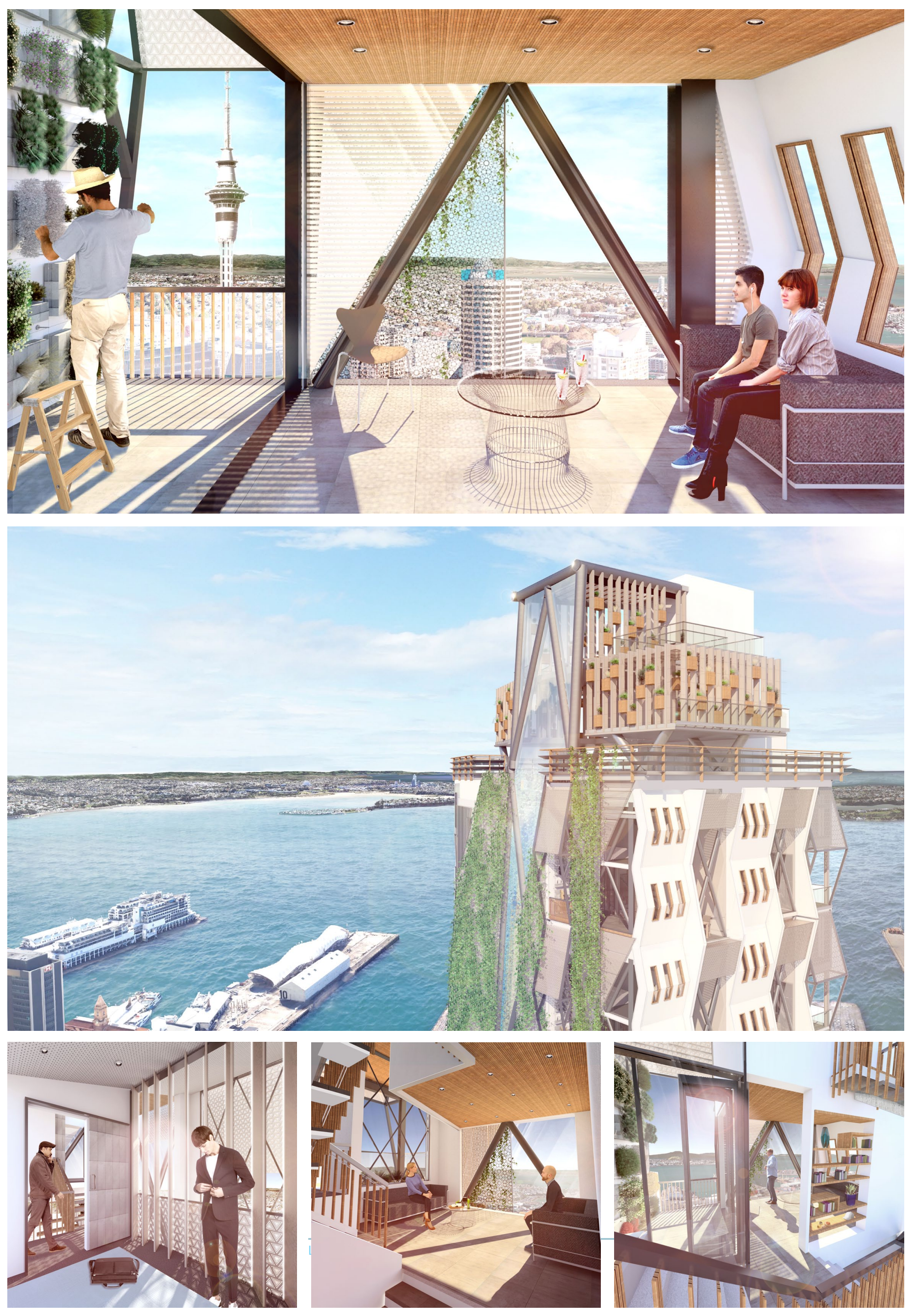


\subsection{INTRODUCTION}

\subsection{THESIS OVERVIEW}

In the next chapter a project review will discuss and critique architecture to illustrate current high-density design and solutions found in alternate architecture typologies. Chapter 3 defines the methodology of this thesis and elaborates on how these issues will be explored and developed through the duration of the thesis. A literature review in chapter 4 collates relevant research and ideas to provide an in depth understanding on the thesis issue and possible solutions. Chapter 5 then details the method of the VR experiments for quantitative research and establishes the key parameters. Chapter 6 and 7 revise the limitations of the experiment and detail the virtual experimentation process in the preliminary design which employs research and theory to form an architectural response. The developed design in chapter 9 follows a similar structure in more detail reviewing the preliminary design and resolving the final architecture. 
This chapter will review a series of projects which use architectural strategies to challenge issues of densification. The investigation will explore a range of building types to establish possible directions for perceptually informed architecture. This chapter focuses on four main points; program overlap, high density design, high density living, and informed architecture. One of the outcomes of this chapter is establishing that one reduced quality must be met by an increase of another. Each design uses different strategies to resolve this issue. To optimise the perceived space these qualities must be investigated and their effect of subjective space.

Figure 5 - Pyramid scheme - Patchwork Architects (MitchellAnyon, 2016).

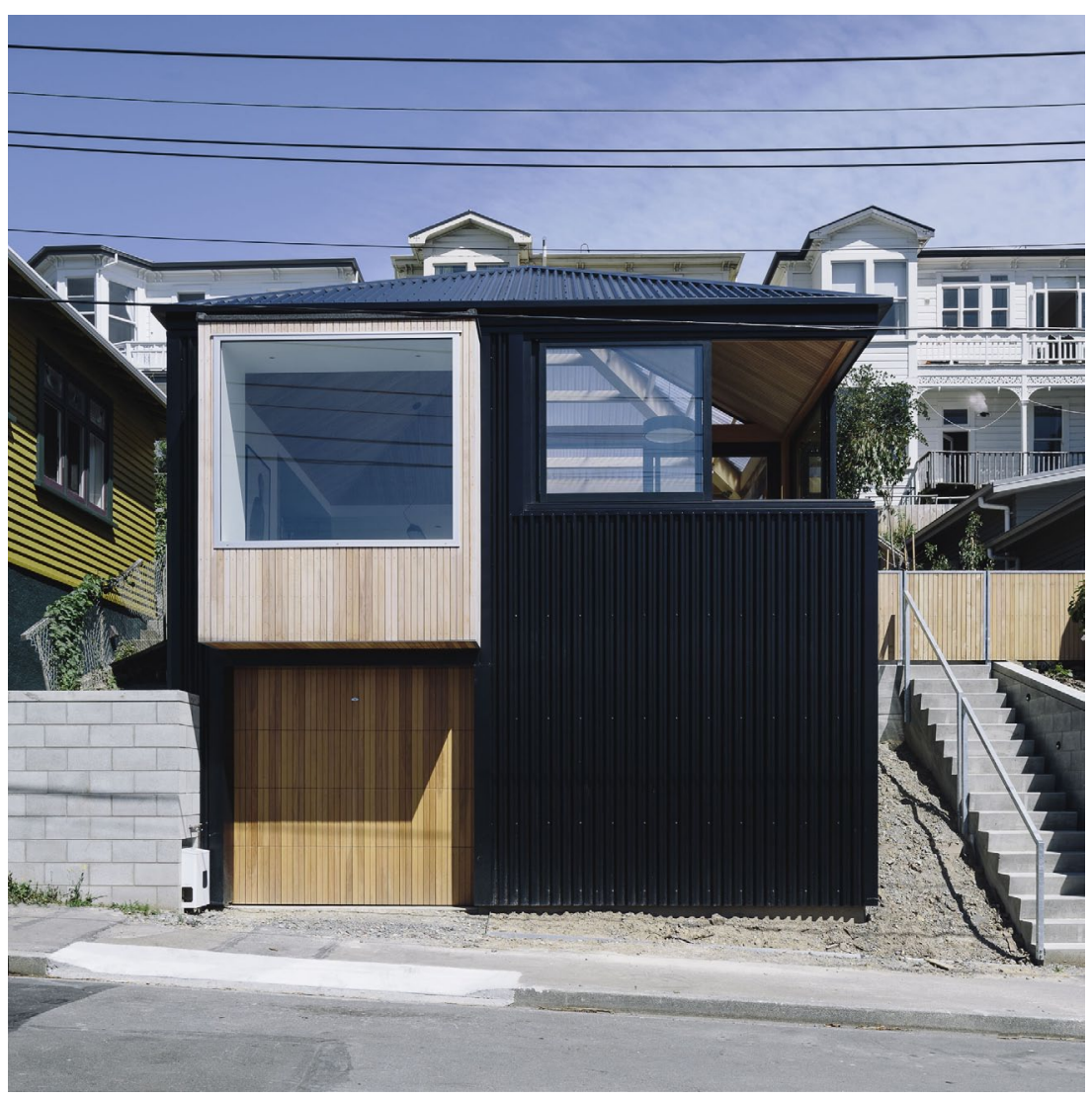

"If you are going to design small spaces, you need to provide generous helpings of other qualities. Volume, light, connectedness, views and materiality all help to create spaces that feel great to be in" (Patchwork Architects, 2017). 
1.6 PROGRAM OVERLAP

Figure 7 - NArchitects Carmel Place 24 - 33 m2 dwellings (Baan, 2016). Micro-apartments award winners in New York

Figure 8 - Small space, big ideas: living in pocketsized apartments (Soo, 2016).

Figure 6 - 60-square-foot $\left(5.5 \mathrm{~m}^{2}\right)$ apartment in Hong Kong (Siu, 2017).
A common strategy used in high density architecture is program overlap. This maximises the efficiency of floor area by allowing the occupant to switch between programs in the same space (Wells, Evans et al. 2016). Hong Kong, with the 4th highest population density of 6,683 People per square kilometre (UN 2015) has examples of extreme high density architecture, as seen in figure 6 . In central Hong Kong $5.5 \mathrm{~m}^{2}$ apartments are lived in by many, only holding the absolute essentials (Lau and Leung, 2001). In many of these situations an increase of space isn't obtainable, leaving only the subjective space to improve living conditions. 'Pocket sized' apartments (Figure 8) investigates how to offset the effects of program overlap by carefully considering form, materiality, light and views to improve the spaciousness and liveability. However, this approach while addressing these issues doesn't improve our understanding of the perceived space or provide concrete methods in which to achieve more liveable small spaces.
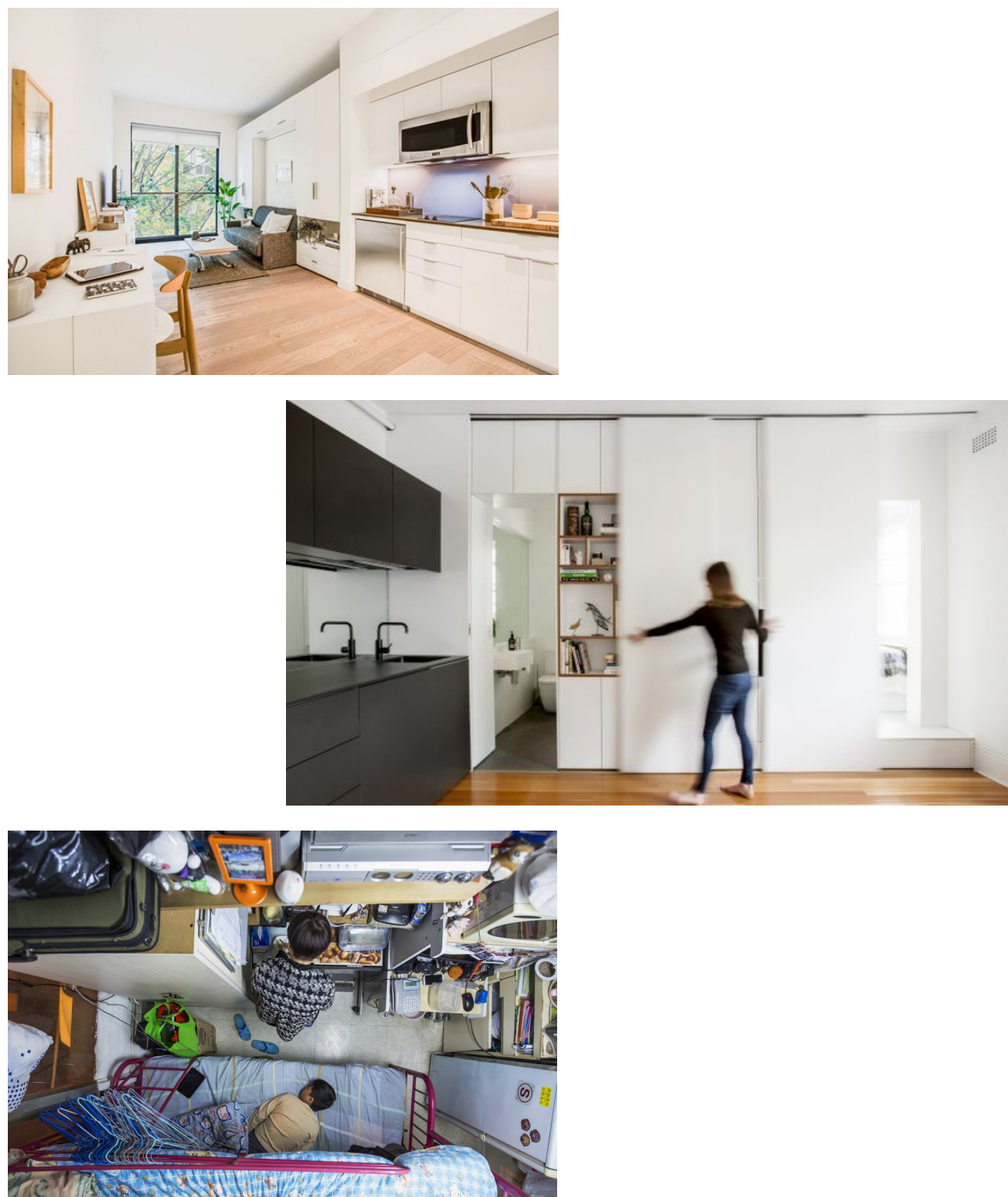
Figure 10 - Suzhou Zhongnan Center, completed 2014 Hotel/ Residential/Office, Suzhou, China (SOM, 2013).

Figure 9 - The Shanghai Tower, completed 2015 Hotel/Offices Shanghai, China (Gensler, 2013).

Figure 11 - The Interlace, completed 2013 Residential complex, Singapore (Baan, 2015). 2015 building of the year.
Another example of program overlap are the micro-apartments of New York city. Carmel Place, which won the Adapt NYC award (Figure 7), was chosen for its innovative layout and building design, with nearly 3 meter ceilings and Juliet balconies that give residents substantial light and air (Brake, 2016). Narchitects designed with the aims to achieve apartments which were spacious, comfortable and flexible. While initially these apartments were taken well, later interviews suggested that long term stays could affect occupant comfort. Kopec in an interview stated "Sure, these micro-apartments may be fantastic for young professionals in their 20's, But they definitely can be unhealthy for older people, say in their 30's and 40's, who face different stress factors that can make tight living conditions a problem" (Urist, 2016). This would suggest the program overlap employed in micro apartment design can not provide adequate living conditions for the large diversity of people who are affected by this growing demand for high density housing. Architectural principles are needed which can explain what is happening in a perceived space to illustrate what is successful and unsuccessful. Establishing principles of spatial optimization within design constraints is essential to improve spaciousness in high density design. These principles are not currently accessible in the architectural profession. To establish these principles to improve spaciousness design, specific research must be supported by a fundamental understanding of perception. The next section will investigate precedents which have successfully improved the spaciousness of design.
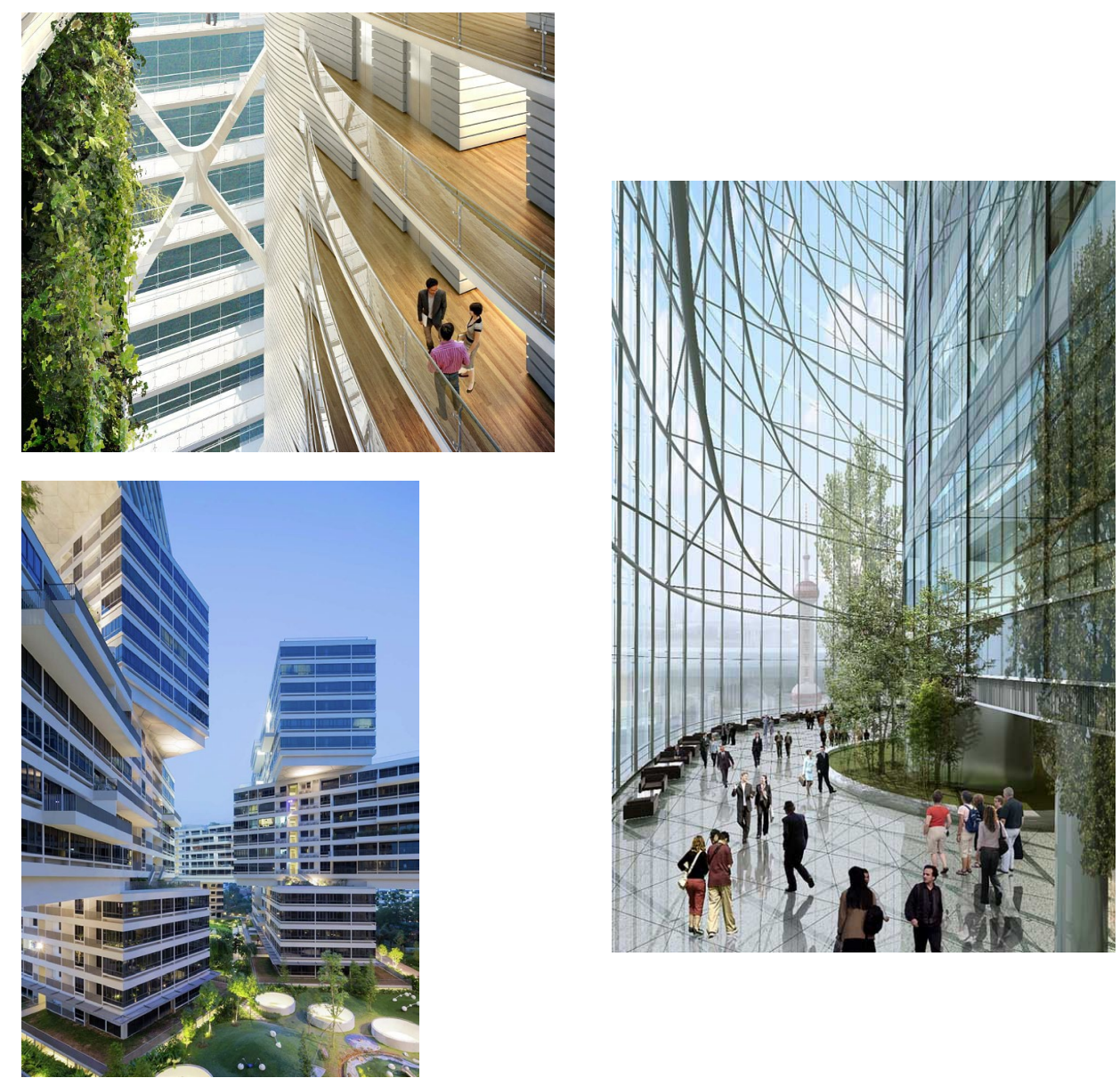
High density design, recognised for its design excellence, has utilised strategies of secondary spaces to ensure successful high density living situations. The Interlace (figure 11) is an example of conscious architecture which designs in accordance to occupant needs. This has achieved world class status with $60 \mathrm{~m}^{2}$ apartments. Carefully designing the interior of the dwelling and providing secondary spaces such as courtyards, gyms and pools, create environments which appear pleasant and spacious. This is also seen in the shanghai tower (figure 9) and suzhou zhongnan center (figure 10) which have architecturally designed circulation spaces which connect the secondary spaces and formulate a greater perceived space through expressing the volume of the building. When occupants make the decision to move to a higher density building they lose immediate space "but they're gaining access to a series of amenities, like a gym with floorto-ceiling park views, a lobby with a public garden" (Urist, 2013). This strategy, similar to increasing other qualities, offers shared spaces as a compromise to reduced living areas. This allows secondary programs to be removed from the dwelling and translate through the building. As consequence the occupant is removed from the confines of the dwelling walls both visually and physically. This strategy could also be internalised by breaking down the dwelling programs into primary and secondary zones to formulate a program hierarchy within a dwelling. If this strategy has been successful on a large scale it could be utilized on smaller scales with a similar result. I intend to extend this research into my own design.

2.3 HIGH DENSITY IN NEW ZEALAND
High density housing is not a social change that all New Zealanders want, some express that it's 'not the kiwi way' (Edmunds, 2017). Nonetheless, high density design is an increasing proportion of the housing market. The 2016 Auckland's Unitary Plan aims to increase housing density by recommending that $25 \%$ more properties be zoned for townhouses and apartments (Council, 2016). Currently Auckland has restrictions on apartment sizes with a minimum floor size of $50 \mathrm{~m} 2$ for one bedrooms, $70 \mathrm{~m} 2$ for two bedrooms and $90 \mathrm{~m} 2$ for three bedrooms. Other restrictions of minimum light penetration and ceiling heights help to keep a minimum living standard for apartments. While these requirements retain a minimum architectural standard they do not provide the insight needed to optimise the perceptual efficiency of high density design. Architectural principles with an understanding of the perceived space has the potential to enable designers to improve high-density design. These architectural principles are not currently available. With a large portion of New Zealand's proposed housing development being of medium to high density it is imperative that designers can provide perceptually informed architecture. Examples of high density buildings to be completed in 2018 in Auckland are the Customs Residential (Figure 12), Pacifica (Figure 13) and Wynyard Central (Figure 14). 
Figure 12 - Customs Residential, 50 story residential building. Completion 2018 (Thorp, 2016).

Figure 13 - The Pacifica, 57 story residential building. Completion 2018 (Plus Architecture NZ, 2017).

Figure 14 - Wynyard Central, 12 story residential complex. Completion 2018 (Willis Bond \& Co, 2016).

\subsection{INFORIMED ARCHITECTURE}
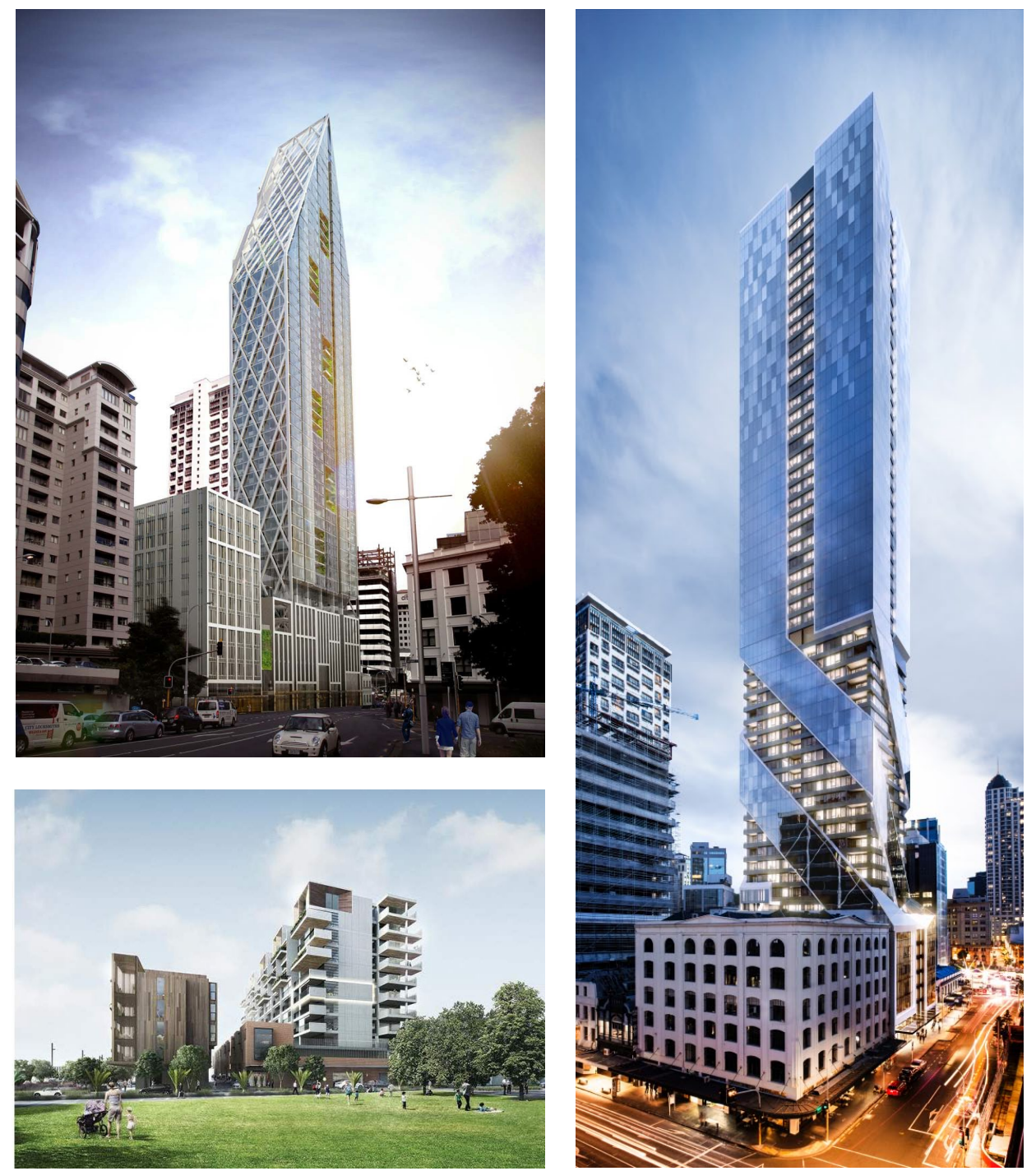

Student accommodation in Germany has taken a revolutionary turn allowing student apartments to be as small as $12 \mathrm{~m} 3$. This has proven to be largely successful due to the research driven design strategies (Paul, 2012). The 'lifestyle student project' was established to provide better informed student housing where there was few options in Germany (Figure 15). Many strategies are used to enhance rooms through a mezzanine bedroom, a roof terrace and the ability of students to paint the fronts of their flats. These elements contribute to the personalization of space and a greater subjective space. This housing community meets the needs of the residents and removes any unnecessary elements to provide cheap enjoyable living, two key requirements for students. The sizes and programs of the units were established for a student demographic through researching their needs. By using a systematic research method to understand and establish the needs for the occupants the architecture was able to achieve its goal. This approach could be taken for professionals and families in a high density context to understand the requirements 


\subsection{PROJECT REVIEW}

of perceived spaciousness. Chapter 4 explores the thesis methodology to investigate and establish optimizable parameters to understand and improve the perceived space in a high density setting.

Figure 15 - Olympic Village Student Quarters halls of residence Munchen, Germany (Raibold, 2016).

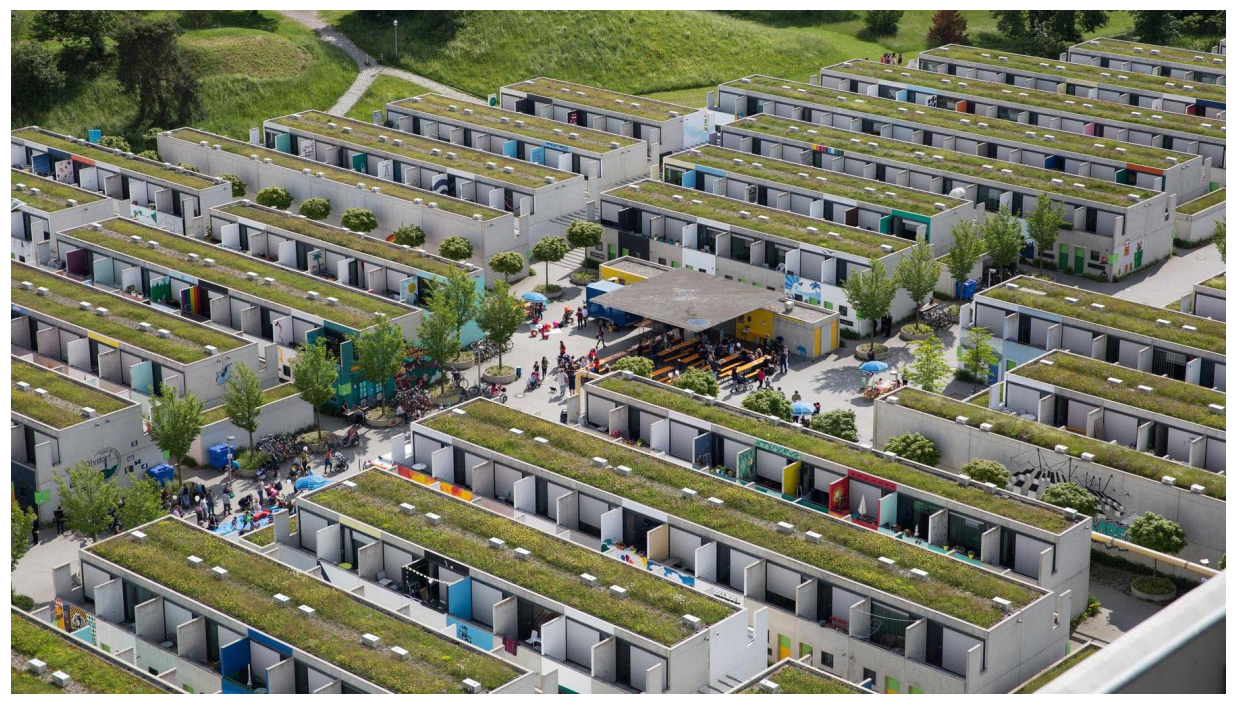

There are a range of approaches to densification in architecture. Program overlap is commonly used to maximise the efficiency of a space. Whether this strategy can afford a larger perceived space will be discussed in the following chapter. Current implemented strategies need more consideration in high density architecture to ensure spacious living environments. This chapter has illustrated that when reducing a quality of a space an increase of other qualities must be employed to ensure successful architecture. However, these precedents cannot provide insight into the fundamental qualities of the perceived space. Further research through a literature review and experimentation is needed to answer the thesis question. In chapter 3 a literature review will explore the implications of densification and review alternate strategies to increasing perceived size and spaciousness. 
Before investigating how to change a perceived space I looked at the fundamentals of perception and the effects of high-density design. Four topics will be discussed with the thesis question in mind. The headings are; Implications of densification, overcrowded stress, perception of space and virtual reality in design and research. In the first two topics discussion regarding issues of densification will illustrate the importance of perceptual understanding. This leads to theories looking at changing perceived space as a way to improve these issues. The following topics look at methods to explore these concepts alongside design theory. This chapter aims to identify the current issues of densification and explore the theoretical possibilities to increase the perceived spaciousness and size of dwellings through design.

Keywords: Occupant wellbeing, Virtual reality, Perception of space, Densification.

3.1 IMIPLICATIONS OF DENSIFICATION
Densification is an inevitable consequence of growing city populations. Projections estimate that by $205075 \%$ of the world's population will be living in cities compared to $50 \%$ in 2007 , and $10 \%$ in 1900 (Nations, 2014). Currently $24 \%$ of urban density around the world is between $10,000-100,000$ people per square kilometre. In 1939 while urbanisation was increasing in Berlin the population density decreased from 29,000 to 5,600 people per square kilometre (Nations, 2014). The population increased by three million people and 800 square kilometres as the city expanded at a significant rate (Bosselmann, 2012). However, once cities reach a certain size, a rate of expansion is no longer sustainable or possible resulting in an increased rate of population density. The $50 \%$ urbanisation increase from the 1900's to the present has resulted in the top 26 largest urban areas in the world to have a population density which is increasing more rapidly than expansion (Cox, 2015). The reduced size of living environments is a consequence of increased population density. Densified living environments can result in discomfort and dissatisfaction, especially in high density housing (Wong et al., 2009). Densification can cause issues in living situations, affecting occupant well-being which needs to be addressed. Simply creating larger high density spaces is not a viable solution as the available space decreases as population density increases (Worchel, 1978). This exert has been taken from the ASA international conference (Griffiths L, 2017b, p. 1)

A solution is needed which designs in response to the perceived space to optimise the perceived spaciousness and size of dwellings. This has the potential to improve the liveability of the high density housing through perceptually informed architecture. 
Evans (2003) explores the unique challenges found when designing for 3.2 OVERCROWDED STRESS high density apartment living. The discoveries in housing and mental health express a common understanding in the fields of environmental and social psychology that densification in urban living can have negative psychological effects on occupants. This leads to the phenomenons of visual overcrowded stress which have been referred to as 'clutter' (Kopec 2006). Clutter is the built environment which visually constrains the individual. Clutter is more commonly thought of as items which are left in an unorderly fashion, yet the built environment itself can cause visual clutter.

By creating smaller living spaces there is a potential to affect the overall well-being and comfort of the occupants (Kopec, 2006). This can lead to living dissatisfaction, discomfort, and in serious cases depression and violence (Solari and Mare, 2012). The most common social effect of densification is overcrowded stress. Overcrowding has three main manifestations (1) stimulus overload, (2) behavioural constraint, and (3) ecological orientations, each of which have either a social or physical evoker (Stokols et al., 1973). Densification in an apartment context largely contributes to overcrowded stress with stimulus overload from physical stressors, to which the built environment effects. Evans et al. (2003) while discussing the factors of overcrowded stress suggests that reducing it is essential for high density housing which can more positively affect occupant well-being.

An increase in psychological space has the potential to reduce the negative psychological effects of overcrowding stress. During an investigation of crowding and density Stokols (1976) suggested that "perceived crowding might be reduced through cognitive or perceptual strategies designed to expand psychological space" (p.69). This indicates that a designed space could alter an individual's perception of space and density resulting in an increase of wellbeing and comfort. Baldassare (1979) found that subjective ratings of perceived crowding correlated strongly to the prediction of living discomfort. People were able to determine the environmental quality of a space through perceived density. This suggests that architecturally designed rooms can improve the wellbeing and comfort of occupants in densified environments by altering the perception of space. This has been supported by Cohen et al. (2013) who discuss the effects of 'crowding' to be a largely subjective response to densification. Booth and Cowell (1976) also tested objective and subjective crowding relationships through survey responses. Thirty-three relationships between density and stress were measured. Twenty-one were of subjective measures of crowding, whereas twelve were of objective measures. If perceived density is largely influenced by subjective measures it would suggest that perceived density can be changed with minimal change to the objective measures. This exert has been taken from the ASA international conference (Griffiths L, 2017b, p. 2) 
Without an explicit understanding of the perceived space and the implications of 'bad design' high-density design could result in living conditions which negatively affect the occupants further.

People perceive the world around them uniquely on an individual level, but there are fundamental laws that define how people experience the physical environment (Evans and McCoy, 1998). This leads to question how the laws of perceived space can be tested to understand perceived spaciousness and size to alter a perceived space. Hayward and Franklin (1974) discuss the relationship between the built environment to perceived openness or enclosure. They conclude that a lower height of back wall $(\mathrm{H})$ divided by the distance to wall (D) has an increased openness. "..impression of openness-enclosure of architectural space is determined by sizedistance relations regardless of actual scale of space. As the value of the H/D ratio increased, perceived enclosure also increased" (Hayward and Franklin,1974, p. 39). The experiment conducted in this research was highly abstracted in practice and does not serve as an adequate equation to challenge densification. Rather this research acts firstly, as insight into the foundational information on the perception of space, and secondly as precedent to informing studies involving perception of space. Sadalla and Oxley (1984) also explored this concept with a series of experiments. From these Sadalla and Oxley (1984) concluded that ratios of a rectangular room greatly influence the perceived size. The understanding of perception within a rectangular form concluded that a greater ratio of length/width implied a larger perceived space. In both of these experiments the fundamentals of perception of space were tested in regular cubic and rectangular form. However, this leaves a gap in understanding around perception of space in irregular form. Typical apartment design is not of regular form so to improve our understanding of perceived density an exploration of perceived space including irregular form in necessary. This exert has been taken from the ASA international conference (Griffiths L, 2017b, p. 3)

The research discoveries in housing and mental house outlines that "Adults in crowded homes suffer less psychological distress when the housing unit has greater depth (Depth = number of interconnecting spaces)" (Evans, Wells et al. 2003). The depth of the rooms allows a visual connectivity through the spaces to form larger perceived spaces. Kopec (2006) also investigated architectural strategies to reduce the negative effects of densification. Kopec suggests that these design strategies can be used to minimize stress and maximize user satisfaction to create more comfortable spaces that will meet the needs of the occupants. However on reading I found the architectural implications and applications of psychological design too general. Explicit architectural principles are required to create perceptually informed research which architects can use. Further investigation of principles and solutions are needed in the field to better inform architecture. 
REVIEW

3.4 VIRTUAL REALITY IN

DESIGN AND RESEARCH
Avishag Shemesha et al. (2016) discuss Virtual Reality (VR) methodology and methods for experimentation in a human oriented context. For their study they conducted experiments to understand the relationship between geometry and subjective perceptions on non-designers or designers. One output of this study concluded that curved geometries were seen as more aesthetically pleasing by non-designers. This is also expressed by Yildirim and Akalin (2009) who looked at satisfaction in living room's in response to geometry. The process used to answer these questions offered valuable insight into the research area. Geometry can either increase or decrease comfort or desirable space objectively. These experiments of the perceived space used methodologies other than VR due to the limitations of VR at the time. VR is now at a reliable level and more advanced to conduct research, becoming commonly used for experimentation in the topic areas (Portman et al., 2015).

Perception of space is a complex response as it is a subjective view of an objective environment. It cannot be explored through traditional technologies as a first person perspective is imperative to fully understand the spatial qualities. To design with an application of the understanding of this response, an appropriate method or tool must be used. Bloomer and Moore (1977) discuss the importance of the human body in architecture for understanding spatial qualities. The understanding of visual perception is discussed to have a lasting effect on architecture and spatial awareness. This leads me to question the drawing mediums of 2D and 3D technologies to approach this problem. These methods, like any other, are an abstraction of space either represented in 2D or 3D form. Each drawing method has its place in the design process (e.g. conceptual drawing). Moreover, VR technology enables additional understanding, by allowing investigation into areas that other mediums can not access. "We believe that the most essential and memorable sense of three-dimensionality originates in the body experience and that this sense may constitute as a basis for understanding spatial feeling in our experience of buildings" (Bloomer and Moore 1977). To design critically in response to the perceived space there must be a level of immersion to fully understand it. Virtual reality forms a level of immersion as it puts the designer in a 1:1 scaled environment in a first person perspective (Schnabel and Kvan, 2003).

The next issue is that perception of space is subjective. Bowman and Hodges (1999) discuss VR's removal of the designer as an external observer and repositioning them as an active participant. The perceived environment is experienced by the designer or subject which allows a subjective interpretation of the design. Providing a more true form in which to experience a design, allows for the removal of incorrect interpretations which comes with abstract designs from drawing mediums. Thus, the subjective interpretation of a space comes from the architecture itself, rather than the abstraction of the drawing representations. This is imperative to designing environments in response to perceived space. This is supported by Schnabel and Kvan (2003) who have done research on understanding space through VR. They conclude in their research 
that "..these tools have significant contributions to the design process by enhancing perception and understanding of 3D volumes" (Schnabel and Kvan, 2003, p.446). Portman (2015) also investigates the use of virtual reality (VR) environments for research and teaching in the context of the architectural discipline. It was discussed how VR has the ability to be utilized in a design laboratory setting and in a visualization/creative designing setting allowing both quantitative and qualitative design research.

Key points have been established in this chapter. Densification can affect occupant comfort and well being, perceptually informed architecture has the potential to increase the spaciousness and size of high density housing without increasing the objective size. Architectural principles can be used to manipulate the perceived space, and VR is a crucial tool in the formation of perceptually inform design. The following chapter explores how the thesis methodology is used to take these findings and develop methods to establish volume parameters and architectural principles.

I will next address how these theoretical discussions will be applied into design through the methodology of the thesis. 


\subsection{RESEARCH OVERVIEW}

Figure 16 - Thesis methodology
The technologies employed by architects in modern practice has changed dramatically over the last few decades. 3D computer modelling and BIM have revolutionised how architects draw and think. New methodologies have and are developing which incorporate these new technologies and the fast pace requirements of the industry. These tools add another sequence to the process providing additional architectural understanding. To investigate the issues of the thesis question a typical architectural method will not suffice. Design which relies entirely on 2D and 3D drawing techniques will not allow a sufficient architectural understanding of the perceived space. A new architectural methodology must be employed to provide additional information of the architecture. VR has been chosen to aid in the design process and has subsequently become an important element to the methods used. The methodologies for this thesis includes an experiment, strategy formulation and design evaluation. Each of these methods combine to achieve the design goals to understand the perceived space, form architectural principles in response to the research, and then implement the principles into an architecture. The benefits of VR will be expressed and would be beneficial to any modern architecture methodology.

The methodological process takes the aims and objectives of the thesis and investigates the issues sequentially through experimentation, strategy implementation and design evaluation (Figure 1). The experiment takes a scientific process to establish a fundamental parameters for the thesis question with quantitative measures. This provides an understanding of the design space which can then be utilised through strategy implementation. This scientific process uses a combination of experiment research and literature to formulate architectural principles which can be transferred in the creation of design solutions. The final sequence is design evaluation where the design is formally critiqued through VR design iterations to find the optimum architectural solutions.

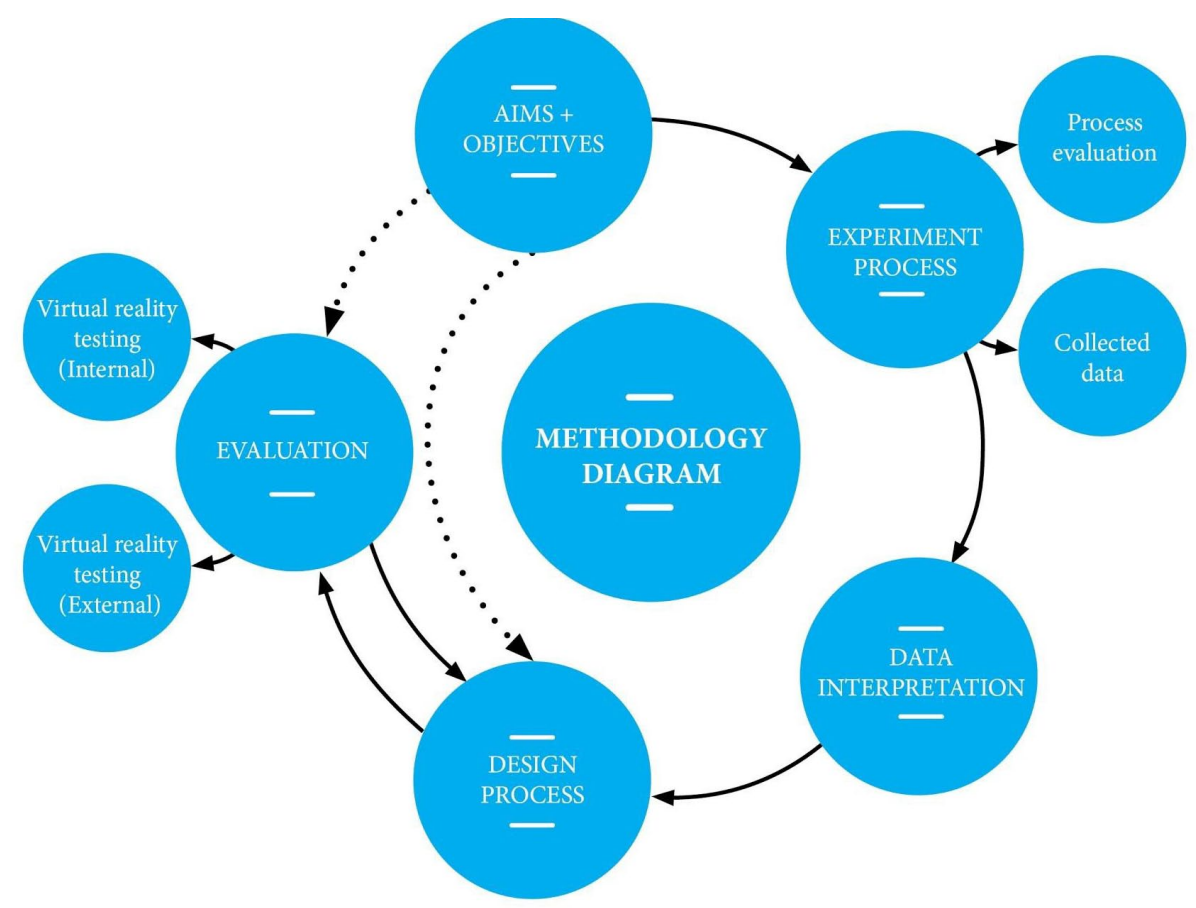




\subsection{TECHNIQUES}

\subsection{METHODOLOGY IN} THE SUBJECT AREA
Virtual Reality (VR) is a crucial addition to design research mediums which increases an understanding of the perceived space. VR has been utilised in two ways, experimentation and evaluation. Experiments have been conducted in the first half of the research to answer whether volume proportion affect perception of space. Optimizable parameters were established as a result. Evaluation is then used to support design decisions tested in VR to develop and apply the experiment research. The thesis question, how can architecturally designed volumes increase perceived size and spaciousness of high-density apartments? is asked in this process. Perception of space is difficult to understand through traditional design techniques as they are a manipulation of the real (Portman, M., et al. 2015). 2D drawings and 3D modelling only offer a representation of a space and cannot fully illustrate the perceptual qualities of an architecture. To achieve a design solution an empirical and informative approach must be taken.

A series of experiments established optimal volume parameters to produce the largest perceived space. The aims of the experiment were to investigate how volume arrangement and proportions affect perception of space and perceived density. The experiment used a volume matching exercise to establish the characteristics of perception of space informed though volume shape. This has led to the understanding that ceiling height and room width are the two key parameters which effect the perceived space. Ceiling height altering perceived size and room width the perceived spaciousness. The method of the experiment is discussed in more detail in chapter 5 .

Evaluation sessions were established to evaluate and develop the design in VR. Each evaluation session had a specific question or issue which needed resolution in response to the thesis aims. The evaluations consisted of internal evaluation and external evaluation using a reflective critique in VR. External evaluation consisted of sessions with either supervisors, colleagues, or participants, where the design was evaluated using specific anchors. This allowed the project to be grounded by the aims of the thesis through the structure of the evaluating process. The evaluation process is discussed in more detail in the preliminary design within chapter 7 .

Experimentation and evaluation through virtual reality is becoming a common method of exploration within the subject area. VR has the ability to illustrate immersive environments and allow them to be experienced in first person perspective (Schnabel and Kvan 2003). This offers an opportunity to test designs in realistic scale before they are built, which has previously not been possible. In past studies of built environments in VR the technology only allowed abstractions or simplifications of a space. The technology is now in a position to allow more in depth exploration of immersive environments (Schnabel and Kvan, 2013). This provides more validity to results as this current technology has the most in-depth environment and realistic movement, overall offering the closest real world representation. 


\subsection{LIMITATIONS}

4.5 SECTION SUIMIMARY
When discussing the issues in the architectural world Design $X$ Collaborative expressed that there is an 'emphasis on appearance'. This has been problematic for people within architecture as their experience and use of the space becomes less important in the design process. "The next stage in design, which is where we are today, is correcting these problems by developing methods of designing for the needs and capabilities of people" (Norman and Stappers, 2016). Some architecture has formed methodologies which do not represent people experience, alientating them as a result. Portman (2015) discusses the methods which are suggested to have the most potential in the discipline to solve this issue. The methodology utilised in Portman's research "take the form of retrospective, cross iteration comparisons through which the first stage investigates research questions and the following stage can develop design alternatives based on the extracted research results." (Portman, Natapov et al. 7). This allows design decisions to be informed by an iterative process based off objective research. This has informed my methodological structure of experimentation and evaluation. Due to the thesis question an objective understanding of densified architecture is required to improve and employ a perceptual understanding.

The literature which explores perception of space predominately comes from pre 2000's, meaning outdated methods have been employed in the majority of the literature (Hayward and Franklin,1974, Gärling, 1970, Sadalla and Oxley, 1984). Nowadays, VR technology has developed substantially, allowing for a re-examining of this topic in the architectural discipline. Critics have discussed the possibility of VR being just another abstraction of the real world, rather than a true representation. However this could be disputed with the research conducted by Anders Hermund (2017) who has investigated the translation of real world and virtual world eye tracking to express the similarities between VR and real experience. It was argued that to receive research out of these spaces you do not need 100 percent realistic environments because the mind fills in spaces, any gaps. This equates to VR being a viable research tool that, although, is still in a developing stage is currently the best tool that can be used to understand spatial qualities without physically building them (Avishag Shemesha et al. 2016). Although there are limitations of VR in regards to the mechanics and visual systems (Stouffs 2013, Maffei 2016), VR advancements allow for more in-depth experimentation that have previously not been possible.

The methodology of experiment and evaluate utilizes both quantitative and qualitative research methods to sufficiently explore the thesis question. This approach has been developed through the literature to provide an appropriate methodology to complete the thesis aims. The experiment method in chapter 5 breaks down the VR experiment methods, providing insight into the techniques used during the qualitative research methods and the production of established parameters. 
The current study uses Virtual Reality (VR) to experimentally investigate how room shape and volume affect perception of space and perceived size to identify optimal design for densified urban apartments. Optimal parameters are defined as (1) room shape that produces the largest increase in perceived space with the smallest increase of objective space (2) rooms that produce high perceived spaciousness and livability ratings. Participants experienced a series of virtual rooms of different shapes and volumes, and were asked to scale a cubed reference room to match the size of the target room. While room shape determined the accuracy of the spatial perception it is suggested that the optimum parameters of ceiling height and room width affect perceived spaciousness and liveability. Defining optimum parameters of room height, width and shape are foundational to providing strategies in apartment design to produce optimum perceived spaciousness and liveability. This research aims to firstly, develop a new method for studying optimal architectural design parameters, and secondly study the relationship between perceived space, shape and volume to form optimum parameters. Future research can then build on these parameters and introduce more complex parameters to produce defensible architectural strategies for optimizing high-density design. This exert has been taken from the ASA international conference (Griffiths L, 2017b, p. 1)

The full conference paper is located in the appendix, pages 106-115. The paper summarises key findings from my thesis and the processes undertaken. Please read through to understand how the optimal high density parameters were established. The following diagrams were used in my final presentation which add illustrations to explain what the graphs are showing (Griffiths, 2017a). 


\subsection{EXPERIMENT METHOD}

Griffiths, L. (2017) Perceptual Architecture, Presentation,

Architecture, Victoria University,

Wellington, 14 November.

Figure 17 - Experiment videos *

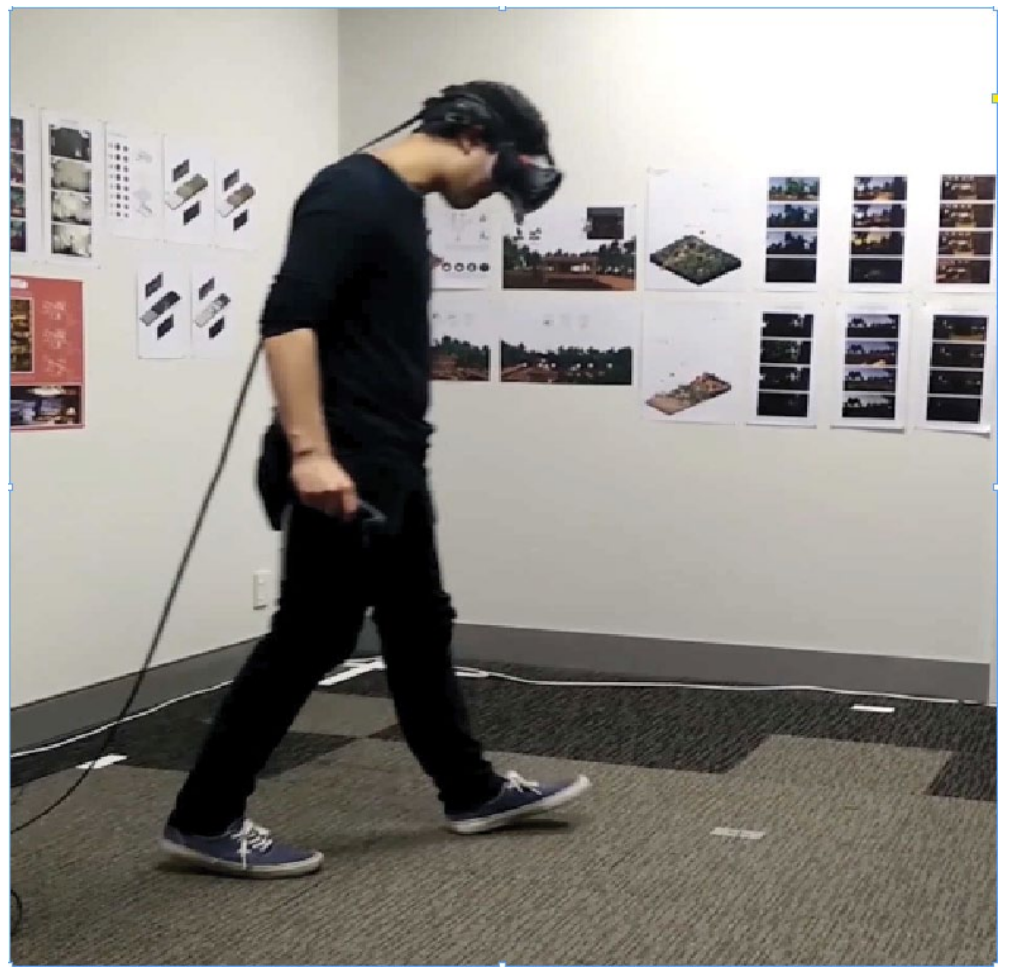

Movement in room

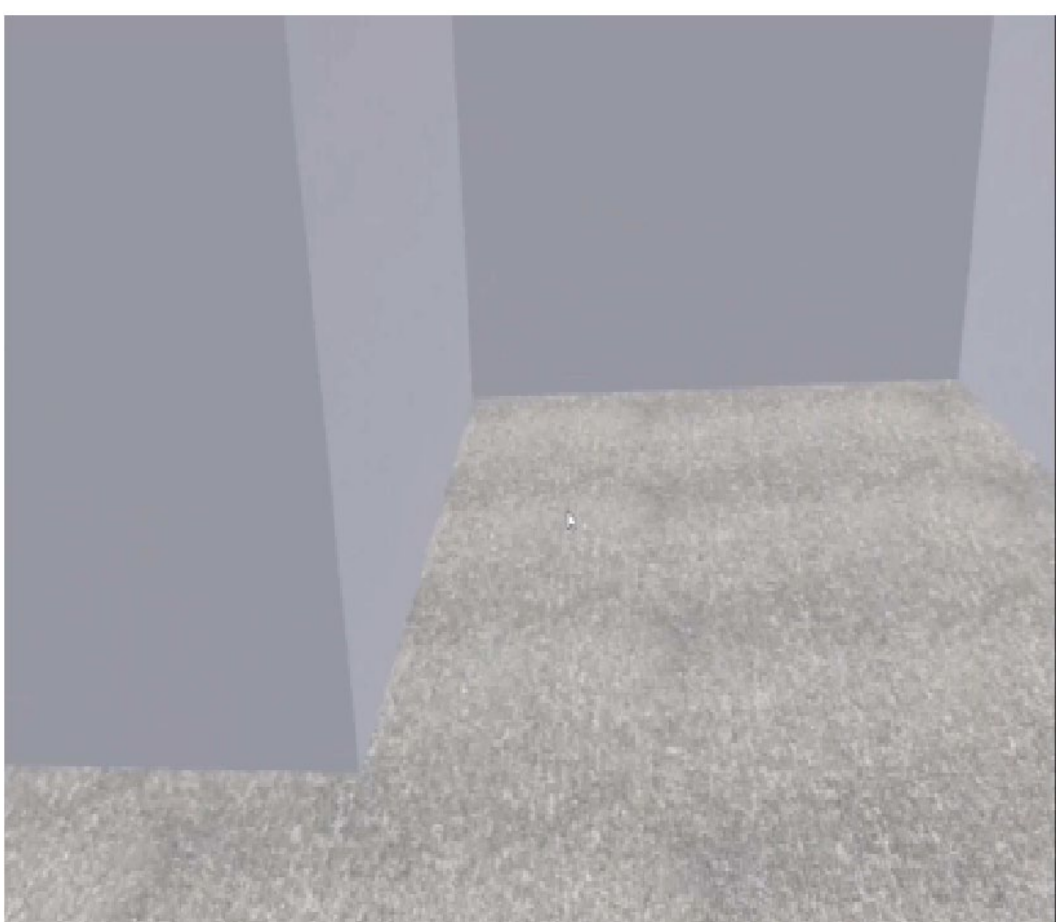

VR experience 


\subsection{EXPERIMENT METHOD}

Griffiths, L. (2017) Perceptual Architecture, Presentation,

Architecture, Victoria University,

Wellington , 14 November.

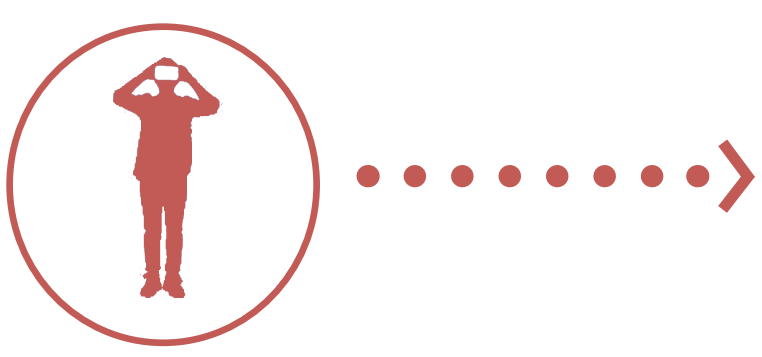

Participant

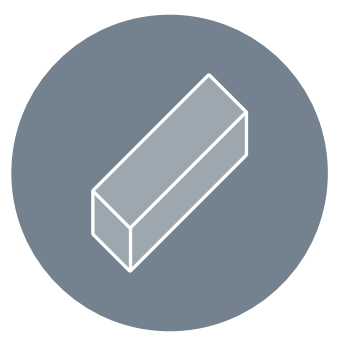

Width (X)

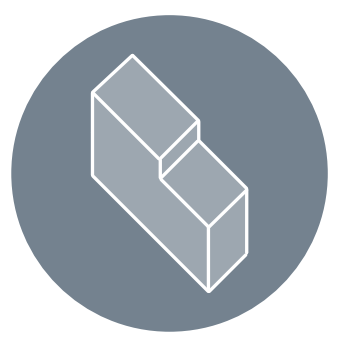

Stepped ceiling

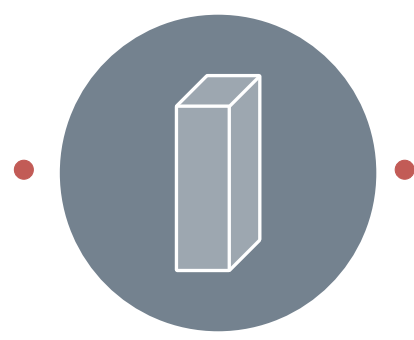

Height (Y)

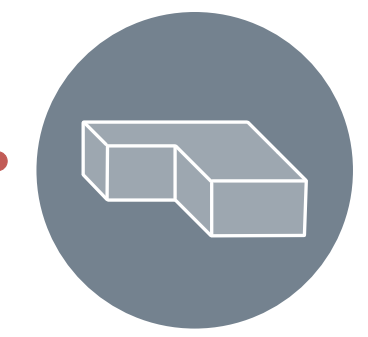

Corner

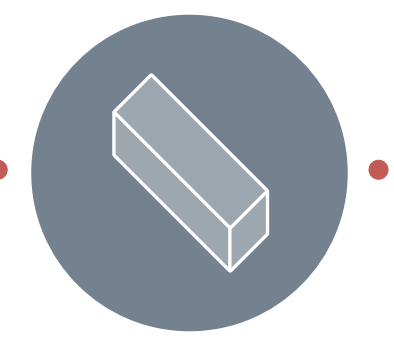

Depth (Z)

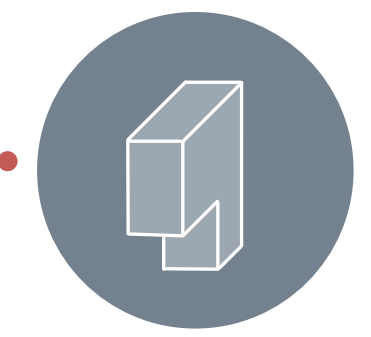

Mezzanine Floor

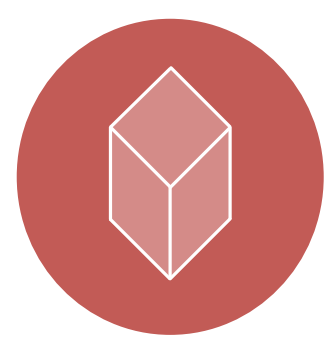

Scale room

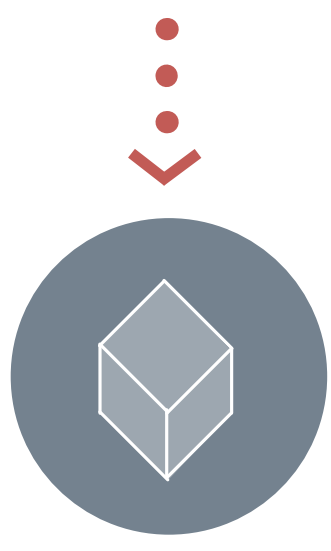

Square

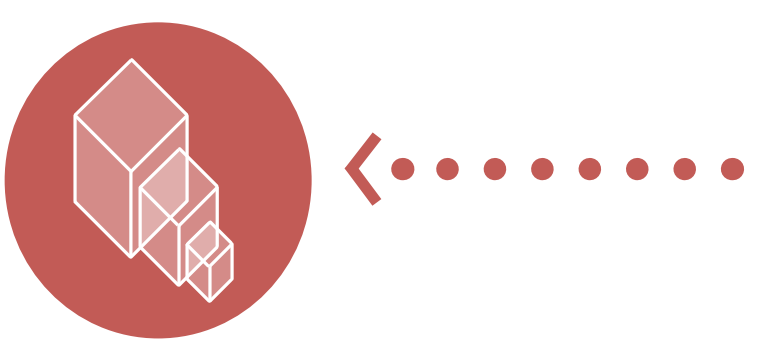

Matching

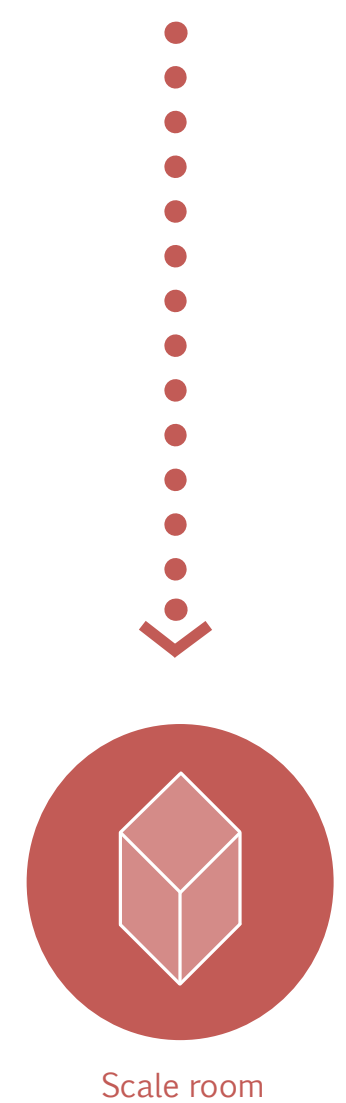

Figure 18 - Method diagram * 


\subsection{EXPERIMENT METHOD}

Griffiths, L. (2017) Perceptual

Architecture, Presentation,

Architecture, Victoria University,

Wellington , 14 November.

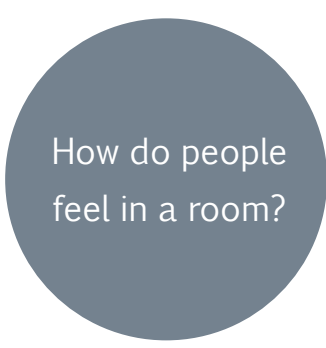

People afford the

space in terms of

use (liveability).

Room width is

supporting behaviour

and liveability.

The perceived

space had large

implications over

objective volume.

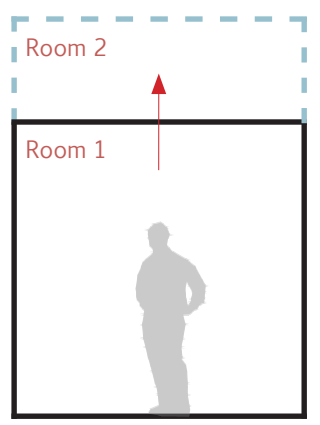

Perceived spaciousness ratings
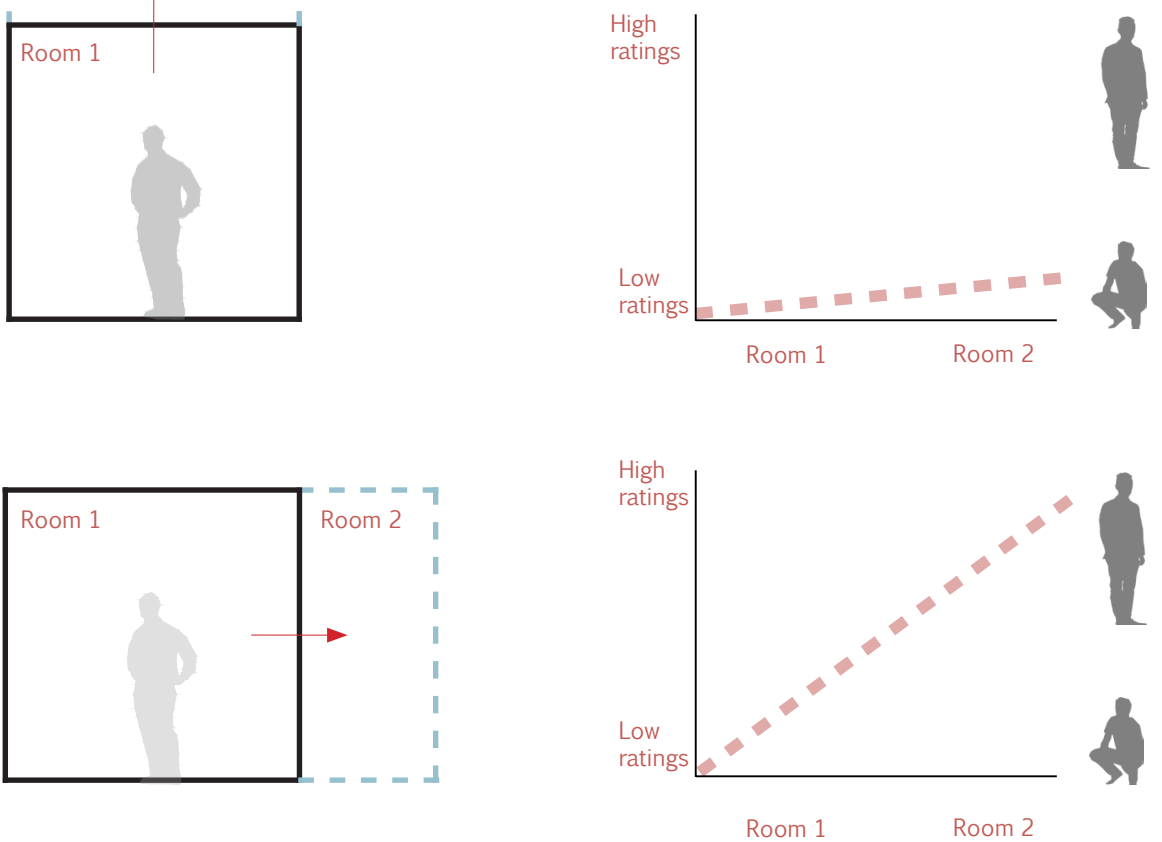


\subsection{EXPERIMENT METHOD}

Griffiths, L. (2017) Perceptual

Architecture, Presentation,

Architecture, Victoria University,

Wellington , 14 November.
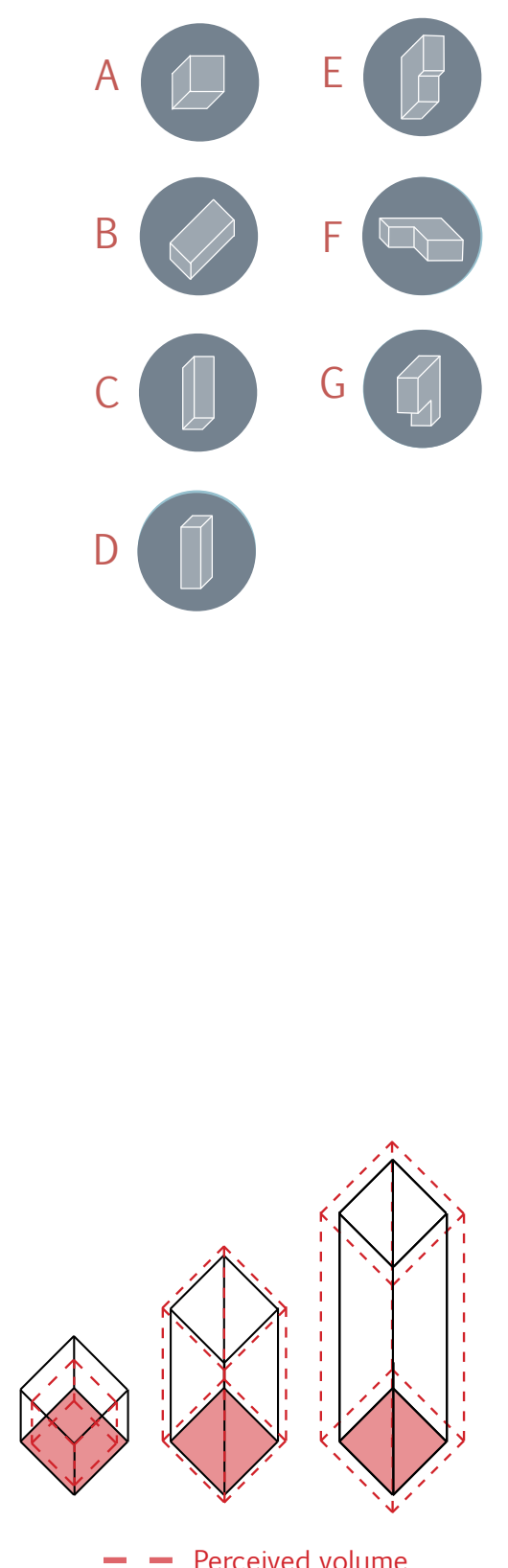

$R=0.283$
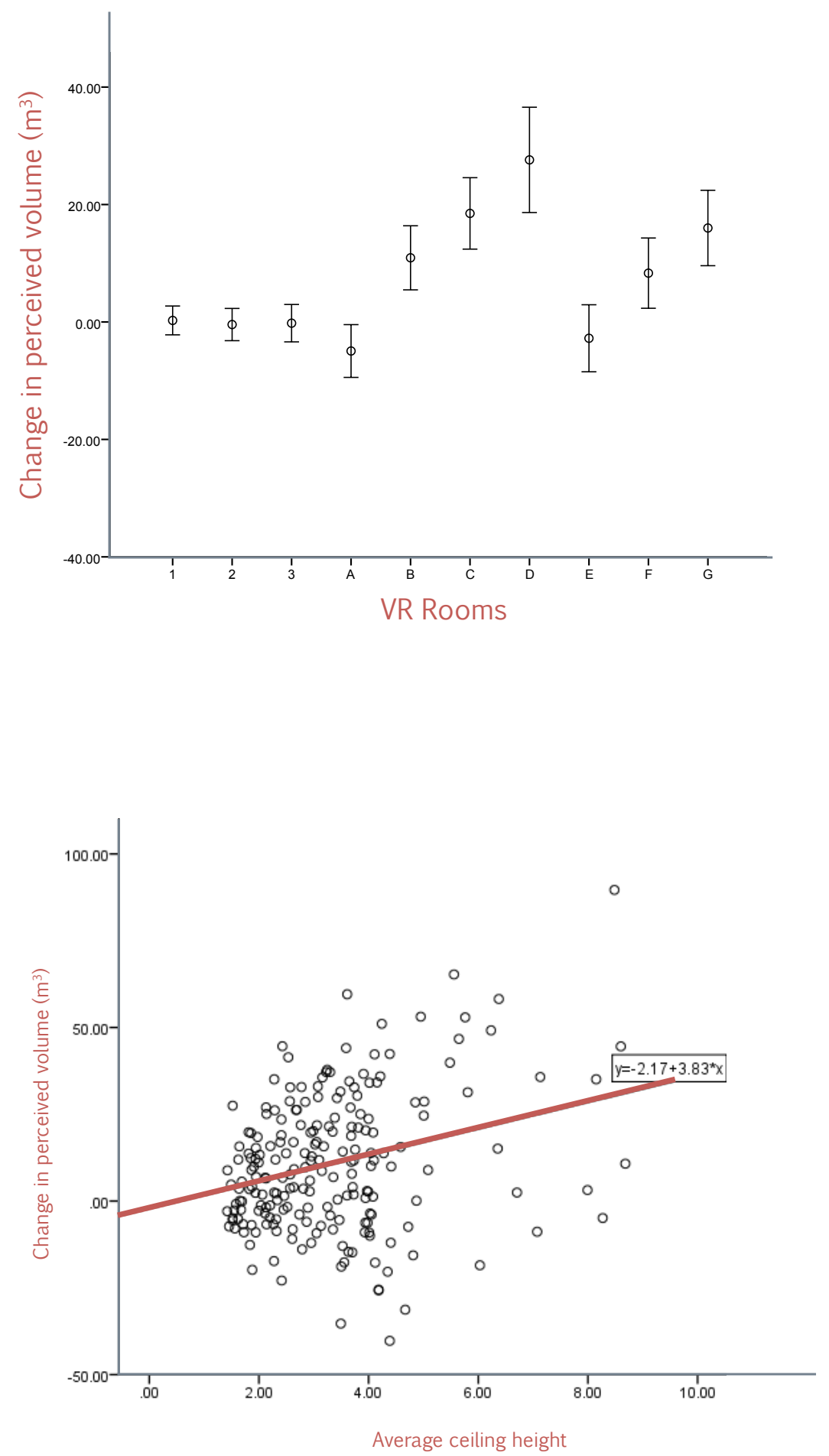


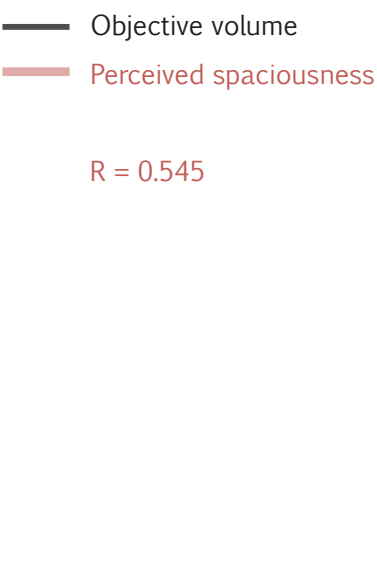

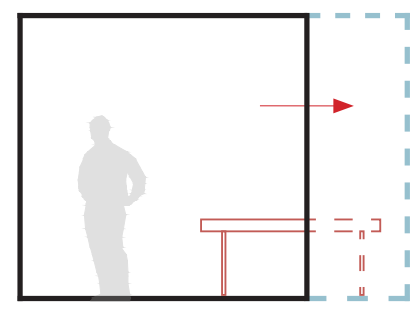

Objective volume

- Increased liveability

$\mathrm{R}=0.825$

\subsection{SECTION SUIMIMARY}
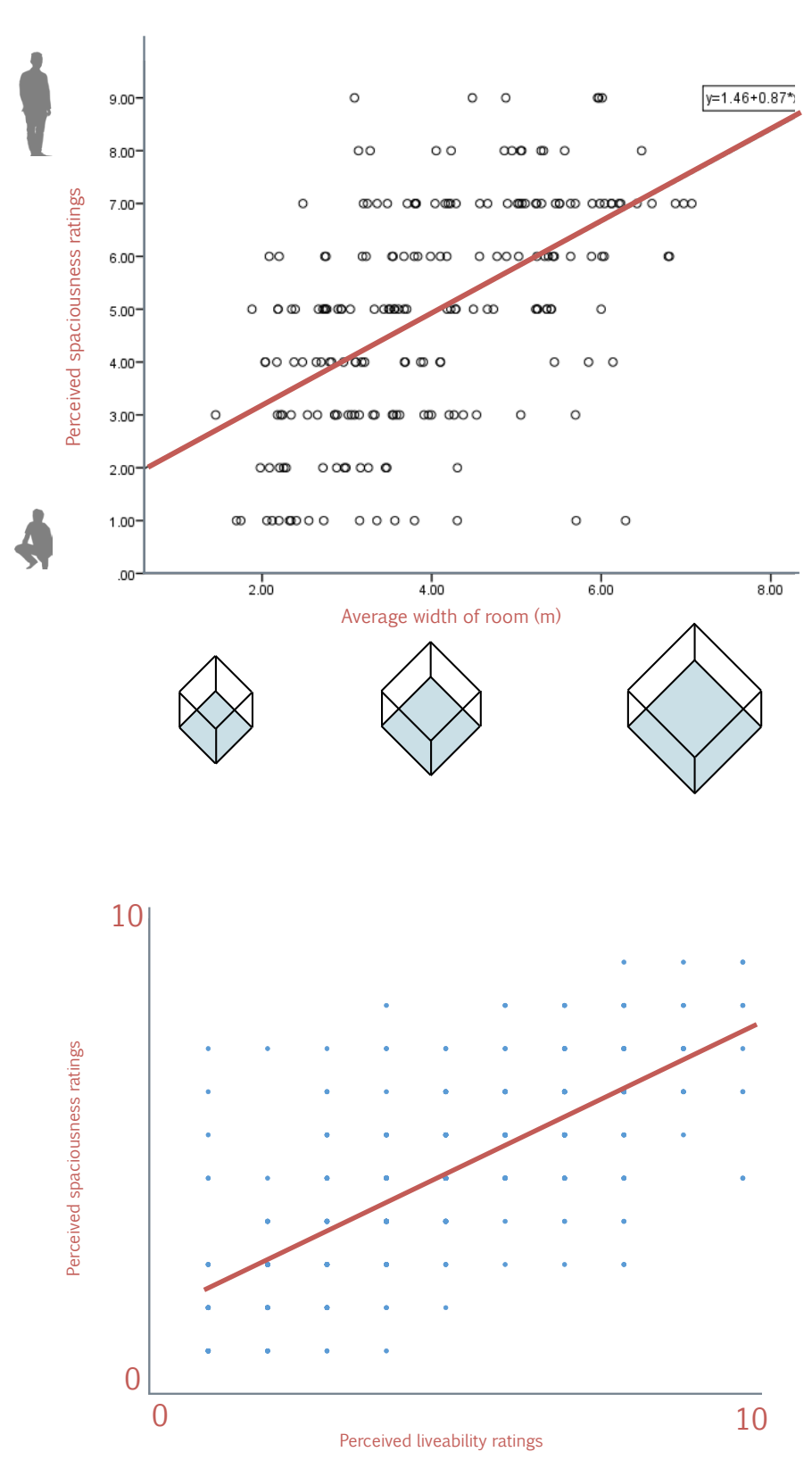

Chapter 6 will investigate how this research can be implemented to answer the thesis question. The preliminary design stage will use a evaluation process, as discussed in chapter 4 , to develop these ideas to produce resolved apartment dwellings. There are many optimising parameters which could be explored but the scope of this thesis is to increase perceived spaciousness and size. The continuation of this research could produce optimising parameters for a multitude of issues such as light, materiality or access. The methodology has been tested which future research could develop and lead to the fully optimization of a dwelling. This chapter (5) establishes not only parameters for my own resolved architecture but also presents a way to utilise VR as means of experimentation for understanding fundamental qualities of design. 


\subsection{OPTIMISING PARAMETERS}
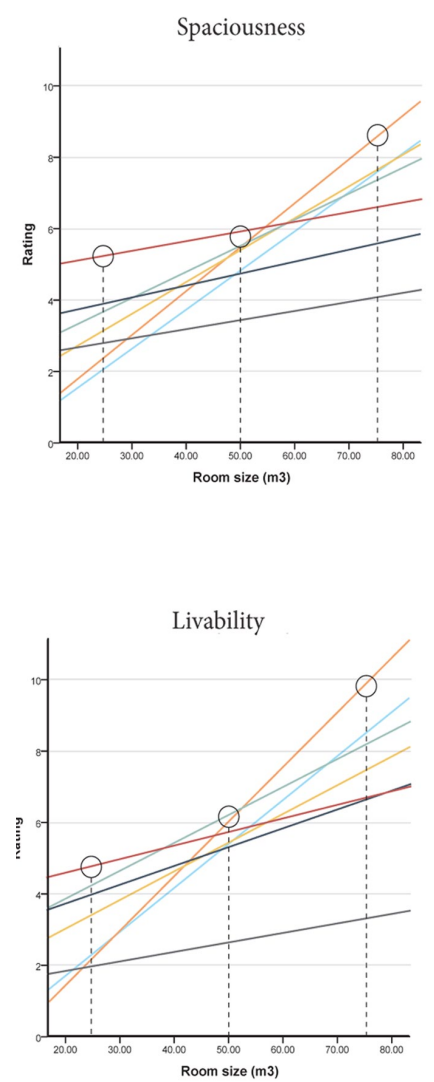

Figure 19 - The optimum spaciousness and liveability of a room proportion changes as volume size increases
This chapter will discuss possible architectural strategies which implement the literature and VR experiment research. The concept of perceptual overlap of primary and secondary zones become one of the primary architectural directions to achieve thesis aim (3), apply the research to provide perceptually informed architecture which increases the perceived spaciousness and size of a dwelling. This will be supported by the optimising parameters established in chapter 5 Experiment Method. The principles of perceptual overlap, extending perceived width and optimization of space are discussed in this chapter. Furthermore, they are implemented into an apartment context through preliminary and developed design chapters.

The two key optimising parameters, as established in my experiment, are the height and width of volume. Height of the room influences the perceived size of a space and width influences the perceived spaciousness of a space. These parameters will be utilized to find the optimum proportions for a given space within the dwelling during the design process. The overall shape of a dwelling for a given size has been established through the experiment method. In Figure 31 it is illustrated that the ideal room proportions change as the room size increase. The sizes, as indicated, have informed the basic foundational shape for each of the dwelling types; one, two and three bedrooms.

From Figure 31 the determined foundational room shapes were room $G$ (mezzanine floor) for the one bedroom, Room E (stepped ceiling) for the two bedroom and Room B (Long / Interconnecting spaces) for the three bedroom. These foundational shapes along side the minimum floor plan requires determined the starting dwelling forms (Figure 32).
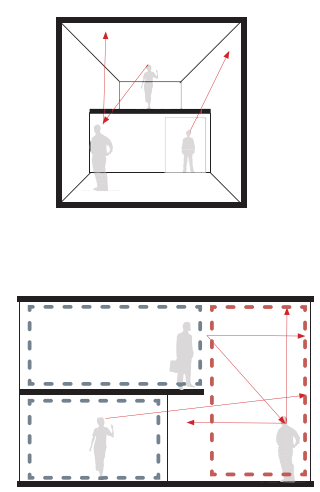
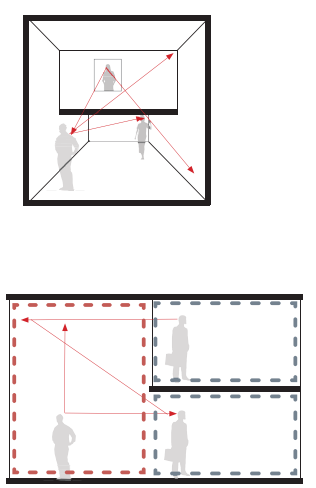
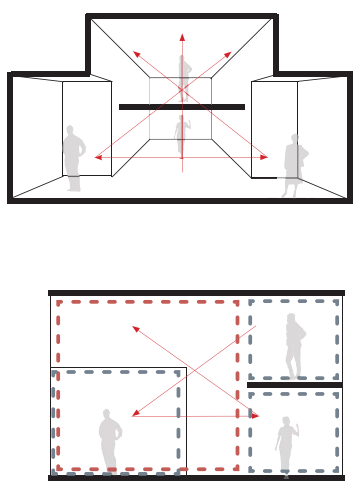

Figure 20 - Room shapes for dwelling types as determined from the experiment 
6.0 CONCEPT WORK

6.2 PERCEPTUAL OVERLAP
The concept of perceptual overlap uses a visual connectivity to expand the perceived width through the parameters of height and width. This was established through the literature research which discussed psychological spaces informed by architectural connectivity. Stokols (1976) and Evans (2003) have both expressed the possible benefits of a perceptual understanding in an architecture to create spaces which can form a psychological space within a high density environment. To achieve the aims of the thesis a perceptual overlap strategy which creates shared psychological spaces will be employed over a typical program overlap. Strategies allow for three main components; perceived width increase, perceptual overlap and interconnecting spaces.

If I were to show you three rooms, a living room, a cupboard and a wardrobe you would base your spaciousness on the program of the rooms. If the programs were switched the spaciousness ratings would decrease dramatically, even though the objective size is the same. This illustrates the importance of program or affordances in perceived space. Strategies should in turn be made in consideration of them. The initial concept thinking explored the possibility of using a primary space to interconnect secondary spaces (Figure 33). The primary space focuses on perceived volume size creating a large open space which connects the rest of the home, both physically and visually. The secondary spaces would focus on program, creating spacious liveable rooms that provide a level of practicality and comfort. The primary zones would use the height parameter to create a larger perceived size of the home, setting up an expectation for the rest of the home. The secondary zone can then share the psychological space of the primary zone resulting in an increase of the perceived width and perceived spaciousness.
Figure 21 - Primary and secondary spaces informed by the optimizing parameters of height and width

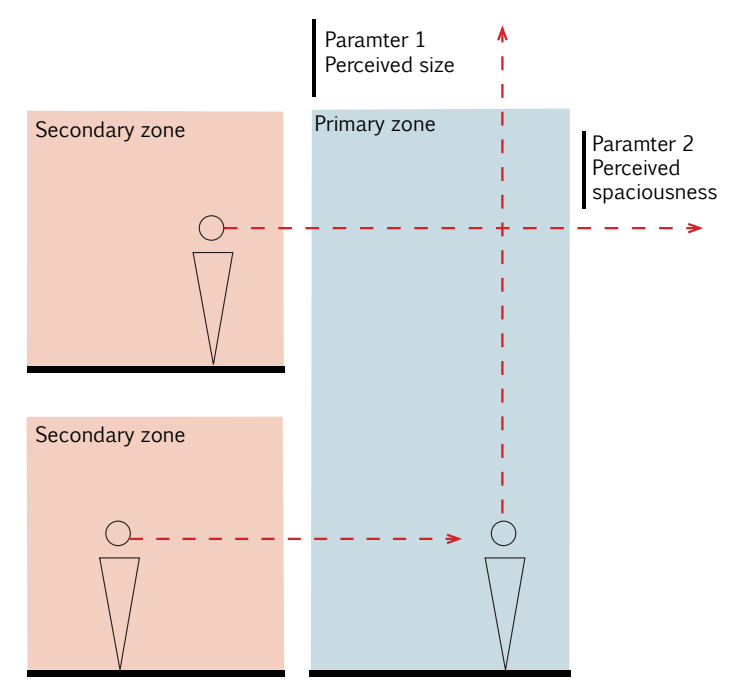


6.0 CONCEPT WORK

6.3.2. OBJECTIVE INCREASE

Figure 22 - Optimizable parameters of a volume
Finding the largest subjective increase for the minimal objective increase is part of the research which aims to establish principles to optimise high-density design. Optimization of space aims to best use the space and to create an optimum return on any improvements or increases of the objective space. With the methods and parameters, including any future parameters, an optimization of a volume can lead to the best output of a design, providing an optimization of the perceived space. This would allow designers to make informed design designs and make quick design decisions while understanding the considerations of the perceived space.
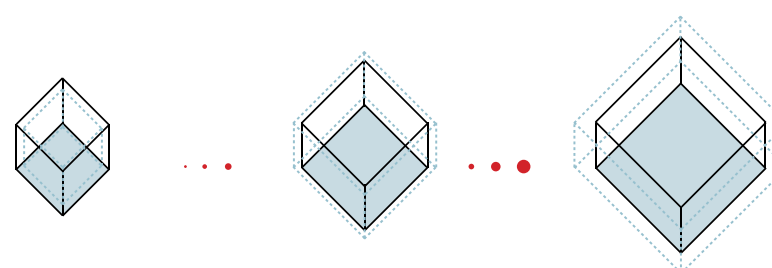

- Objective volume

- - Perceived spaciousness
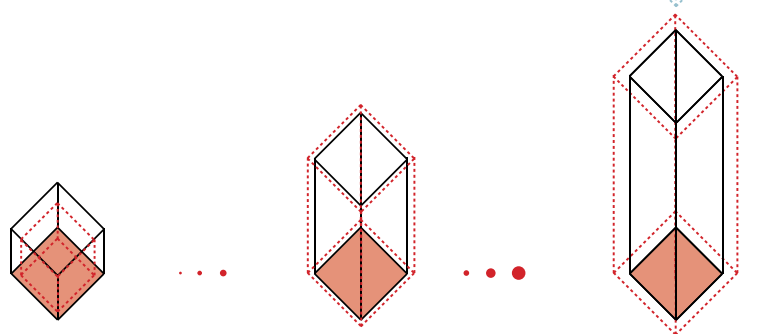

_ Objective volume
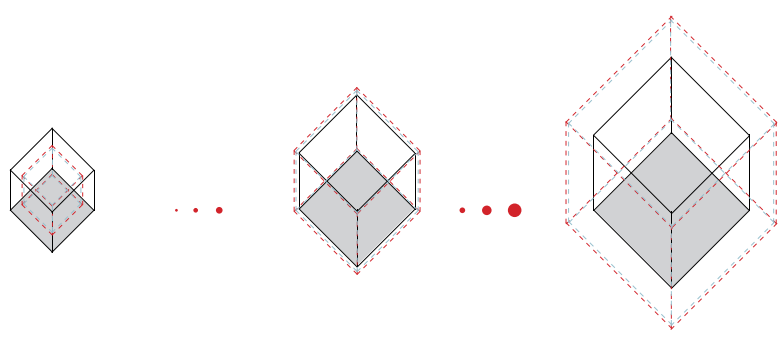

_ Objective volume

- - Perceived volume

- - Perceived spaciousness

This has been explored through the VR experimentation stage to establish the optimum proportions. Through this process the optimum use of the space has been explored, tested and implemented. This will be explored further in chapter 7 including a confirmatory design which investigates the translation of the established parameters to nonabstracted environments.

6.3.3. EXTENDING PERCEIVED

Extending the perceived width aims to increase the line of sight within WIDTH the dwelling to increase perceived spaciousness. This creates a transparency through the building by visually connecting spaces. One solution which could achieve this are split floor levels. This would allow the privacy and practicability required in a living setting yet create the extension of perceived width. Evans (2003) states that a visual connectivity through a space has the potential to expand a subjective 
space. Kopec (2006) expresses similar thoughts, stating that shared psychological space has the potential to also expand a subjective space. By extending the line of sight through the programs of the dwelling, interconnecting spaces can share psychological space to expand the perceived size and width of a dwelling. This solution of split floor levels allowed the perceptual overlap principle to also be more successful (Figure 35). Offsetting the views out of secondary spaces will allow improved privacy and practicality of the secondary spaces.

Figure 23 - Extending line of sight through split floor plates. *
6.3.4. LIMITATIONS

\subsection{PRECEDENTS}
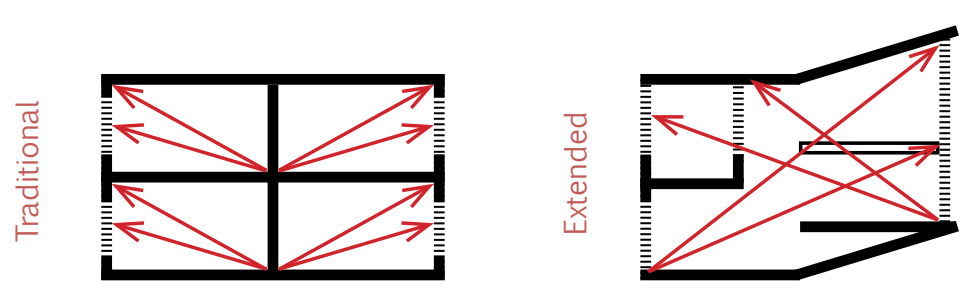

The experiment utilised a methodology in which to establish optimum parameters for high density design. The desired output of future studies would be complete virtual optimization which can predict the perceived space of a design to aid in design decisions. The project needs further studies to reach this goal. The limitations of the initial experiment is that the rooms were firstly abstracted in form and secondly only provided initial basic room strategies. To extend the understanding in research area these ideas need to be pushed further. This process aims to provide a foundational start by challenging how to increase perceived spaciousness and volume in a high-density context. A study in chapter 7 confirms that the parameters translate into non-abstract environments and explores other impacting design qualities such as light and materiality. These steps address the limitations of the first experiment to provide reliability, context and validity to the research.

This section investigates strategies for materiality, light and movement. A limitation of the research is that these qualities directly influence the perceived space but cannot be explained by the quantitative research. A qualitative design evaluation explore optimum solutions for these qualities. Precedent designs look at important design elements such as materiality, light and movement to form initial design iterations for evaluation. "With regard to architecture, perceptual communications are conveyed through contexts of space, form, light, color, object and material. These component expressions form a design language that informs user perceptions" (Voort, 2017). An analysis on key precedent provide initial iterations in which to evaluate these architectural qualities as they are impactful on the perceived space and cannot be overlooked. This is the next step for future development. 


\subsection{CONCEPT WORK}

Figure 24 - Studio

Apartments In Three Modern Styles (Szkudlarek, 2017). Open plan kitchen and living room layout for two bedroom

Figure 25 - Luxurious \& Inspiring Penthouses (Edition, 2016). Window shapes and double height translating light and views

Figure 26 - $\quad$ A Super Small Apartment That Adapts To Its Owner's Needs (The Goort , 2015). Mezzanine floor moving between double and single height to create open and private spaces

Figure 27 - Small Apartment with Snug Storage (Svirid, 2014). Angled ceiling planes directly light into the dwelling
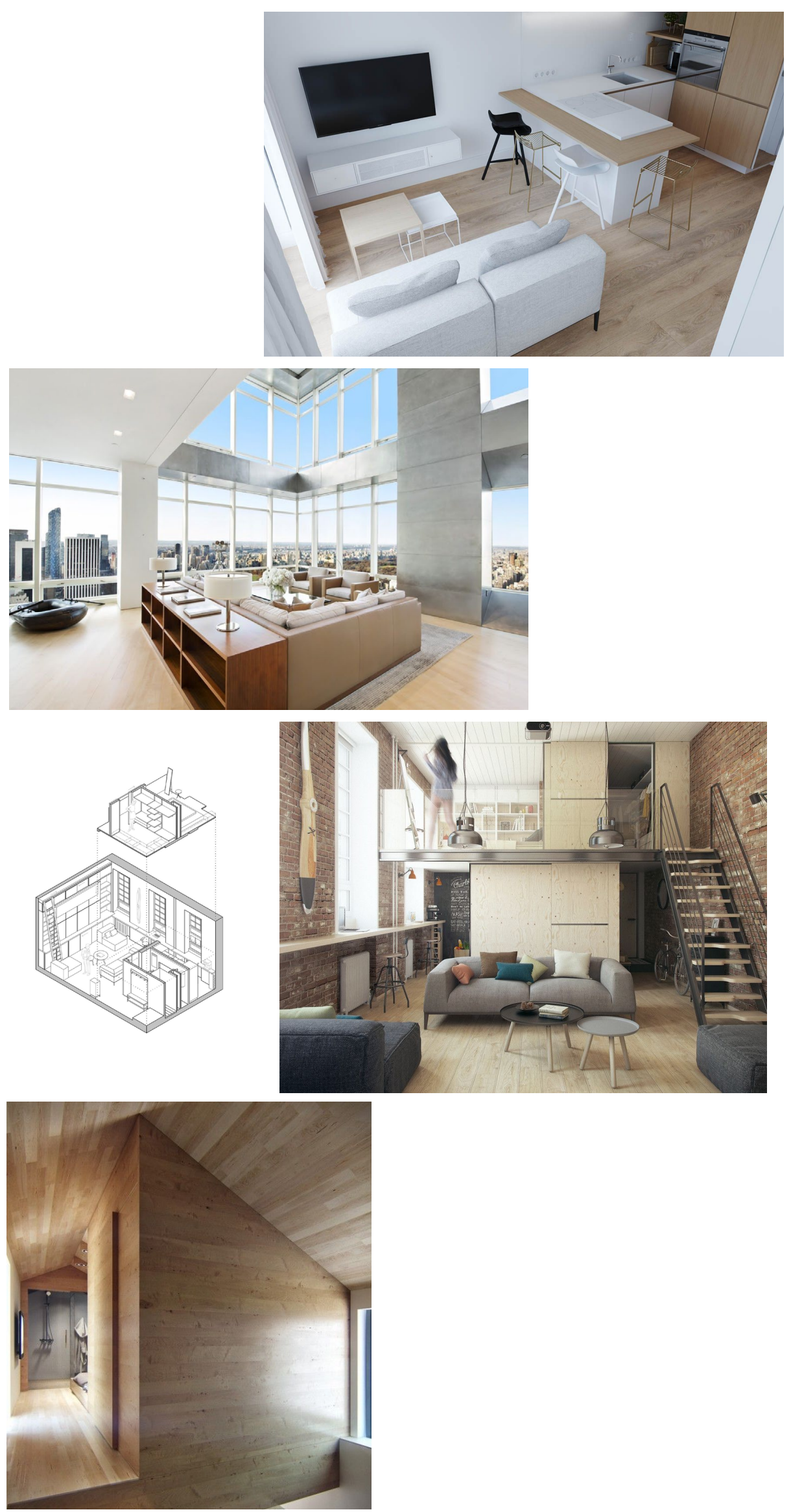


\subsection{CONCEPT WORK}

Figure 28 - Arquitectura - G , Barcelona (Hevia, 2017). Sky light translating light and creating soft borders.

Figure 29 - $\quad$ Cisco Campus (Studio O+A 2017). Materiality expressing the volume of the dwelling by adding depth and texture

Figure 30 - $\quad$ Pedro Ferreira conversion (Morgado, 2017). Open stairways which don't constrict the movement on lower floors but express an implied volume

Figure 31 - Traditional Spanish market, Madrid Spain (Jump \& Fly, 2016). Ceiling textures which create interest and provide depth.

Figure 32 - Balance (Kravtsov, 2016). Recesses boundaries create weightless connections
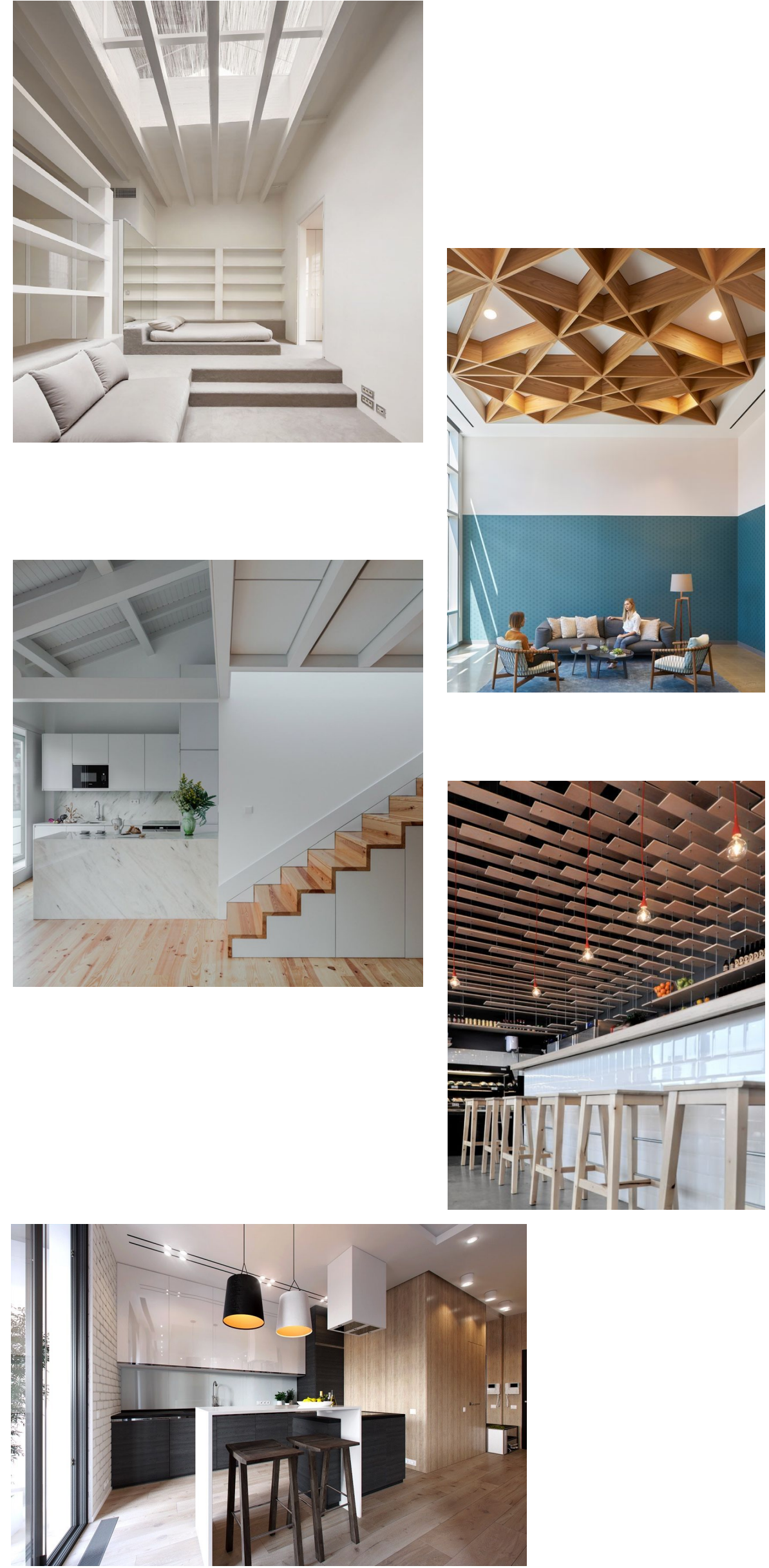


\subsection{CONCEPT WORK}

Figure 33 - Kelly Behun penthouse (Powers, 2015). Window seats which bring the occupant to the exterior of the dwelling

Figure 35 -

Cor \& Partners Muca, Algueña (Frutos, 2011). Ribbed panels which express volume and movement

Figure 34 - Economic \& Masters Building (Cutillas, 2011) Window shafts, direct light into and views out of the dwelling
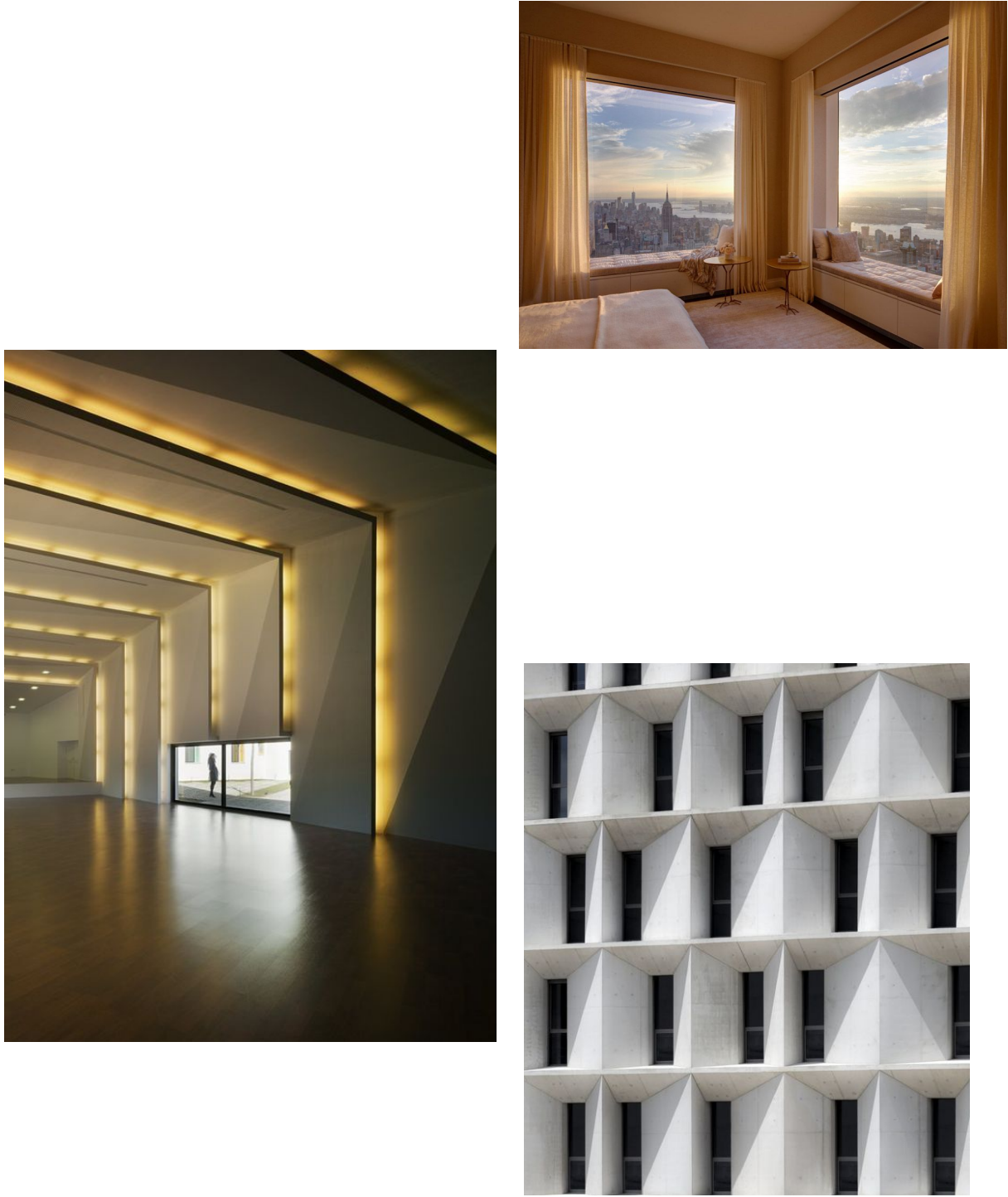

These designs have highly considered materials and forms which I have reflected on in my developed designs, they go beyond my initial parameters to play with spatial qualities. Figure 46 interests me as panel shifts express a change in volume. The strip lighting turns the negative details into a focus point which translates the expression of form. This strategy could express the research parameters through horizontal and vertical shifts.

Creating a vertical light penetration is difficult in a high rise building. Designs like in figure 40 would not be possible in this typology. Through double height spaces light penetration at a high angle could be achieved. This is seen in figure 37 which has double height windows to maximise light and views. Another possible solution is to use angles planes such in figure 39 to bounce light around a space and optimise the light productivity. This has the potential to created lighter spaces while increasing the spaciousness of a dwelling. These planes must enable an optimal use of light and not obscure it like in figure 46 . While this panel system looks interesting it is actually reducing the light intake of the rooms beyond. 


\subsection{CONCEPT WORK}

6.5 SECTION SUMIMARY
Perceptual overlap and the optimizing parameters of height and width of a volume have led to the architectural principles of perceptual overlap, optimization of space and extending perceived width. These principles have the potential to increase perceived size and spaciousness within an architecture. The following chapter will take these abstract principles and develop them through architectural experimentation and iteration to inform design solutions. 
This chapter investigates design solutions through a series of design iterations using virtual reality (VR) evaluation processes. The concept design principles have been established through the literature and thesis VR experiment research. This chapter will identify architectural and perceptual issues and explore design solutions to address them. The aim is to develop the thesis principles of; perceptual overlap, extending width and optimization of space. 2D and 3D drawing is used to form initial solutions of which a final selection undergo a VR evaluation process. VR in this process is essential as it allows quick fire design iteration and design understanding of perception of spaciousness and size in a volume. The VR process included myself and on occasion colleagues and supervisors. The evaluation process was in a formal format which had key questions and criteria to judge the success of an iteration. To recognize the optimum solutions the same rating system was used from the experiment in chapter 5 (see table 2). There was also the addition of an architectural quality rating to inform these decisions. The process resonates between large and small scale investigations and solutions to ensure a coherence between the architectural principles and overall architecture to answer the thesis question. Chapter 7 concludes with a confirmatory experiment to illustrate that the research from chapter 5 , in an abstracted setting, translates and is significant in more complex non-abstracted settings. This process finalises the architectural principles which have then been implemented into the design to create perceptually informed architecture.

Qualitative design evaluation will be implemented alongside the quantitative research established in chapter 5 . The current understanding of the perceived space are the two parameters and optimising between them (Figure 48). The evaluation process focuses on where future research could take place such as developing the parameters, adding parameters and a real world context through qualitative processes.

Figure 36 - $\quad$ Future research direction *
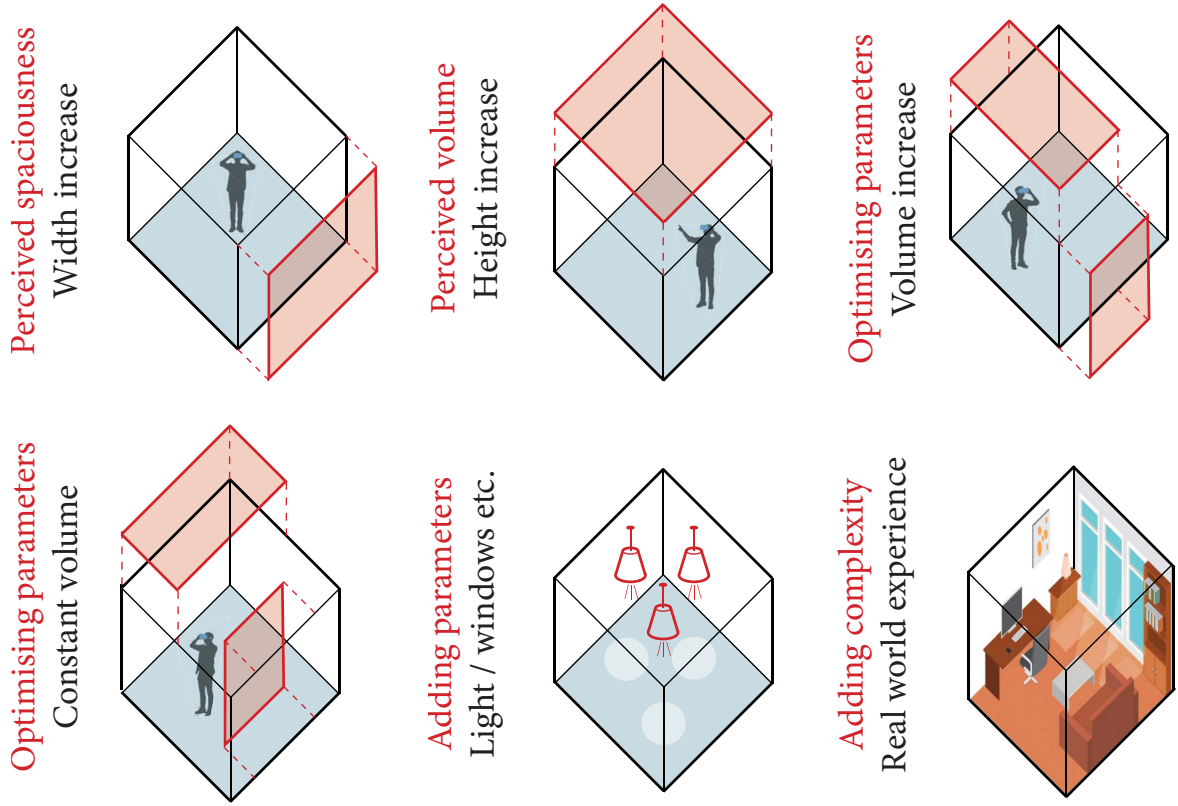
To begin translating conceptual drawings to virtual three-dimensional space a quick exercise, to understand the transition between 2D and 3D drawing to VR and how this affects perception of space, was undertaken. This exercise began by creating simple models with the constraints of floor areas, 45, 70 and 90 square meters. The models were based on the concept design research which established foundational volume forms (Figure 50). The spaciousness was rated in response to my understanding of the space in a 3D modelling program (Revit). The ratings ranged from 1 (Enclosed) - 5 (neutral) - 10 (Open) as seen in blue in Figure 49, Figure 50, Figure 51. Once all ratings for each room were complete, these models were translated into a VR program (Unity). In the first transition from 3D computer modelling to VR there was an incredible difference between the spaces. Perception of space was greatly increased compared to the interpreted volume within Revit. Spaces which were initially rated open were far more open than initially thought. This was similar to the spaces which were rated as enclosed, they were far more enclosed than initially thought. What this illustrates is that every design decision made that affects perception of space must be tested in this process as 3D modelling cannot sufficiently illustrate these changes.
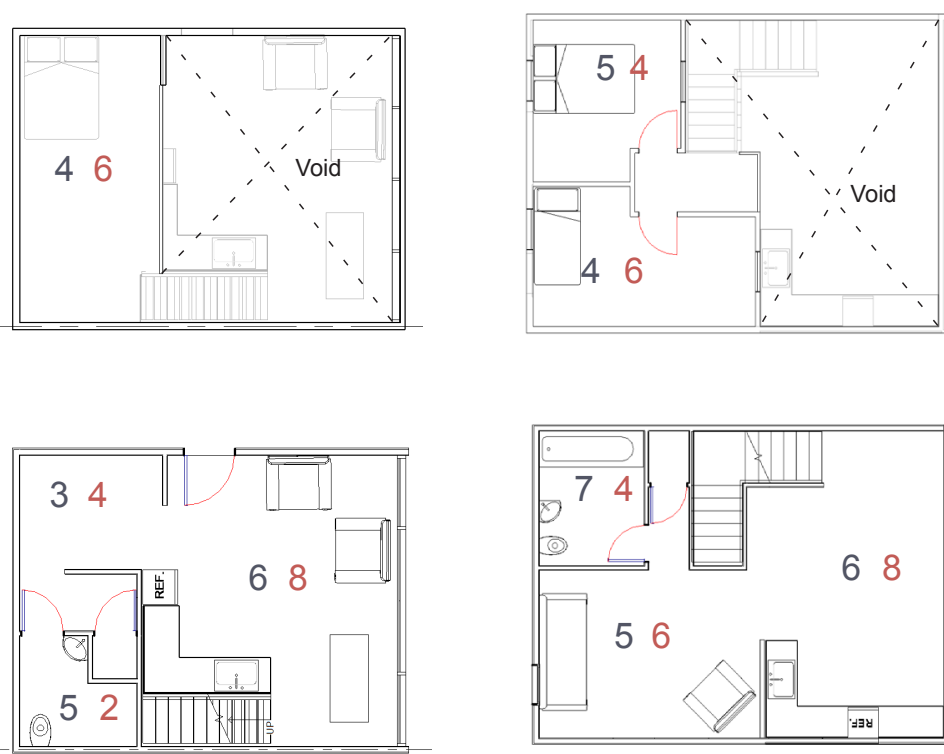

Figure 37 Bedroom, $45 \mathrm{~m}^{2}$.
One

(1)

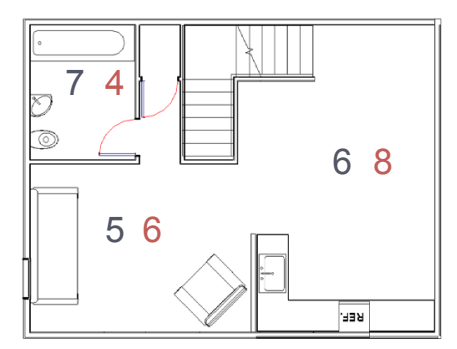

Figure 38 - Two Bedroom, $70 \mathrm{~m}^{2}$.
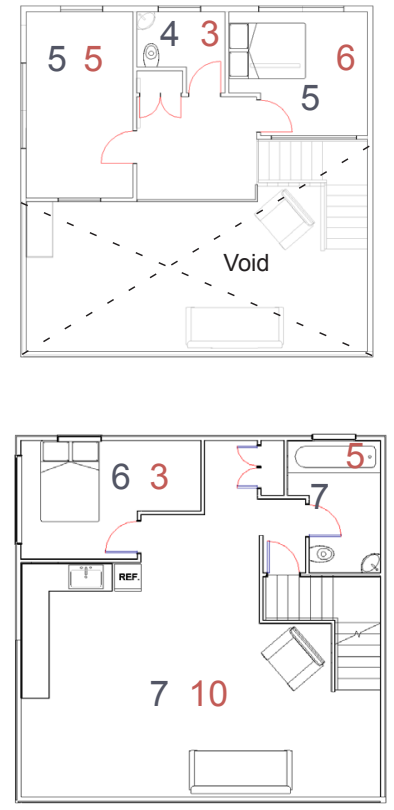

Figure 39 - Three Bedroom, $90 \mathrm{~m}^{2}$. 
One Bedroom

Figure 41 - Dwelling foundational shapes

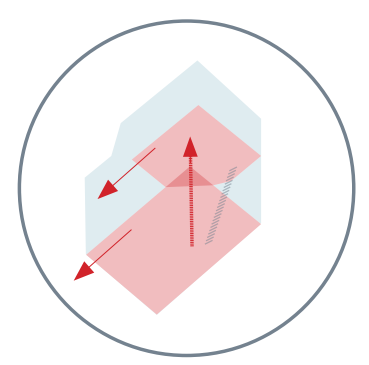

Two Bedroom
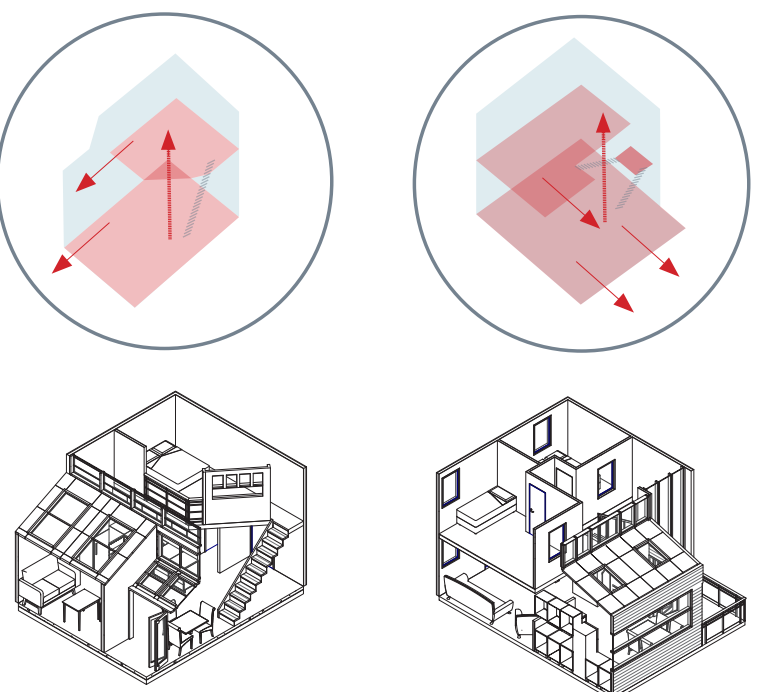

\section{Three Bedroom}

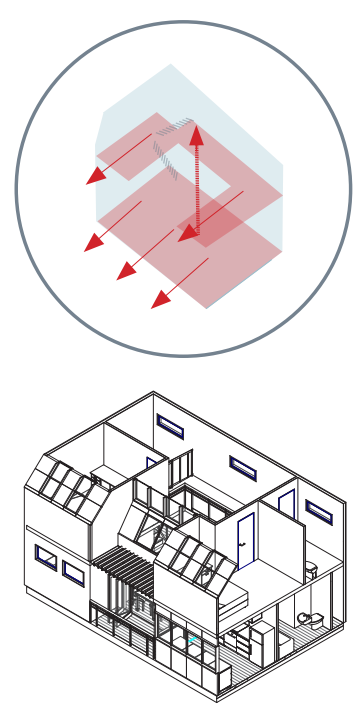

Figure 40 - http:// www.aucklandcity. govt.nz/council/ documents/central/ pdfs/appendix12.pdf
7.2 PRIMIAR AND SECONDARY ZONES
A MATRIX OF MINIMUM GROSS FLOOR AREAS (IN $\mathrm{M}^{2}$ ) FOR COMPONENTS OF VARIOUS RESIDENTIAL APARTMENT TYPES

\begin{tabular}{|c|c|c|c|c|c|c|c|c|c|c|c|c|}
\hline & Living & $\begin{array}{c}\text { Kitchen/ } \\
\text { Eat }\end{array}$ & $\begin{array}{c}\text { Bedrm } \\
1\end{array}$ & $\begin{array}{c}\text { Bedrm } \\
2\end{array}$ & $\begin{array}{c}\text { Bedrm } \\
3\end{array}$ & $\begin{array}{c}\text { Bathrm } \\
1\end{array}$ & $\begin{array}{c}\text { Bathrm } \\
\quad 2\end{array}$ & Laundry & WR+Entry & Balcony & TOTAL & ROUNDED \\
\hline Studio & 11.00 & 5.10 & 9.00 & 0.00 & 0.00 & 3.00 & 0.00 & 0.84 & $0.72+0.36$ & 5.00 & 35.02 & $35.00 \mathrm{~m}^{2}$ \\
\hline 1 bed & 15.00 & 10.80 & 9.00 & 0.00 & 0.00 & 3.00 & 0.00 & 0.84 & $1.08+0.36$ & 5.00 & 45.08 & $45.00 \mathrm{~m}^{2}$ \\
\hline 2 bed $^{1}$ & 24.00 & 13.20 & 9.00 & 9.00 & 0.00 & 3.00 & 0.00 & 1.26 & $2.16+0.36$ & 8.00 & 69.98 & $70.00 \mathrm{~m}^{2}$ \\
\hline $3+$ bed $^{2}$ & 28.00 & 16.20 & 9.00 & 9.00 & 9.00 & 3.00 & 3.00 & 1.26 & $3.24+0.36$ & 8.00 & 90.06 & $90.00 \mathrm{~m}^{2}$ \\
\hline
\end{tabular}

To challenge densification the dwellings have been confined to the minimum floor plan requirements as set by the Auckland city council (Figure 52). Likewise the programs within the dwellings are restricted to the standards set by the Auckland district plan. By keeping to these restrictions the highest level of density can be explored within a New Zealand context. The programs will be classified as either primary or secondary zones as per the concept perceptual overlap. A series of sketch experiments explored possible arrangements, which were then explored and evaluated in VR. Secondary zones require a level of privacy and practicality which determined their suitability while zoning programs (Table 3). The sketches explore four possible primary zones; living room, kitchen, circulation spaces and mixed program (Figure 55).

Table 1 - Primary and secondary zones

Zones:

\begin{tabular}{l|l}
\hline Primary & Circulation \\
Secondary & Bedroom, Living Room, Bathroom, Laundry \\
Mixed & Balcony, Kitchen, Entry
\end{tabular}


Balcony

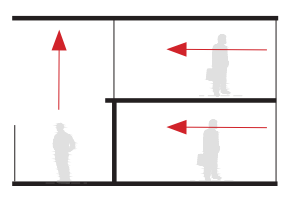

Sp.

S.

Q., 1,

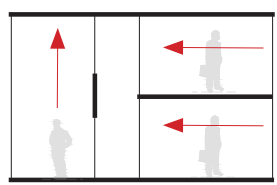

Figure 42 - Spatial planning iterations

Sp.
Kitchen

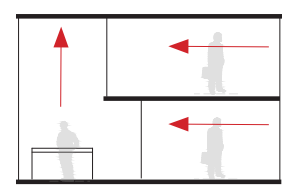

Sp.

S.

Q.

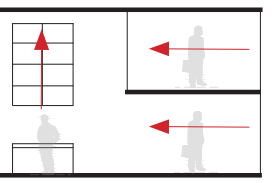

S.

Q.
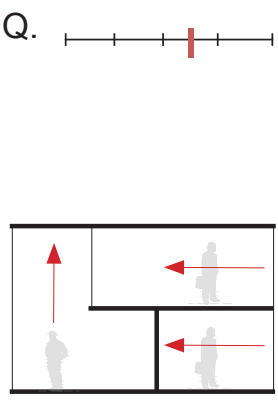

Sp. $\longmapsto, 1$,

S. $\longmapsto, 1$,

Q. $\longmapsto, 1,$,

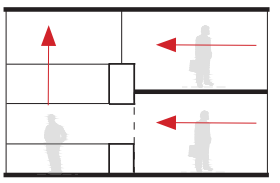

Sp

S

Q.

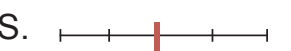

Q.

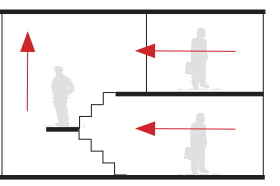

Sp.

S.

Q.

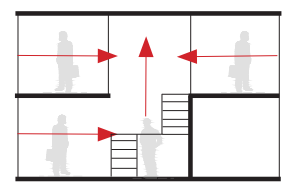

Sp.

S.

Q.
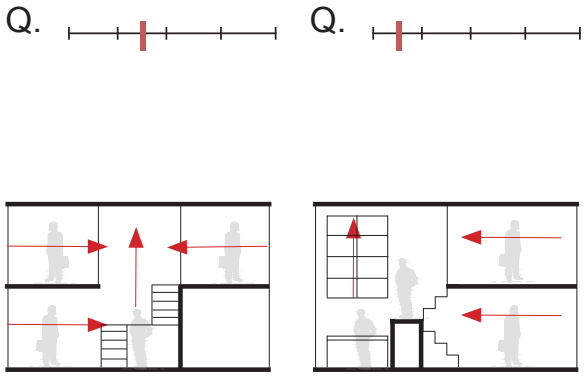

Sp.

S.

S. $\longmapsto, 1,$,

S. $\longmapsto, 1,1$,

Q.

Q.

Q.

Q.
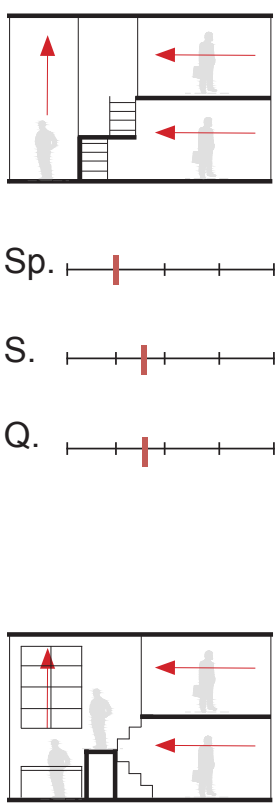

Q.

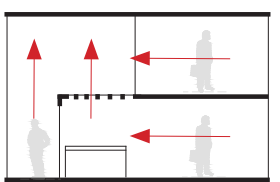

Sp.

S.

Q.

Sp. $\longmapsto, \longmapsto$,

S. $\longmapsto, 1,1$,

Q.

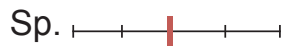

S. $\longmapsto, 1,1$,

Q. $\mapsto,,$, $\longmapsto, 1,1-1$

S. $\longmapsto, \longmapsto, \longmapsto$

$\mapsto,$, 
On reflection, having one set primary zone added a limitation to the design. It did not allow the architectural intent of perceptual overlap. A perceptual transparency was required to be experienced through the dwelling. The primary zone should not be dictated by a single program of the dwelling. Therefore, the primary zone uses a mixed program. This includes the circulation of space, and kitchen or dinning. The programs with a minimum level of privacy required and the most frequently used by all occupants are designated to this primary zone.

\subsection{FORIM EXPLORATION}

\begin{tabular}{|l|}
\hline Key \\
Spaciousness \\
S. Size \\
Architectural \\
quality
\end{tabular}

Figure 43 - Form shape iteration

A series of volume shape arrangements have been explored over a range of scales (Figure 55). The limitations of the experiments in cubic form resulted in a lack of understanding of angular forms. This process investigates the spatial changes within volumes which use angular moments. I rated each space by spaciousness, size and architectural quality to explore optimal volume forms at a range of sizes. I found that angular volumes had a large effect on the perceived space and had a much larger subjective increase of space over an objective increase. This process added insight in possible volume arrangements to explore in later developed design iterations and evaluations.

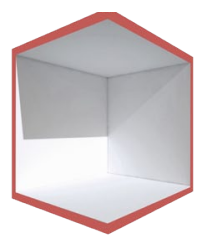

Sp.

S.

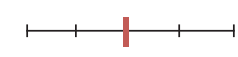

Q.
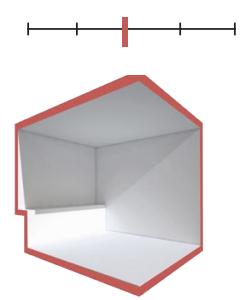

Sp.

S.

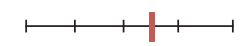

Q.
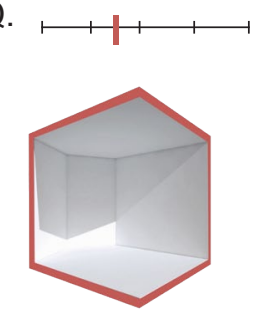

Sp.

S.

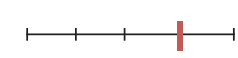

Q.

S.

Q.

Sp.

S.

Q.

S.
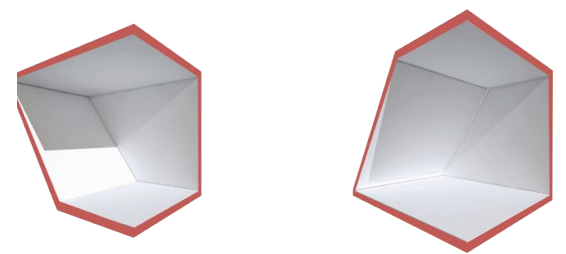

Sp.

S.
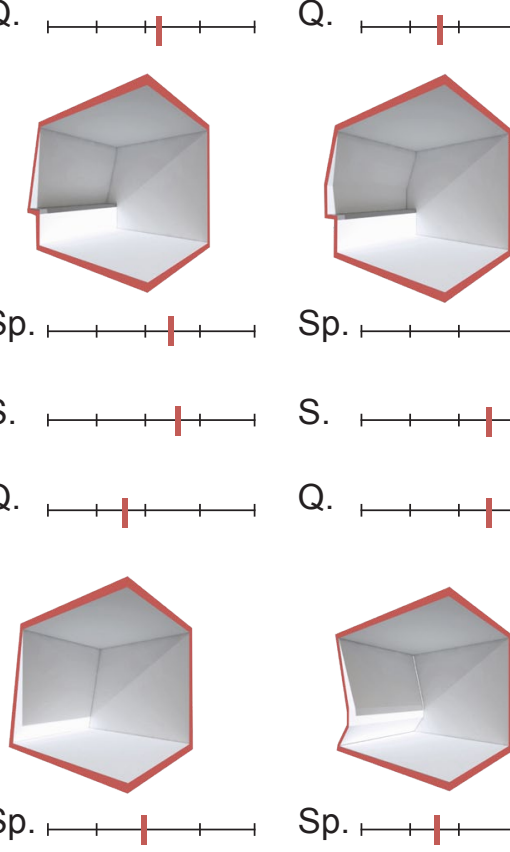

Sp.

S.

Q.
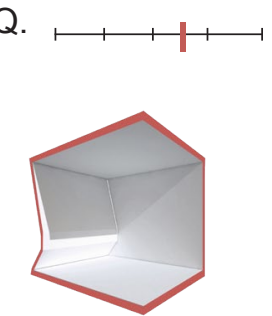

Sp.

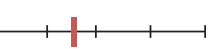

S.

Q.

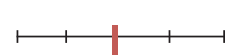

S.

Q.

Sp.

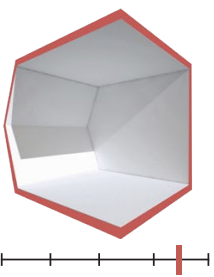

S.

Sp. $\longmapsto, 1$,

S.

Q.
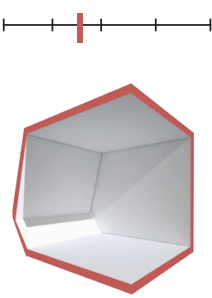

Sp.
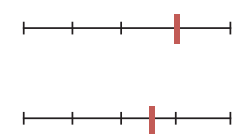

Q. 


\subsection{FORIM DEVELOPIMENT}

Bedrooms are a secondary space needing a high level of liveability and spaciousness. Design iteration explores opportunities to increase spaciousness in a bedroom context through form shifts. The previous evaluation process identified optimal angular forms which will be tested with materiality, windows and lighting. Option 3 had the largest subjective increase with the smallest objective increase. Option 3 was chosen for further iteration because it afforded the largest space while providing the practicability of sunlight and views. The largest angle out is at eye level meaning that spatial understanding is formed to allow a maximum subjective increase. By increasing room width it is possible to increase the perceived spaciousness and liveability of the room, as per the thesis aims. This process was also undertaken for a living room context (Figure 57).
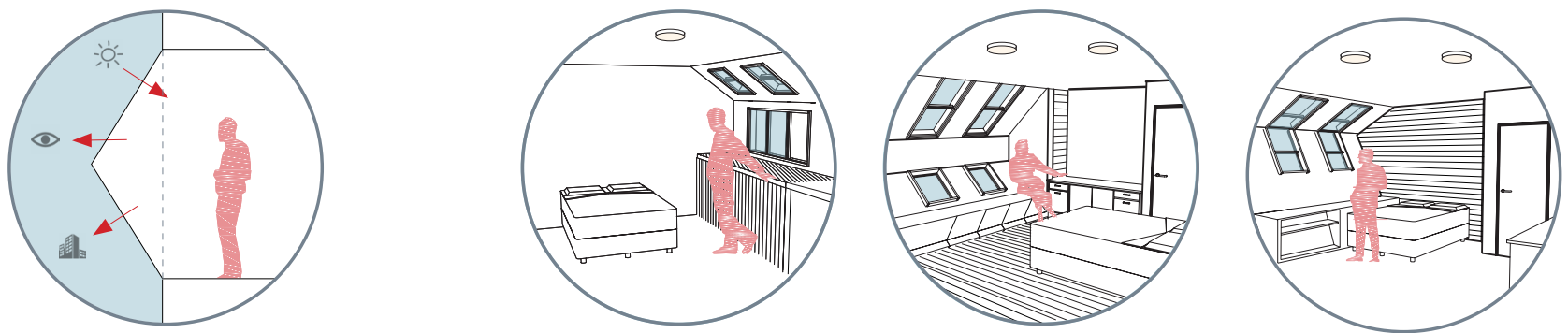

Figure 44 - Form context within a bedroom setting
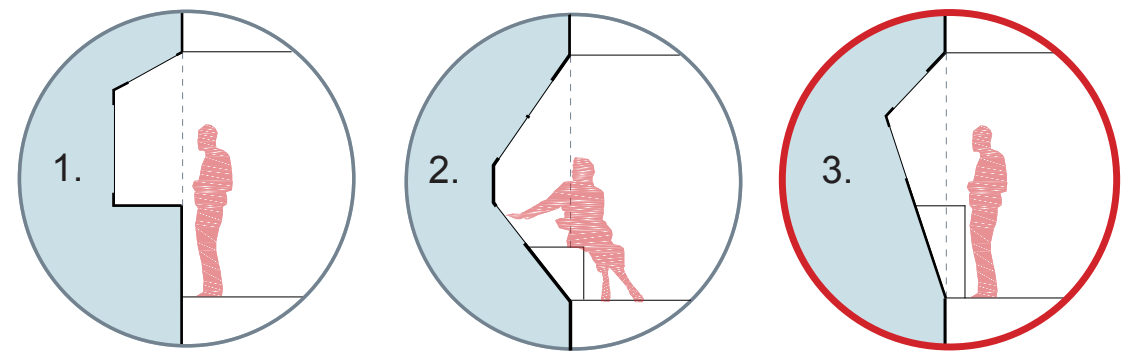

Sp

Sp.

Sp.

S. Size

Architectural quality

S.

S.

S.

Q.

Q.

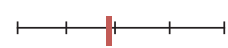

Q.
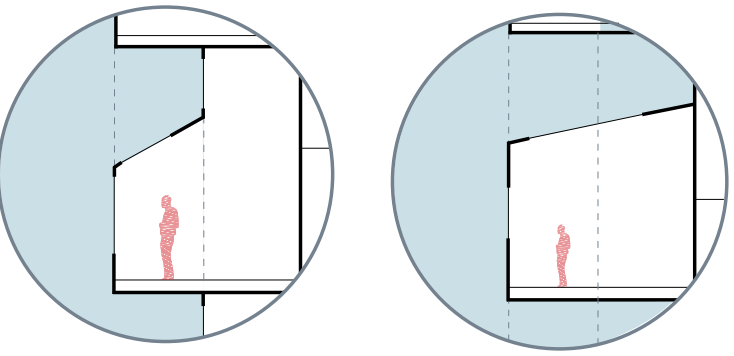

Sp.

Sp.

Figure 45 - Form context within a Living Room setting

Sp.

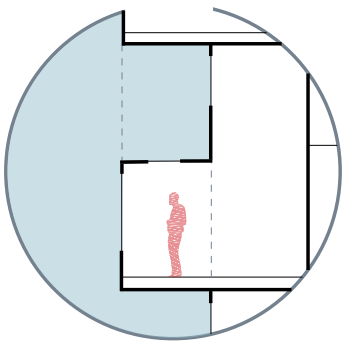

S.

Q.

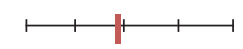

S.

Q.

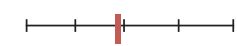

S.

Q. 


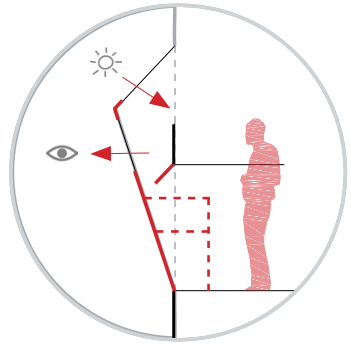

Figure 47 - Bedroom window form context

\section{Key \\ Spaciousness}

S. Size

Architectural quality
Figure 46 - Final secondary zone window form *
One of the crucial parts of the evaluation process is to determine the success of qualitative research implementation. Materiality, architectural quality and perceived space cannot be reduced to numbers or abstraction but must be experienced. This stage in the evaluation process was to put the research into context to understand the implications of the design while in use. These iterations reflected ways in which the space could be used. Seating was decided as the best application of the space to bring the occupant to experience external qualities such as light. Other applications which were tested were; draws, head of bed, desk and storage, but all reduced the spaciousness of the space. Next an architectural language was to be developed, which could express the research implementation and not diminish it.
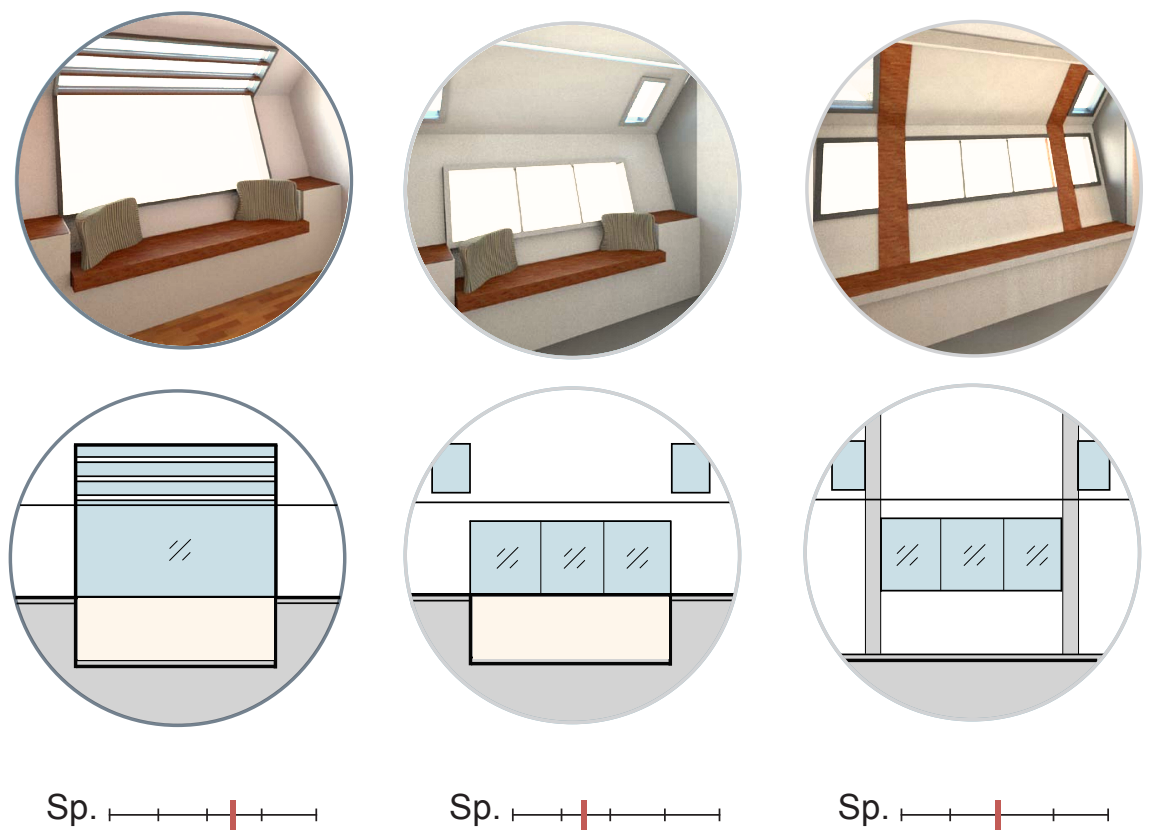

S.

S.

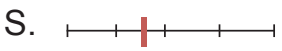

Q.

Q.

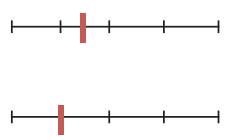

Q.

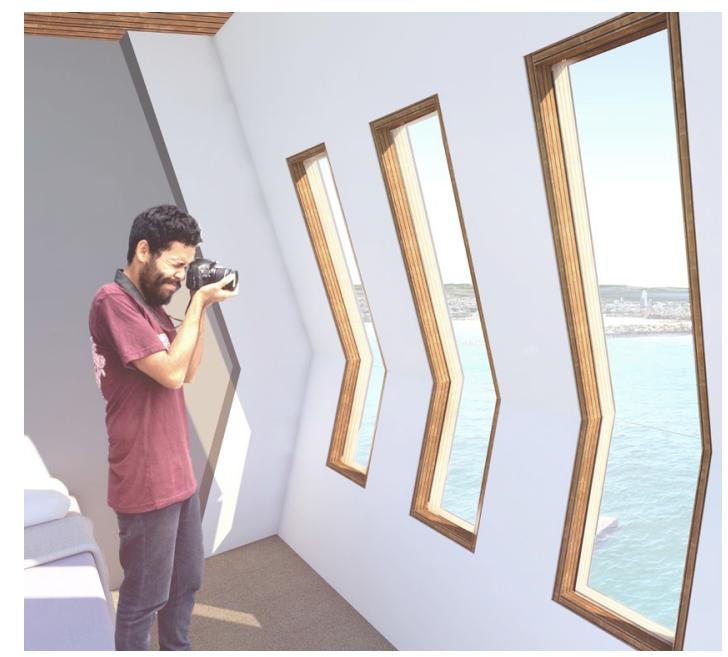

It was concluded that cluttering the design decreased the success of increased perceived spaciousness. Simple architectural moves, focusing on light and materiality, were shown to be the best solutions to achieve the goal of improving spaciousness. 
Figure 49 - Final basic form movements
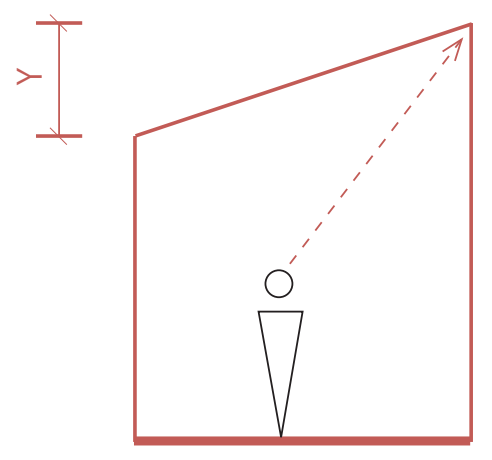

The evaluation process developed the architectural principle of increasing the line of sight to improve perceived spaciousness. This was explored through form development which illustrated that each plane of a volume did not need to increase to its maximum on an axis to gain the benefits of the optimizable parameter. The perceived width can be achieved at only $50 \%$ the objective increase through angled planes and understanding of line of sight. Two main form movements have been established, one increasing on the $Y$ axis to improve perceived size and the other on the $X$ axis to improve perceived spaciousness (Figure 63).

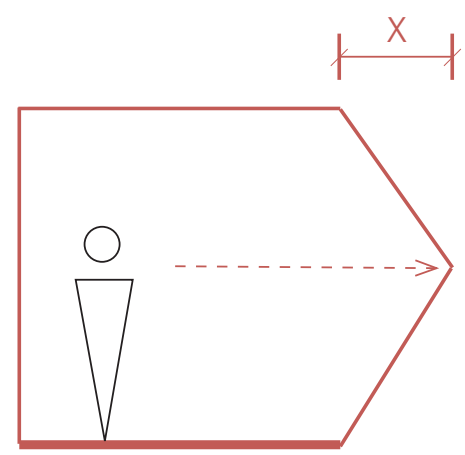

Three main architectural locations to increase perceived size and spaciousness within the dwellings through form have been established through this process (Figure 62). Visual connection through primary and secondary zones and optimization of space have all been informed through the VR evaluation process to improve perceived size and spaciousness within high-density design.

Balcony

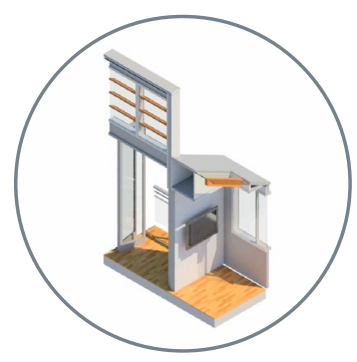

Sp.

S.

Q.

Form quality

Key

Spaciousness

S. Size

Architectural context within a Living Room setting 
Materiality is a key component to architecture and the perceived space. It was found in this evaluation process that floor and ceiling texture had large effects on the perceived environment. The evaluation process set up a built environment and rated the space with each material change. While colour had an impact, reflectivity, texture and shading influenced the space far more.

Figure 50 - Final material selection explored through VR design evaluation cos

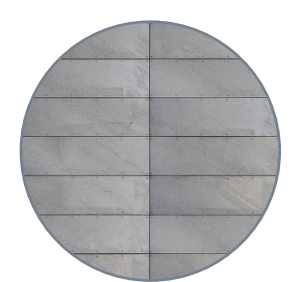

Wall material

Floor material

Frame material
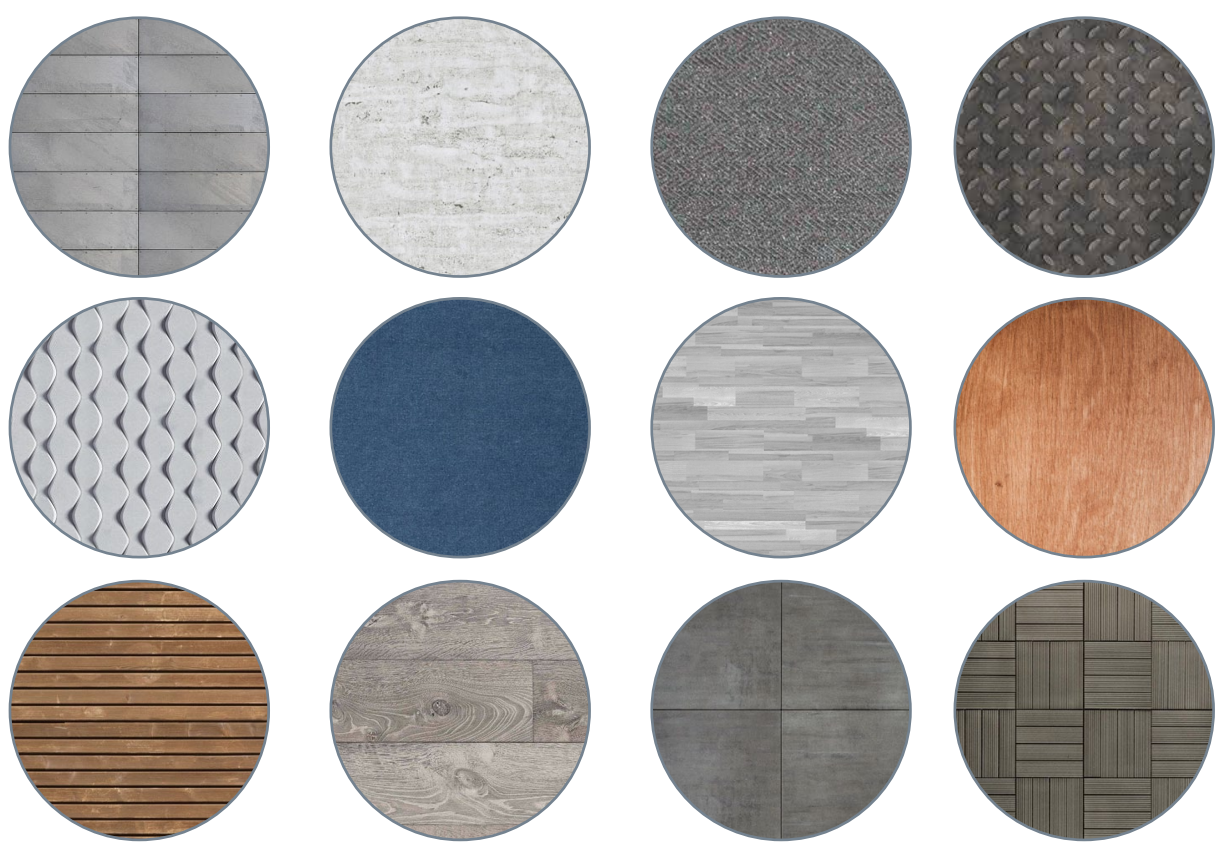

The ceilings were largely affected by contrasting and coarse textures. The largest increase of the perceived space was found in wood slat ceilings or 3D ceiling panels. The three dimensions and shadows that were created by the forms created a depth which increased the visual understanding of the volume. Wood slat was chosen because the warmth of the texture added to the architectural quality

Carpet made the space feel smaller yet more comfortable. This contrasted with wood flooring which made the space feel open but hard. Over a series of design tests I decided to go with stone tile flooring in the living and dinning rooms because it made the apartment feel larger and more spacious. The glossy texture of the stone reflected dim light around the space increasing the perceived volume.

It's important to note that the program unity does not allow a true representation of materiality. To fully explore the optimal solutions through materiality a more detailed iteration process is needed. The lack of expenses meant that only free textures or hand-made textures could be explored, which was limiting. 

7.0 PRELIMINARY
DESIGN

7.6 BUILDING ITERATION
Parallel to the VR evaluation I began to develop dwelling models. This process explored other areas of the building to form the largest subjective increase with the smallest objective increase at the largest scale. The reflective design process allowed me to experience the design and make informed decisions to continue or improve the design while in discussion with every iteration component. This allowed a coherency between small and large scale design iteration to ensure the thesis aims were being met.

Figure 51 - Dwelling

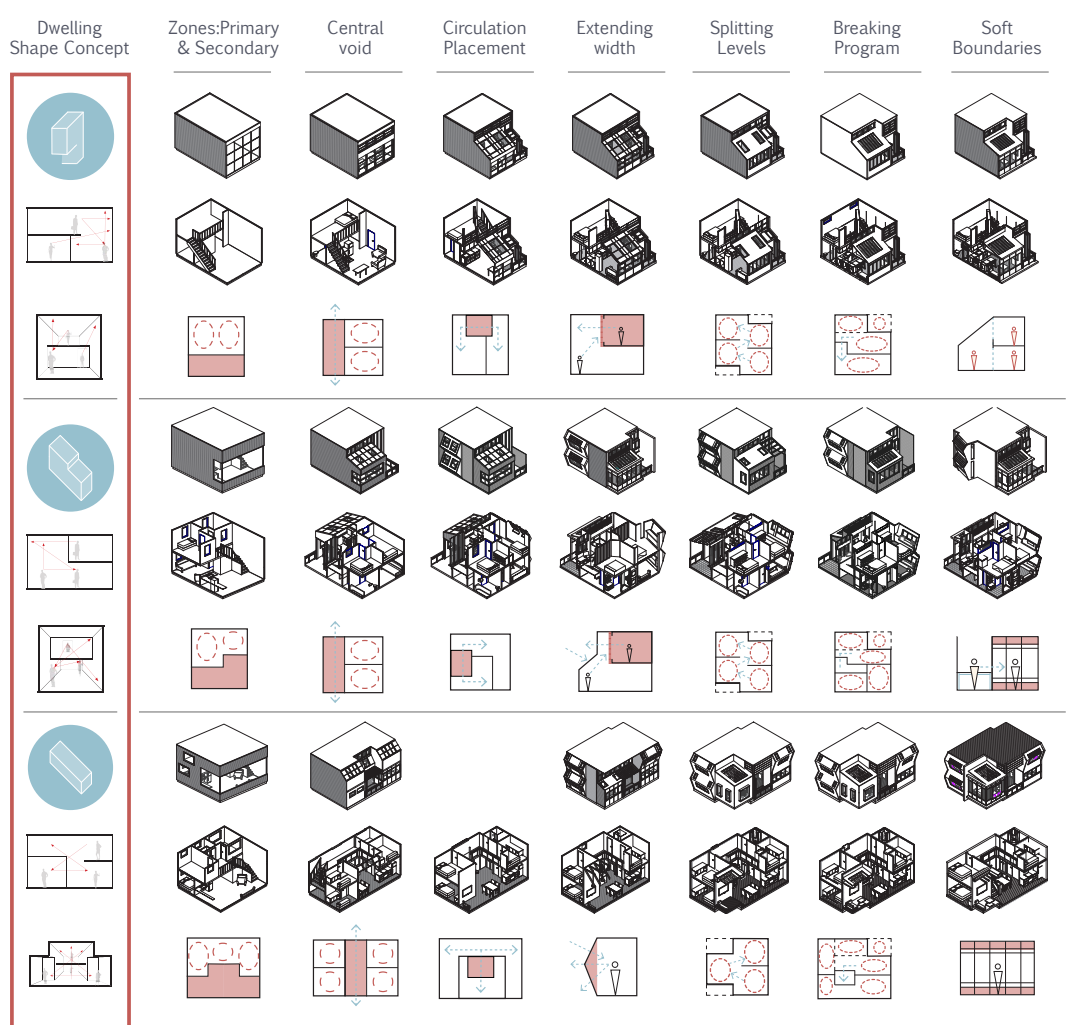

Dwelling strategies such as primary and secondary zones were developed through these large scale architectural iterations. Questions or issues were extrapolated to explore design solutions which would then lead to the next iteration (see figure 63). The compiling of this process informed the design solutions in a systematic sequence so that all areas can be explored and questioned. 2D drawing would conceptualise the issue and then the subsequent design solution was developed into 3D models. The final cuts of those models that had the most potential were then translated into VR to evaluate the spaces. The benefits of this process is that it allows the designer to continuously be put into context and re-establish the design goals of the project. Experiencing unsuccessful iterations increased the understanding of space dramatically and almost instantly allowed design discussions to take place. The virtual environment created a creative atmosphere in which to explore, design, and experience, allowing a perceptually informed design. 


\subsection{PRELIMINARY DESIGN}

7.7 BUILDING RATIONAL

Figure 52 - Building form rational
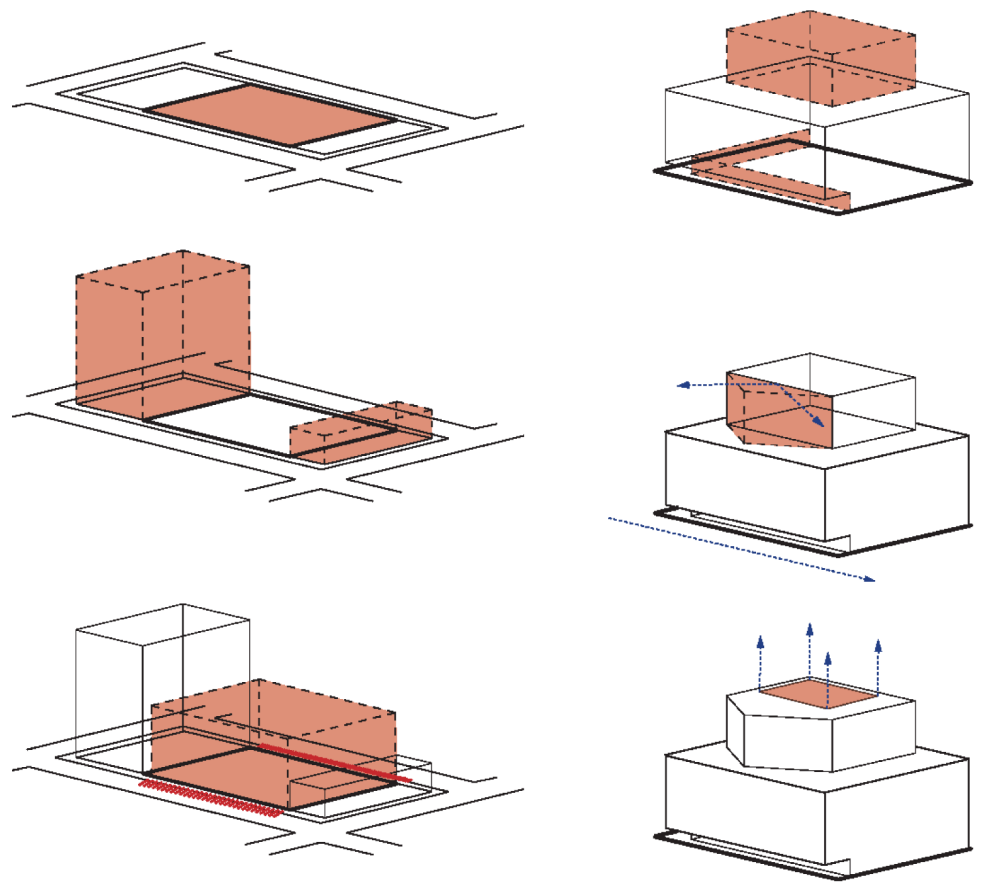

Site

Base
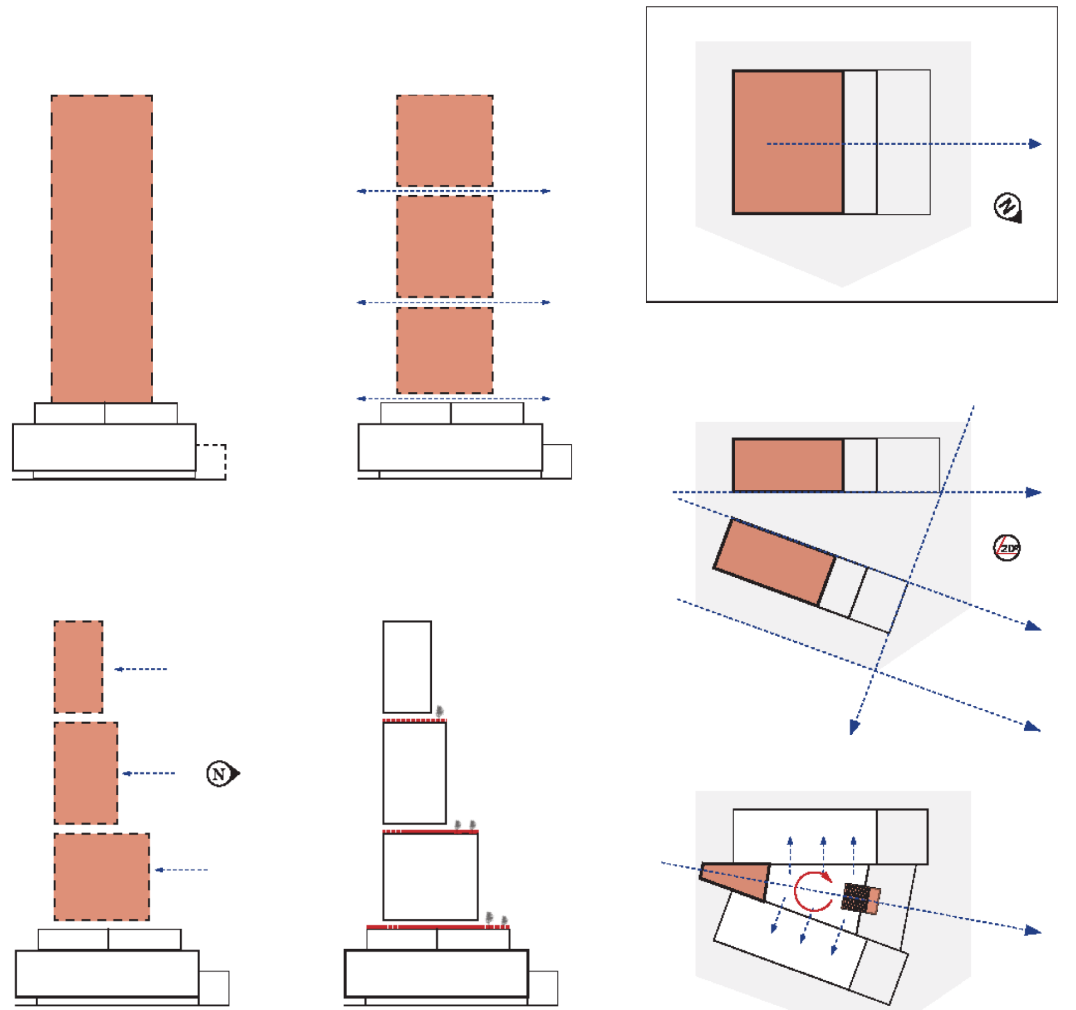

Height

Plan 


\subsection{FACADE}

\section{DEVELOPIMENT}

Figure 53 - $\quad$ Facade iterations
A design rationale for the overall building scheme has been developed to accommodate the apartments and secondary spaces for this thesis (Figure 30). Firstly, site and base iteration dedicated a section which could be of retail, parking or office typology. This section is out scope for the design research as it does not directly relate to apartment design. Secondly, height breaks down the buildings mass to establish three main components. These components form three apartment arrangements of the one, two and three dwelling types. Thirdly, plan investigates the typical parallel dwelling arrangement in a long yet tall corridor space which feels claustrophobic, even though the objective space is rather large. An expanding floor plate from the elevator bay creates the perspective of a larger space. The floor plate opening to the feature staircase and double height windows looking over the city forms an expansion of the research parameters to form a spacious environment.
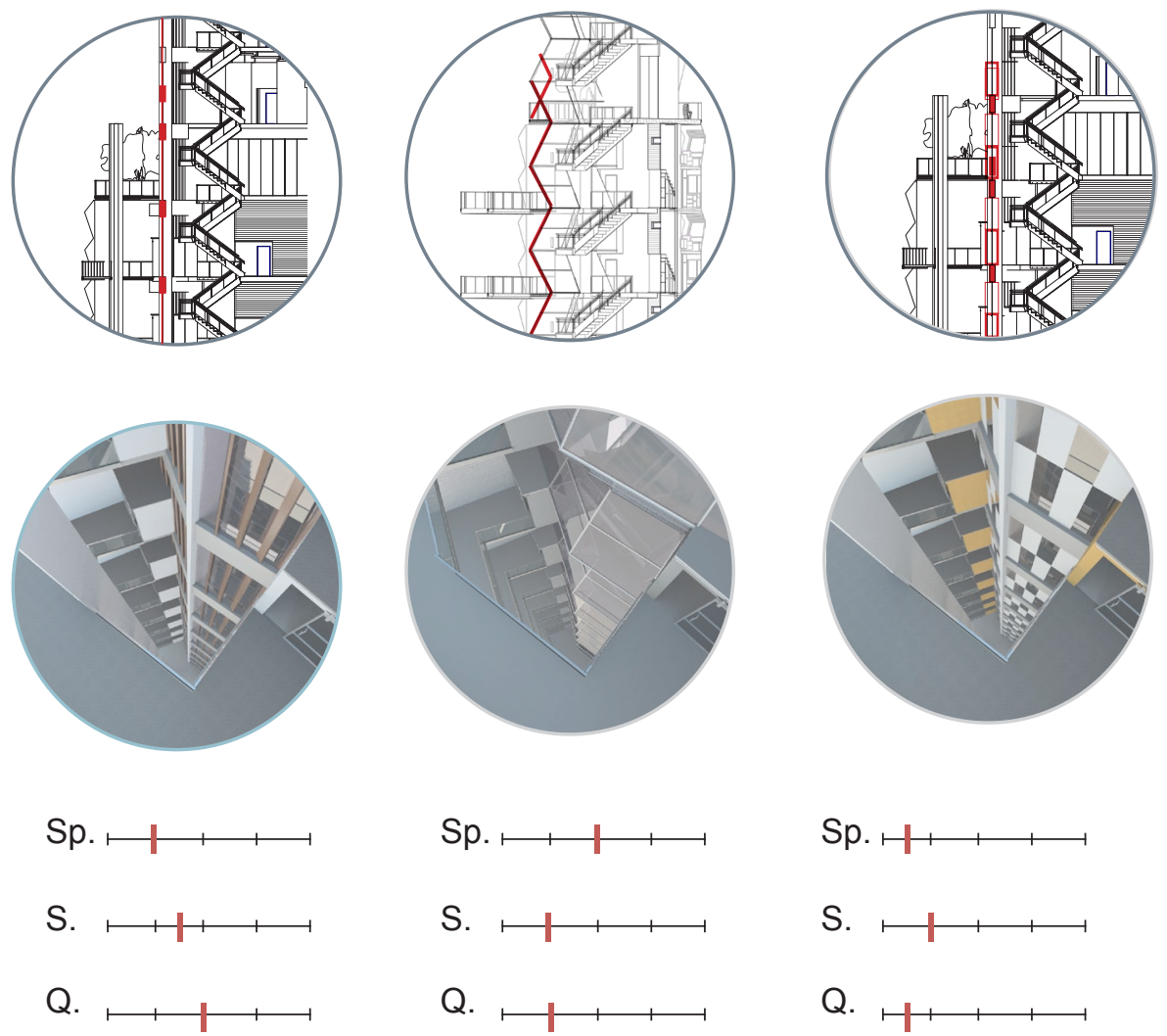

S.

Q.

The facade iterations did not meet the requirements of the thesis. The design was too sharp resulting in chaotic architecture. The facade wasn't reading as a single entity which was necessary to tie the building together. A series of iterations explored design solutions which would allow for a single entity. The highly active architecture of the dwellings needed to be contrasted to a single architectural moment to express a coherent design language. Each of the design iterations were unsuccessful as they were not enhancing the research expression of dwellings and circulation spaces. Further development was needed to achieve the thesis goals. 
This experiment has confirmed that the parameters defined in the previous experiment translate into non-abstracted environments. In the experiment participants experienced three apartment designs with a randomly selected order. The designs were constructed from the end of preliminary two bedroom dwelling and was manipulated with the optimising parameters (Figure 65). Dwelling 2 had an increased height of $50 \%$ and decreased width of $50 \%$. It was predicted that the perceived size would increase and spaciousness decrease as per the experiment research. The opposite was expected for dwelling 3 with an increased spaciousness and decreased perceived size. The dwelling types kept consistent volumes to ensure valid results. The participants had two minutes to look around the design before being asked to verbally complete questions describing their perception of the design in terms of perceived liveability and spaciousness. Once complete, the participants were asked to return to the Scale Room to best match the Room's volume size. 15 subjects participated in the 30 minute experiment to allow for reliable results. The aim was to include many various interior elements, such as materiality, to express the significance of the design parameters when altered. Refer to the appendix for the criteria for selecting the participants.

Table 2 - Experiment questions

1) On a scale to 1 (Strong No) - 5 (Neutral) - 10 (Strong Yes) rate if you would like to use Room \#/ Scale room.

2) On a scale to 1 (Enclosed) - 5 (Neutral) - 10 (Open) rate the spaciousness of Room \#/ Scale room.

Figure 54 - Confirmatory experiment designs

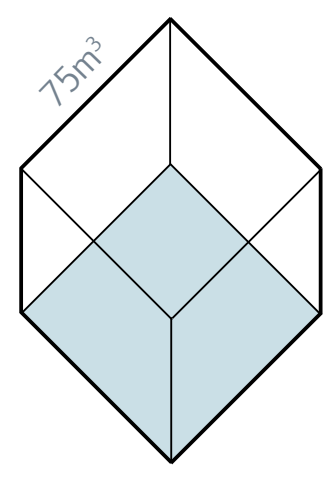

Design 1

Preliminary final

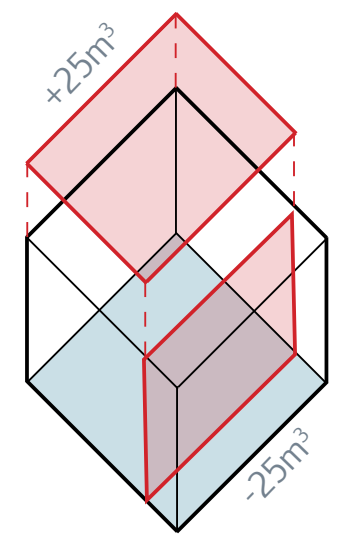

Design 2

Decreased width Increased height

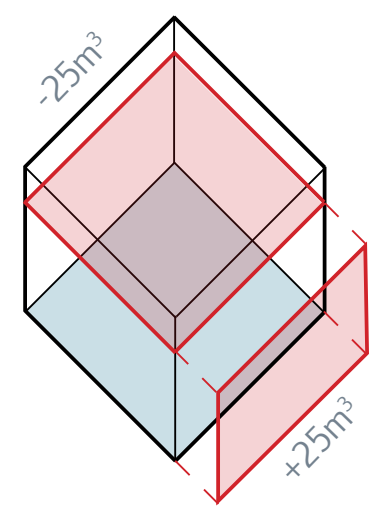

Design 3 Increased width Decreased height 


\subsection{PRELIIMINARY DESIGN}

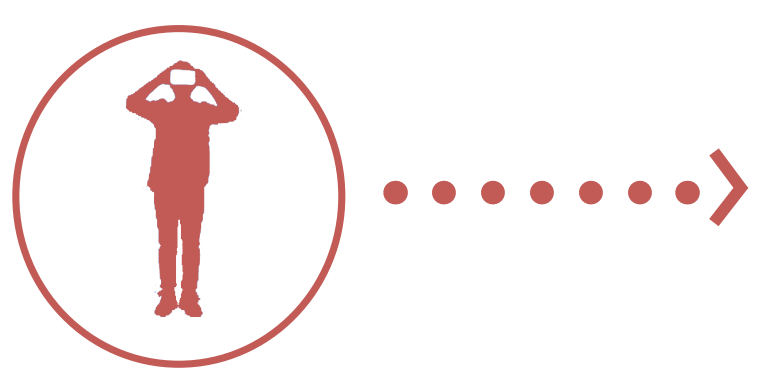

Participant

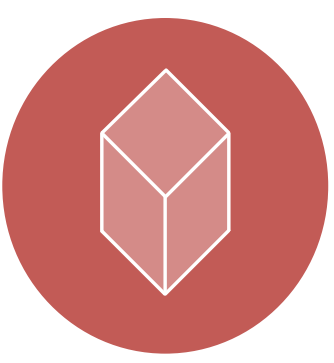

Scale room

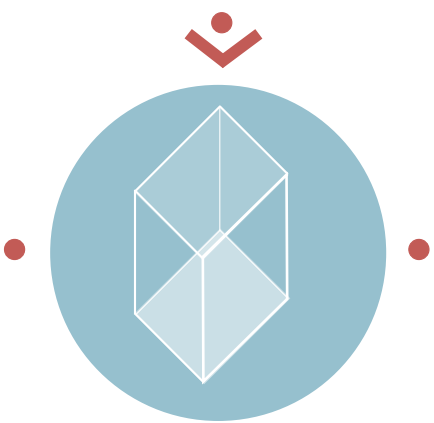

Design 2

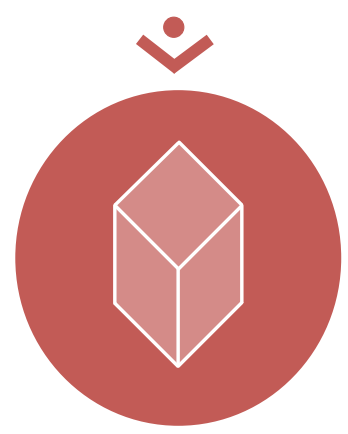

Scale room

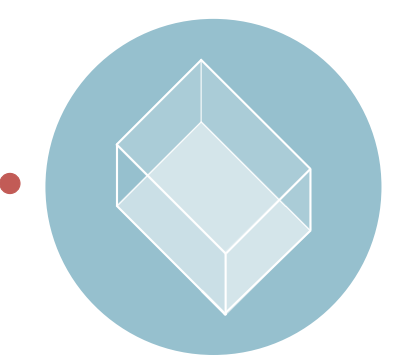

Design 3

Design 1

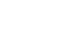

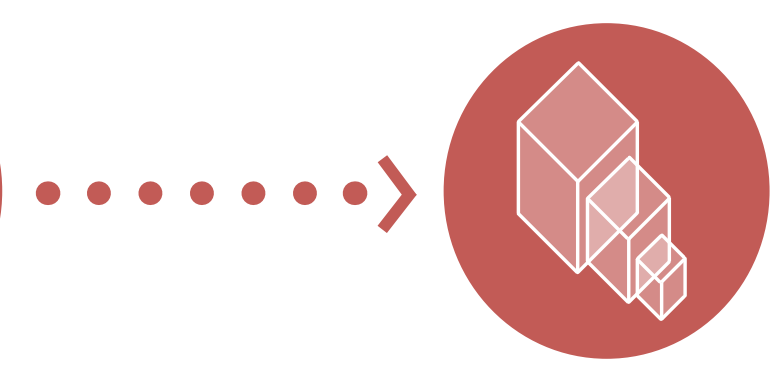

Matching

Figure 55 - Confirming that the VR experiment parameters translate to non-abstracted environments method * 


\subsection{PRELIMINARY DESIGN}

7.10 RESULTS

Figure 56 - Perceived volume size increases when ceiling height is increased in a nonabstracted setting *
The data from the first experiment illustrates that the outcomes can be predicted when manipulating the two parameters of height and width. This demonstrates that the parameters are still impactful in realistic environments. As height increased the perceived volume increased, as seen in Figure 67. Likewise as average room width increased perceived spaciousness increased, as seen in Figure 68.

\section{Perceived volume}

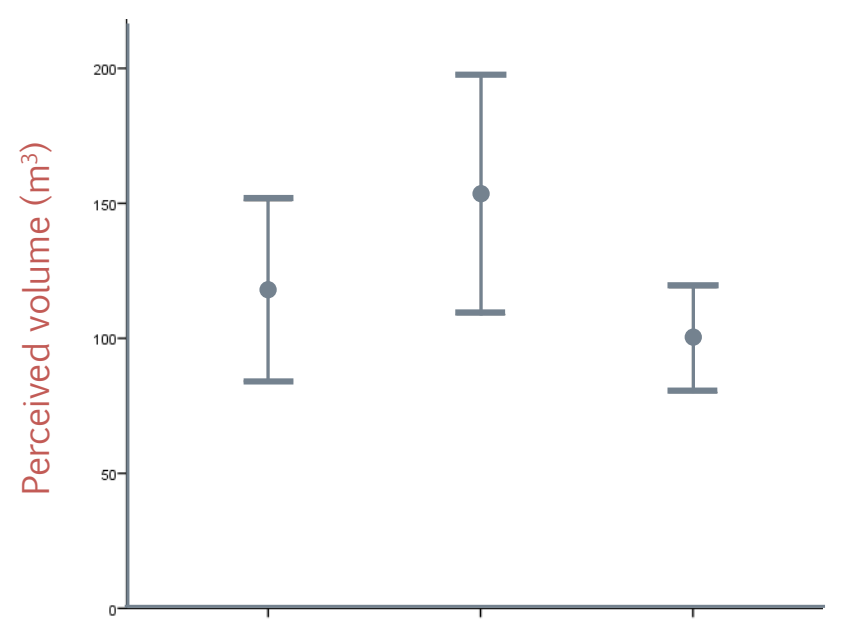

Design 1 Design 2 Design 3

Figure 57 - Perceived spaciousness decreases when room width is increased in a nonabstracted setting *
Perceived spaciousness (s) and liveability

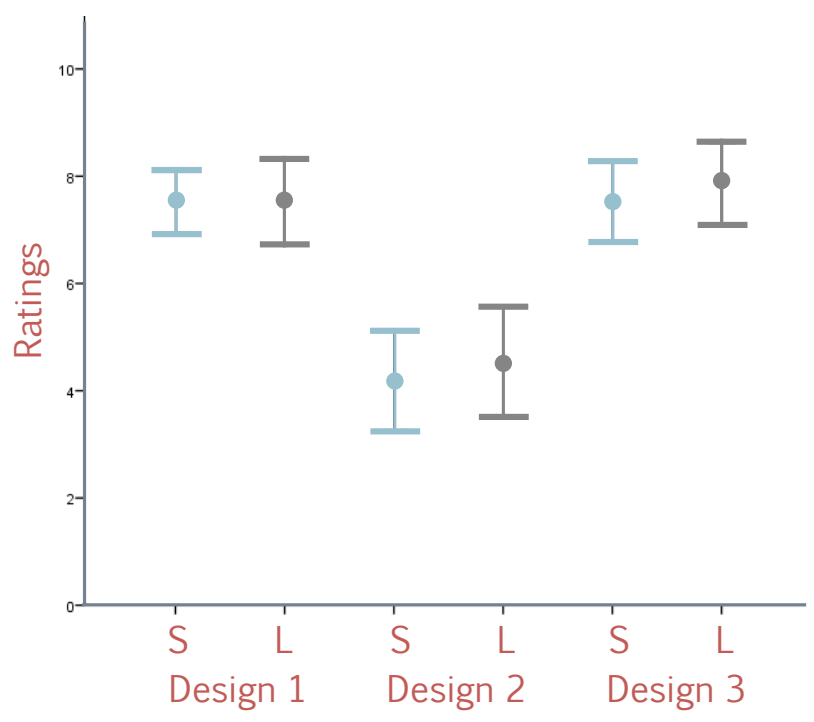




\subsection{PRELIIMINARY DESIGN}

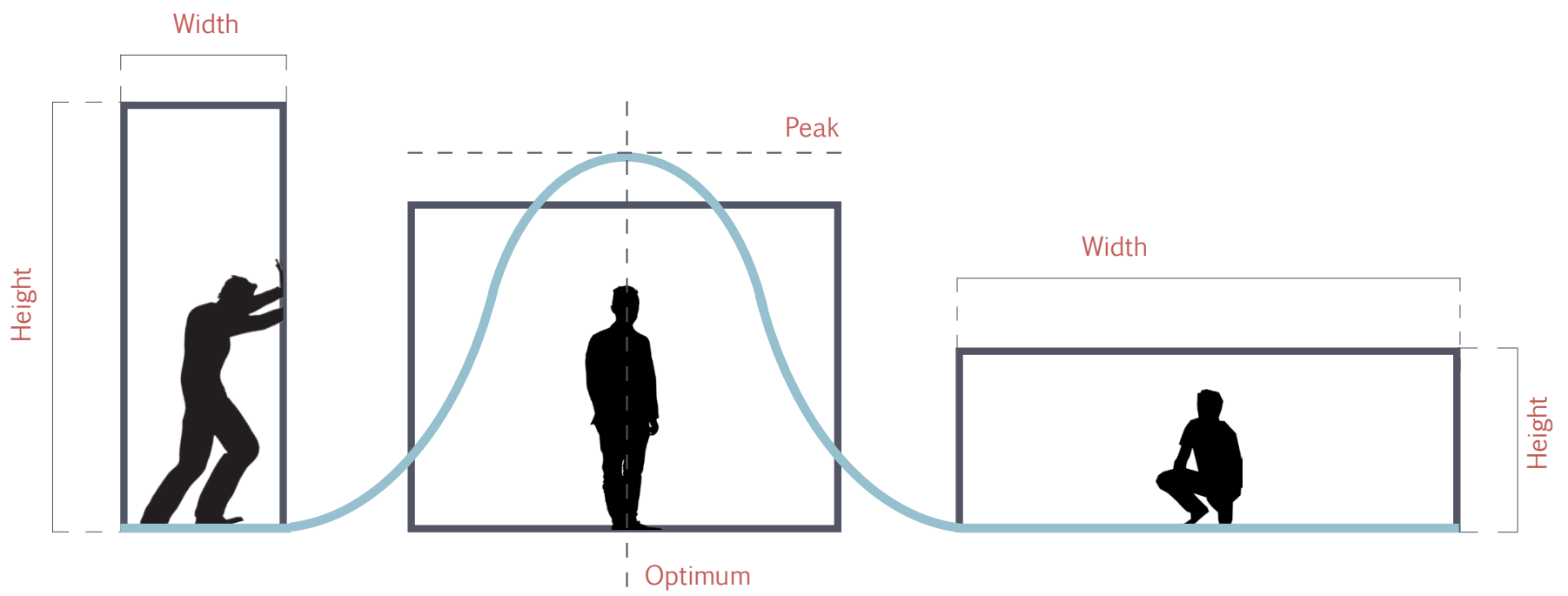

Figure 59 - optimizing parameters - establishing parameters thresholds *
Figure 58 - $\quad$ Optimal solution between perceived spaciousness and size (Figures 33 and 34$)^{*}$
I hypothesized that perceived spaciousness would not a have a linear relationship to room width at a constant volume but rather a curve (Figure 70). If you imagine a square room and you increase the width of the room while keeping a constant volume until the ceiling was $1 \mathrm{~cm}$ above the ground then that room would not be perceived as spacious. Therefore, there must be a curved relationship in which spaciousness increases to a peak and then reduces. This has been suggested in Figure 68 that by increasing the room width the spaciousness and livability ratings did not increase. This illustrates that design 1 sits around the peak of the curve. However, though design 1 and design 3 have the same spaciousness ratings design 1 has a larger perceived size. Figure 69 illustrates that design 1 is the optimal solution for both perceived spaciousness and volume.

\section{Optimum solution}

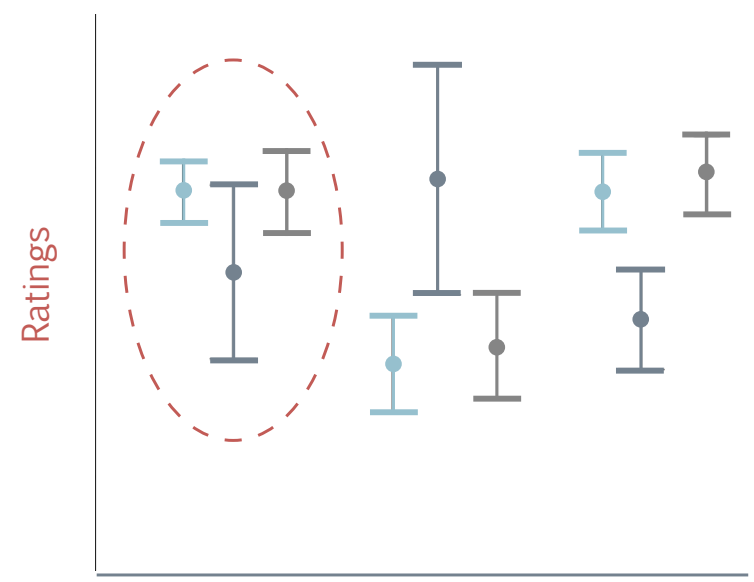




\subsection{PRELIMINARY DESIGN}

\subsection{FINAL PRELIMINARY DESIGN}

The dwelling types each focus on the primary and secondary zoning within. This strategy enables the architectural principles of perceptual overlap, extending width and optimization of space to take place. Each of these dwellings are still set at the minimum floor plan requirements as set by the Auckland city council as an opportunity to challenge high-density apartments in a New Zealand context.

Figure 60 - Final preliminary dwelling designs
One bedroom dwelling

Two bedroom dwelling

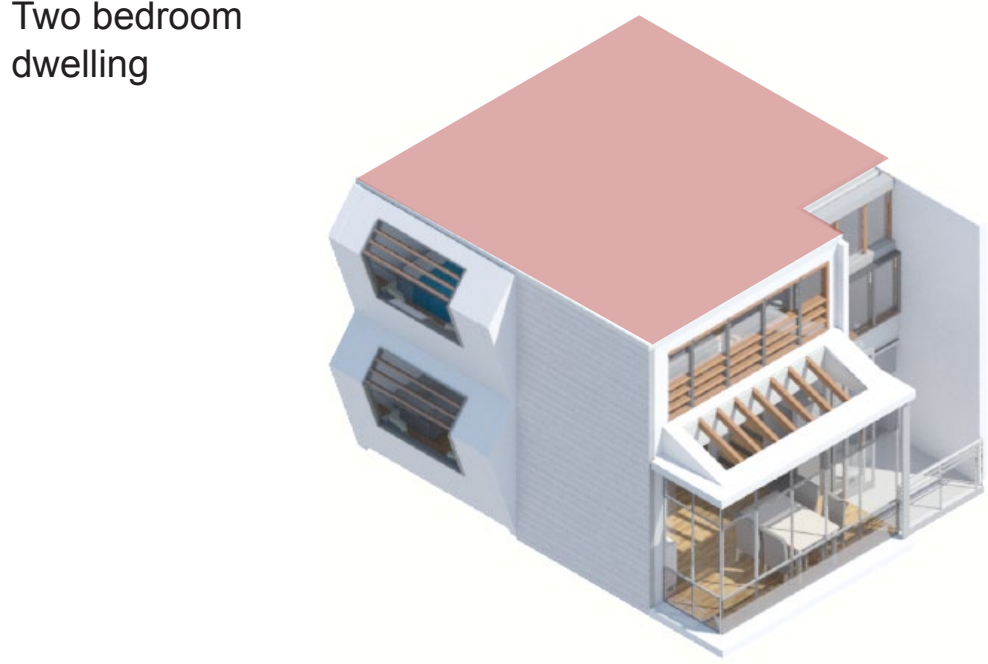

Three bedroom dwelling
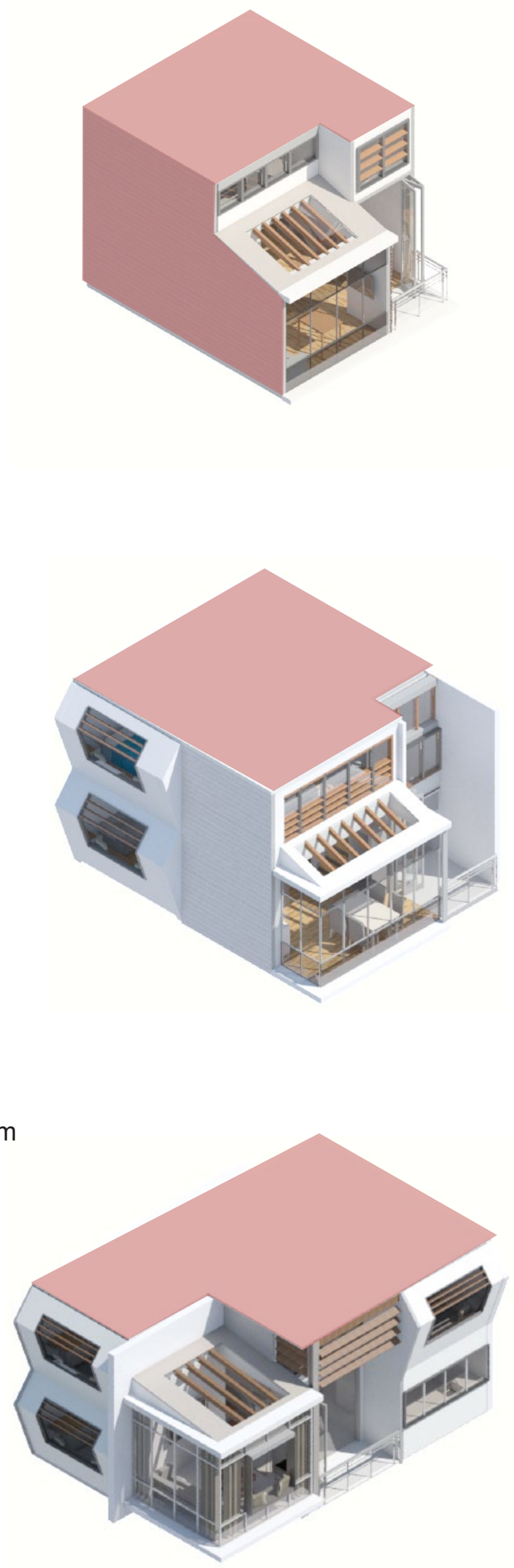


\subsection{PRELIMINARY DESIGN}

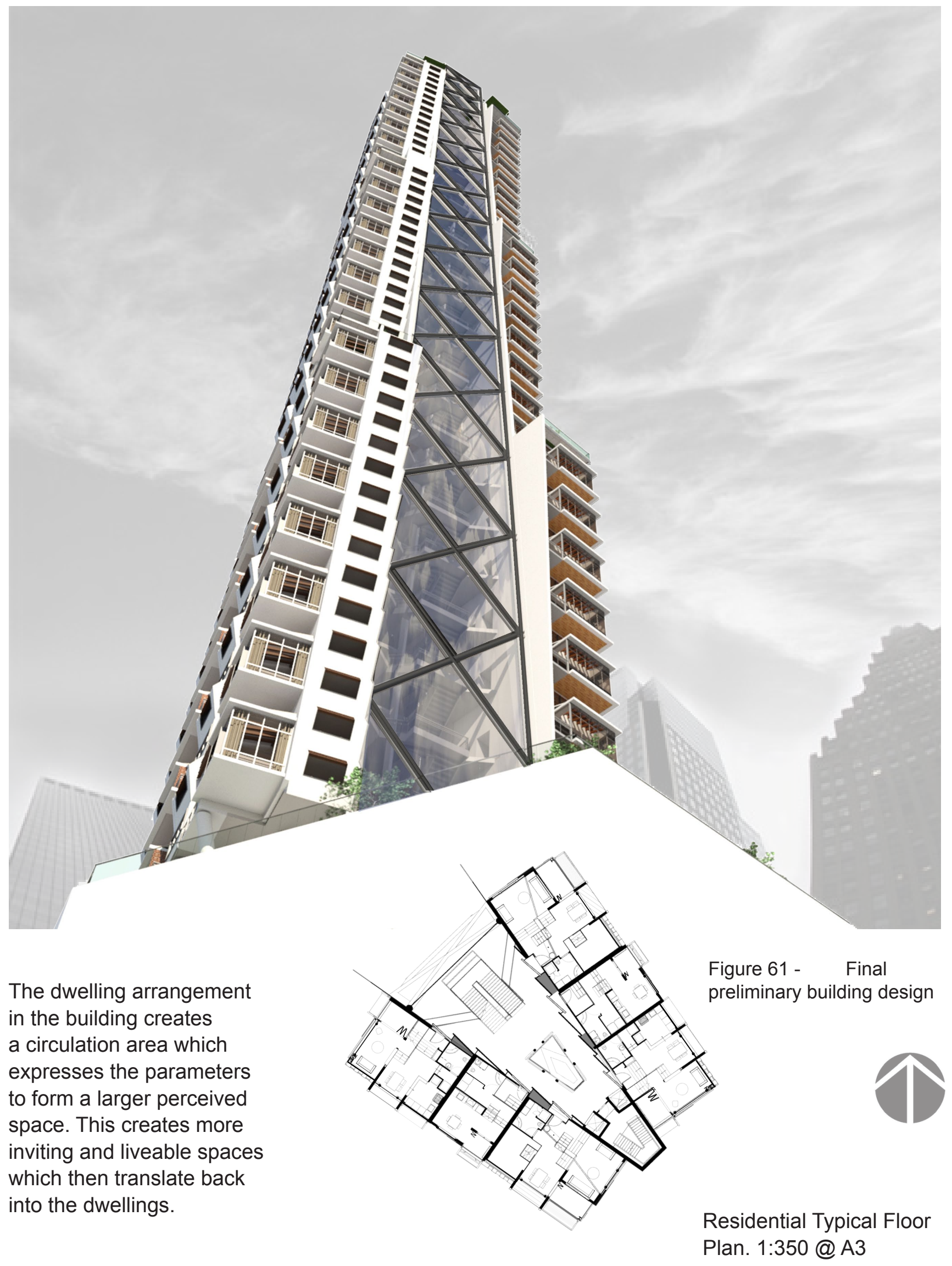

Plan.1:350@A3 


\subsection{PRELIMINARY DESIGN}

The dwellings in section

(figure 74) illustrate the primary zone, which acts as the centre of the dwelling. The secondary zones can then share the subjective space increasing the perceived width of the rooms. This creates more spacious and liveable environments by utilising the architectural principles.

Figure 62 - Preliminary design dwelling section

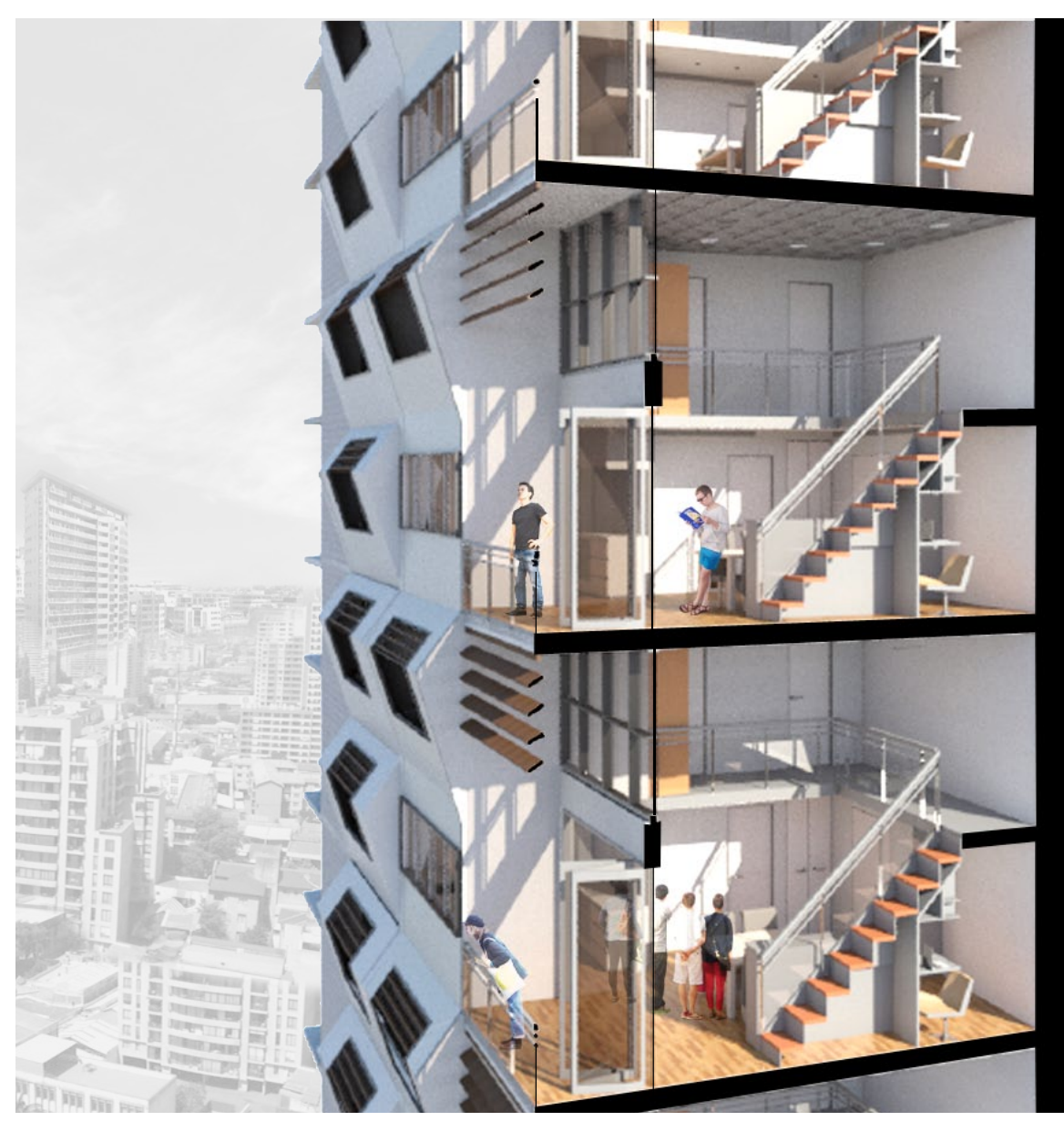

Figure 63 - Preliminary design building perspective elevation
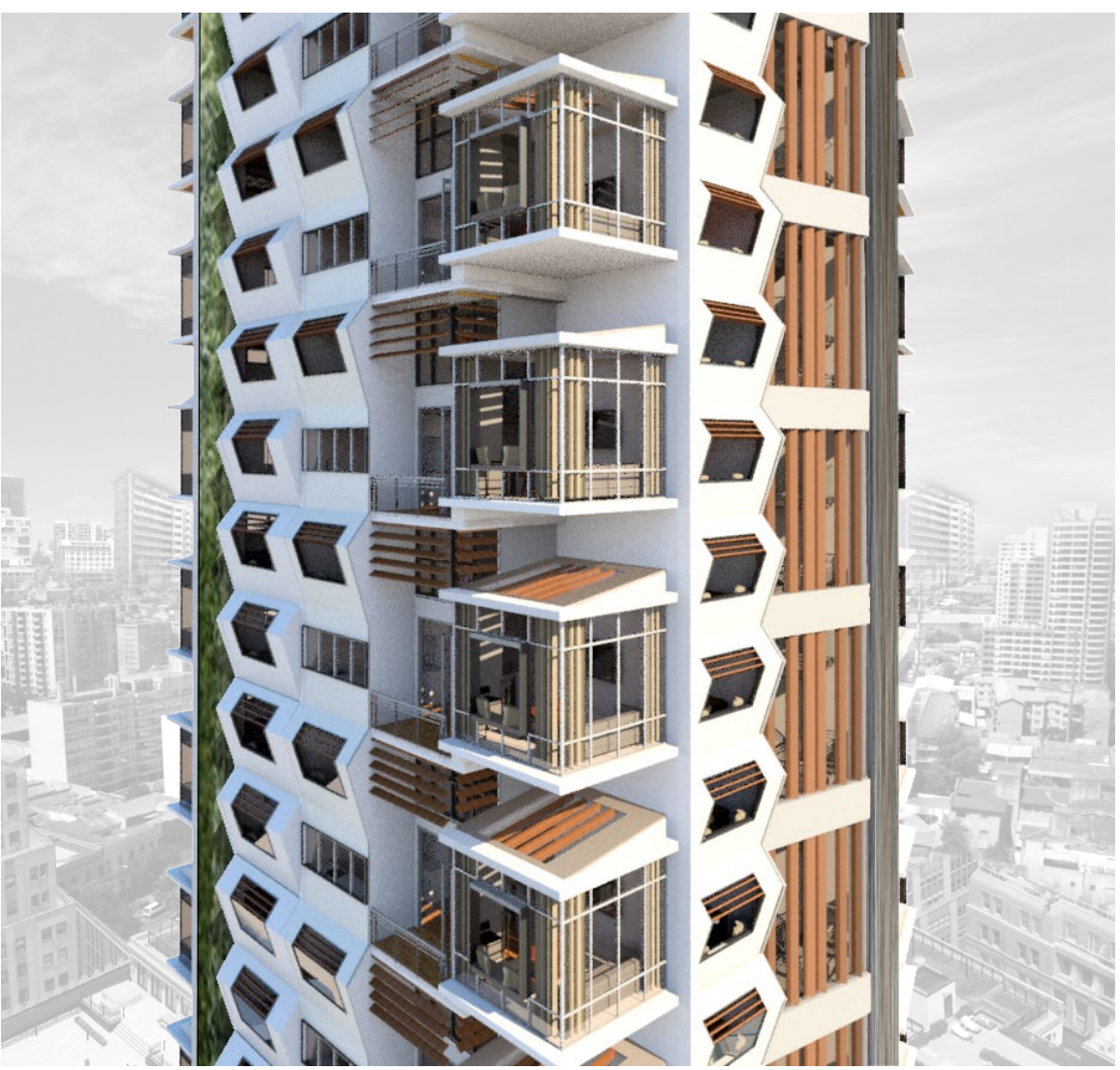


\subsection{PRELIMINARY DESIGN}
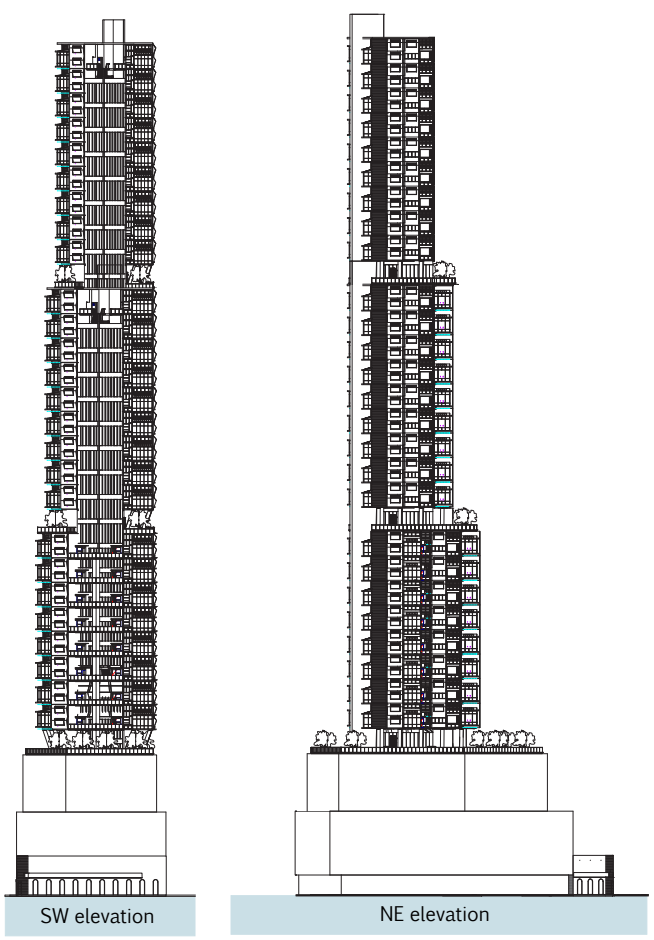

Figure 64 - Preliminary design building elevation

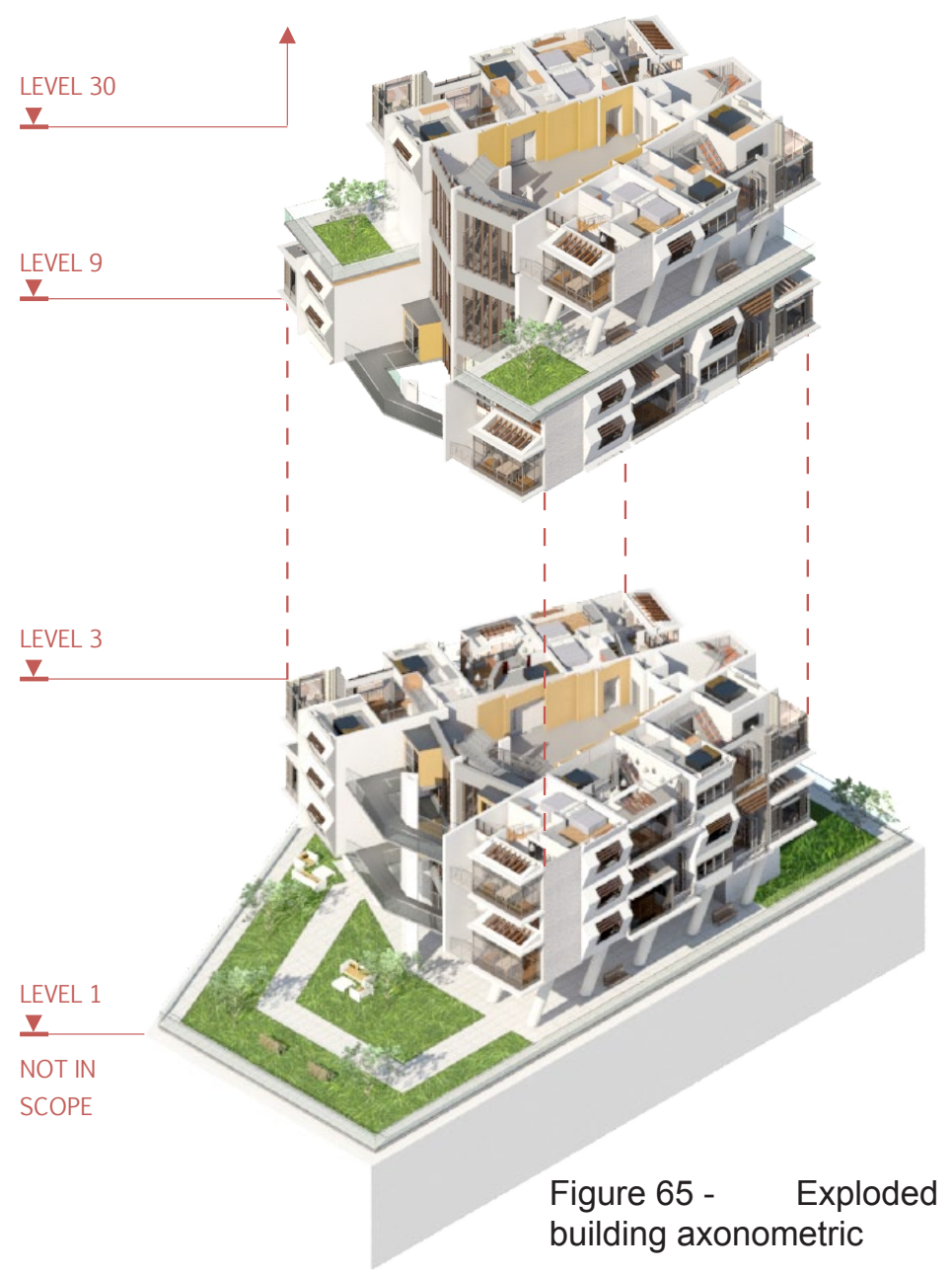

\subsection{PRELIMIINARY DESIGN REFLECTION}

\subsection{SECTION SUMIMARY}

The preliminary design has been constricted by the initial design setting. This has resulted in an architecture which isn't reflective of the research or the implementation of principles. The developed design will address this issue by rethinking original spatial planning. The design can then develop to fully resolve the dwelling types. This process has been crucial for architectural principle development/implementation by exploring design process to identify person scale issues. The developed design will tie together these resolutions to formulate a coherent architecture by focusing on design solutions which use the architectural principles.

This chapter has investigated initial design solutions through the VR evaluation process. The foundational architectural principles established in chapter 6 have been developed to improve our understanding of the perceived space. This insight will be transferred into final design solutions in chapter 8 which focus on both large and small scale design to ensure a coherent architecture which reflects the goals of the thesis. 


\subsection{PRECEDENTS}

Figure 67 - $\quad$ Makoto Tanijiri on Architectural Education and "Japaneseness" (Suppose Design Office, 2016). Split floors plates exposing dwelling volume

Figure 66 - House $\mathrm{N}$, Japan. (Baan, 2008). Double height spaces which translate light

Figure 68 A new office space for Spicebox (Ano, 2013). Pod architecture which separates room programs which expressing each
I have been linear in my design approach, limiting myself to the confines of more conventional architectural design which lies outside my research topic. For my design to truly represent my process and experiments the designs must have a transparency to them. This has been explored in Japanese architecture which use spaces within spaces, removing the rigid barriers of conventional thinking and modelling. This chapter will be working through the developed design to focus on the architectural quality and translation of research into the designs. The aim for this chapter is to resolve the issues from the preliminary design and formulate highly developed dwellings and secondary building spaces.

I have found that designing alongside my research has generated various outcomes. My preliminary design was heavily influenced by conventional architectural techniques. I focused more on my architecture parameters from my experiment research which were very basic in design. After revising my preliminary designs and my research into architecture precedent I have found that my design lacked architectural intent. On reflection, I have found that working with precedent throughout the design process is essential when creating architectural design solutions. I now look to architecture precedent to explore how I might use relevant materials within my developing design, that are not restrained to conventional thinking.

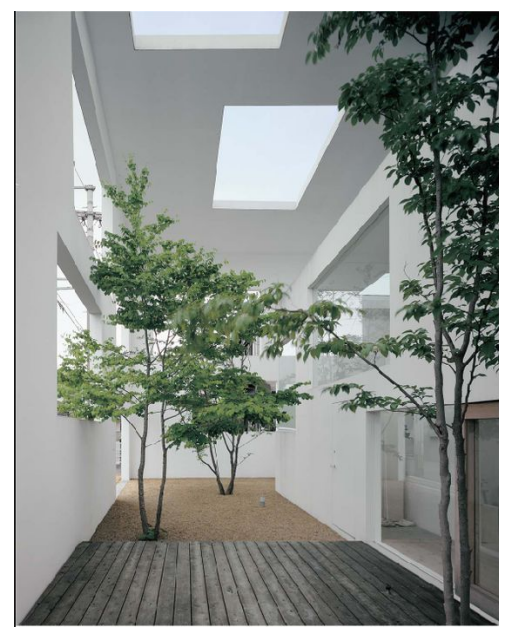

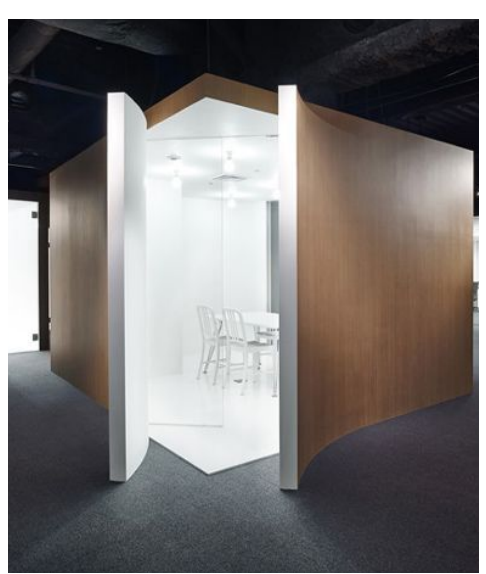




\section{DESIGN}

Figure 69 - Dandesign, Nagoya, Japan (Mizuno, 2014). Light weight stair structure which enables a visual connection Figure 70 -
Onsen Fujiya

Ginzan (Ozuhazawa-shi , 2006). Materiality of wood slat which expresses form, texture and colour to enhance a space

Figure 71 - Barn Style Home Design by Japanese Architecture Firm (Suzuki, 2011). Broken light entry to disperse around the dwelling

Figure 72 - $\quad$ SANAA Studios, Tokyo, 'House with growing plants' ( Nishizawa, 2015). Using penetrations through floors which communicated between different spaces

Figure 73 - A simple and modern Japanese house by Studio Synapse (Torimura , 2012). Light weight ceilings which communicate soft volumes

Figure 74 - Koya No Sumika, mA-style Architects" (Nakamura, 2013). Utilising ceiling space to express form and design
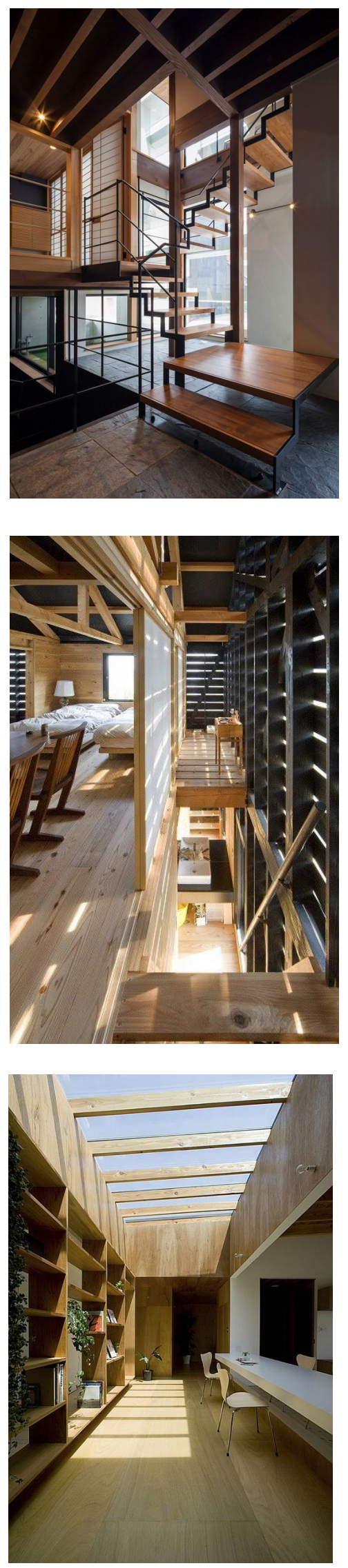
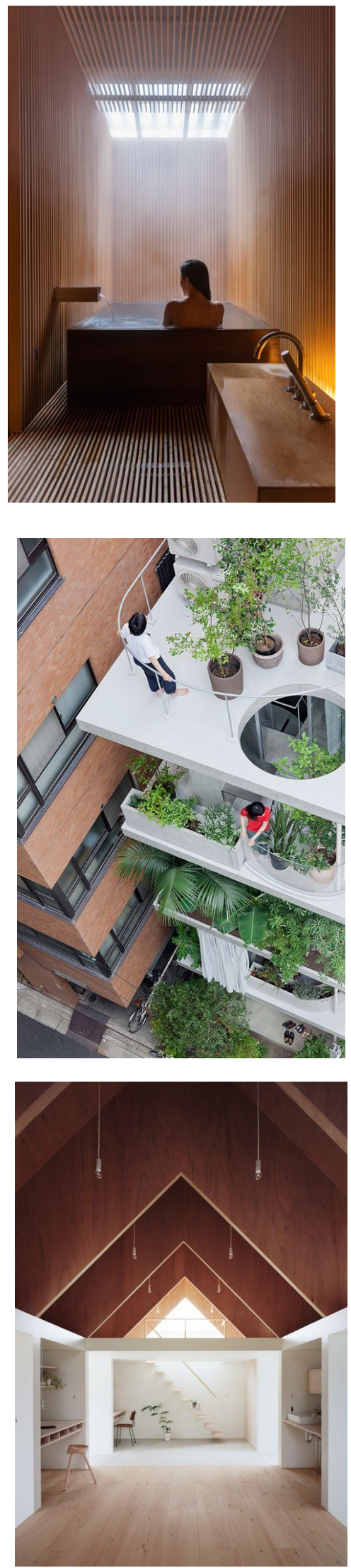
Figure 75 - The Ludwig Erhard House (LEH) located in the Berlin district of Charlottenburg in the Fasanenstraße, 1998 (Willebrand, 1998)

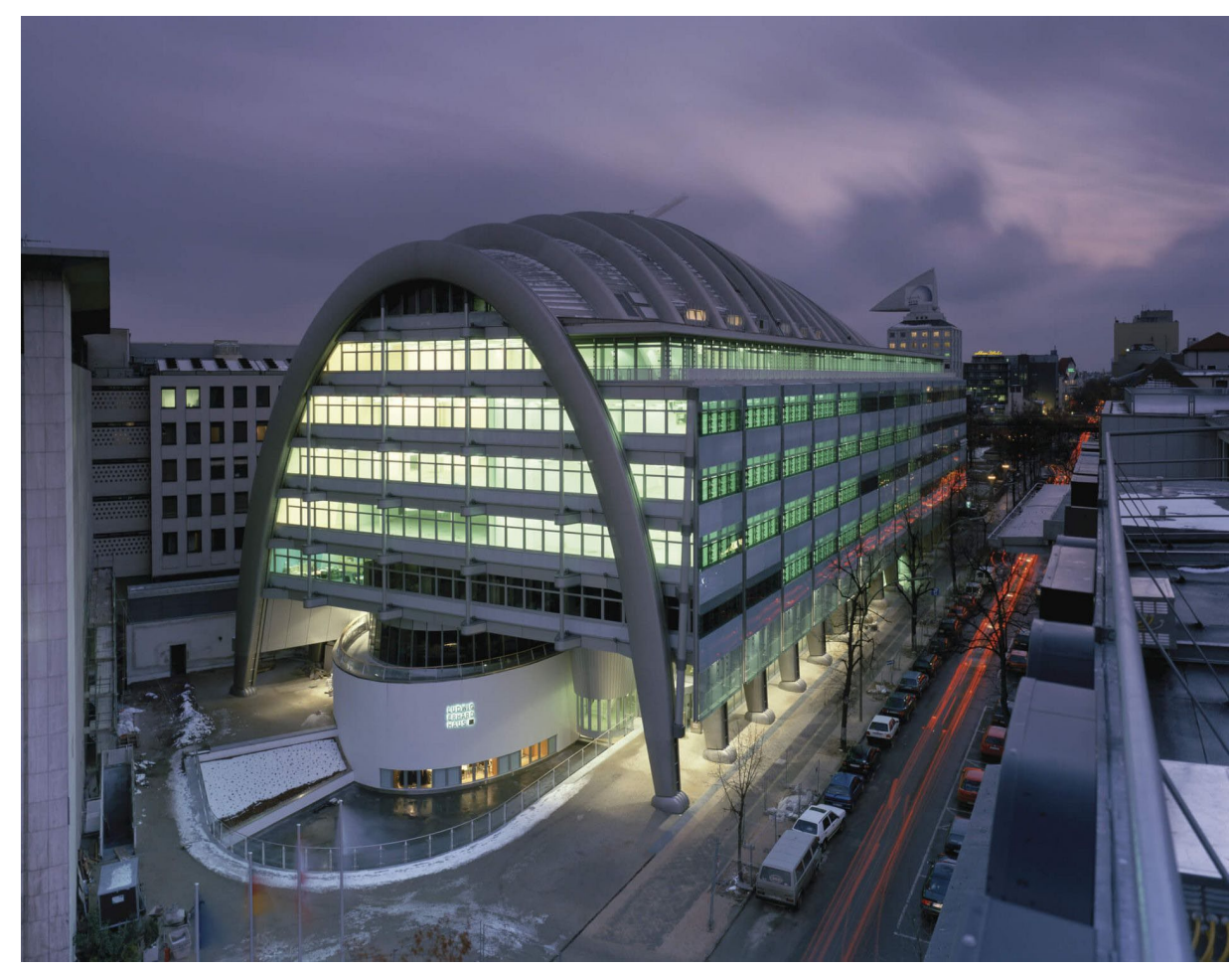

The Ludwig Erhard House (Figure 89) uses hanging columns which allows the ground floor to be virtually structure free. The design intent of the building was to create a large inviting atrium which the structural systems enable. This could be a possible solution to use in a dwelling structure to create further transparency to the ground floor programs.

Materials light and arrangement are all impactful components to the perceived space (Patchwork Architects, 2017). Architectural solutions use materiality to combine these components such as the texture of wood slat on light penetration to express the textures and contrasts of wall and ceiling planes (Figure 84). Floor plate penetrations can also be used to express volume and form a visual connectivity between spaces (Figure 86). One key directive for this thesis is to form a transparency through the architecture which has currently not been achieved. Figure 81, Figure 83 , and Figure 85 each separate the volume between programs yet allow the visual connectivity to remain. Figure 38 uses a split floor plate with double height vertical spaces to connect the spaces. Figure 82, reminiscent of Japanese architecture, uses pods within larger volumes to create program hierarchy while allowing a freedom of volume. Lastly, Figure 88 uses form and materiality to express volume and formulate a larger perceived space, utilising the ceiling volume. These precedents will guide the following process to rethink the implementation of architectural principles. 
To begin the developed design I rethink how the dwellings can implement the design research. The constrained interiors of the preliminary design needed to express more transparency in order to reflect the design goals. Firstly, an exercise of removing the solid elements of walls and floors from the dwelling was required to rethink transparency (Figure 90).

Figure 76 - Design process stripping away unneeded elements within the dwellings.

Figure 77 - Design process forming clusters which can fit within a volume and not shut it off.
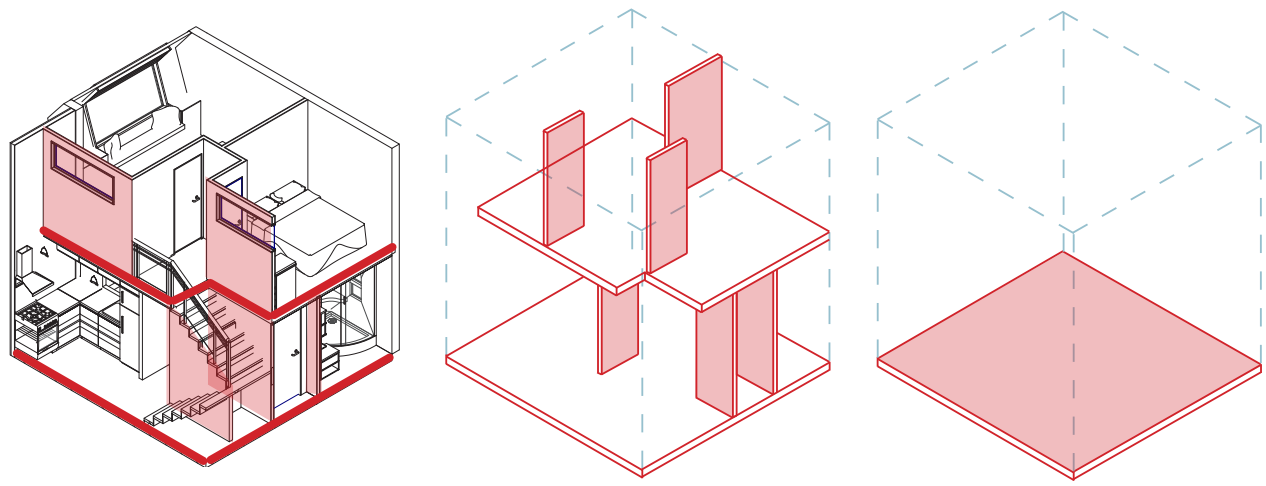

The floor plates of each program were split to allow a visual connection through the dwelling (Figure 91). Pods were then placed around the floor programs to allow for a level of privacy and practicality. However, this did not achieve the desired output as rooms were exposed to the living environment while also not creating a large subjective increase. A design solution was needed which could extend the perceived width without encroaching on the surrounding programs. The pods have progressed the design towards the goals of the thesis but still needed development to form the required visual transparency and connectivity.
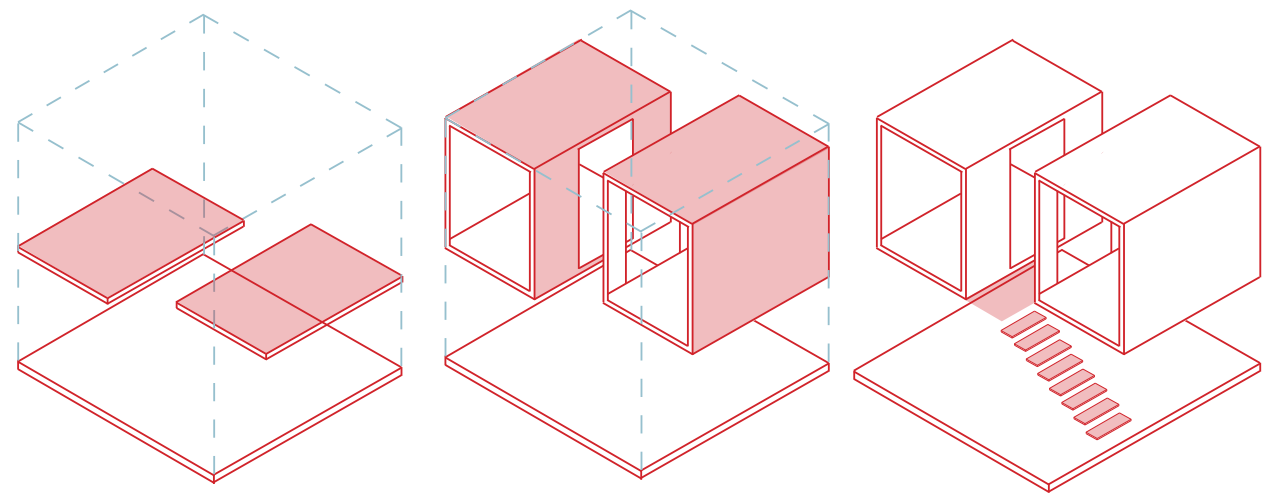


\subsection{CREATING TRANSPARENCY}

Figure 78 - Design process changing dwelling framework to increase line of sight
Figure 79 - Design process to best implement the architectural principles while allowing privacy and practicality
Issues of privacy and practicality arose when removing the cocoon of a room and exposing it to the scrutiny of the living environments (Figure 92). Occupants could directly inspect the surrounding programs. A perspective shift had the potential to create more successful design solutions. The dwelling framework when moved vertically creates a uneven volume in which the perceived space could be staggered.
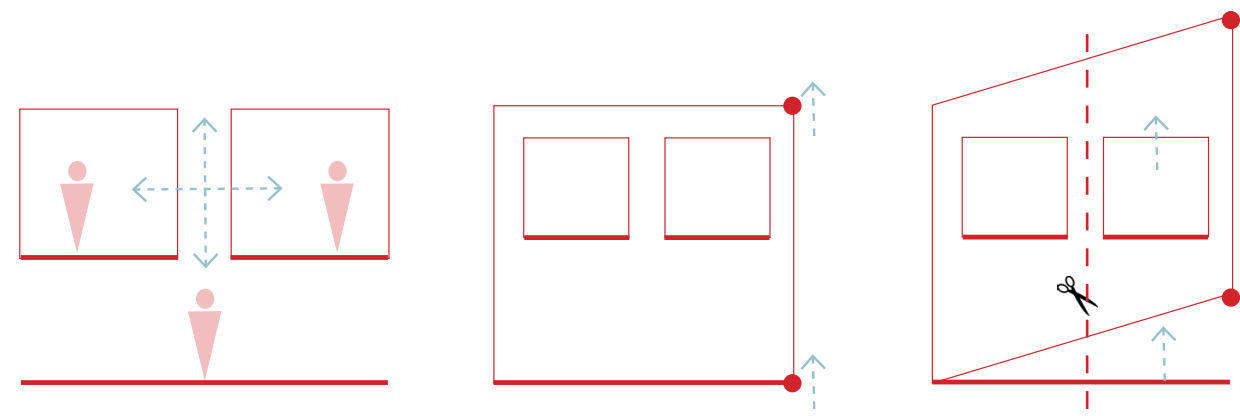

Shifting the floor plates provides the practicality and privacy required to create liveable apartment dwellings (Figure 93). The shifting floor plates form the transparency through the dwelling while addressing these issues. The floor plates navigate around the primary zone as discussed in chapter 7 and the floor plates become the secondary zones; rooms, living rooms, kitchens and bathrooms. By doing this the lines of sights are angled in which the ceiling planes are expressed rather than the room programs. This implies spatial qualities without diminishing the experience within. Extending the line of sight is also improved as the dwelling framework shift creates longer widths due to height differences. The line of sight in a traditional dwelling is much shorter as sight is restricted to a horizontal axis. Comparatively, the shifting floor plates create a diagonal line of sight improving the spaciousness of the rooms as per the research parameters. Spaciousness and size has been explored in an internal context. Next an external evaluation is done through the continuing discussion of the facade.
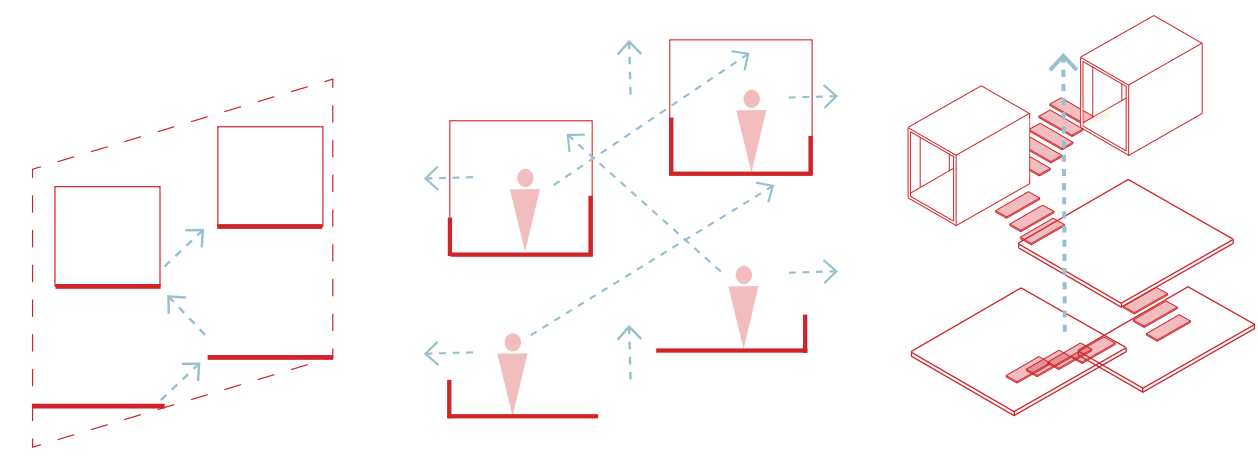


\section{DESIGN}

8.4 FACADE RATIONAL

Figure 80 - Final facade design *

Figure 81 - Facade pattern in axonometric *

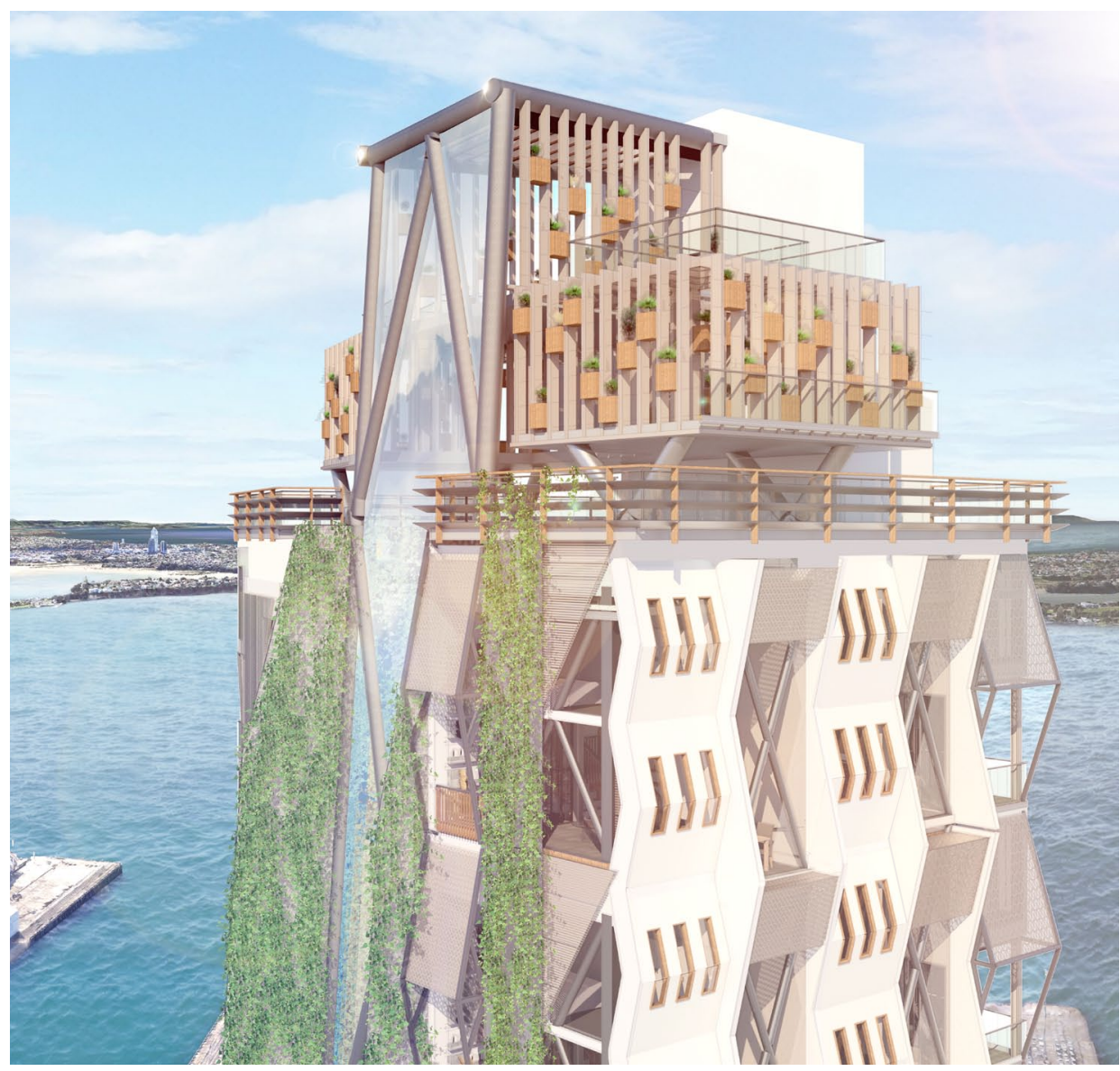

The facade rational add to the perceived space by using forms which push and pull out to the exterior of the building. The angular motions of the shear walls neighbouring the cross bracing directs the eye to the exterior on a diagonal axis rather than vertical. This has been shown to expand the perceived volume through the experiment parameters and the qualitative design evaluation.

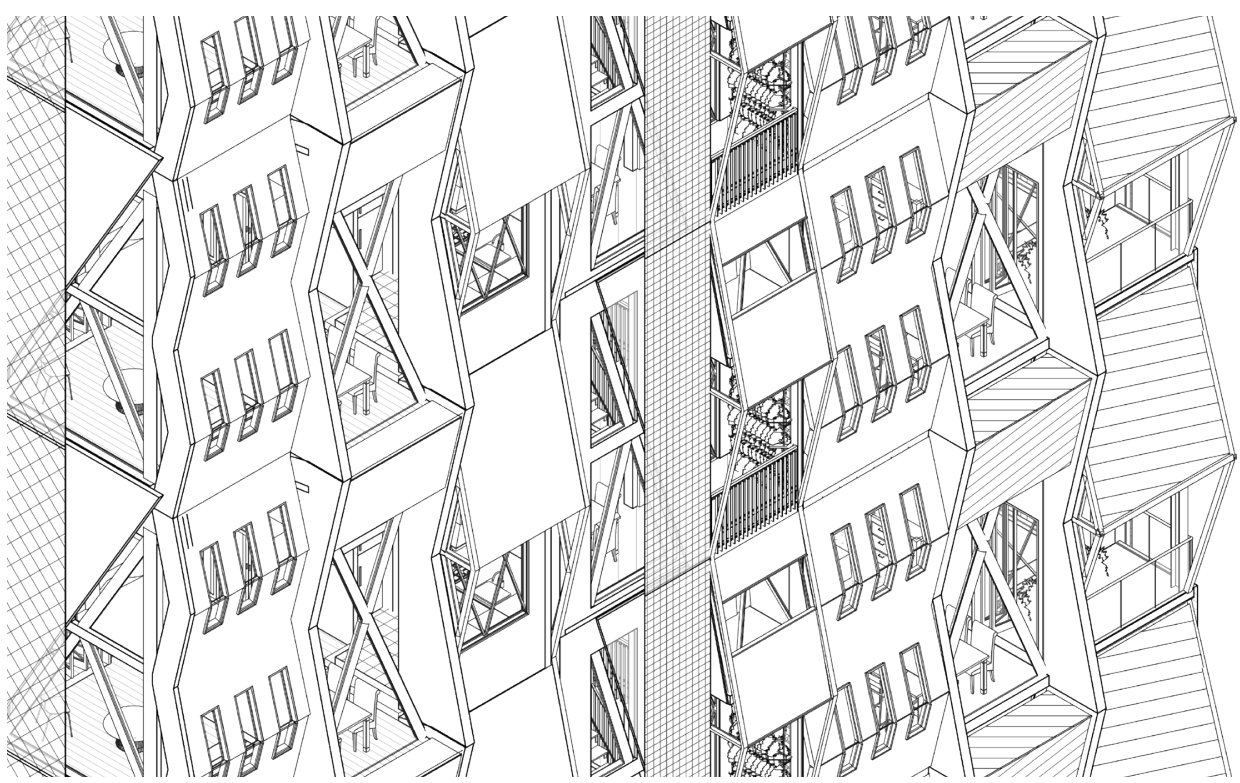




\section{DESIGN}

The facade pattern was constricted to form the dwelling top and base. This would allow a repeating pattern that runs through the facade of the building.

Figure 82 - Facade pattern iteration
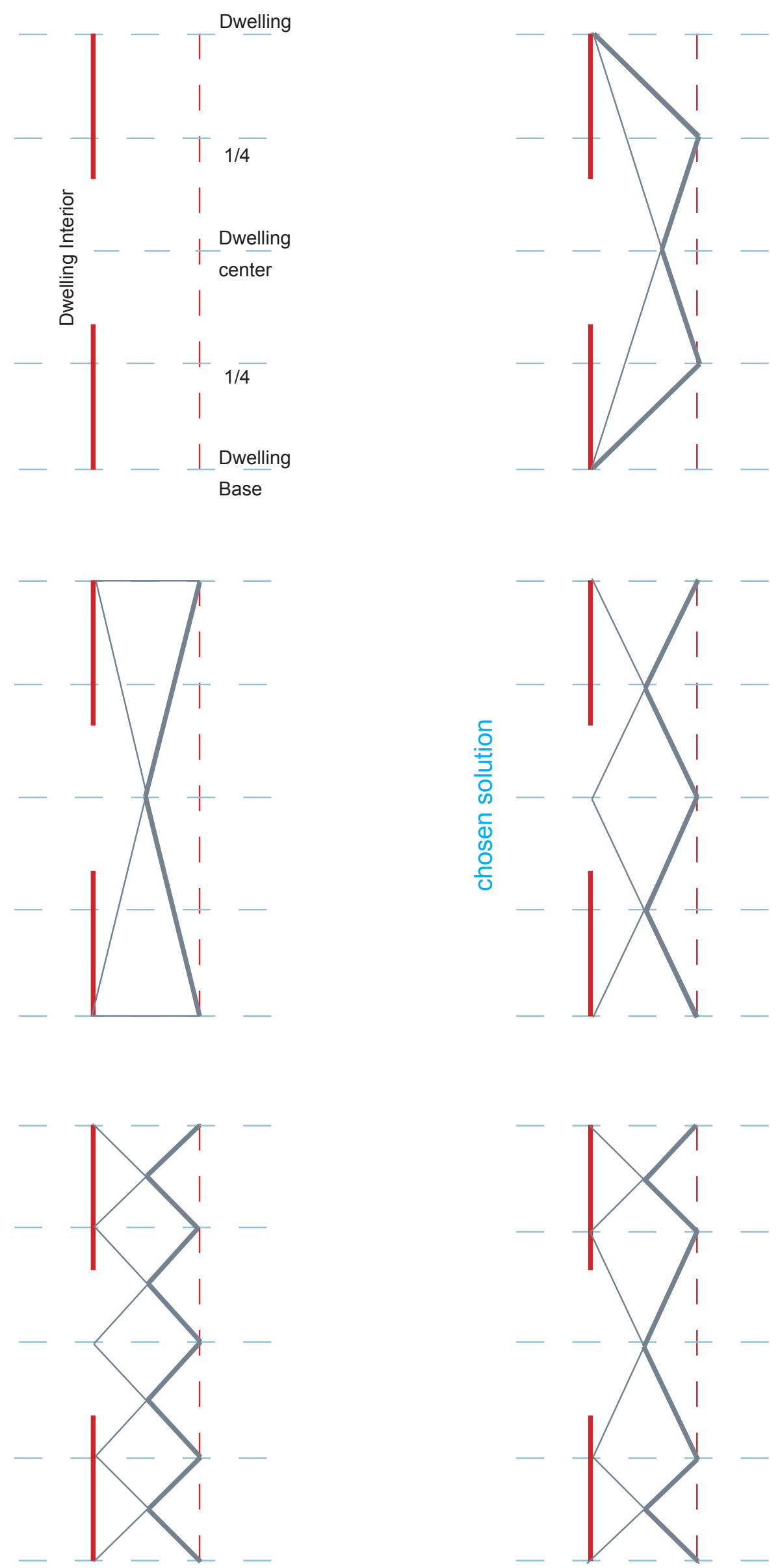
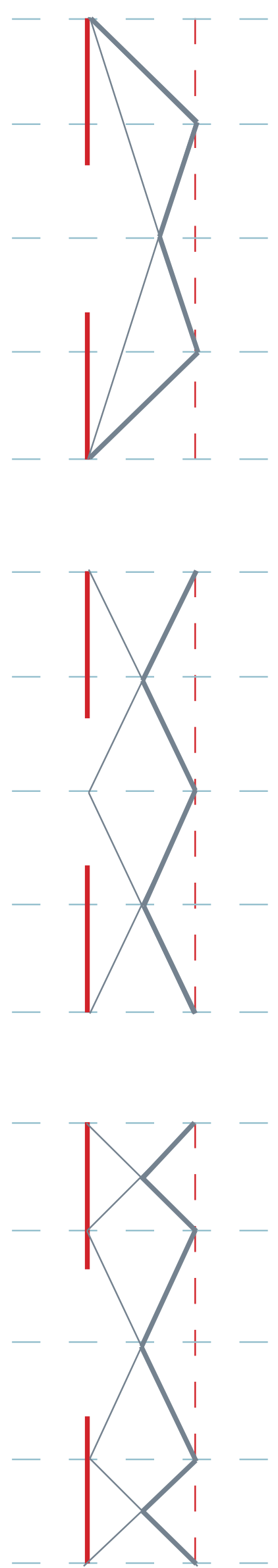
8.5 STRUCTURE INFORIMING Previously discussed in this chapter was the possibility of hanging SPACE columns in tension (Figure 98). Implementing this strategy has allowed a visual connectivity by creating unobstructed views through the base of the dwelling. This opens up the ground floors to transfer light, views and increased width through the dwelling as per the thesis design goals. Freeing the lower levels from structural interference can be achieved with columns in tension. Structure was not a highly considered element because this is a conceptual project. Exploring further structural solutions for greater transparency would be useful to research for future studies to expand on this development process.

Figure 84 - Tension column sketch diagram

Figure 83 - Final three bedroom dwelling living room
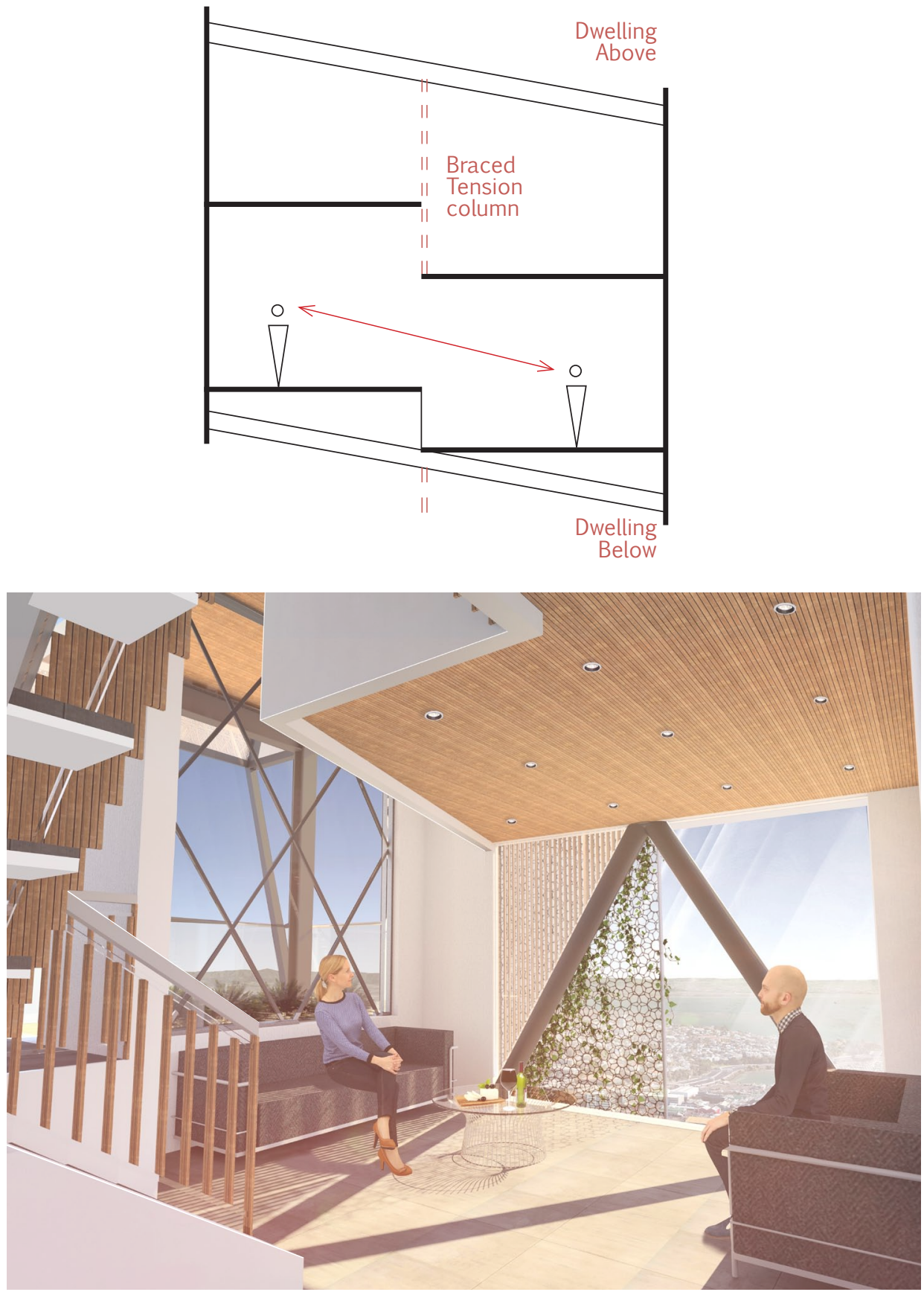


\section{DESIGN}

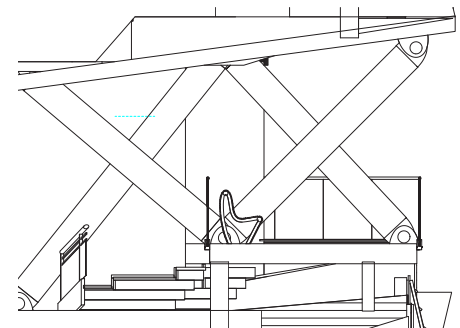

Figure 85 - Final iteration A (left)

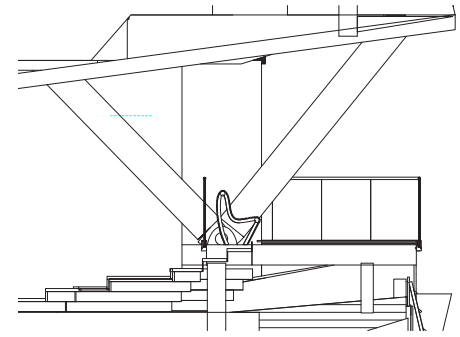

Figure 86 - Final iteration B (right)
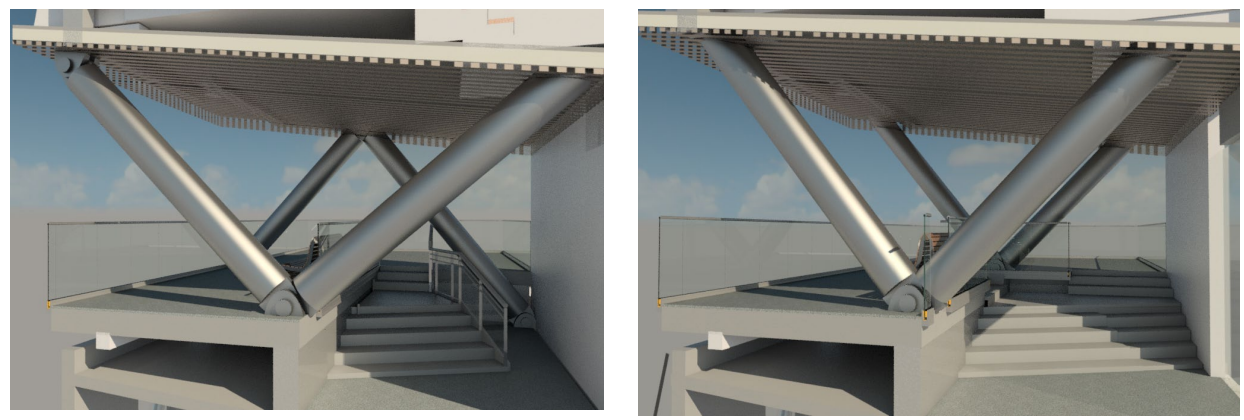

The structural grid had a large part to play on how the perceived space could be expanded on the public balconies. The columns come together at the floor shift point grounding the change with a solid transition. By angling the columns to allow a diagonal ceiling plane that encompasses the surrounding views, the space become more navigable and spacious. However, when layering the structural members the space became cluttered and caused a reduced perceived spaciousness and size (Figure 99). The $\mathrm{V}$ shaped columns expressed the ceiling plane angle better creating a more inviting public area through the design goals of increasing perceived spaciousness and size (Figure 100).

This evaluation process has been taken with all design solutions. Those being, evaluating spaciousness, size and architectural quality. Only a select few iterations have been selected to discuss and illustrate this process.

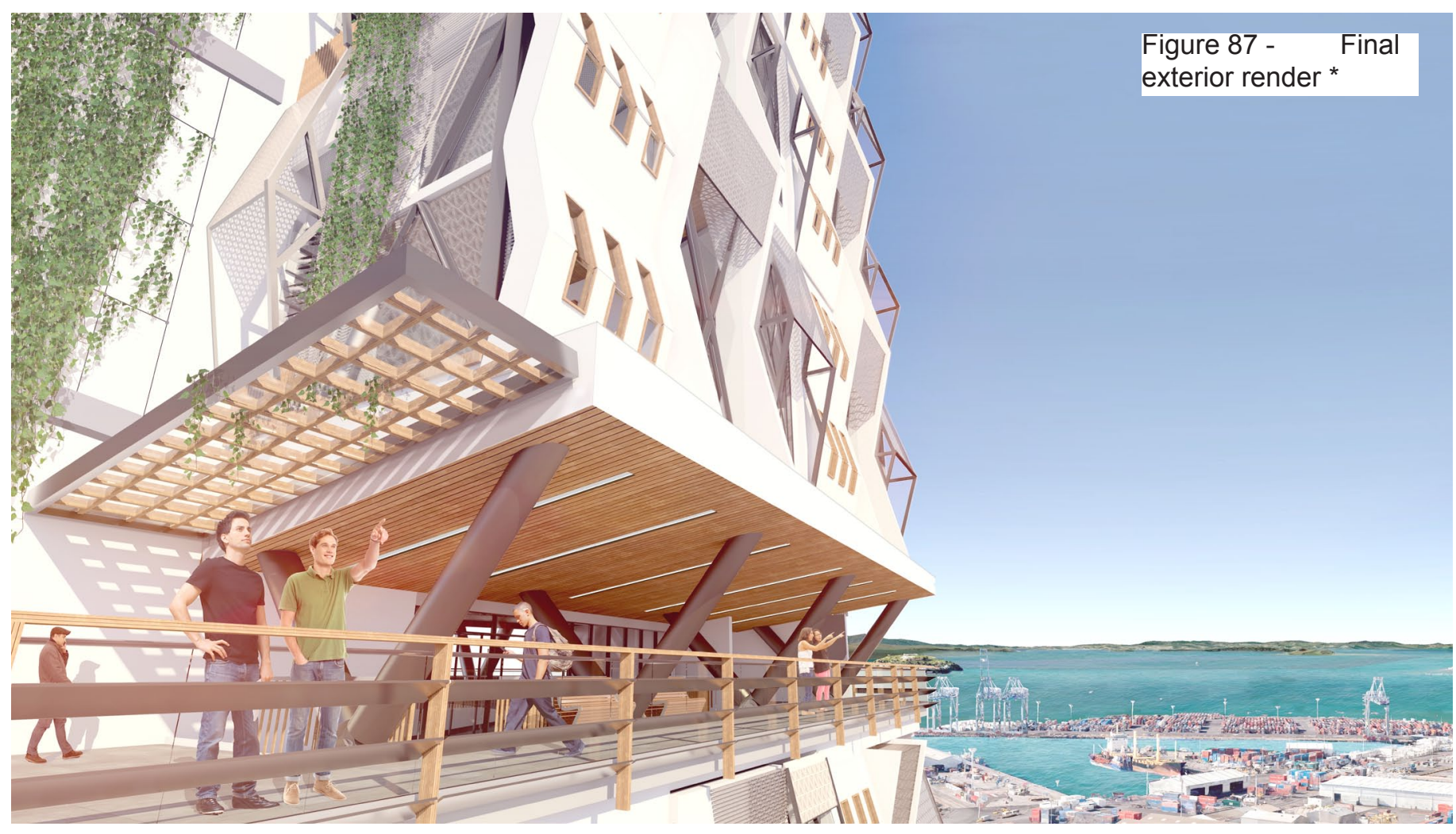


8.6 PERCEPTUAL OVERLAP

Figure 88 - Primary and secondary zones within the Two Bedroom dwelling *

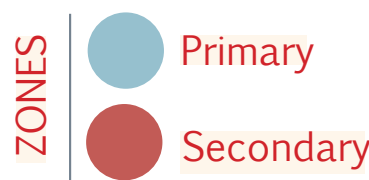

Traditionally high density apartment design employs a program overlap which allows rooms to switch between use and storage to create more usable space. The program overlap diminishes the perceived space overtime, as expressed in the literature review, which is why a perceptual overlap was employed. The perceptual overlap uses the design solution of split floors to allow for practicality and privacy, required in a dwelling. The circulation spaces make up most of the primary zones and form a physical and visual journey up the dwelling, exposing the full volume. The secondary spaces spiral around the primary zone so that the subjective space can overlap to create an extended perceived width, as seen in Figure 102. These design solutions allow the architecture principle to afford a larger and more spaciousness interior creating a more living high density design.
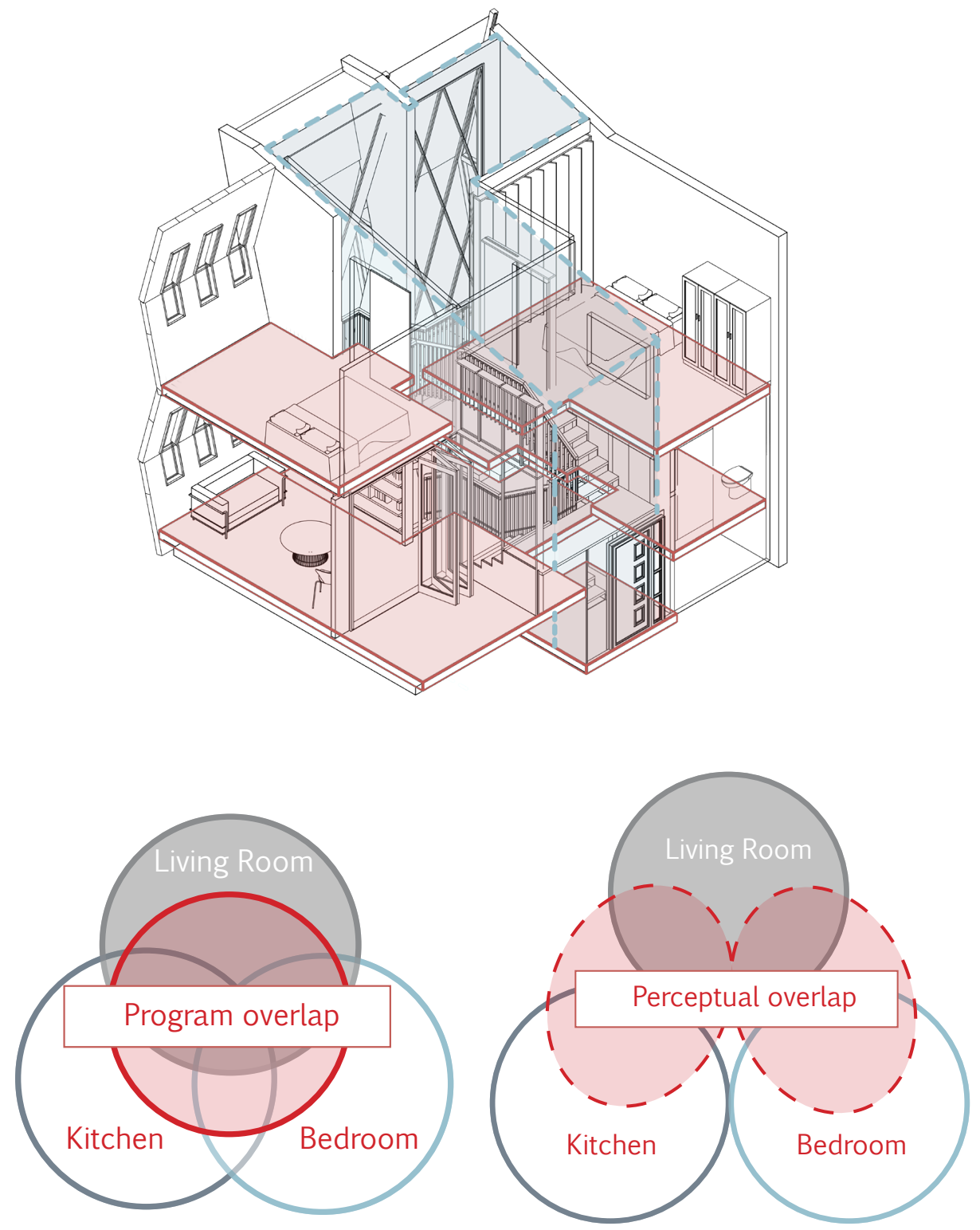


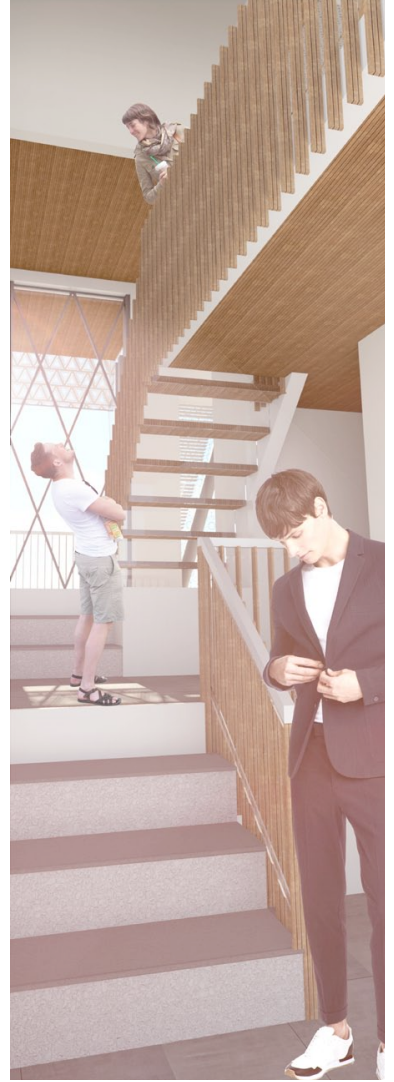

Figure 89 zone, One Bedroom dwelling *

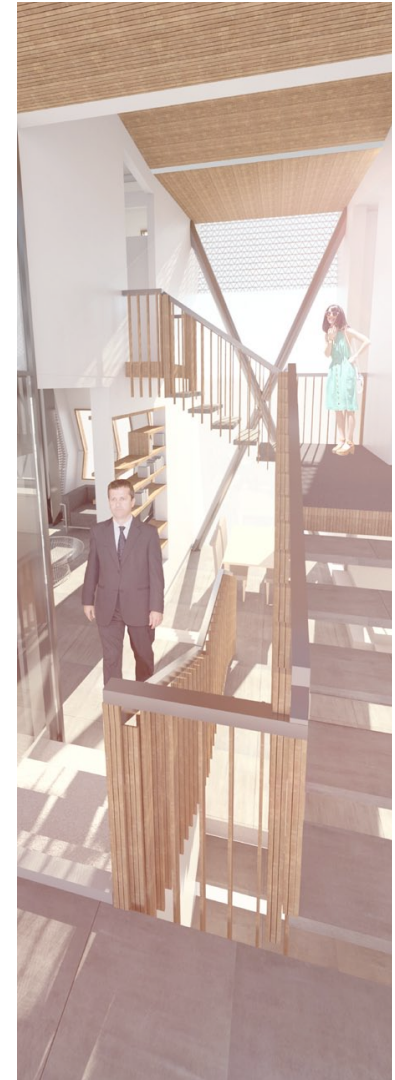

Figure 90 - Primary zone, Two Bedroom dwelling *

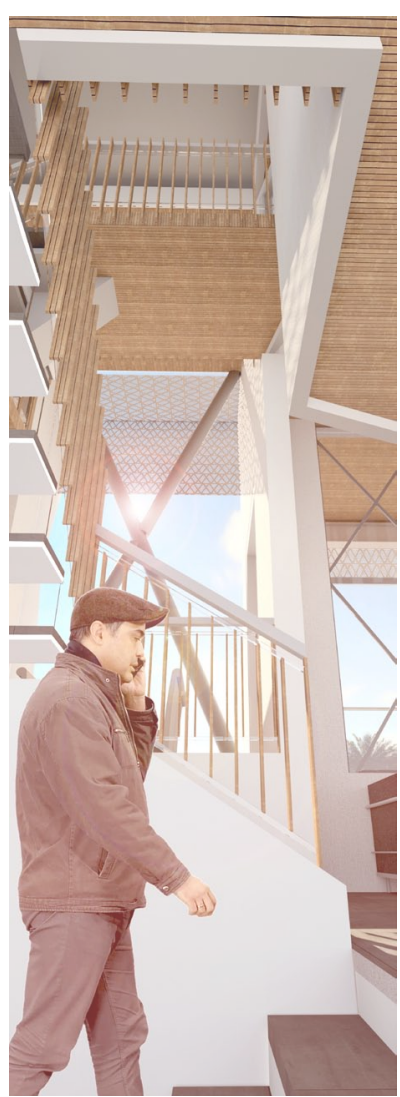

Figure 91 -

Primary zone, Three Bedroom dwelling *

The primary zones add to the perceived width of secondary spaces, as seen in figures 101,102 and 103. Balconies, mezzanine floors and internal windows are design solutions which utilise the width parameter to increase the spaciousness of spaces. The design solution is determined by the required privacy of the program to allow for a practical application of the research.

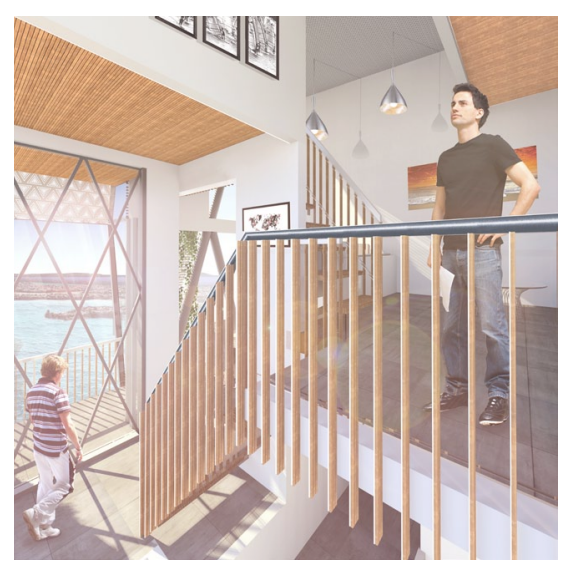

Figure 92 - Secondary zone, One Bedroom dwelling *

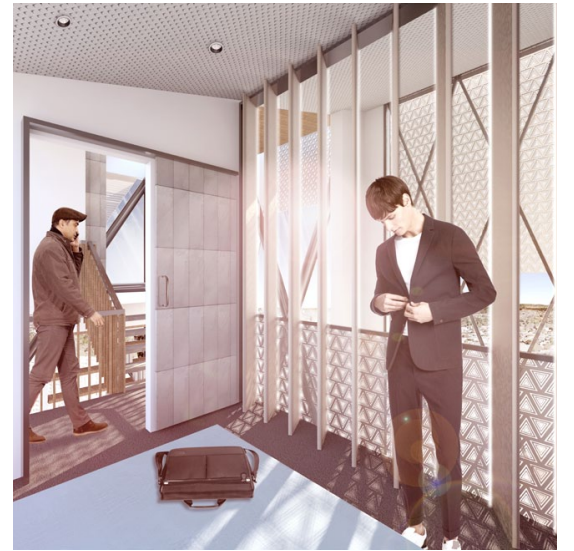

Figure 93 - Secondary zone, Two Bedroom dwelling *

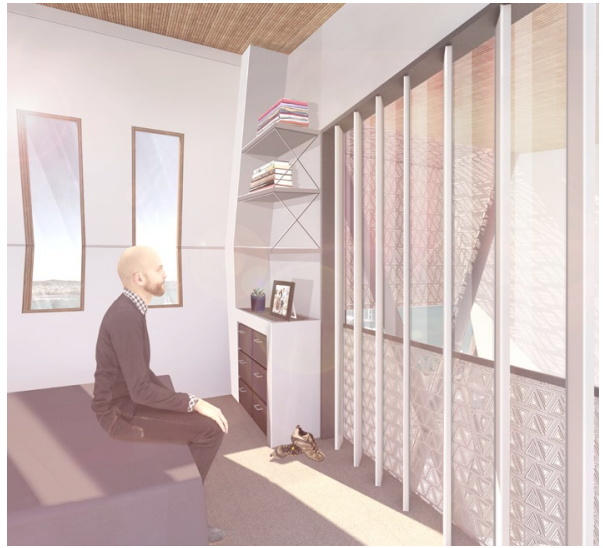

Figure 94 - Secondary zone, Three Bedroom dwelling * 
8.0 DEVELOPED DESIGN

8.7 EXTENDING WIDTH

Figure 95 - Extending the line of sight to create a more spacious environment *
The first design solution implemented to extend perceived width was to split the floor plates. The views out from primary and secondary zones formed implied spaces by expressing continuing ceiling and floor planes rather than exposing the program within. This differs to traditional stacked floors by extending the line of sight through the dwelling (Figure 106). Design solutions which have helped achieved the design goals are the angled ceiling planes and walls which extend the perceived space by adding a subjective width. The secondary zones are able to also extend the perceived width without imposing on privacy within the space (Figure 107).

Traditional

\section{Extended}

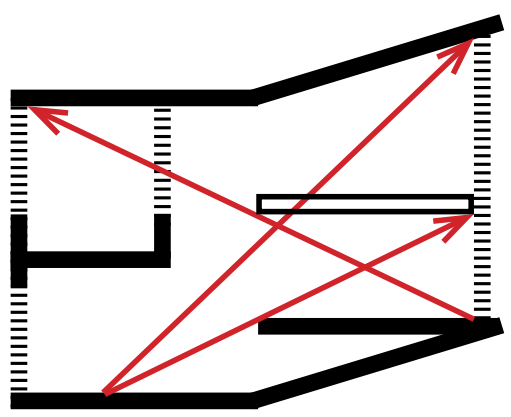

Figure 96 - Two Bedroom dwelling section

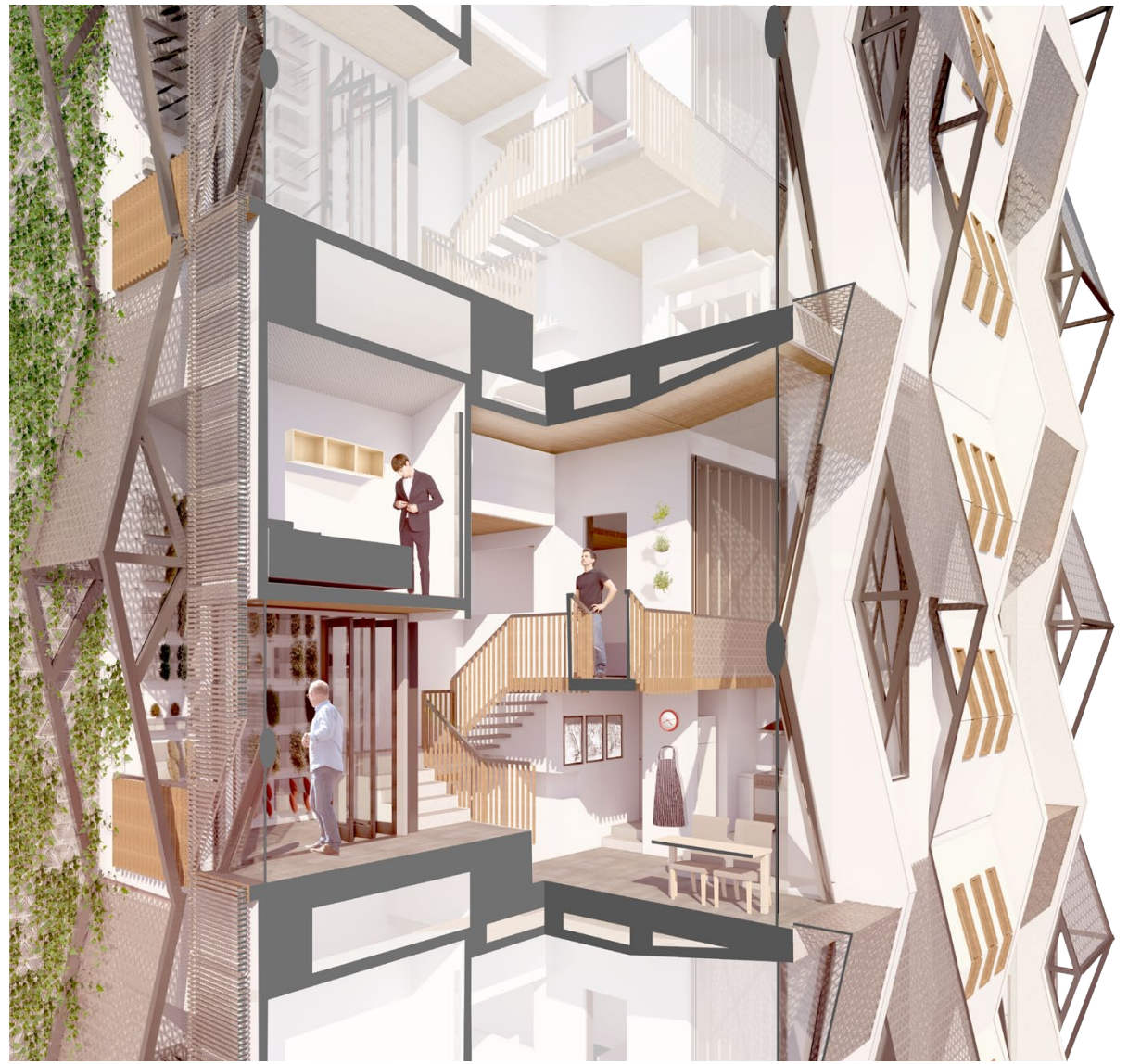


8.8 OPTIMIZATION OF SPACE The principle of optimization of space explores all architectural elements which contribute to the perceived space and systematically evaluated the design. The output forms the largest subjective increase with no or minimal objective increase. This principle aims to forms spaces which make the best possible use of the space, increasing the spaciousness and liveability of a room. This principle is more method based which explores a multitude of options including form, materiality, light and movement. For the thesis this principle focuses on qualitative evaluation methods to inform design decisions.

This process through the developed design chapter primarily expands on the evaluations conducted in the preliminary stages. The evaluations of materiality, lighting, movement and layout were all critically tested as the design progressed to ensure a coherent relationship between developed components and the final design. The three key conclusions established from this process are, 1. Wood slat ceiling materiality and texture (Figure 109), 2. architectural layering of materials and thicknesses (Figure 108), 3. light penetration from angular windows (Figure 110). These optimise perceived spaciousness, size and liveability for the thesis dwelling designs. This process does not provide transferable optimizable qualities and must be undertaken for a particular design.
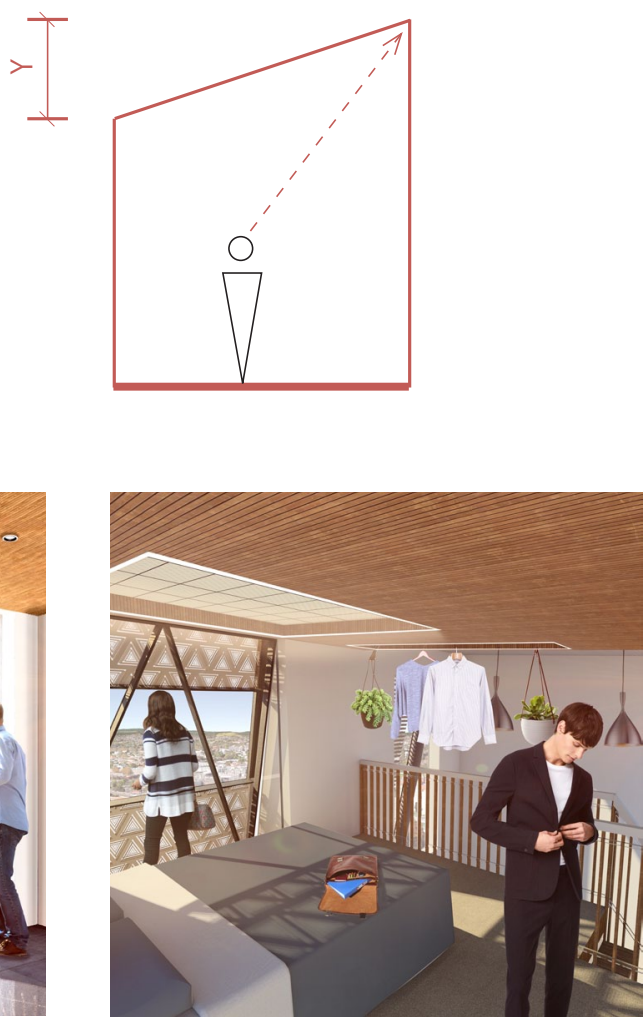
room *
Figure 97 - Architectural layering and materiality informing more spacious environments. Three Bedroom dwelling living

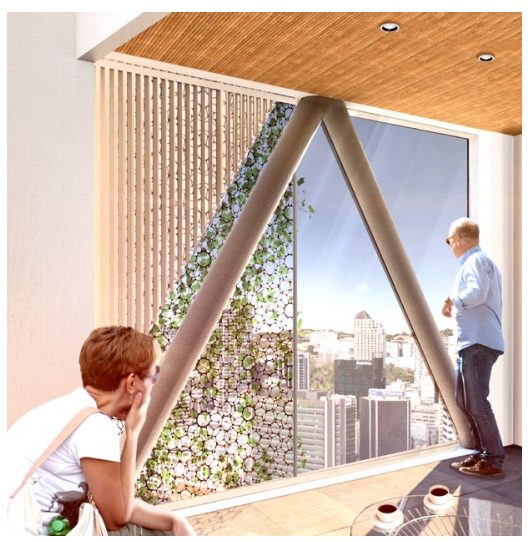

Figure 98 - Ceiling materiality affording more spacious spaces. One Bedroom dwelling Bedroom *
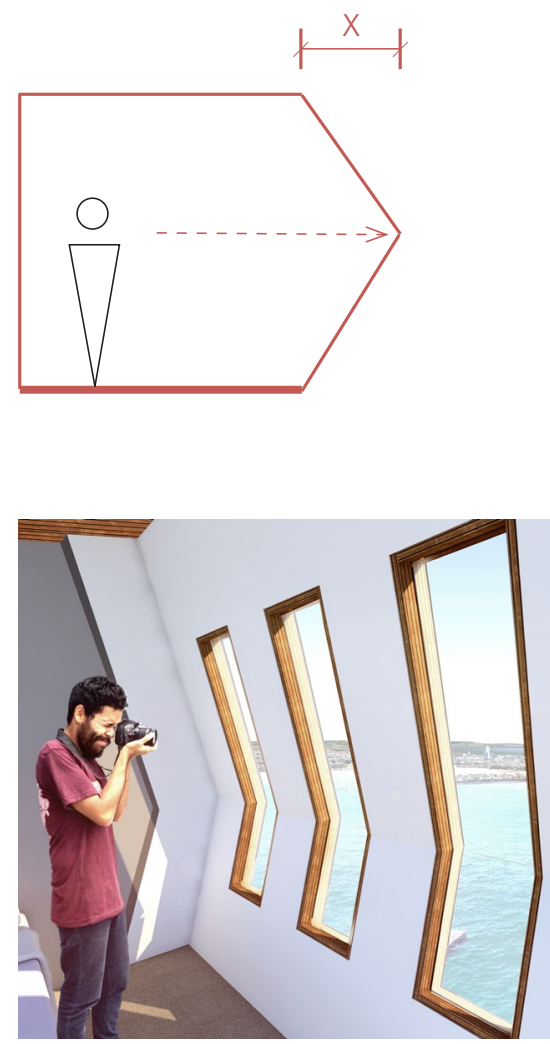

Figure 99 - $\quad$ Form shifts used to create larger subjective spaces. Three bedroom dwelling Bedroom. * 


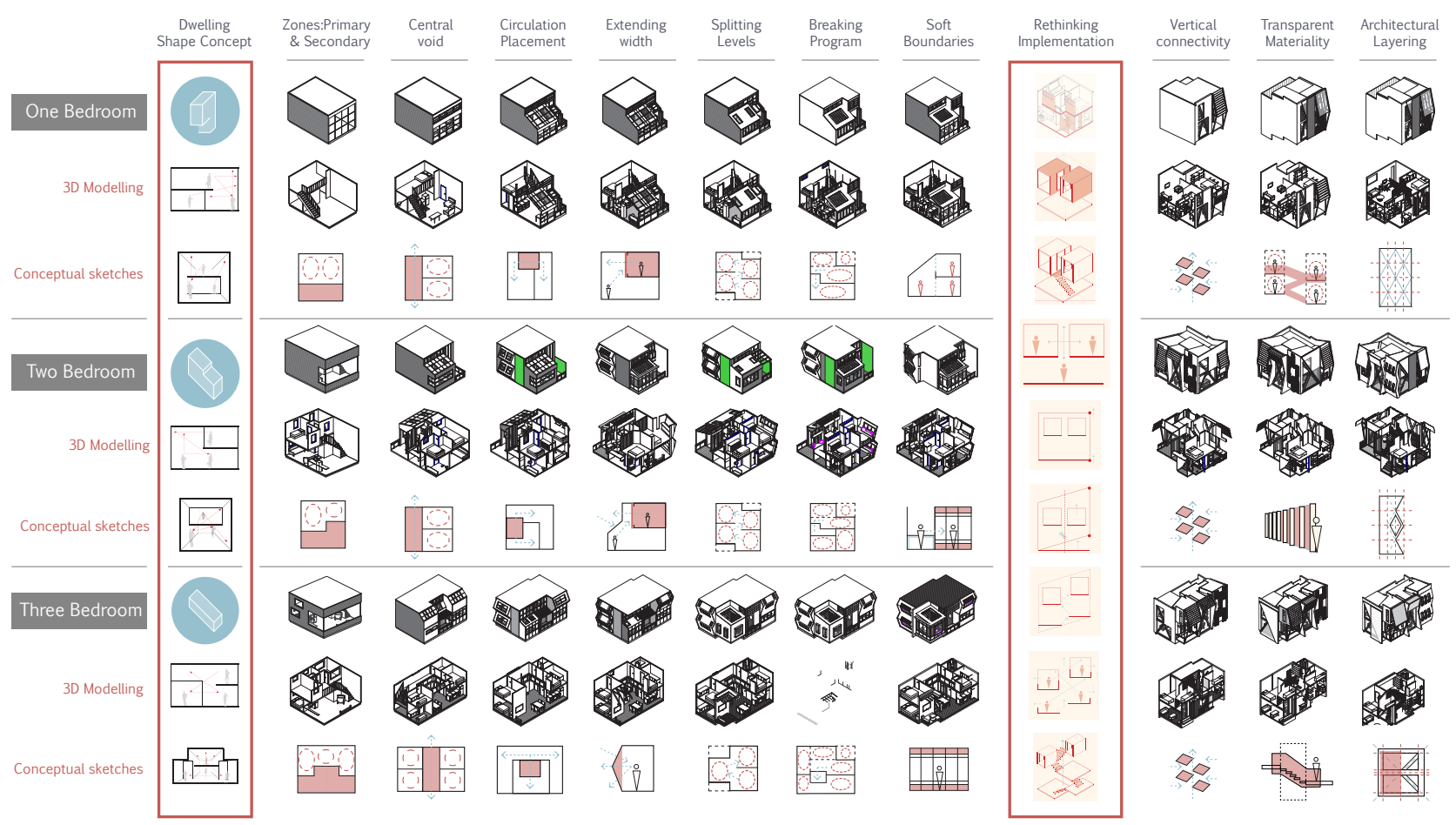

Figure 100 - Final dwelling iteration matrix *

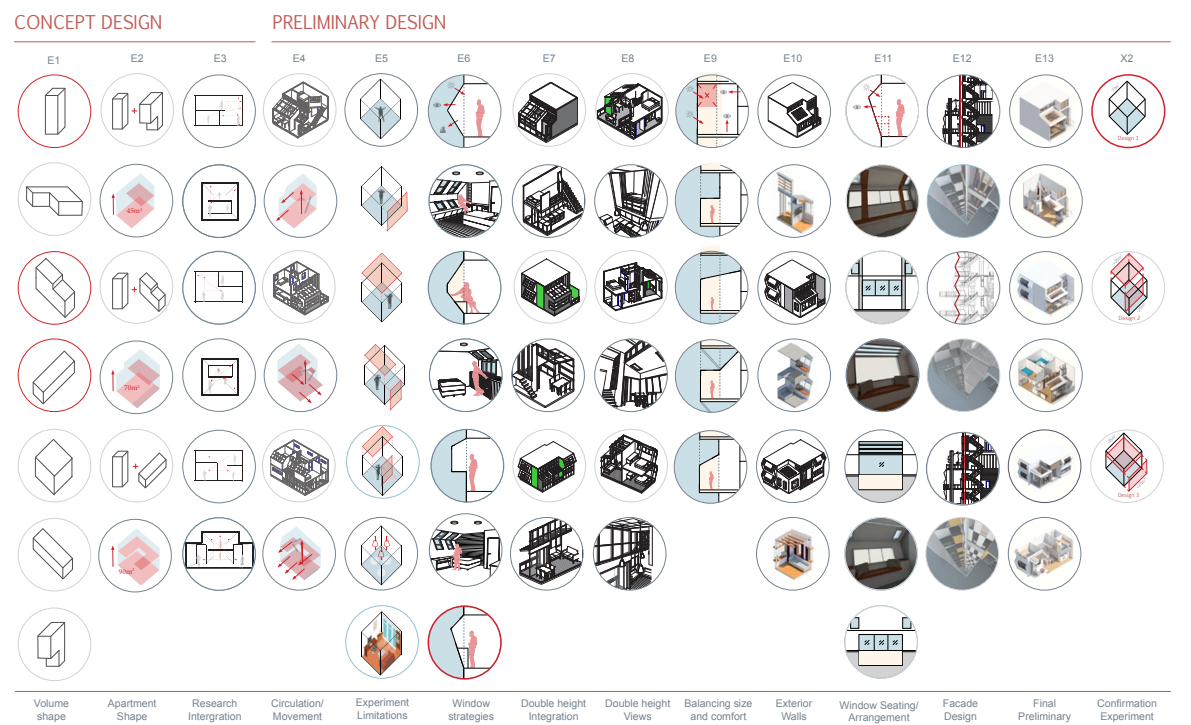

Figure 101 - Final

VR evaluation matrix

\section{Evaluation key \\ Chosen solution \\ Investigating \\ Tested}

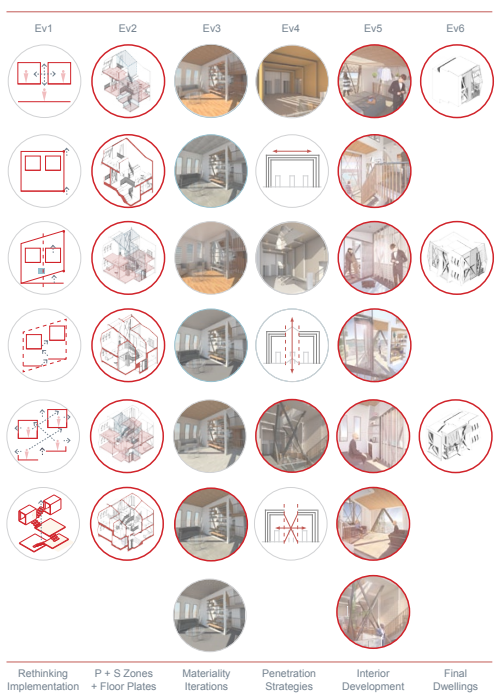

The VR evaluation process was happening parallel to the dwelling design iterations. This ensured that both large and small design scales was considered while also being tested in context. The iteration matrixes illustrate some of the design iterations taken through diagram to portray what was being investigated. When investigating a perceived space, a 2D representation is difficult in the summarisation of the investigation points and discoveries. This matrix however should elude to the iterative nature of each investigation and how they tie together. 
Figure 102 - Final One Bedroom dwelling *

Figure 103 - Final Two Bedroom dwelling *

Figure 104 - Final Three Bedroom dwelling *

\subsection{SECTION SUIMIMARY}
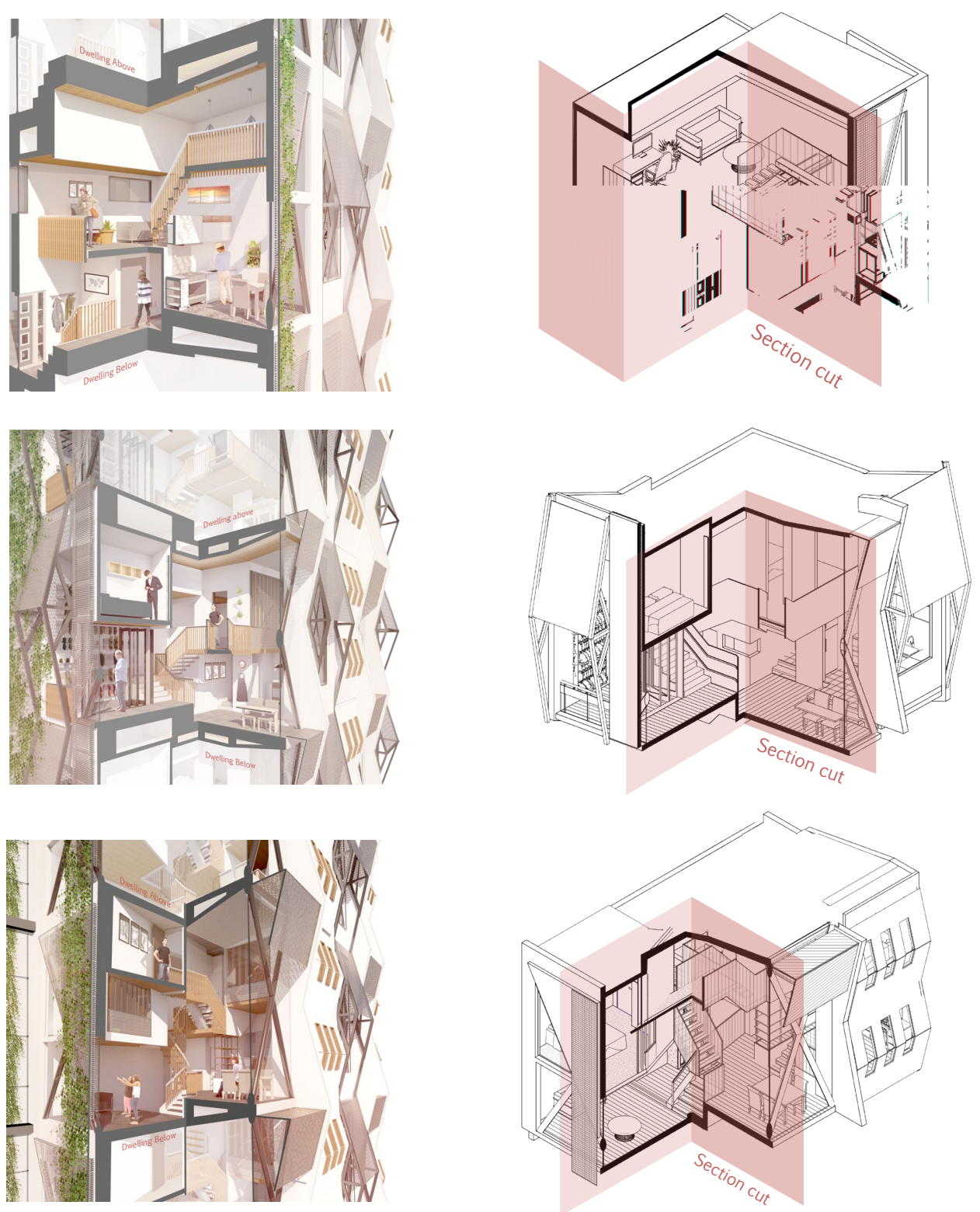

The developed design has evolved the three main principles of perceptual overlap, extending width and optimization of space to provide appropriate design solutions. The solutions have been evaluated through the VR methodology to formulate reflective and informed design decisions to best answer the thesis question.

The following chapter goes through the final design and breaks down how the design implements the research and meets the thesis goals. This chapter has been previously delivered during the design review and portfolio submission on the 10th of November. The subsequent chapter concludes the thesis by reflecting on the successful and unsuccessful moments within this process. Possible future applications and research directions are discussed which would extend the resolution of this thesis and provide more informed design methodologies. 


\subsection{FINAL DESIGN}

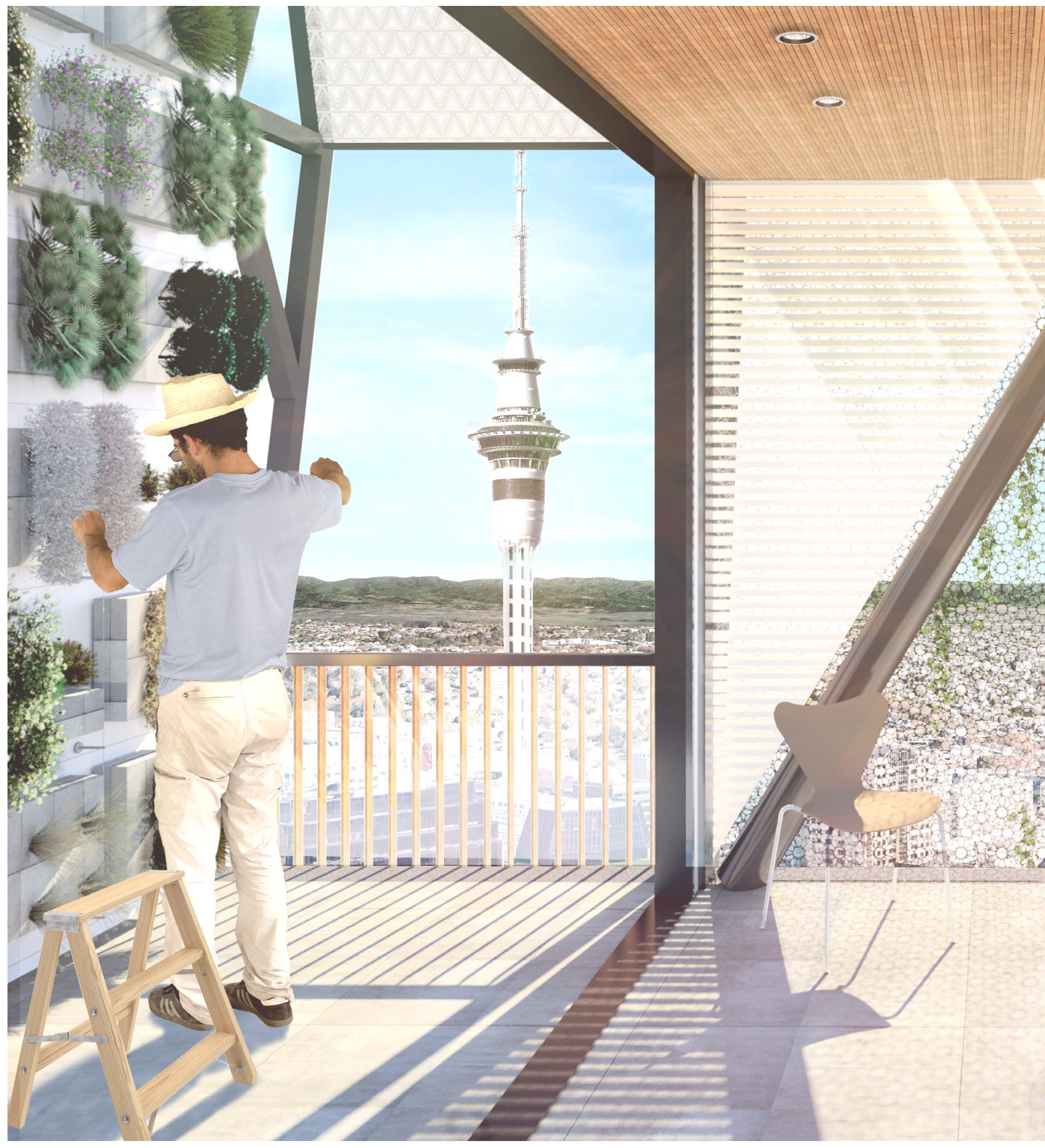

Griffiths, L. (2017) Perceptual Architecture,

Presentation, Architecture, Victoria University,

Wellington , 14 November. 


\subsection{FINAL DESIGN}

One bedroom
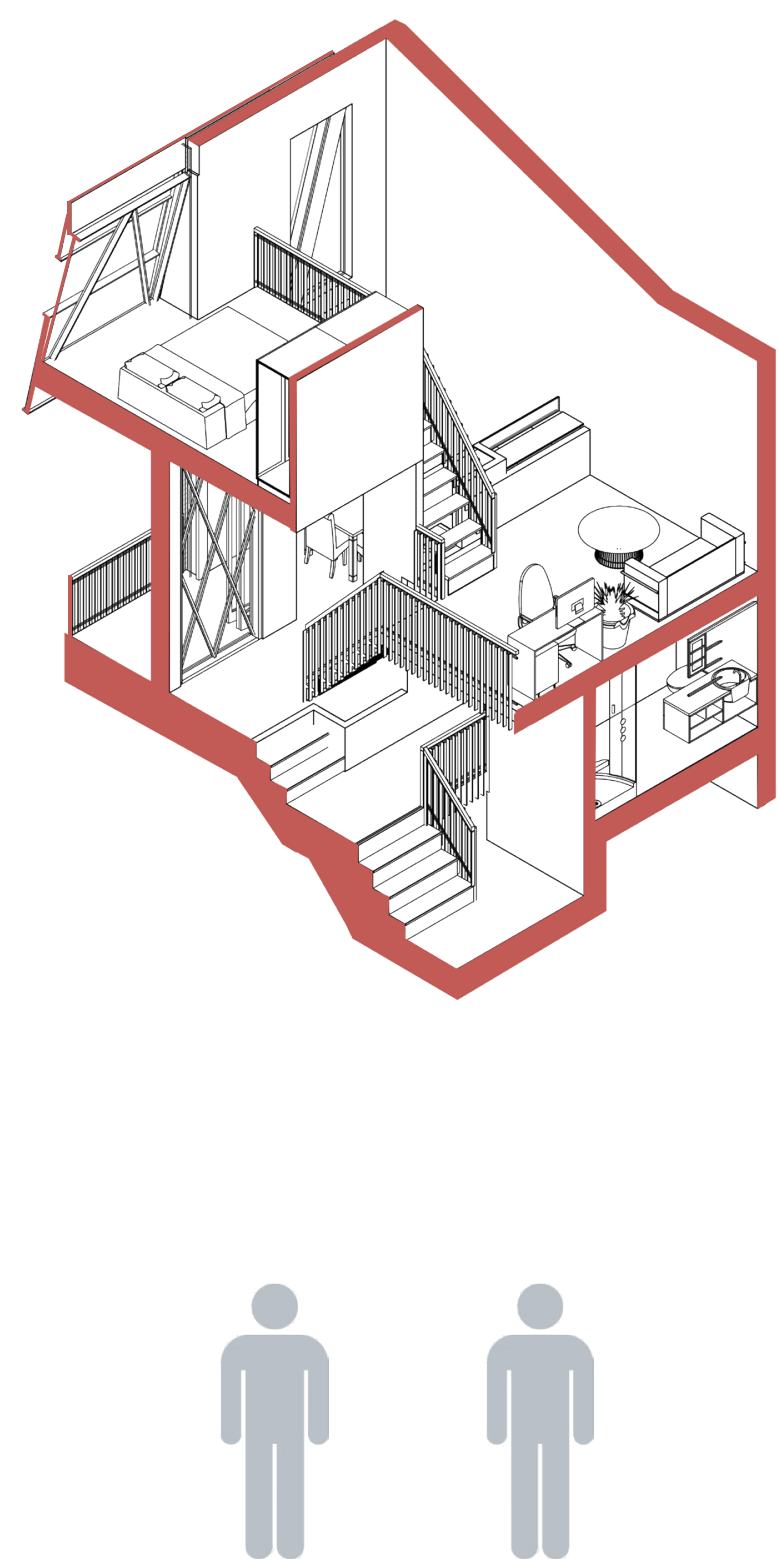

Two be
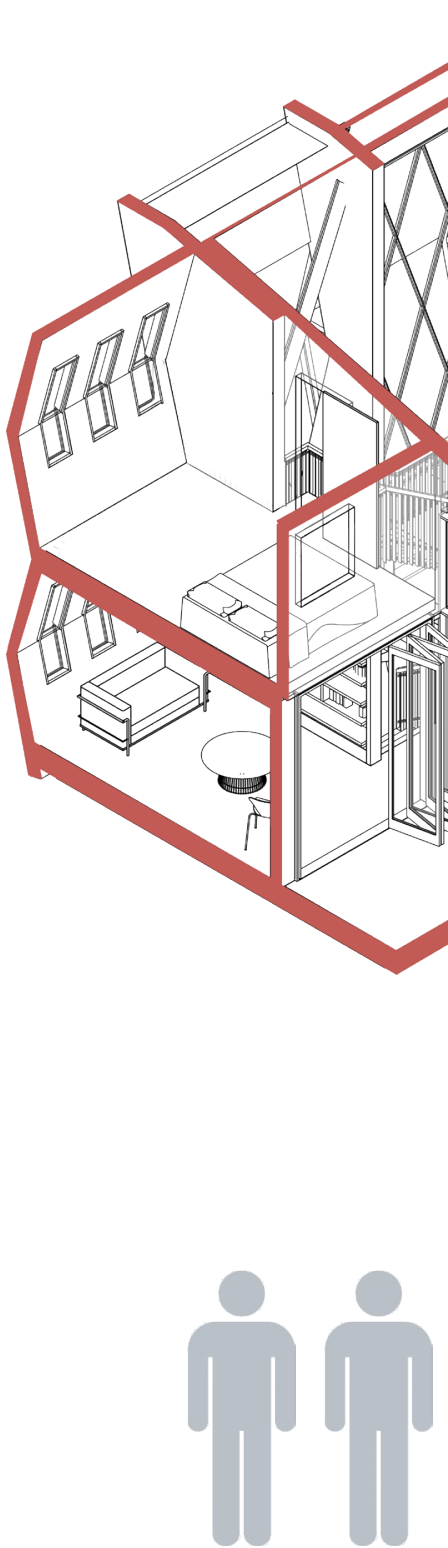

Griffiths, L. (2017) Perceptual Architecture,

Presentation, Architecture, Victoria University, Wellington , 14 November. 
droom
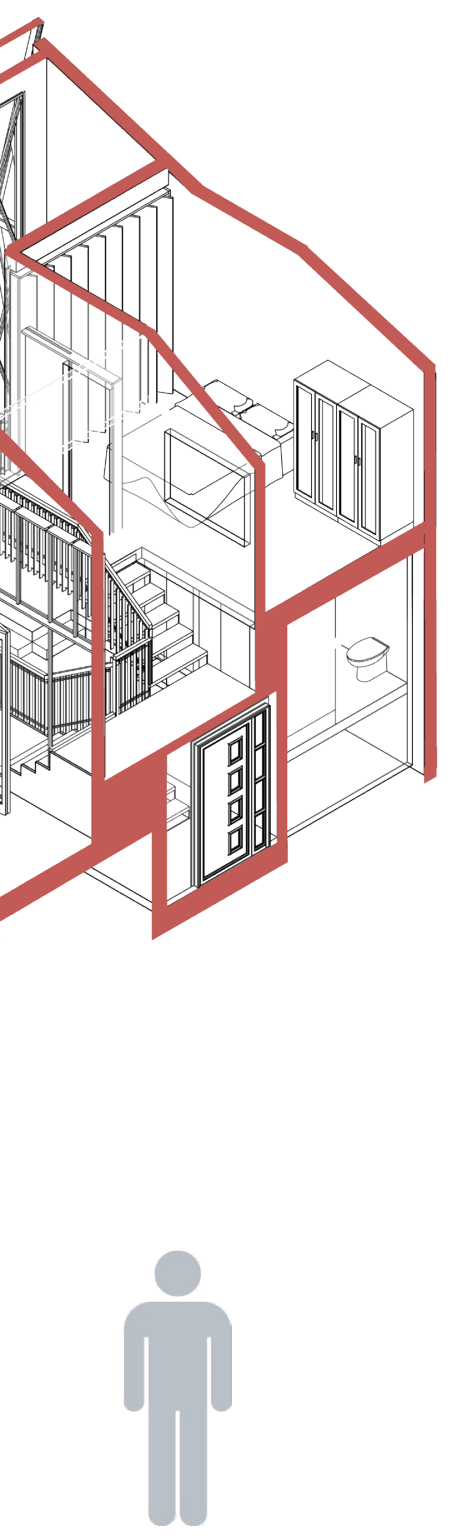

Three bedroom
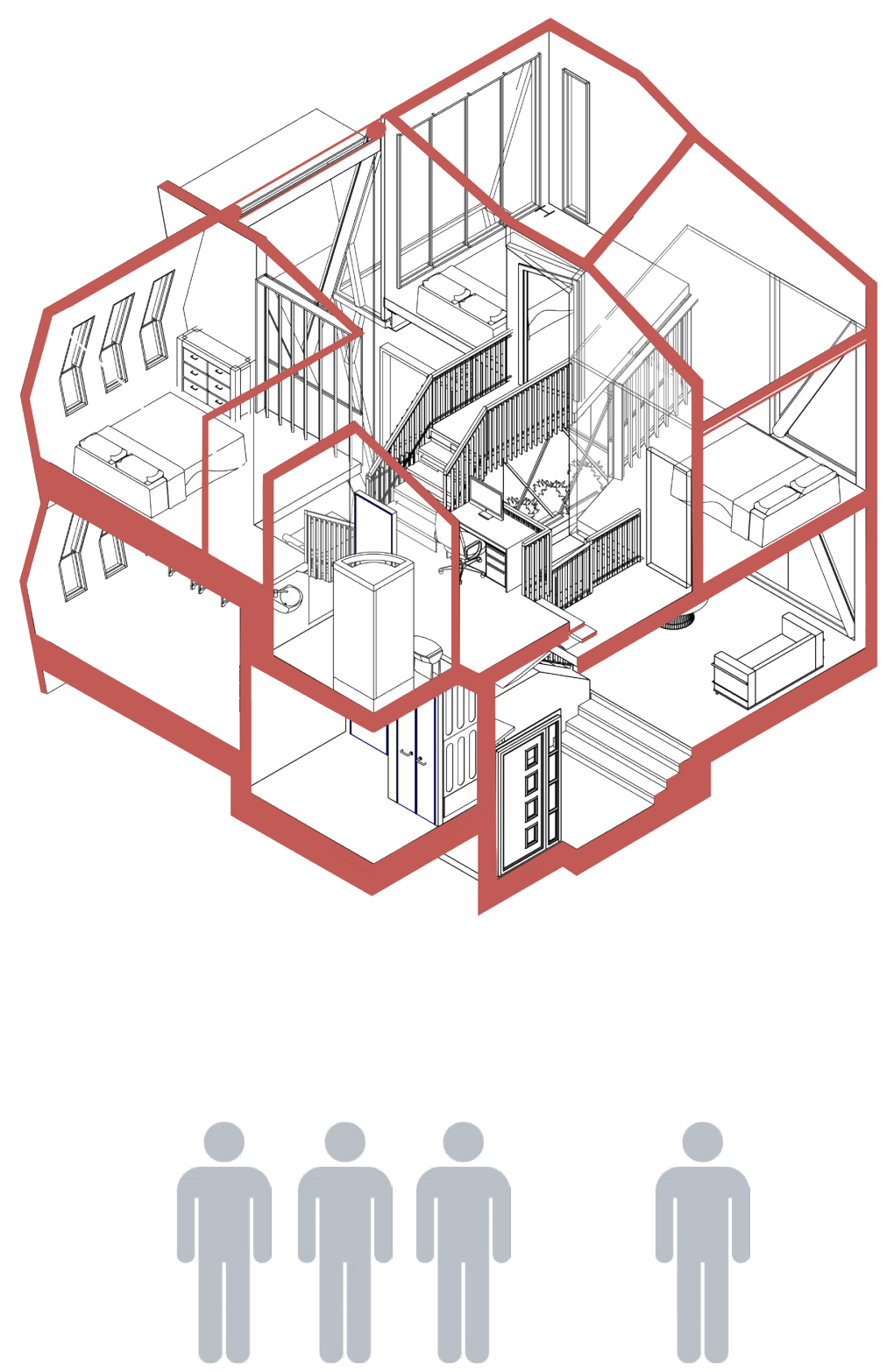


\subsection{FINAL DESIGN}

One bedroom
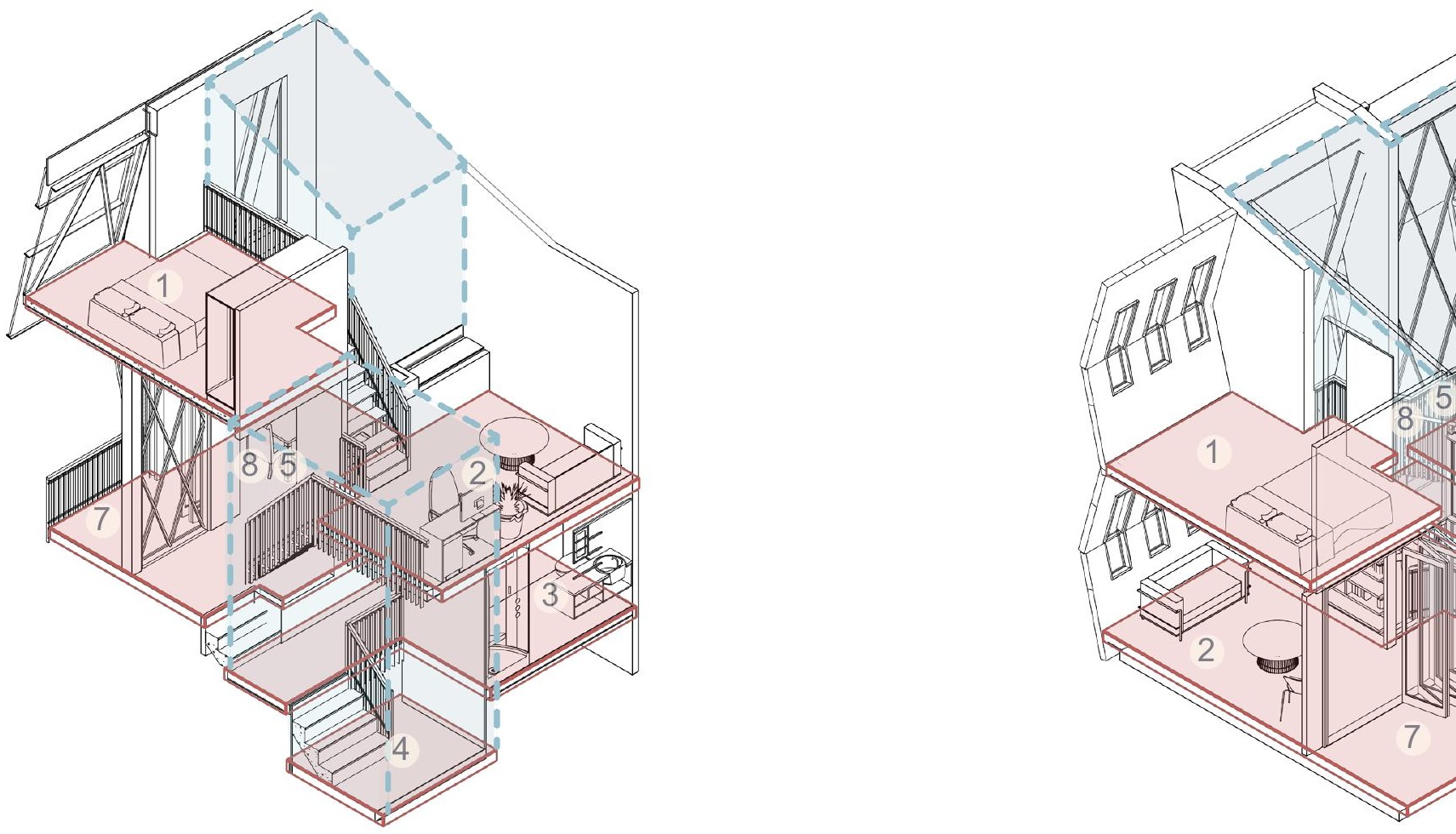

Griffiths, L. (2017) Perceptual Architecture,

Presentation, Architecture, Victoria University,

Wellington , 14 November.

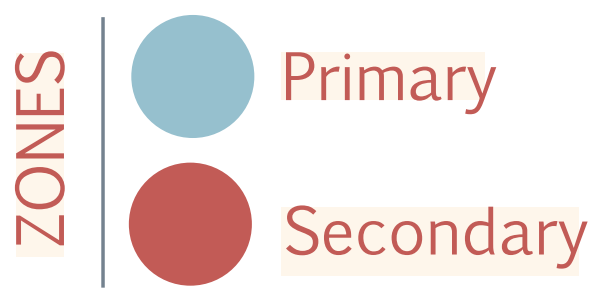




\section{Three bedroom}

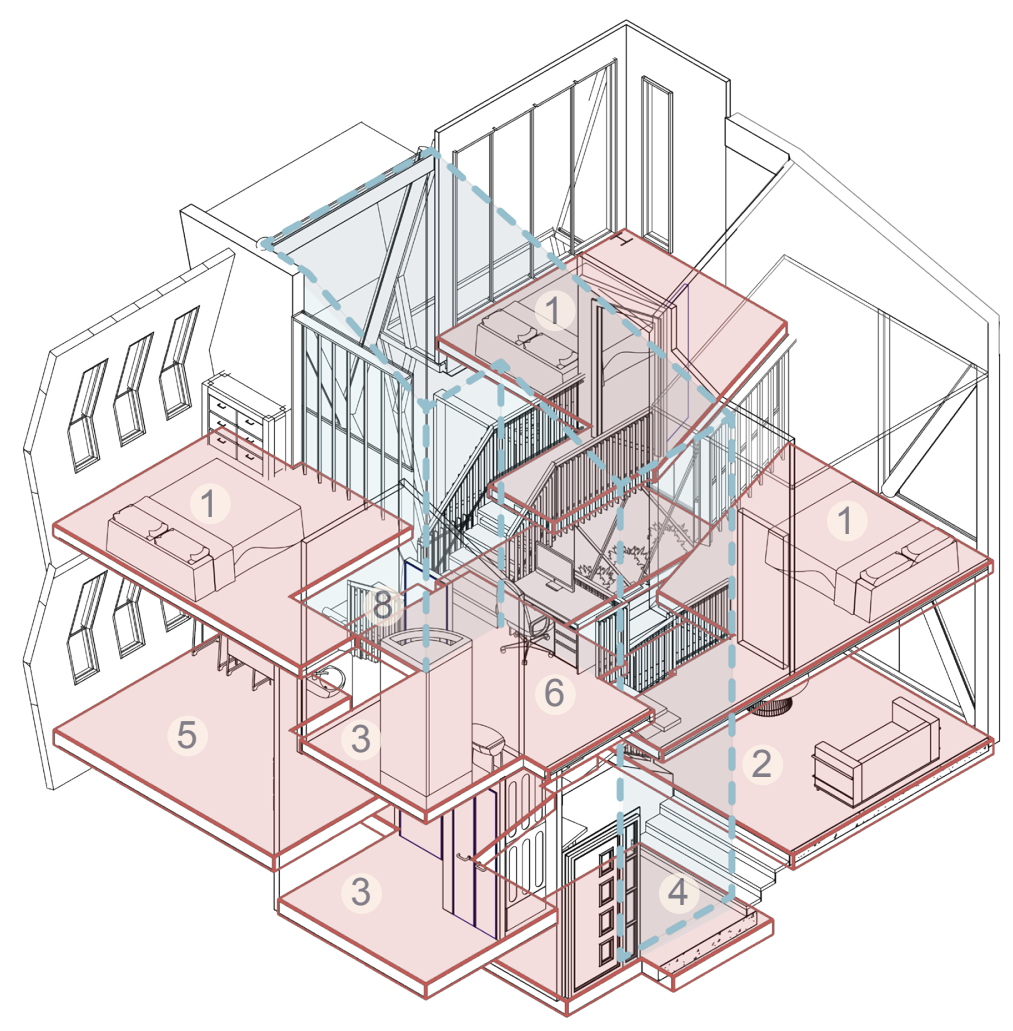

\section{Dwelling Key}
1. Bedroom
5. Kitchen
2. Living
6. Study
3. Bathroom
7. Balcony
4. Entry
8. Dining 


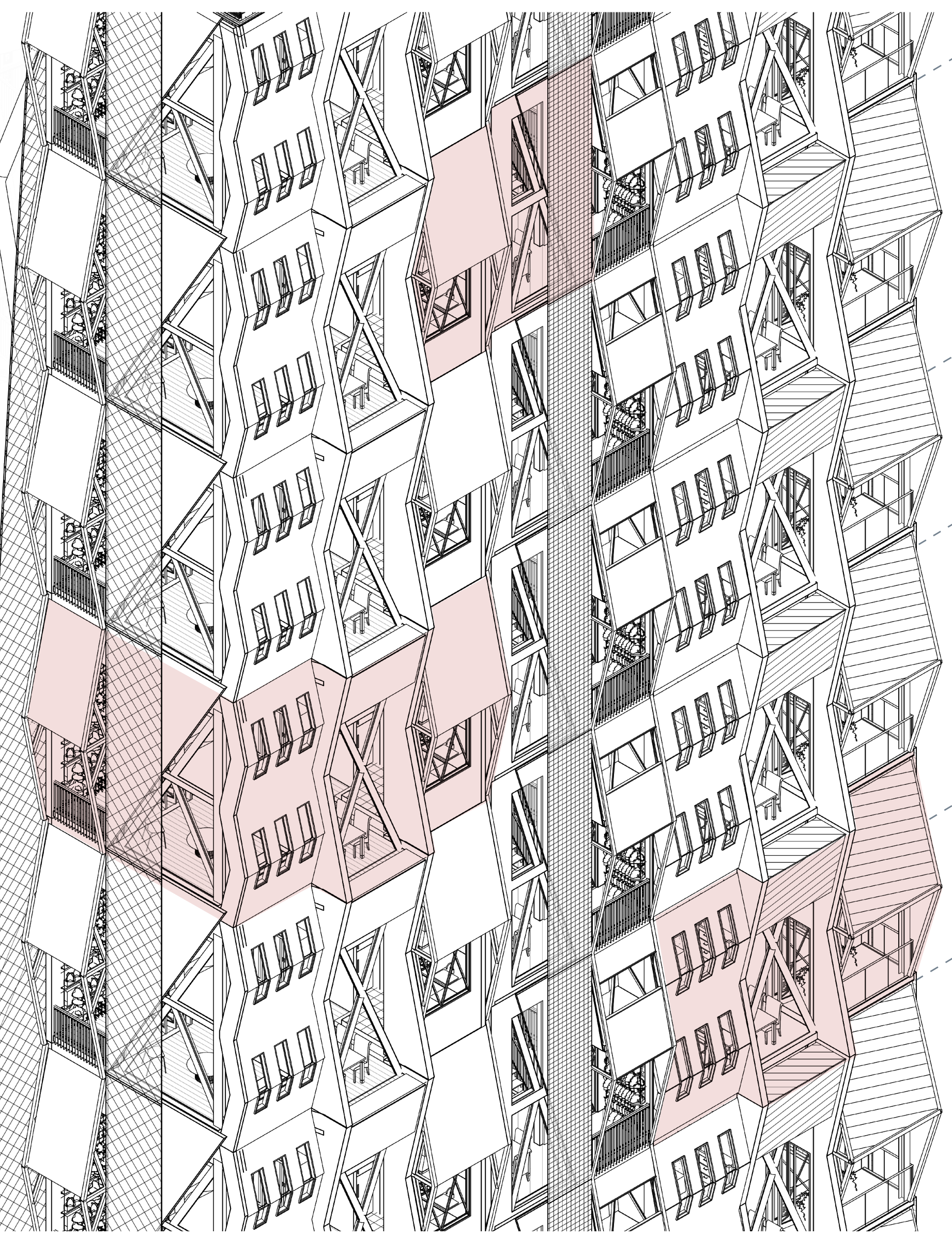

Griffiths, L. (2017) Perceptual Architecture,

Presentation, Architecture, Victoria University,

Wellington , 14 November. 


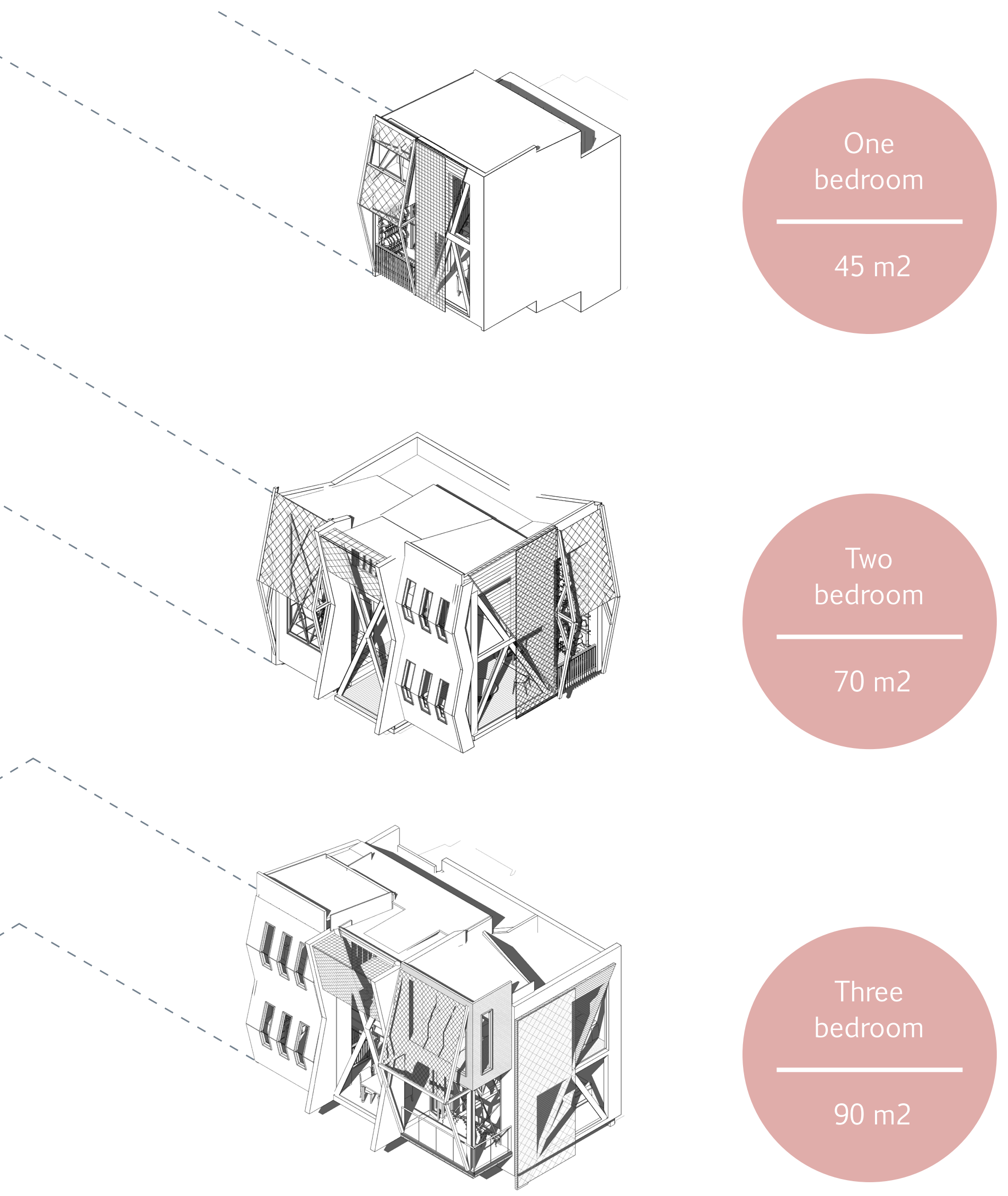




\section{ONE BEDROOM UNIT}

Griffiths, L. (2017) Perceptual Architecture, Presentation, Architecture, Victoria University, Wellington , 14 November.

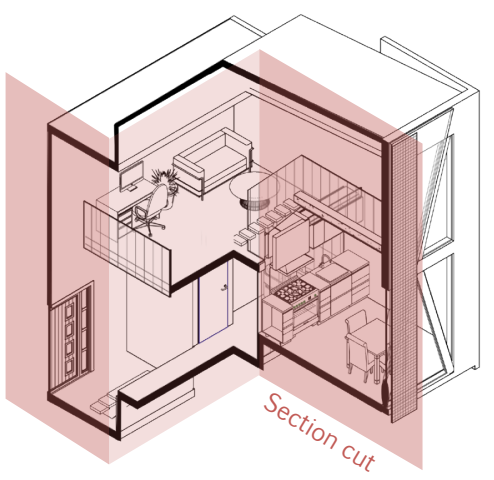

The one bedroom dwellings formulate a single living environment using the architectural principles. A mezzanine floor creates a perceptual overlap and visual connectivity to the dwelling volume. This maximises the perceived volume to create a larger and more spacious environment (Griffiths L, 2017b).
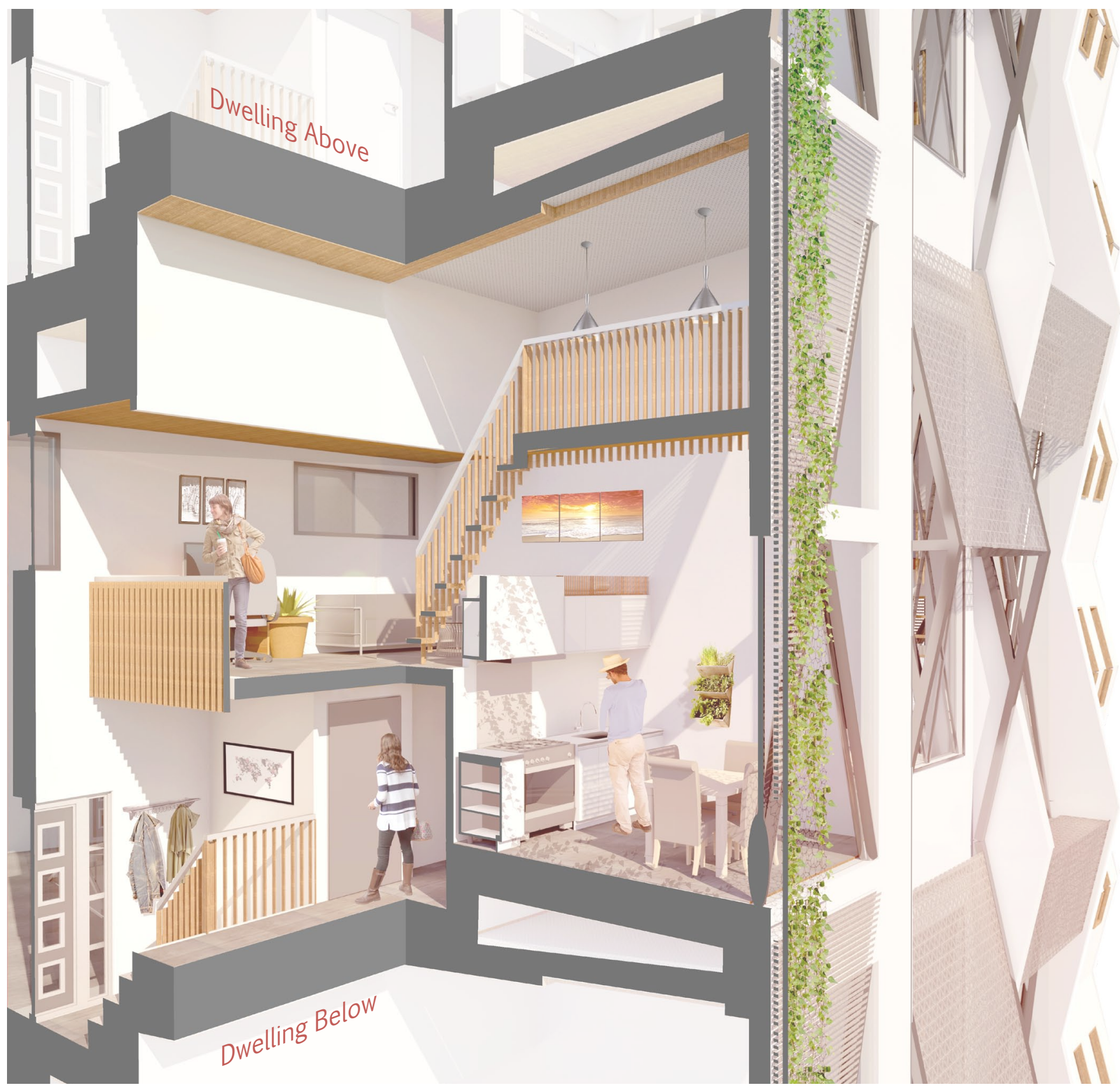


\section{VOLUME TRANSPARENCY}

Griffiths, L. (2017) Perceptual

Architecture, Presentation,

Architecture, Victoria University,

Wellington , 14 November.
The primary zone of the dwelling visually connects the secondary programs. As per the design principles this creates more spacious spaces without increasing the objective volume size (Griffiths L, 2017b).

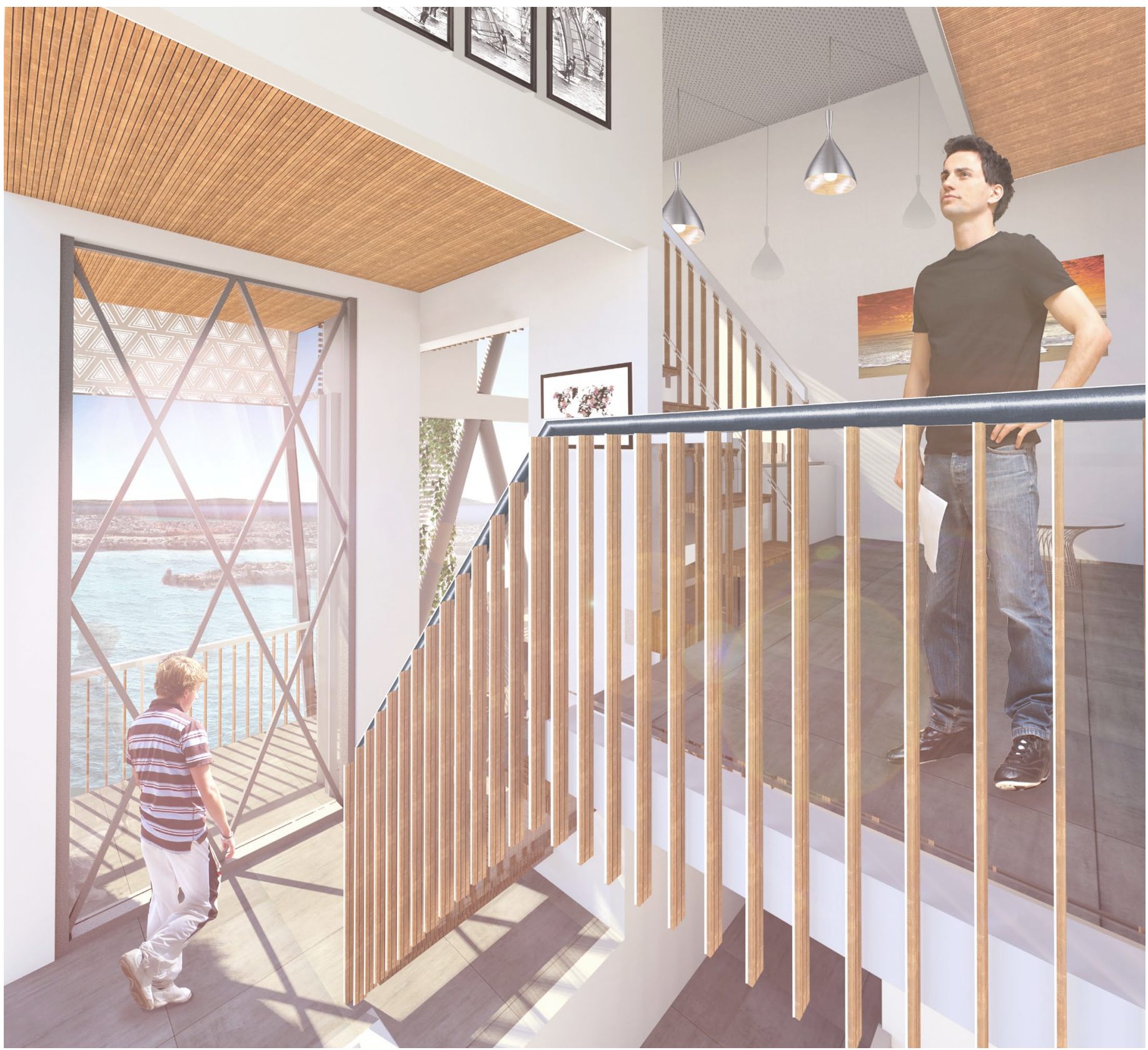




\subsection{FINAL DESIGN}

\section{INCREASING \\ SPACIOUSNESS}

Griffiths, L. (2017) Perceptual

Architecture, Presentation,

Architecture, Victoria University,

Wellington, 14 November.

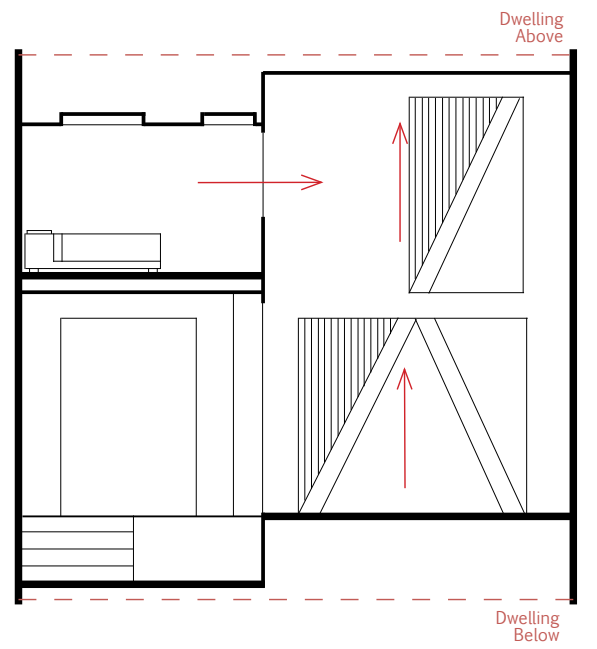

Program pockets separate

the spaces to allow for privacy from activity from the rest of the dwelling. This provides a visual connectivity without the disruption of invasive noise and exposed privacy (Griffiths L, 2017b).

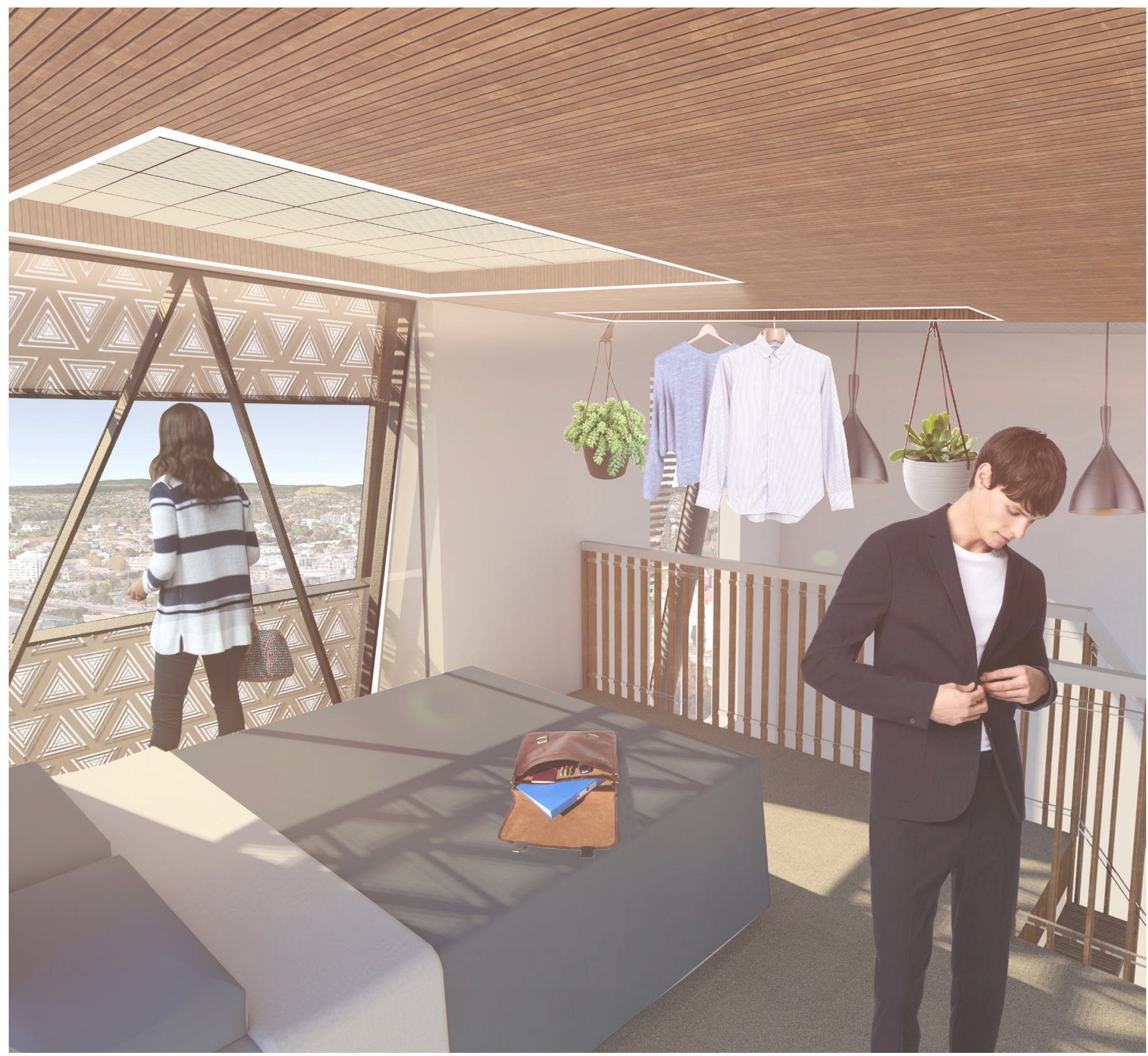




\section{TWO BEDROOM UNIT}

Griffiths, L. (2017) Perceptual

Architecture, Presentation,

Architecture, Victoria University,

Wellington , 14 November.

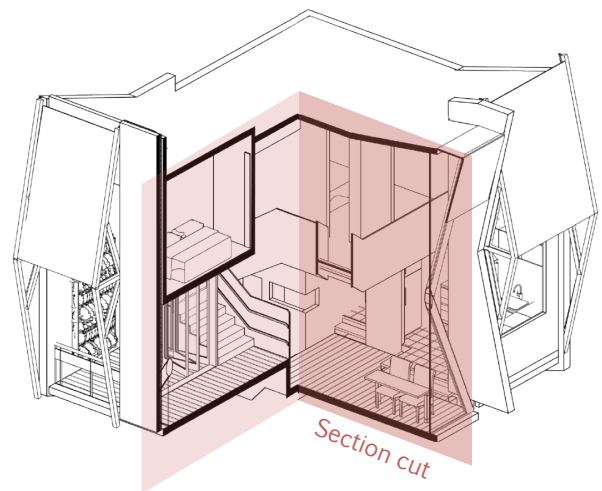

The two bedroom dwellings

formulates a coherent

living hierarchy using the

architectural principles.

Pockets containing the secondary zones creates a perceptual overlap and visual connectivity to the dwelling volume (Griffiths L, 2017b).

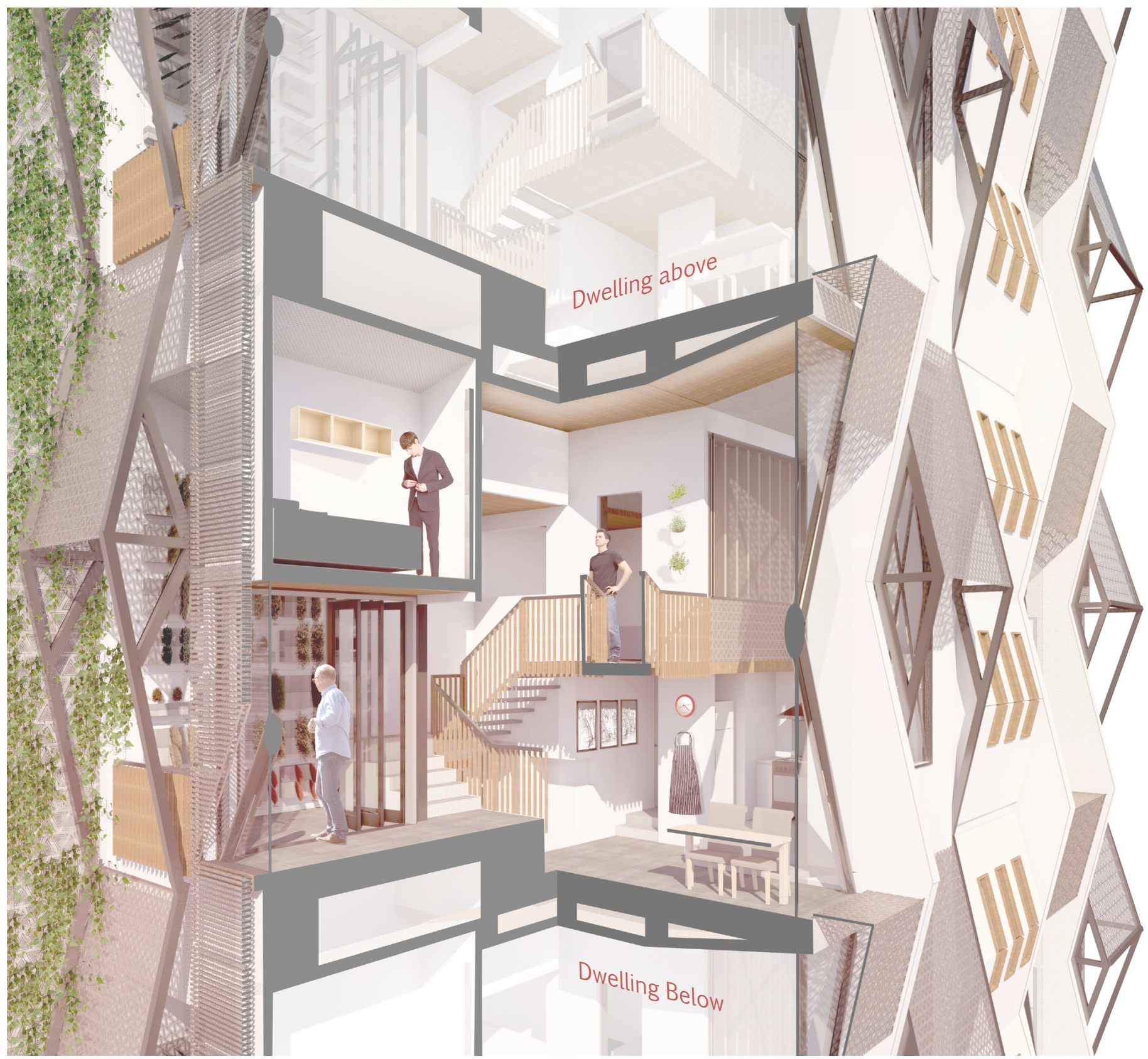




\section{SPATIAL CONNECTIVITY}

Griffiths, L. (2017) Perceptual

Architecture, Presentation,

Architecture, Victoria University,

Wellington, 14 November.
Permeability of the

architecture facilitates the perceptual overlap as well as creating more spacious environments. The circulation space inhabits the primary zone to express a visual coherence of volume and movement (Griffiths L, 2017b).

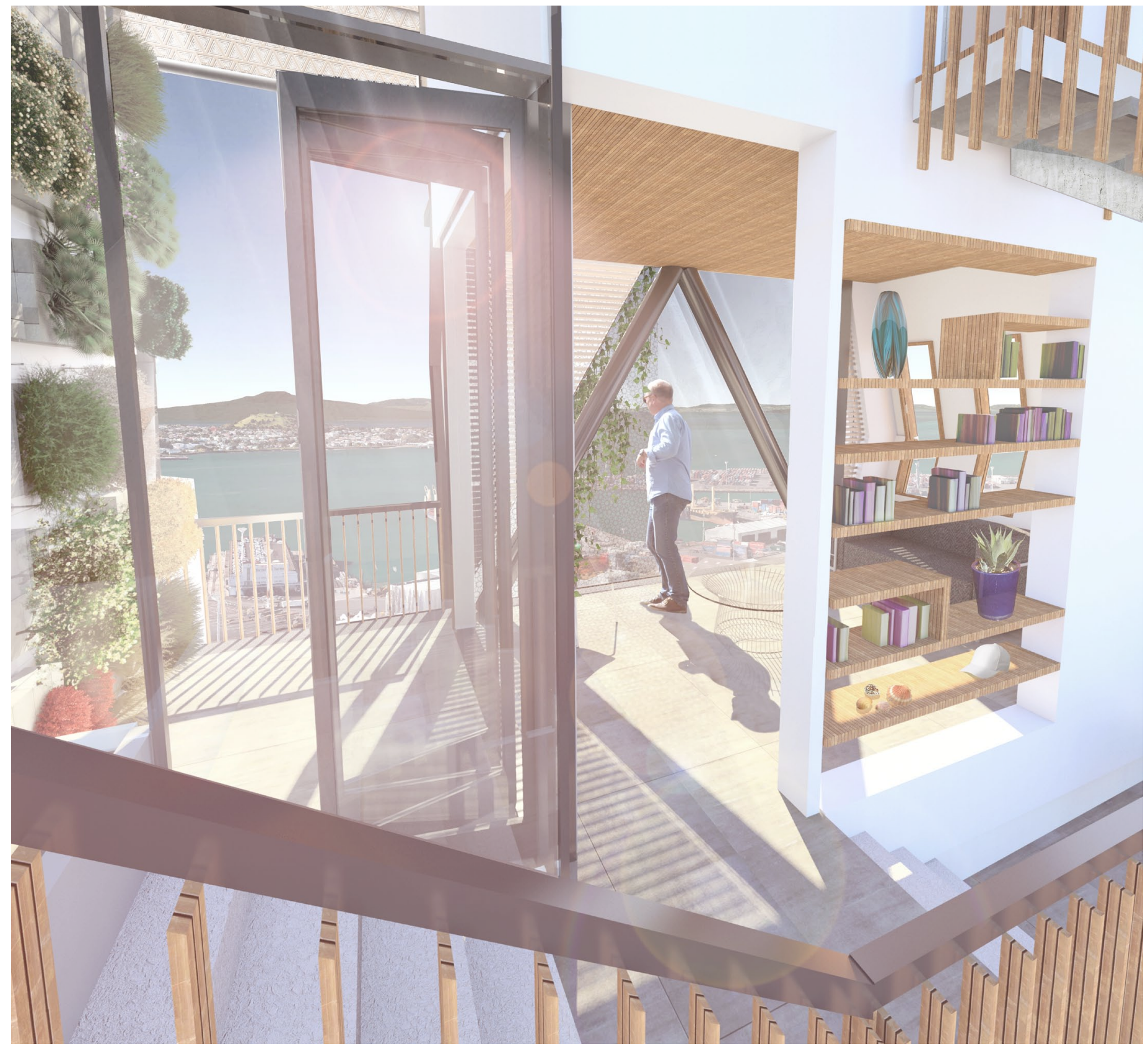




\section{PERCEPTUAL OVERLAP}

Griffiths, L. (2017) Perceptual Architecture, Presentation, Architecture, Victoria University, Wellington , 14 November.

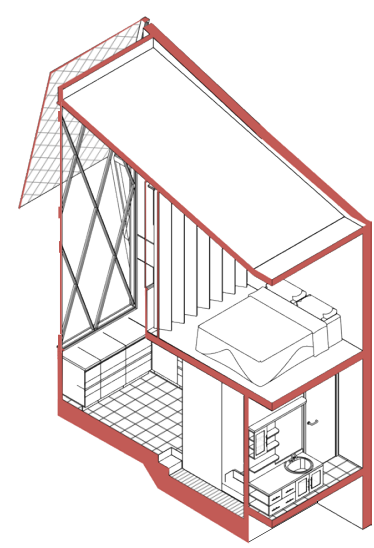

The secondary programs utilise existing volumes to expand the perceived space. The visual elongation of ceiling planes forms an implied space. These interventions improve the feeling of spaciousness within spaces, both in primary and secondary zones (Griffiths L, 2017b).

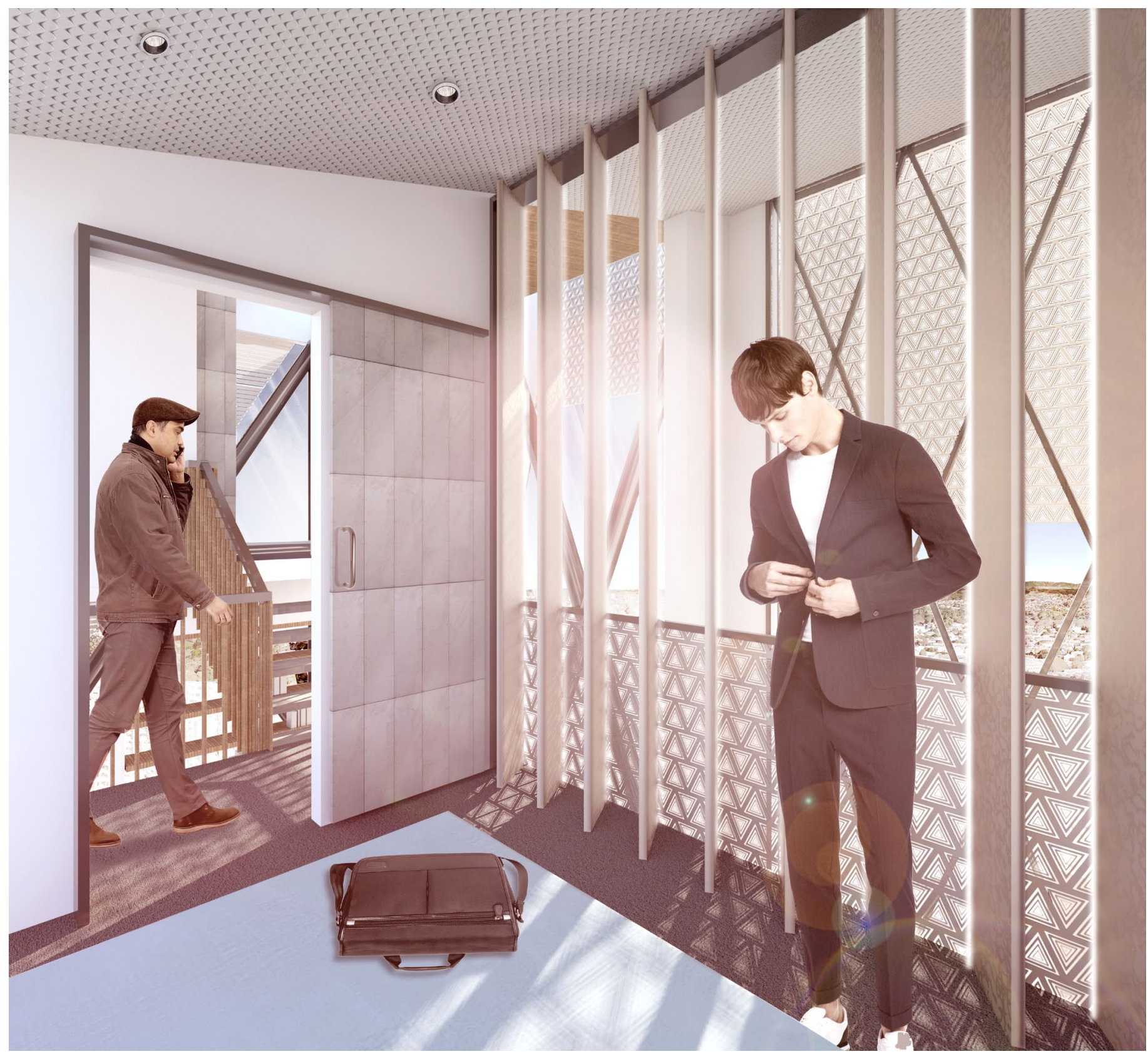




\section{THREE BEDROOM UNIT}

Griffiths, L. (2017) Perceptual Architecture, Presentation, Architecture, Victoria University, Wellington, 14 November.

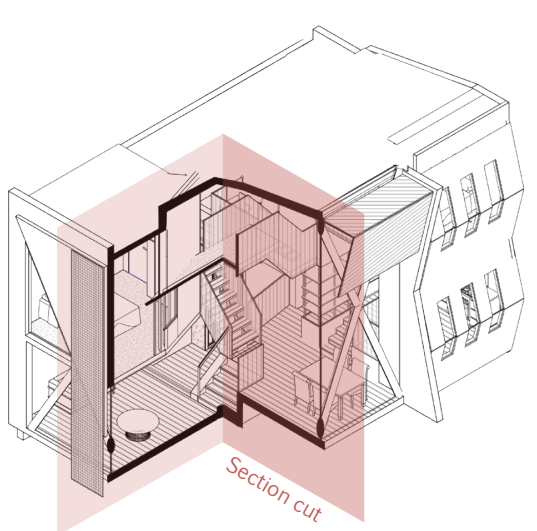

The three bedroom dwellings utilize the architectural principles to optimise the available space. The staggered floor plate allows a perceptual overlap to occur without impeding on privacy or practicability. The volume is shared between the dwelling zones to increase the overall perceived size and spaciousness, and thus liveability (Griffiths L, 2017b).

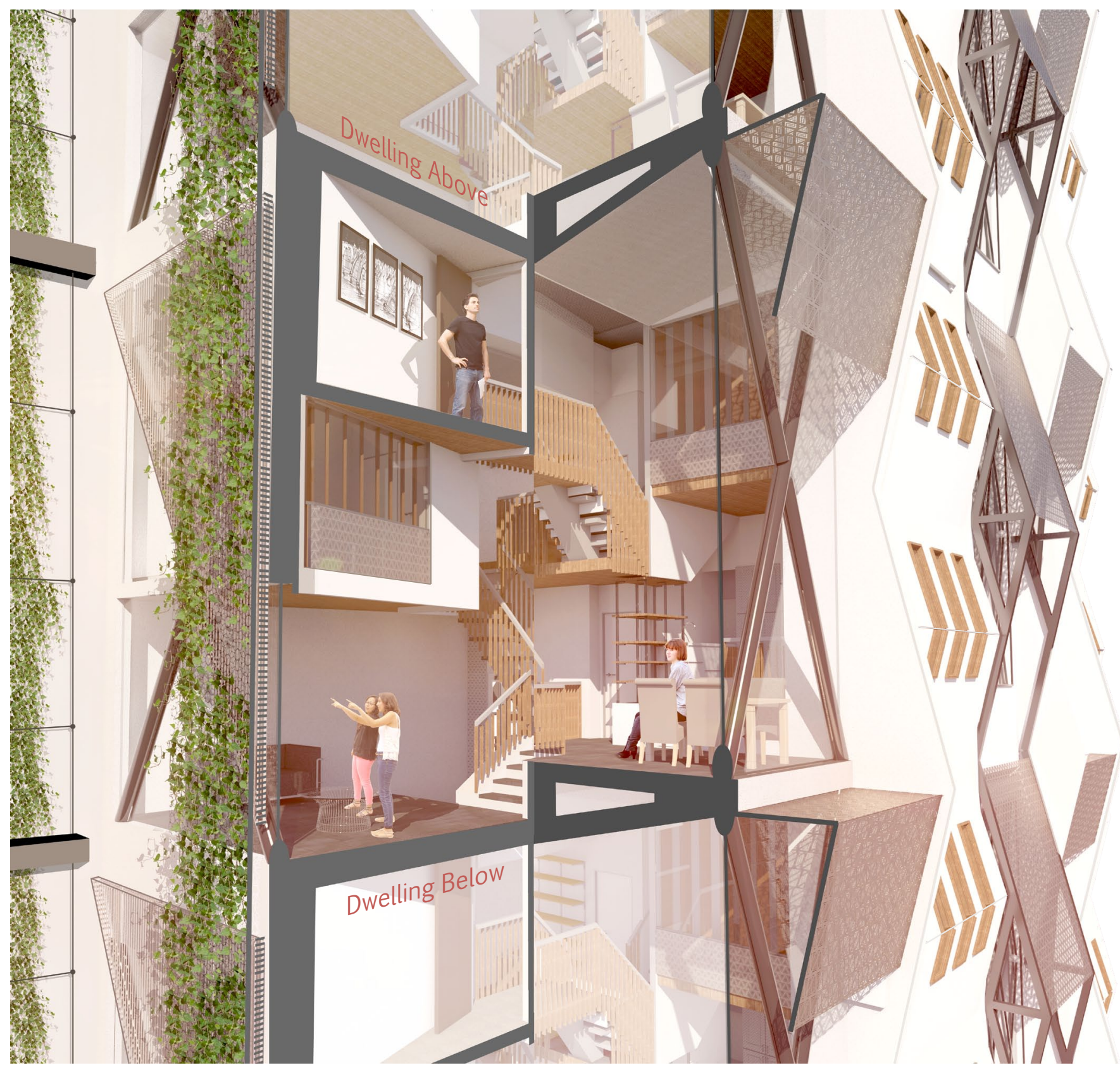




\section{COMMUNICATING VOLUME}

Griffiths, L. (2017) Perceptual

Architecture, Presentation,

Architecture, Victoria University,

Wellington , 14 November.
The primary zone visually connects the dwelling to all secondary zones. The volume is instantly communicated as soon as you enter the interior. By illustrating the entire volume the perceived size and spaciousness is improved, creating more liveable high density dwellings (Griffiths L, 2017b).

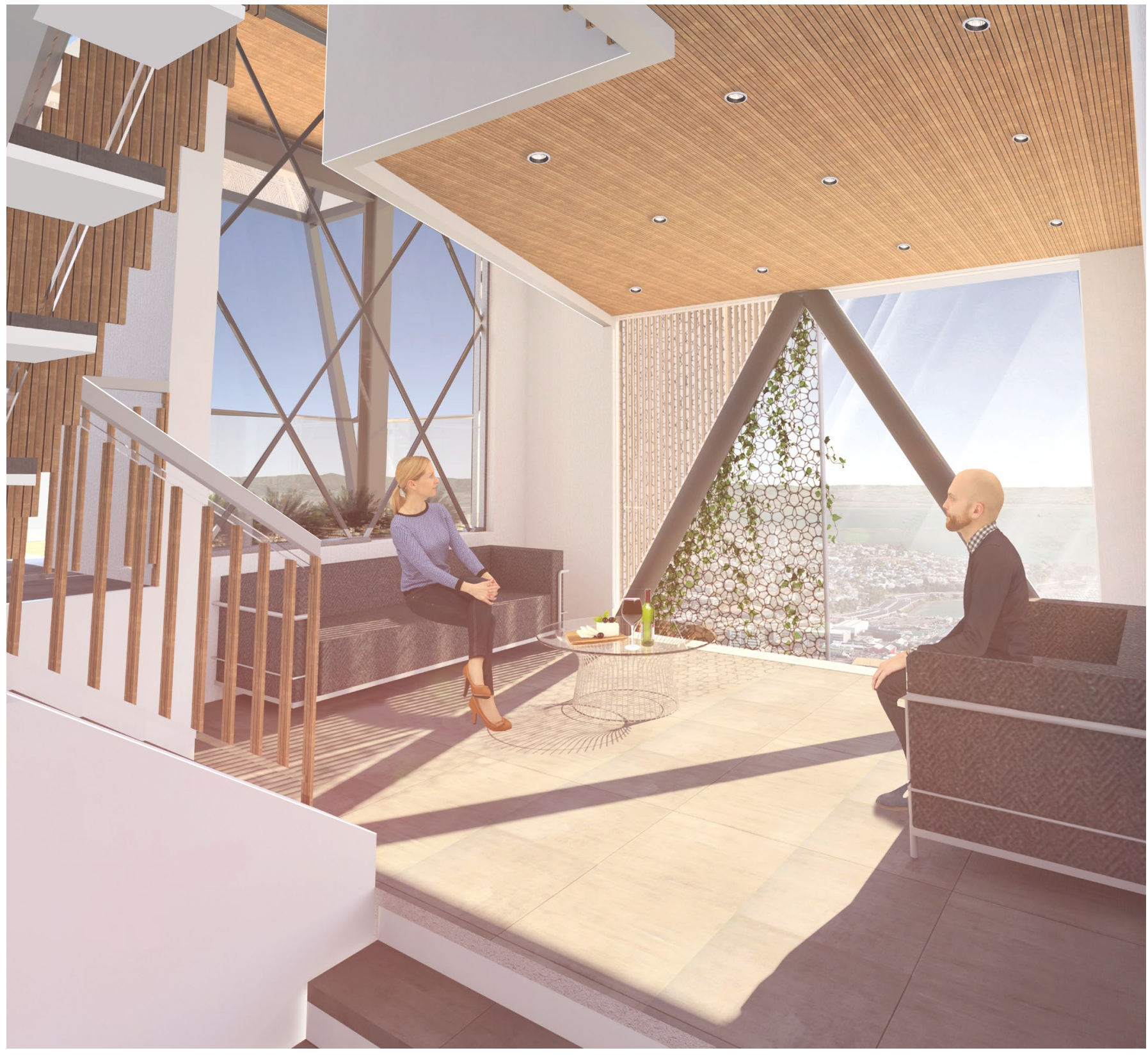




\section{EXPANDING SPACES}

Griffiths, L. (2017) Perceptual Architecture, Presentation, Architecture, Victoria University, Wellington, 14 November.

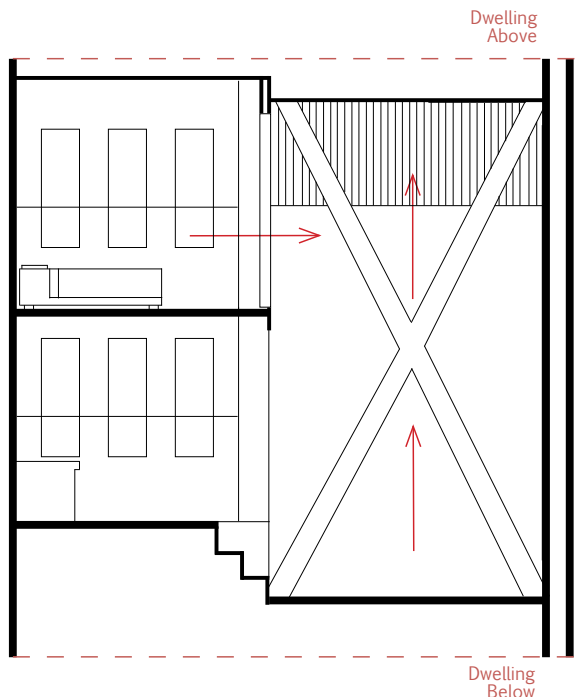

By creating a connection of widths between spaces the room can share the perceived volume to expand the subjective space. This allows relatively small spaces to feel more spacious and as a result more liveable (Griffiths L, 2017b).

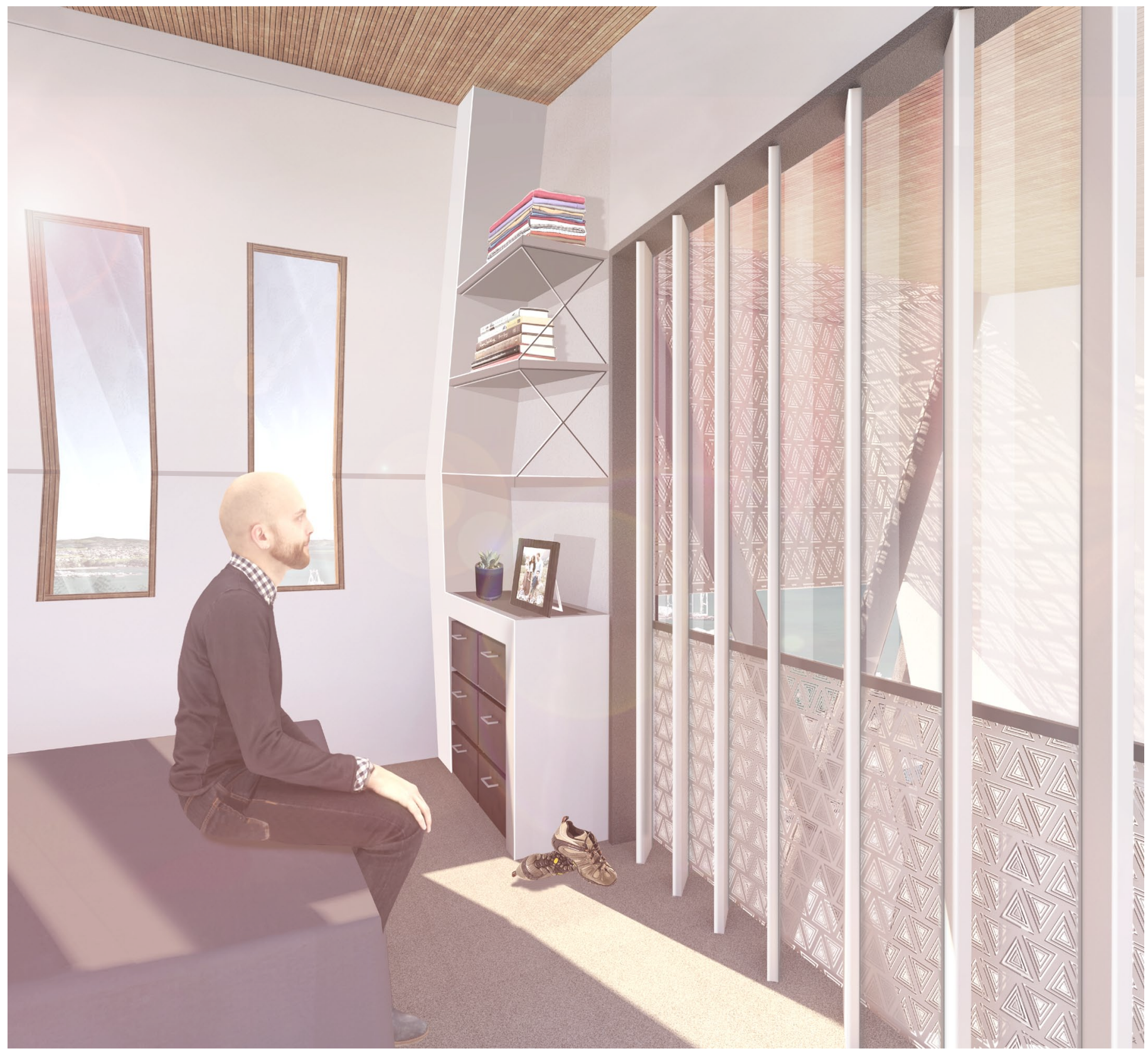




\subsection{FINAL DESIGN}

\section{EXPRESSING \\ PARAMETERS}

Griffiths, L. (2017) Perceptual

Architecture, Presentation,

Architecture, Victoria University,

Wellington , 14 November.

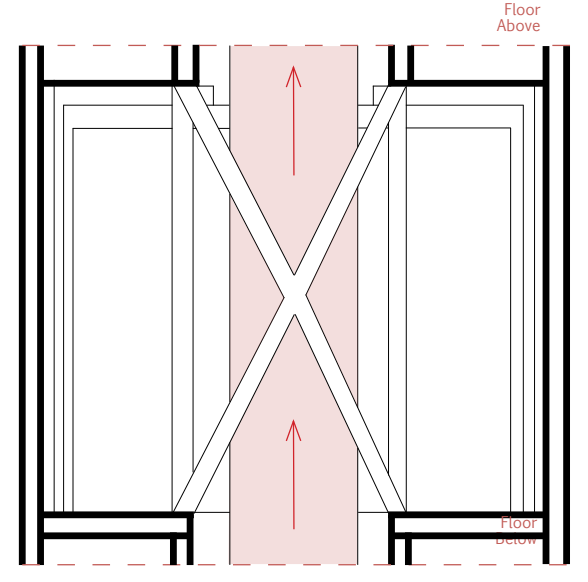

Expanding the perceived space can be achieved by expressing the buildings mass through Panel shifts which extend in both height and width. The perceived space is expanded by implementing the research parameters, illustrating the potential of informed spatial arrangement (Griffiths L, 2017b).

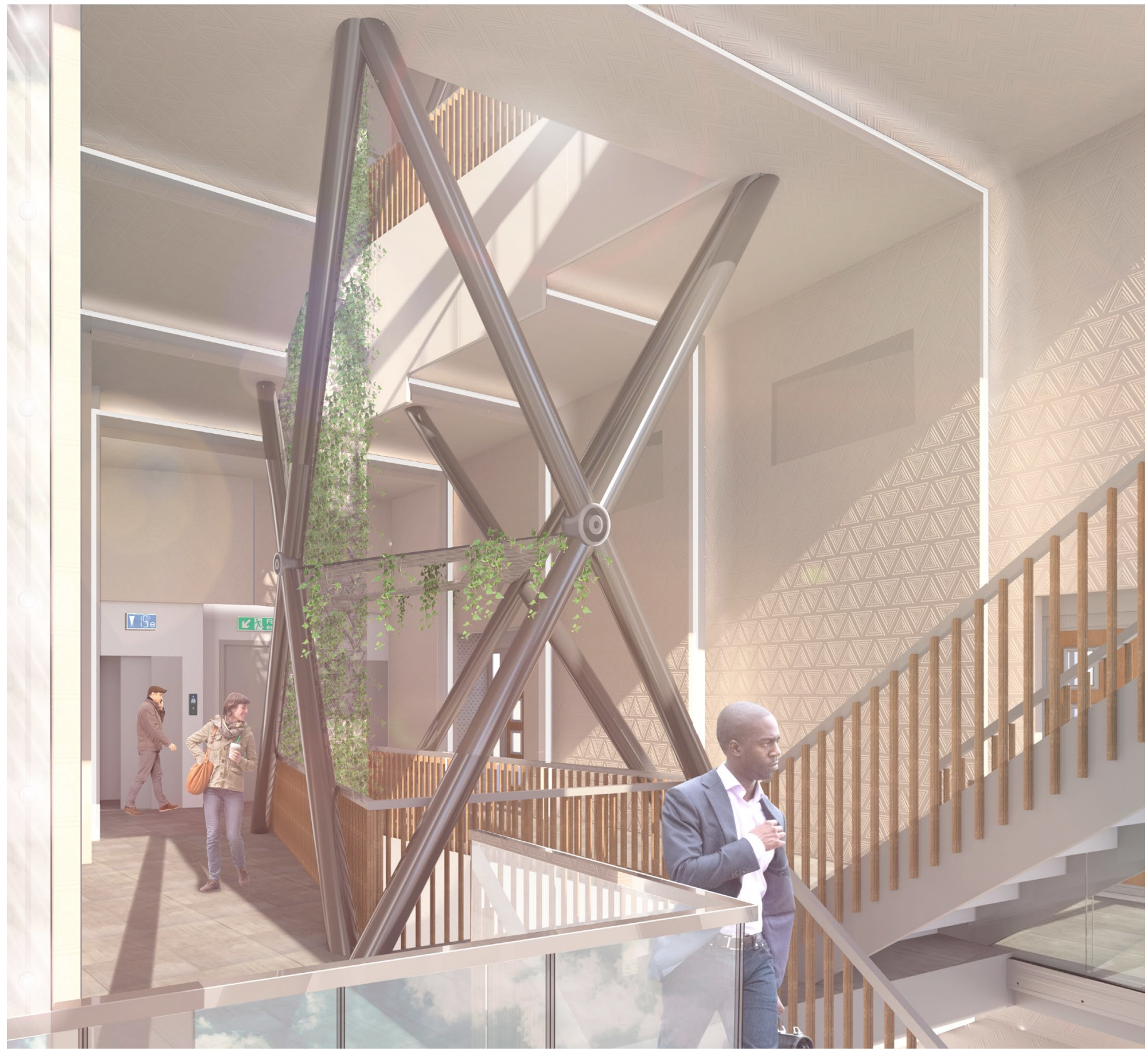




\section{EXTENDING LINE OF SIGHT}

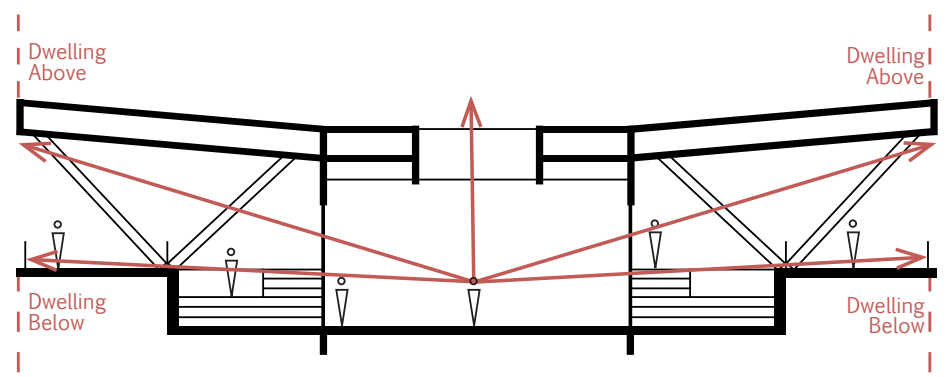

By expanding the subjective size through increasing the perceived height, a larger angle for sun light penetration can also create an inviting and open community space. Using the parameters alongside traditional design principles is imperative to form successful perceptually informed architecture (Griffiths L, 2017b).

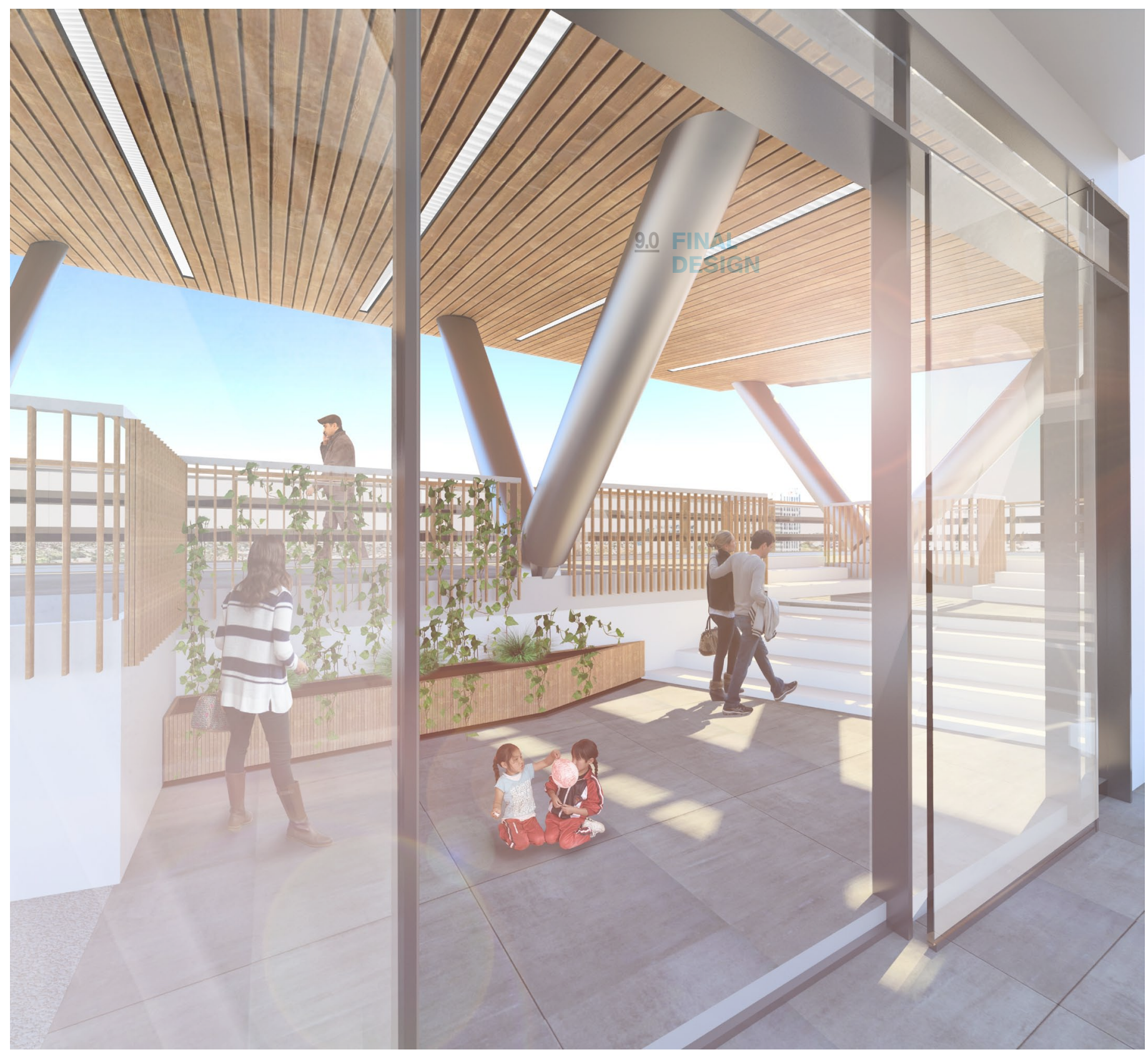

Griffiths, L. (2017) Perceptual

Architecture, Presentation,

Architecture, Victoria University,

Wellington, 14 November. 


\subsection{FINAL DESIGN}

\section{COMMUNITY SPACES}

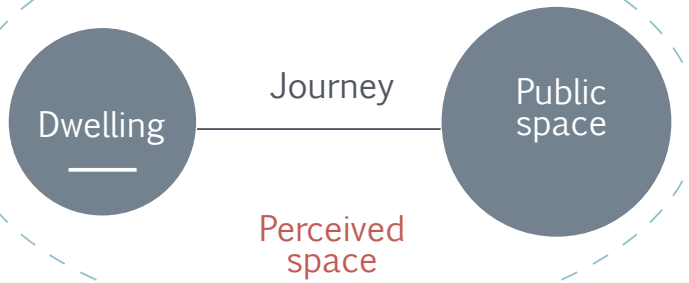

This extends the building program for the occupant, removing people from the confines of their home. Extending program has the potential to create an external overlap which recognises the journey to public space as an extension of the home (Griffiths L, 2017b).

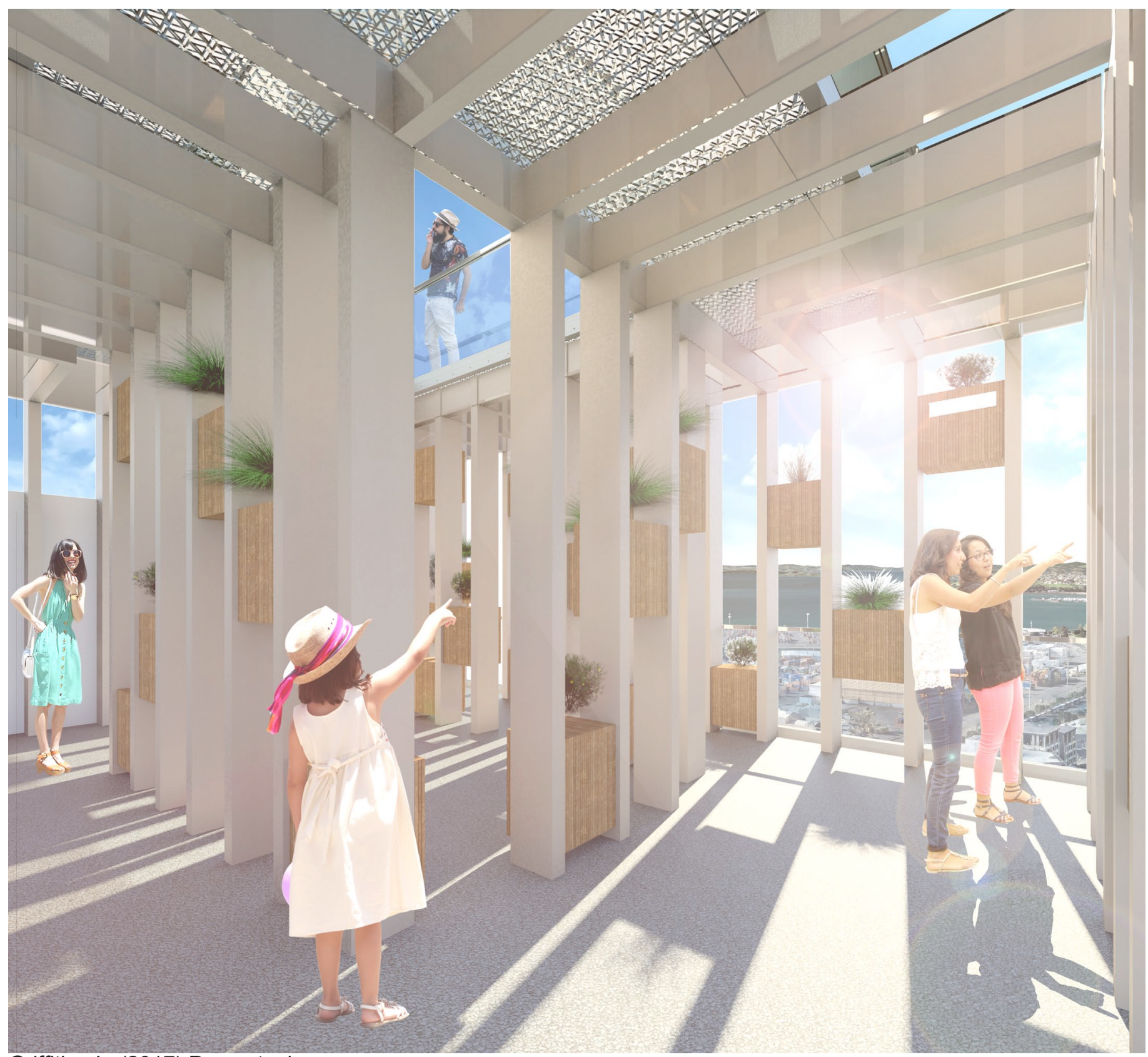

Griffiths, L. (2017) Perceptual

Architecture, Presentation,

Architecture, Victoria University,

Wellington, 14 November. 


\subsection{FINAL DESIGN}

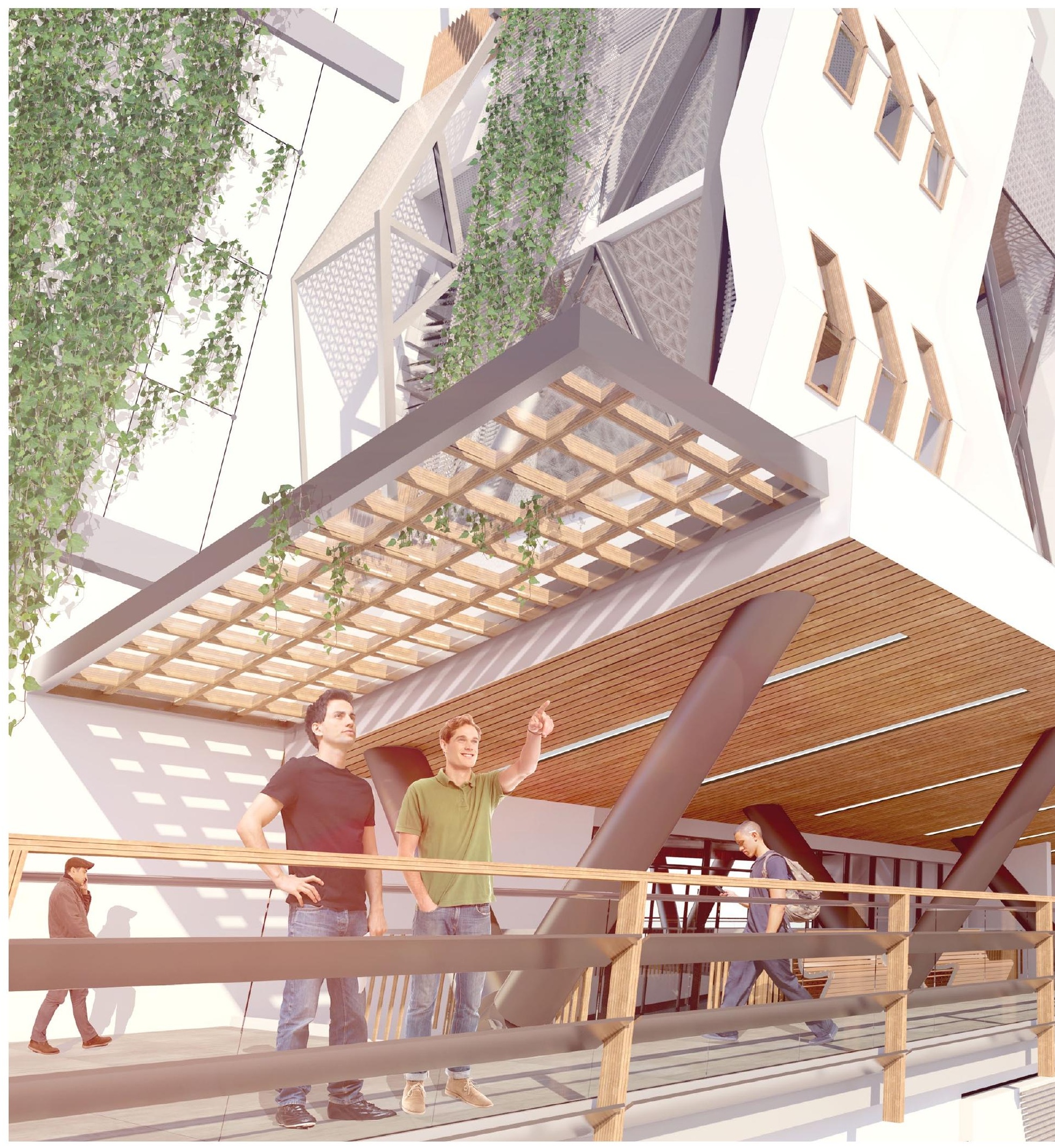

Griffiths, L. (2017) Perceptual

Architecture, Presentation,

Architecture, Victoria University,

Wellington , 14 November. 


\subsection{FINAL DESIGN}

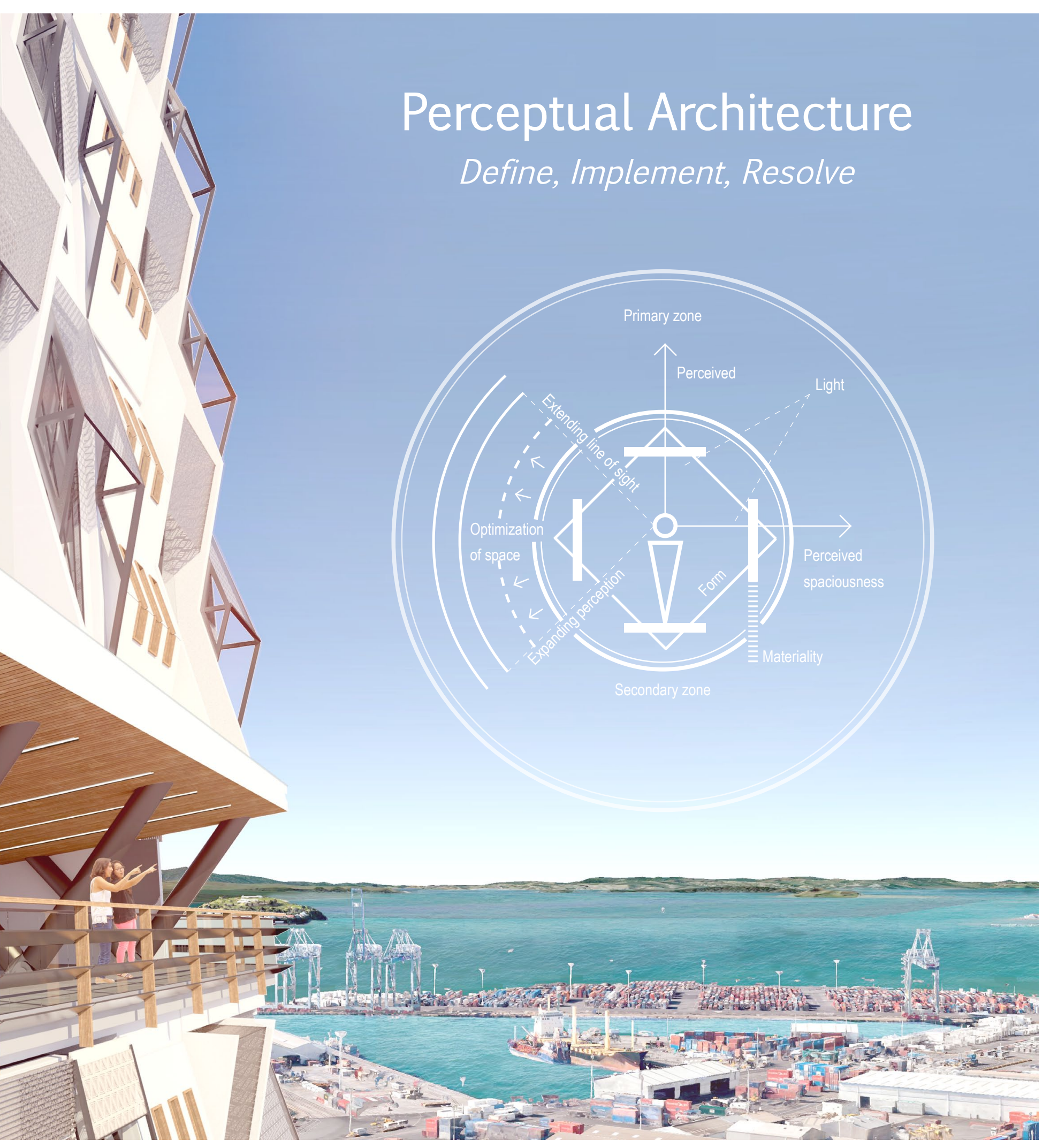




\subsection{CONCLUSION}

\section{End of thesis-2017}

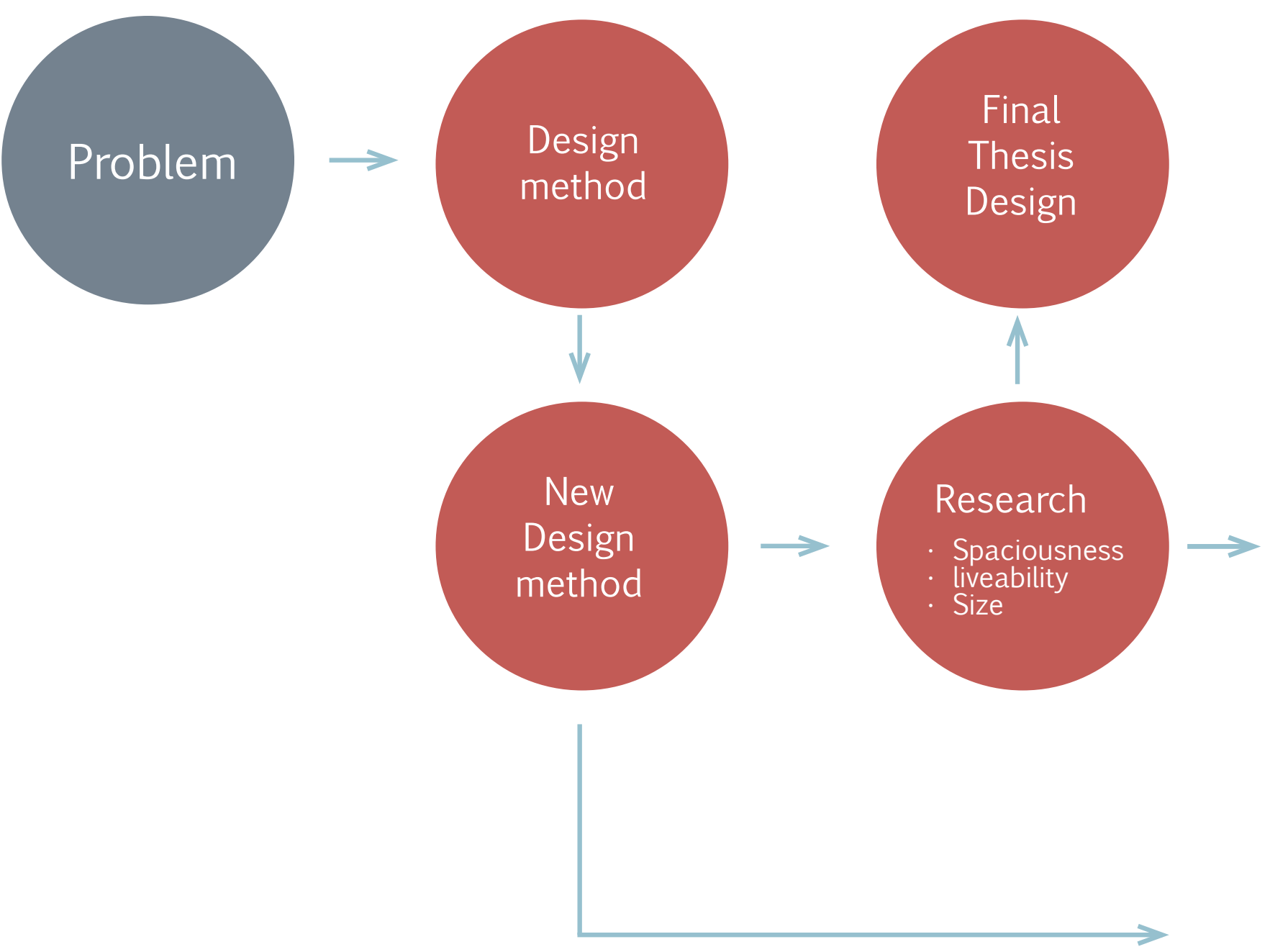

Griffiths, L. (2017) Perceptual

Architecture, Presentation,

Architecture, Victoria University,

Wellington, 14 November.

10.1 CURRENT RESEARCH

This thesis has provided two key optimising parameters of a volume, defined perceived spaciousness, and size and liveability. These parameters provide insight into how the perceived space affects a person and how an architect might be able to change this. The aims of this thesis is to provide fundamental research into how designers can understand the perceived space and use it to inform design decisions. As foundational research, there is much development needed before it can be applied to the practice of architecture. However, it does establish the potential of the research topic and aims to inspire future designers and researchers to consider these elements. 


\section{Future direction}

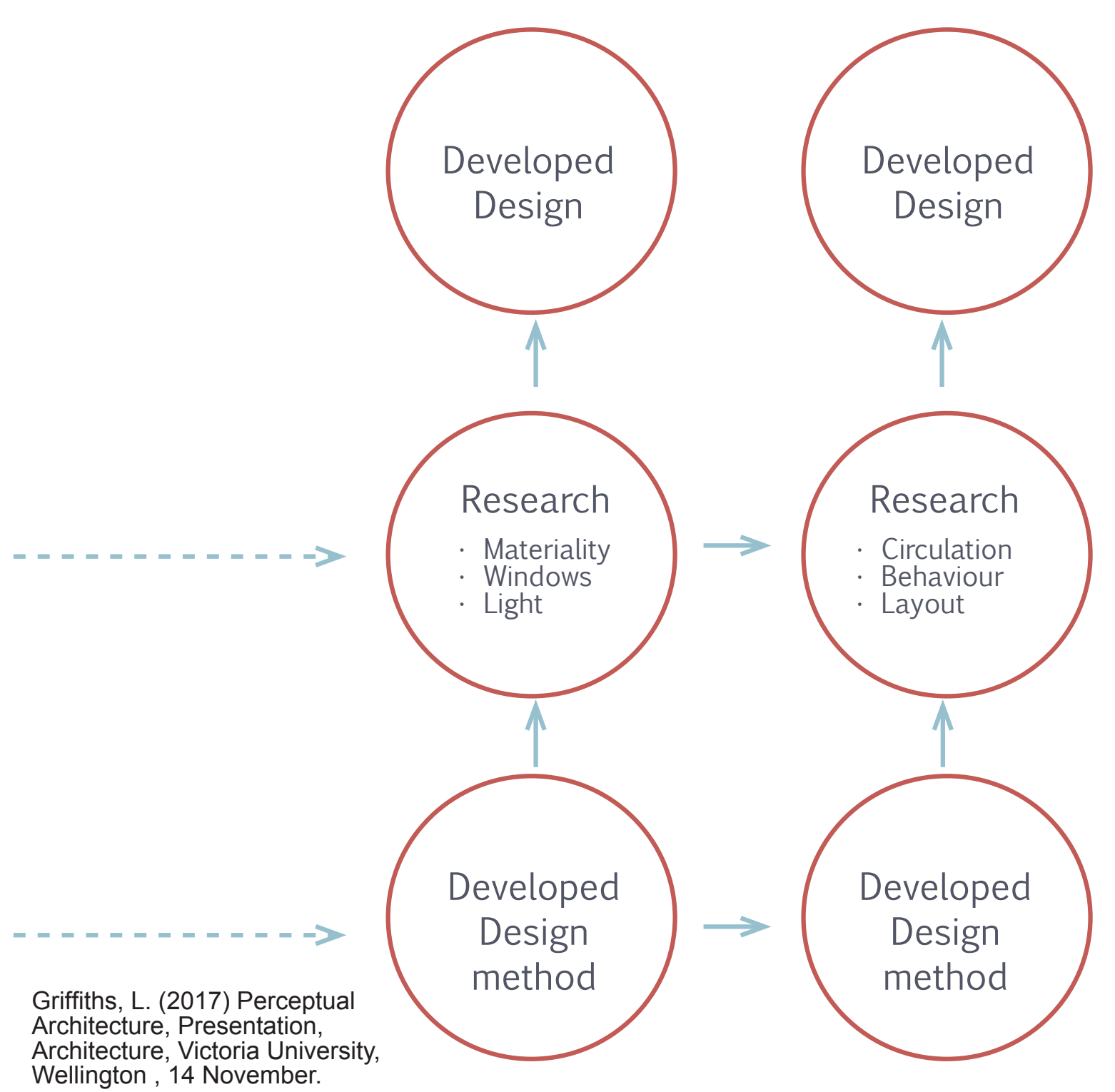

10.2 FUTURE RESEARCH

The next step for this research is to define subsequent parameters which could broaden the applications of the research. The parameters and evaluations will become more complex as parameters continually add more information in the explored design. The result of this would be a system to fully optimise a design with complex questions about perception. Examples of possible areas of development would be perceptual responses to material, light, program arrangement and colour. Each of these areas of perception fundamentally change the perceived space and are needed for designing a fully optimizable methodology which caters to the responses of the occupant. By understanding how people perceive a space designers can make more informed design decisions with the intention to create better architecture. 
In this thesis a methodological structure of define, implement and resolve is used to create perceptually informed architecture. A series of processes were employed those being, experimentation, evaluation and design iteration. These form an architecture which answers the thesis question. Each of these steps were crucial to answer how high density apartments can be designed to be perceived larger and more spacious. The process initially explored the fundamentals of the perceived space which formed two key optimising parameters. The research then developed architectural principles which manipulate perception to create the desired setting through VR evaluation. The principles developed were; perceptual overlap, extending perceived width, and optimization of space. The final architecture was then developed to facilitate the design and literature research by utilising the principles to inform design solutions.

Each of the thesis components of define, implement and resolve could have been a thesis on its own. Having less than year to complete this project meant that I have only exposed the possibilities of these components. This is an area that I would have liked to further explore. However, what has arisen from this research is the explicit recognition of subjective experience in objective areas. I think this is hugely important in the future of architecture, to ensure that architects are designing for people by taking into consideration their experiences of the built environment.

I would like to acknowledge a range of people who aided of the completion of this thesis. I sincerely appreciate the help of the participants of the experiment who took their own time to partake. I would also like to acknowledge the help provided by Daniel Innes who aided in the coding of the experiments. Without his help the experiment would have not been feasible. And finally my supervisors, Dr. Antony Pelosi and Dr. Steve Lamb, who gave me the insight and motivation to finish the thesis to a level that I am proud of . Each provided a perspective with their expertise of which I am now more knowledgeable. 
1. Hermund, A. (2017) speculation on the representation of architecture in virtual reality: how can we (continue to) simulate the unseen? Architectural science association international conference, Wellington, New Zealand, 30 November.

2. Baldassare, M. (1979) Residential crowding in urban America, ed., Univ of California Press.

3. Booth, A. and Cowell, J. (1976) Crowding and health, Journal of Health and Social Behavior, 204-220.

4. Bosselmann, P. (2012) Urban transformation: Understanding city form and design, ed., Island Press.

5. Bloomer, K. C. and C. W. Moore (1977). Body, Memory, and Architecture, Yale University Press.

6. Bowman, D. A. and L. F. Hodges (1999). "Formalizing the design, evaluation, and application of interaction techniques for immersive virtual environments." Journal of Visual Languages \& Computing 10(1): 37-53

7. Cohen, S., Evans, G. W., Stokols, D. and Krantz, D. S. (2013) Behavior, health, and environmental stress, ed., Springer Science \& Business Media.

8. Cox, W. (2015) Demographia world urban areas, 11th Annual Edition ed. St. Louis: Demographia. Available: http://www. demographia. com/db-worldua. pdf. Date of access, 30, 2015.

9. Council, A. C. (2016). Report to Auckland Council Overview of Recommendations. I. h. panel.

10. Edmunds, S. (2017) Is it time for New Zealanders to get over aversion to apartments? Available from: <http://www.stuff.co.nz/ business/property/91375226/is-it-time-for-new-zealanders-to-getover-aversion-to-apartments> (accessed 29/11/2017).

11. Evans, G. W. and McCoy, J. M. (1998) When buildings don't work: the role of architecture in human health, Journal of Environmental psychology, 18(1), 85-94.

12. Evans, G. W., Wells, N. M. and Moch, A. (2003) Housing and mental health: a review of the evidence and a methodological and conceptual critique, Journal of social issues, 59(3), 475-500.

13. Gärling, T. (1970) Studies in visual perception of architectural spaces and rooms, Scandinavian journal of psychology, 11(1), 124-131.

14. Gilchrist, A. L. (1979) The perception of surface blacks and whites, ed., WH Freeman.

15. Griffiths, L. (2017a) Perceptual Architecture, Presentation, Architecture, Victoria University, Wellington, 14 November.

16. Griffiths, L. (2017b) A virtual reality experiment to define optimum high density apartment parameters, Architectural science association international conference, Wellington, New Zealand, 30 November.

17. Hayward, S. C. and Franklin, S. S. (1974) Perceived opennessenclosure of architectural space, Environment and Behavior, 6(1), 37-52.

18. Judd, D. B. (1940) Hue saturation and lightness of surface colors with chromatic illumination, JOSA, 30(1), 2-32.

19. Kopec, D. A. (2006) Environmental psychology for design, ed., 
Fairchild New York.

20. Lau, K. Y. and Leung, B. (2001) A Comparison of Indicators Used in Measuring Housing Affordability in Hong Kong and Their Validity, ed., Department of Public and Social Administration, City University of Hong Kong.

21. Maffei, L., et al. (2016). "Immersive virtual reality in community planning: Acoustic and visual congruence of simulated vs real world." Sustainable Cities and Society 27: 338-345

22. Manav, B. and Yener, C. (1999) Effects of different lighting arrangements on space perception, Architectural Science Review, 42(1), 43-47.

23. Nations, U. (2014) World Urbanization Prospects: The 2014 Revision, Highlights. Department of Economic and Social Affairs, Population Division, United Nations.

24. Norman, D. A. and Stappers, P. J. (2016) DesignX: complex sociotechnical systems, She Ji: The Journal of Design, Economics, and Innovation, 1(2), 83-106.

25. Ojose, B. (2008) Applying Piaget's theory of cognitive development to mathematics instruction, The Mathematics Educator, 18(1).

26. Paul, J. (2012) STUDENT HOUSING. Available from: Goethe-Institut <https://www.goethe.de/en/kul/arc/20359151.html> (accessed 29/11/2017).

27. Piaget, J. (1976) Piaget's theory, Handbook of child psychology, 1.

28. Portman, M., et al. (2015). "To go where no man has gone before: Virtual reality in architecture, landscape architecture and environmental planning." Computers, Environment and Urban Systems 54: 376-384.

29. Sadalla, E. K. and Oxley, D. (1984) The Perception of Room Size The Rectangularity Illusion, Environment and Behavior, 16(3), 394405.

30. Schnabel, M. A. and Kvan, T. (2003) Spatial understanding in immersive virtual environments, International Journal of Architectural Computing, 1(4), 435-448.

31. Seltman, H. J. (2012) Experimental design and analysis, Pittsburgh: Carnegie Mellon University, 428.

32. Siegler, R. S., DeLoache, J. S. and Eisenberg, N. (2003) How children develop, ed., Macmillan.

33. Solari, C. D. and Mare, R. D. (2012) Housing crowding effects on children's wellbeing, Social science research, 41(2), 464-476.

34. Stokols, D., Rall, M., Pinner, B. and Schopler, J. (1973) Physical, social, and personal determinants of the perception of crowding, Environment and Behavior, 5(1), 87.

35. Stokols, D. (1976). "The experience of crowding in primary and secondary environments." Environment and Behavior 8(1): 4986.

36. Shemesh, A., et al. (2016). "Affective response to architectureinvestigating human reaction to spaces with different geometry." Architectural Science Review: 1-10. 
37. Stouffs, R., Janssen, P., Roudavski, S. and Tunçer, B. (2013) What is happening to virtual and augmented reality applied to architecture?,Conference on Computer-Aided Architectural Design Research in Asia (CAADRIA 2013), 10.

38. Sharpin, A. B. and P. R. b. P. Kos (2006). "The Social and Environmental Effects of Residential Infill Development in New Zealand." Urban Development Strategy Working Paper 6.

39. Sadalla, E. K. and D. Oxley (1984). "The Perception of Room Size The Rectangularity Illusion.” Environment and Behavior 16(3): 394405.

40. Voort, M. V. (2017) Sensory Perception Through Architecture. Available from: HKSstories <www.hksinc.com/insight/sensoryperception-through-architecture/> (accessed 16 Novemeber).

41. Wong, S.-K., Lai, L. W.-C., Ho, D. C.-W., Chau, K.-W., Lam, C. L.K. and Ng, C. H.-F. (2009) Sick building syndrome and perceived indoor environmental quality: A survey of apartment buildings in Hong Kong, Habitat International, 33(4), 463-471.

42. Worchel, S. (1978) Reducing crowding without increasing space: Some applications of an attributional theory of crowding, Population \& Environment, 1(3), 216-230.Baldassare, M. (1979). Residential crowding in urban America, Univ of California Press.

43. Yildirim, K. and Akalin, A. (2009) Problems related to the dimensions

12.1 FIGURE LIST
Figure 1 - 4 Griffiths, L. (2017) Perceptual Architecture, Presentation, Architecture, Victoria University, Wellington, 14 November.

Figure 5 - $\quad$ Ben Mitchell-Anyon, 2016. Pyramid scheme by Patchwork Architects.

Figure 6 - Tyrone Siu, 2017. 60-square-foot $\left(5.5 \mathrm{~m}^{2}\right)$ apartment in Hong Kong.

Figure 7 - $\quad$ Iwan Baan, 2016. NArchitects', Carmel mirco-apartments.

Figure 8 - Jennifer Soo, 2016. Small space, big ideas: living in pocketsized apartments.

Figure 9 - Gensler, 2013. Shanghai Tower, completed 2015 Hotel/Offices Shanghai, China.

Figure 10 - SOM, 2013. Suzhou Zhongnan Center, completed 2014 Hotel/ Residential/Office, Suzhou, China.

Figure 11 - Iwan Baan, 2015. The Interlace, completed 2013 Residential complex, Singapore. 2015 building of the year.

Figure 12 - Peddle Thorp, 2016. Customs Residential, 50 story residential building. Completion 2018.

Figure 13 - $\quad$ Plus Architecture NZ, 2017. The Pacifica. 57 story residential building. Completion 2018.

Figure 14 - Willis Bond \& Co, 2016. Wynyard Central, 12 story residential complex. Completion 2018.

Figure 15 - Andrea Raibold, 2016. Olympic Village Student Quarters halls of residence - Munchen, Germany.

Figure 16 - Author original 
Figure 17 - 18 Griffiths, L. (2017) Perceptual Architecture, Presentation, Architecture, Victoria University, Wellington , 14 November.

Figure 19 Griffiths, L. (2017) A virtual reality experiment to define optimum high density apartment parameters, Architectural science association international conference, Wellington, New Zealand, 30 November.

Figure $20-23$ Author original

Figure 24 - $\quad$ Marta Szkudlarek, 2017. Studio Apartments In Three Modern Styles.

Figure 25 - James Edition, 2016. Luxurious \& Inspiring Penthouses.

Figure 26 - The Goort , 2015. A Super Small Apartment That Adapts To Its Owner's Needs.

Figure 27 - Denis Svirid, 2014. Small Apartment with Snug Storage.

Figure 28 - José Hevia, 2017. Arquitectura-G uses only light tones for Barcelona apartment renovation.

Figure 29 - Studio O+A, 2017.Cisco Campus.

Figure 30 - João Morgado, 2017. Pedro Ferreira converts abandoned Porto house into flats with pine and marble surfaces.

Figure 31 - Jump \& Fly, 2016. Traditional spanish market, Madrid - Spain.

Figure 32 - Dima Kravtsov, 2016. Balance, kyiv.

Figure 33 - Richard Powers, 2017. 432 Park Avenue penthouse receives makeover from Kelly Behun.

Figure 34 - $\quad$ "Economic\&Masters Building UNAV / Juan M. Otxotorena" 15 Jul 2013. ArchDaily. Accessed 7 Dec 2017.

Figure 35 - David Frutos, 2011. Cor \& Partners Muca, Algueña.

Figure 36 - Griffiths, L. (2017) Perceptual Architecture, Presentation, Architecture, Victoria University, Wellington.

Figure 37 - 39 Author original

Figure 40 - District Plan (2011) Central Area Section: Appendix 12 Minimum Residential Apartment Standards.

Figure $41-54$ Author original

Figure 55 - 59 Griffiths, L. (2017) Perceptual Architecture, Presentation, Architecture, Victoria University, Wellington , 14 November.

Figure 60 - 65 Author original

Figure 66 - I Iwan Baan, 2008. House N, Japan.

Figure 67 - Suppose Design Office, 2016. Makoto Tanijiri on Architectural Education and "Japanese-ness" in Design.

Figure 68 - Daici Ano, 2013. A new office space for Spicebox.

Figure 69 - S Shigetomo Mizuno, 2014. Dandesign, Nagoya, Japan.

Figure 70 - Yamagata ken Ozuhazawa-shi, 2006. Ginzan Onsen Fujiya.

Figure 71 - Y Yukiharu Suzuki, 2011. Barn Style Home Design by Japanese Architecture Firm. 
Figure 72 - $\quad$ Ryue Nishizawa, 2015. SANAA Studios, Tokyo, 'House with growing plants'.

Figure 73 - $\quad$ koichi torimura, 2012. A simple and modern Japanese house by Studio Synapse.

Figure 74 - Kai Nakamura, 2013. Koya No Sumika / mA-style Architects.

Figure 75 - Jens Willebrand, 1998. The Ludwig Erhard House (LEH) located in the Berlin district of Charlottenburg in the Fasanenstraße, 1998.

Figure 76 - 79 Author original

Figure 80 - 81 Griffiths, L. (2017) Perceptual Architecture, Presentation, Architecture, Victoria University, Wellington, 14 November.

Figure 82 - $\quad$ Author original

Figure 83 - $\quad$ Griffiths, L. (2017) Perceptual Architecture, Presentation, Architecture, Victoria University, Wellington , 14 November.

Figure 84 - 86 Author original

Figure 87 - 104 Griffiths, L. (2017) Perceptual Architecture, Presentation, Architecture, Victoria University, Wellington , 14 November. 
Figure 105 - IMAGE

COURTESY OF ASA

INTERNATION CONFERENCE

(Griffiths L, 2017b)

M. Aurel (eds.), Back to the future: The next 50 years, 51st International Conference of the Architectural Science Association 2017, pp. 1-11. C2017, The Architectural Science Association and Victoria University of Wellington.

\title{
A virtual reality experiment to investigate optimum high- density apartment parameters
}

\author{
Llewelyn Griffiths ${ }^{1}$, Steve Lamb ${ }^{2}$ and Antony Pelosi ${ }^{3}$ \\ 1, 2, 3 Victoria University, Wellington, New Zealand \\ ${ }^{1}$ llewelyn.griffiths, ${ }^{2}$ steve.lamb ${ }^{3}$, antony.pelosi \\ $@ v u w . a c . n z$
}

The current study uses Virtual Reality (VR) to experimentally investigate how room shape and volume affect perception of space and perceived size to identify optimal design for densified urban apartments. Optimal parameters are defined as (1) room shape that produces the largest increase in perceived space with the smallest increase of objective space (2) rooms that produce high perceived spaciousness and livability ratings. Participants experienced a series of virtual rooms of different shapes and volumes, and were asked to scale a cubed reference room to match the size of the target room. While room shape determined the accuracy of the spatial perception it is suggested that the optimum parameters of ceiling height and room width affect perceived spaciousness and liveability. Defining optimum parameters of room height, width and shape are foundational to providing strategies in apartment design to produce optimum perceived spaciousness and liveability. This research aims to firstly, develop a new method for studying optimal architectural design parameters, and secondly study the relationship between perceived space, shape and volume to form optimum parameters. Future research can then build on these parameters and introduce more complex parameters to produce defensible architectural strategies for optimizing high-density design.

Keywords: Occupant wellbeing, Virtual reality, Perception of space, Densification.

\section{Introduction}

\subsection{Densification}

Densification is an inevitable consequence of growing city populations. Projections estimate that by $205075 \%$ of the world's population will be living in cities compared to $50 \%$ in 2007 , and $10 \%$ in 1900 (Nations, 2014). Currently $24 \%$ of urban density around the world is between $10,000-100,000$ people per square kilometre. In 1939 while urbanisation was increasing in Berlin the population density decreased from 29,000 to 5,600 people per square kilometre. The population increased by three million people and 800 square kilometres as the city expanded (Bosselmann, 2012). However, once cities reach a certain size a rate of expansion is no longer sustainable or possible resulting in an increased rate of population density. The 50\% urbanisation increase from the 1900's to the present has resulted in the top 26 largest urban areas in the world having a population density which is increasing more rapidly than expansion (Cox, 2015). The reduced size of living environments is a consequence of increased 


\author{
Figure 106 - IMAGE \\ COURTESY OF ASA \\ INTERNATION CONFERENCE \\ (Griffiths L, 2017b)
}

population density. Densified living environments can result in discomfort and dissatisfaction, especially in high density housing (Wong et al., 2009). Densification can cause issues in living situations affecting occupant wellbeing which needs to be addressed. Simply creating larger high density spaces is not a viable solution as the available space decreases as population density increases. "It is simply impossible to increase the amount of space available to individuals incarcerated in cities" (Worchel, 1978, p. 28). By taking a scientific approach we can establish the optimum measures to improve spatial responses in high density design. A defensible set of optimal design parameters which challenges the issue of densification are required. These parameters are a crucial development to providing high density architecture which optimise liveability, spaciousness and perceived size.

\subsection{Overcrowded stress}

By creating smaller living size conditions there is a potential to affect the overall wellbeing and comfort of the occupants (Kopec, 2006). This can lead to living dissatisfaction and discomfort and in serious cases depression and violence (Solari and Mare, 2012). The most common effect of densification is overcrowded stress. Overcrowding has three main manifestations stimulus overload, behavioural constraint, and ecological orientations, each of which have either a social or physical evoker (Stokols et al., 1973). Densification in an apartment context largely contributes to overcrowded stress with stimulus overload from physical stressors, which the built environment effects. Evans et al. (2003), while discussing the factors of overcrowded stress suggests that reducing it is essential for high density housing which can more positively affect occupant wellbeing. An approach which can increase the subjective or psychological space with minimal objective increase will help to minimise the effects of densification. An increase in psychological space has the potential to reduce the negative psychological effects of overcrowding stress. During an investigation of crowding and density Stokols (1976) suggests that "perceived crowding might be reduced through cognitive or perceptual strategies designed to expand psychological space" (p.69). This indicates that a designed space could alter an individual's perception of space and density resulting in an increase of wellbeing and comfort. Baldassare (1979) found that subjective ratings of perceived crowding correlated strongly to the prediction of living discomfort. People were able to determine the environmental quality of a space through perceived density. This suggests that architecturally designed rooms can improve the wellbeing and comfort of occupants in densified environments by altering the perception of space, as supported by Cohen et al. (2013). He discuss the effects of 'crowding' to be a largely subjective response to densification. Booth and Cowell (1976) also tested objective and subjective crowding relationships through survey responses. Thirty-three relationships between density and stress were measured. Twenty-one were of subjective measures of crowding, whereas twelve were of objective measures. If perceived density is largely influenced by subjective measures it would suggest that perceived density can be changed with minimal change to the objective measures.

\subsection{Perception of space}

People perceive the world around them uniquely on an individual level, but there are fundamental laws that define how people experience the physical environment (Evans and McCoy, 1998). This leads to question how the laws of perceived space can be tested to understand perceived size and subsequently alter perceived space. Hayward and Franklin (1974) discuss the relationship between the built environment to perceived openness or enclosure. They conclude that a lower height of back wall $(H)$ divided by the distance to wall (D) has an increased openness. "..impression of openness-enclosure of 
Figure 107 - IMAGE

COURTESY OF ASA

INTERNATION CONFERENCE

(Griffiths L, 2017b)

architectural space is determined by size-distance relations regardless of actual scale of space. As the value of the H/D ratio increased, perceived enclosure also increased" (p. 39). The experiment conducted in this research was highly abstracted in practice and does not serve as an adequate equation to challenge densification. Rather this research acts as an insight into the foundational information into perception of space. Additionally as precedent, forming studies involving perception of space. Sadalla and Oxley (1984) also explored this concept with a series of experiments. From these Sadalla and Oxley concluded that ratios of a rectangular room greatly influence the perceived size. The understanding of perception within a rectangular form concluded that a greater ratio of length/width implied a larger perceived space. In both of these experiments the fundamentals of perception of space were tested in regular cubic and rectangular form. However, this leaves a gap in understanding around perception of space in irregular form. Typical apartment design is not of regular form so to improve our understanding of perceived density an exploration of perceived space including irregular form is necessary.

\subsection{Conservation of space}

In the current study, subjects were asked to scale a cube to match the volume of another shape; a conservation of space task. Conservation refers to the ability to determine that a certain quantity will remain the same despite adjustment of the apparent size or shape (Siegler et al., 2003). Piaget (1976) tested children's perceptions of space by testing the concept of conservation by tipping the same amount of liquid into two vessels of the same volume yet different shapes. The exercise illustrated that children would rate the tallest of the vessels to be larger when asked which container had the most liquid. "Children's perceptions in this stage of development are generally restricted to one aspect or dimension of an object at the expense of the other aspects" (Ojose, 2008, p. 27). This ability develops around late childhood (Piaget, 1976). The proposed experiment will test the ability to apply conservation of space in more complex scenarios to investigate which aspects or dimensions of rooms produce larger perceived spaces. The method of experimentation with VR allows an in depth evaluation of architectural understanding, architectural qualities, and observation of user experience and perception of space. The medium of VR grants a controlled environment to conduct research enhancing perceptual understanding of 3D volumes (Schnabel and Kvan, 2003). The ability to experience the rooms in a first person perspective means a measure of perception of space can be observed and recorded. This would not be possible with another medium with the same level of immersion and reliability. The results of the experiment will suggest how apartments could be designed to feel more spacious and reduce the perceived density of the space. We hypothesise that room shape will have a relationship towards the perceived size of a space, resulting in a positive or negative association (perceived larger or smaller) at a constant volume. This would result in a room shape having a larger psychological space increase than the objective space increase while increasing perceived livability and spaciousness. We also predict that it will be harder for the participant to match volumes as room size increases.

\section{Method}

\subsection{Participants}

For the VR experiment 30 subjects participated in the study with a demographic ranging from 20 to 50 years of age with an average of 26.7 years old. The sample of $33.3 \%$ females over represents males. The sample size is derived from the application 'Piface' power and sample size calculator to achieve $80 \%$ 


\title{
12.0 APPENDIX
}

\author{
Figure 108 - IMAGE \\ COURTESY OF ASA \\ INTERNATION CONFERENCE \\ (Griffiths L, 2017b)
}

power, or $95 \%$ confidence Intervals with an accuracy of 5 or $10 \%$. Subjects were selected if they had not had education in the field of design. Conservation of space is a developed ability which can only improve with education (Judd, 1940). This informed the decision to exclude any participants with architectural education who may have a trained eye or advantage in the experiment.

\subsection{Materials}

\subsubsection{Equipment and software}

The VR equipment used was a HTC Vive, $2160 \times 1200,90 \mathrm{~Hz}$ refresh rate, with a 110 degrees field of view, and a tracking area of 15x15 feet. Alienware Aurora R5 Processor connected the VR equipment and programs with an Intel(R) Core(TM) i7-6700, CPU @ 3.40GHz, 3401 Mhz, 4 Core(s) 8 Logical Processor(s), RAM 16.0 GB, CPU Intel Core i7 (6th Gen) 6700 / 3.4 GHz Type Core i7, and NVIDIA GeForce GTX 1070. Excel 2013 and IBM SPSS Statistics 24 were used during the data analysis and to produce graphs. Steam VR and Unity 5.5.1 were used to run the experiment.

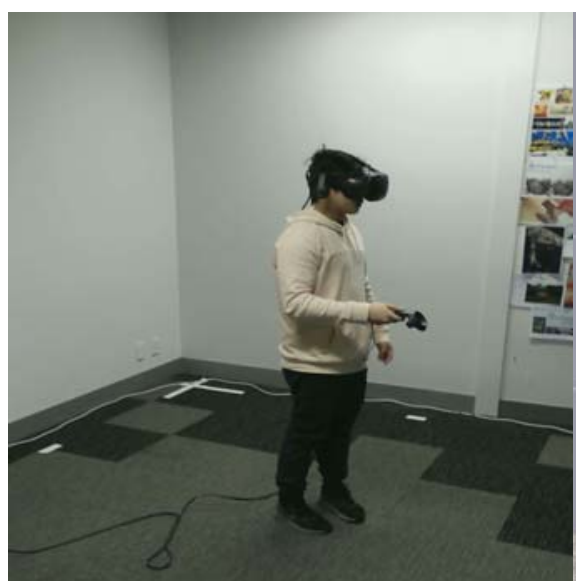

Figure 1: VR set up and equipment

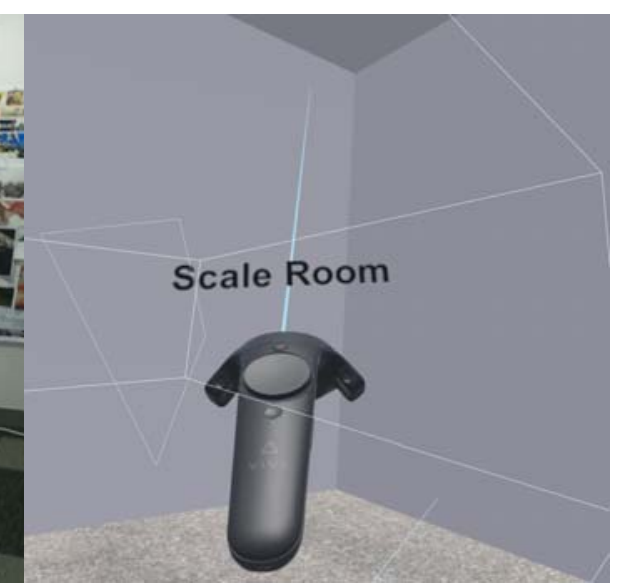

Figure 2: In-experiment VR view

\subsubsection{Rooms and set up}

Perceived illuminations affect perception of space so well defined edges are needed to accurately perceive a room (Gilchrist, 1979). A grey scale allowed the wall definitions to stand out more than the white, allowing for a clear understanding of the shape. Without a clear definition of the rooms boundaries the participants would struggle to interpret the space. Lighting and colour also has an effect on perception of space (Manav and Yener, 1999). A single lighting system with constant light and colour was chosen to create a consistent light dispersal over each Room. Room sequence was randomised across all participants to remove any learning trends. Words were programmed to appear at the top of the controller which stated which Room they were in with minimal visual interference. This was to reduce any confusion the participant may experience which could affect the results of the study by putting them off task. Participants were also asked an exit question of whether they had experienced any motion sickness of which zero were reported. 
Figure 109 - IMAGE

COURTESY OF ASA

INTERNATION CONFERENCE

(Griffiths L, 2017b)

Perception of space is a subjective response which requires a within subject study process to effectively remove subject to subject variation (Seltman, 2012). The dependent variables are the shaped rooms. The rooms were selected for basic shapes which allow a wide range of investigation and of which can be associated with the most typical apartment proportions and shapes. The independent variables are the sizes of a Scalable Room which the subjects manipulate. The scalable Room will be referred to as the Scale Room. The Scale room is a $50 \mathrm{~m}^{3}$ cubed room which is scaled at the end of each Room sequence to match the Room's volume. The Rooms had a baseline of $50 \mathrm{~m}^{3}$, same as the Scale Room before manipulation. However, for each participant the Rooms randomize in size within a range of -+50\% (25$75 \mathrm{~m}^{3}$. This removes a size effect bias which could affect the data output. After the matching is complete the Scale Room reverts back to $50 \mathrm{~m}^{3}$ to allow for a consistent starting point for each participant. The in experiment questions were chosen with the anchor points of enclosed - neutral - open, and strong no neutral _ strong yes, to understand the perceived spatial qualities of the rooms (table 1).

Table 1: Experiment questions

\begin{tabular}{|c|c|}
\hline Pre-experiment questions: & Post Room scaling questions: \\
\hline $\begin{array}{l}\text { 1) What is an estimate of the size of your current } \\
\text { living room in cubic meters? }\end{array}$ & $\begin{array}{l}\text { 1) On a scale to } 1 \text { (Strong No) - } 5 \text { (Neutral) - } 10 \\
\text { (Strong Yes) rate if you would like to use Room \#/ }\end{array}$ \\
\hline 2) How many people use the living room typically? & Scale room as a living room. \\
\hline $\begin{array}{l}\text { 3) How would you rate the spaciousness of your } \\
\text { current living room? } 1 \text { (Enclosed) - } 5 \text { (Neutral) - } 10 \\
\text { (open) }\end{array}$ & $\begin{array}{l}\text { 2) On a scale to } 1 \text { (Enclosed) }-5 \text { (Neutral) - } 10 \\
\text { (Open) rate the spaciousness of Room \#/ Scale } \\
\text { room? }\end{array}$ \\
\hline $\begin{array}{l}\text { 4) How would you rate the comfort of your } \\
\text { current living room? } 1 \text { (Uncomfortable) - } 5 \\
\text { (Neutral) - } 10 \text { (Comfortable) }\end{array}$ & \\
\hline $\begin{array}{l}\text { 5) How many hours a week do you play video } \\
\text { games? } \\
\text { 6) Have you used VR before? }\end{array}$ & \\
\hline
\end{tabular}

\subsection{Procedure}

Participants were individually bought into the VR laboratory and asked to fill in pre experiment questions, see table 1, and subject information. Once the experiment process was explained the subjects were introduced to the Scale Room. The experiment started with a 'size test' for each participant to determine the individual's ability to match volumes. Three cubed rooms, no shape change, with a randomly selected order were set for the size test with sizes of $30 \mathrm{~m}^{3}, 40 \mathrm{~m}^{3}$ and $60 \mathrm{~m}^{3}$. The participant had 30 seconds to explore a Room before going back to the Scale Room to best match the Room's volume size. The participants were given a 10 second warning before the end of the time limit. When the participant was confident (or as close as) that the volumes are matched they were given another the 30 seconds in the Room after which they were allowed to make any alterations. This process illustrated the individual's and the group's ability to match same shape volumes with reasonable accuracy. 
Figure 110 - IMAGE

COURTESY OF ASA

INTERNATION CONFERENCE

(Griffiths L, 2017b)
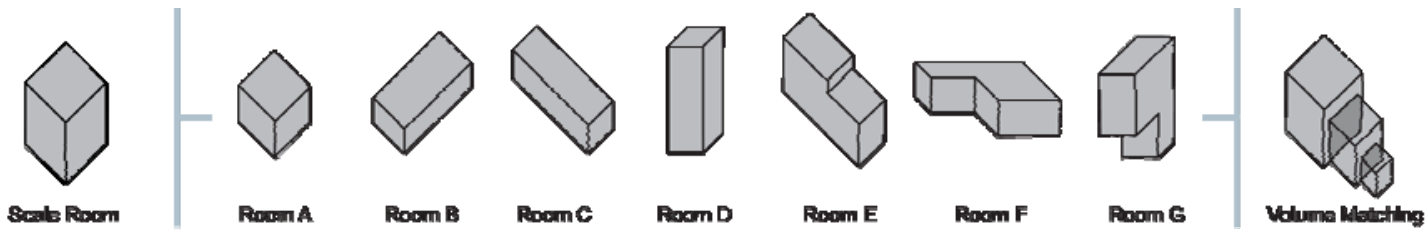

Figure 3: Virtual room shapes

For the next part of the study the subjects followed the same process with a series of different shaped rooms (Figure 3). The subjects had 30 seconds in the Room before returning to the Scale Room to match the volume. Once complete the participants were asked to verbally complete questions describing their perception of both the Scale Rooms and Shaped Room in terms of perceived liveability and spaciousness. Once the questions were completed the participant repeated the process with the subsequent Room's, as seen in figure 3 .

\subsection{Analysis strategy}

The size $\left(\mathrm{m}^{3}\right)$ of both the Rooms and the Scale room (after scaling) was recorded after each sequence. This data showed the perceived size accuracy of a room which illustrated a larger or small perceived space. For example a participant scaled the Scale Room to $50 \mathrm{~m}^{3}$ where the Room experienced was $40 \mathrm{~m}^{3}$. This illustrates that the participant perceived the Room to be $+25 \%$ or $10 \mathrm{~m}^{3}$ larger than its objective size. A positive percentage or size indicates that the volume was perceived larger than the objective size. Likewise a negative result indicates a smaller perceived size. At the end of each Room sequence the subjects were asked to rate the livability and spaciousness of both the Room and the Scale room. Questions on livability and spaciousness were asked to firstly, establish how spaciousness and liveability are effected by room shape and volume. Secondly, to establish whether they had a relationship to the accuracy in perceived size of a room, of which none was established. The data produced were numbers ranging from 1-10 with specific anchor points, see table 1.

\section{Results}

The experiment variables are the dependent variable of Room shape and volume, and the independent variable of the Scale Room volume after manipulation by the subject.

\subsection{Perception of space}

There is a clear relationship between perceived size accuracy and volume shape (Figure 4). Participants almost always overestimate the size of the room, though the effect was stronger in some rooms. Room $D$ has the largest perceived space and Room A the smallest perceived space with the same objective size (figure 4 and 5). As expected the size tests (Rooms 1-3) show minimal perceived size variance as room shape was constant. The randomization of the rooms had equal distributions around 50m3 (figure 5). There is a slight decrease in average Room size in Room B however there is an insignificant difference. 


\subsection{APPENDIX}

Figure 111 - IMAGE

COURTESY OF ASA

INTERNATION CONFERENCE

(Griffiths L, 2017b)

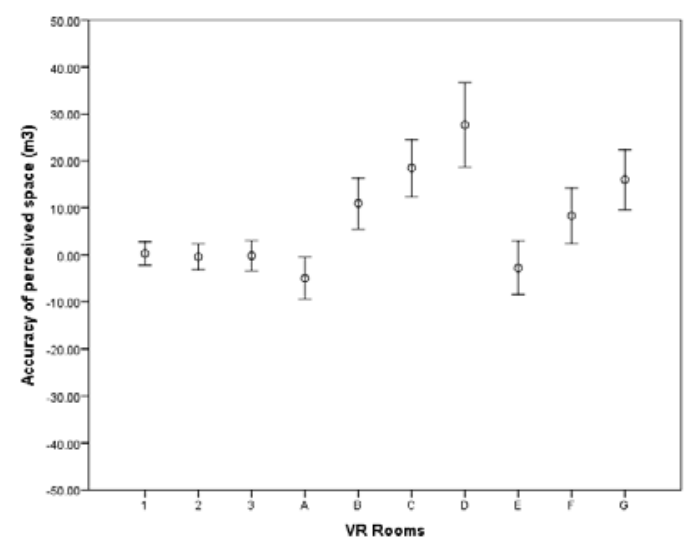

Figure 4: Accuracy of perceived space over each Room. A larger perceived space is an overestimation of the room size.

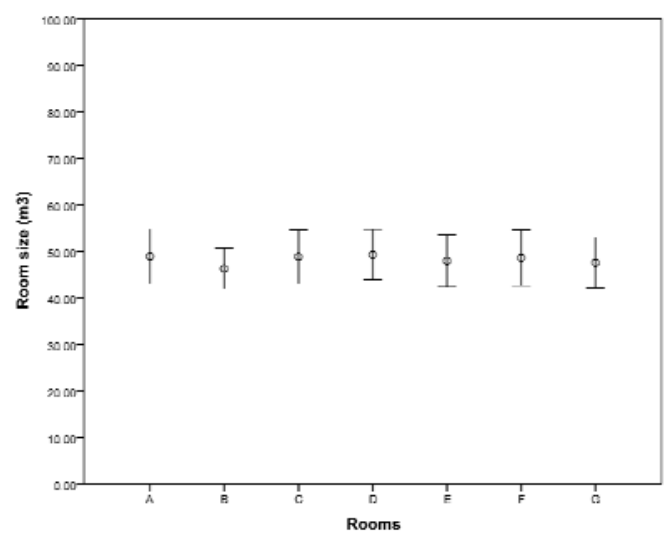

Figure 5: Average room sizes during the experiment, showing no systematic bias.

Average room width follows a moderate correlation of $r=0.545$ (Figure 6). This suggests a relationship between the two variables but suggests the possibility of other contributing factors. There is also a weak correlation between ceiling height and perceived size accuracy where $r=0.283$. This suggests that multiple contributing factors influence the perceived size accuracy of a room.

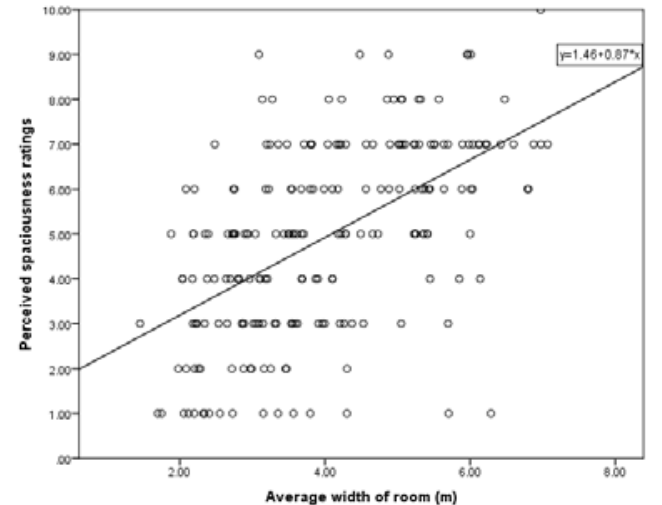

Figure 6: Moderate positive correlation between average room width and perceive spaciousness, $r=0.545$.

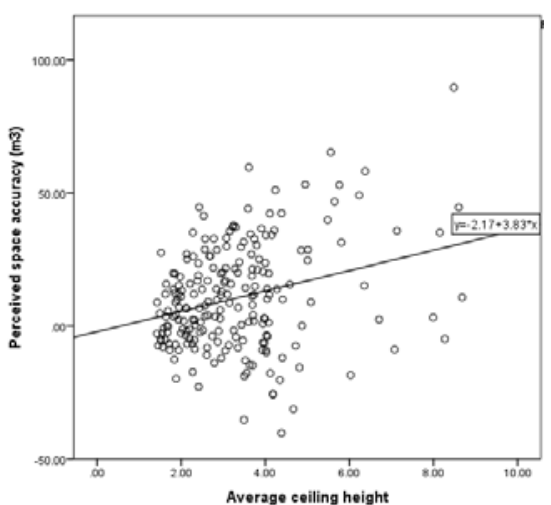

Figure 7: Weak positive correlation between ceiling height and perceived size accuracy, $r=0.283$.

As room size increases volume matching accuracy decreases (figure 8). Perceived Liveability and spaciousness is strongly correlated to perceived liveability, $r=0.872$ (Figure 9). 


\subsection{APPENDIX}

Figure 112 - IMAGE

COURTESY OF ASA

INTERNATION CONFERENCE

(Griffiths L, 2017b)

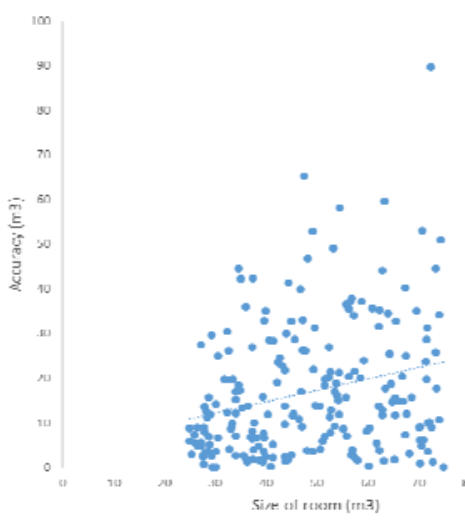

Figure 8: As room size increases the accuracy of volume matching decreases.

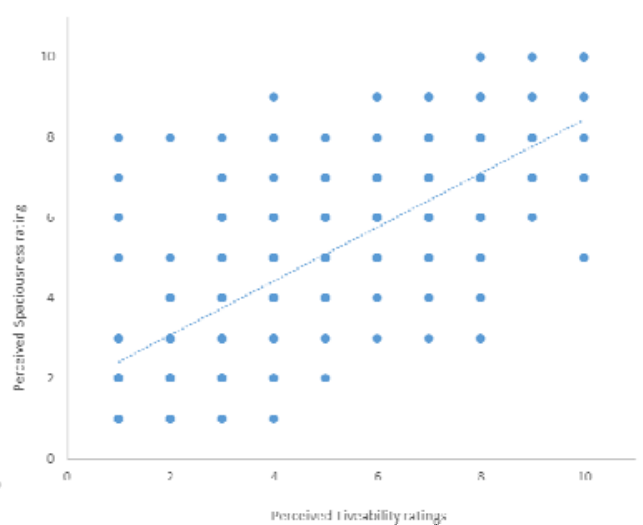

Figure 9: Positive correlation between perceived spaciousness and liveability $r=$ 0.872 .

As room size increases the optimum room shape changes. This suggests that multiple parameters determine an optimum room at a given size. This differs from our original hypothesis that perceived liveability and spaciousness would have a positive relationship to perceived size. Room $\mathrm{G}$ is the ideal room in terms of perceived spaciousness and livability at small volumes $\left(20-40 \mathrm{~m}^{3}\right)$ and Room $B$ at the large volume $\left(60-80 \mathrm{~m}^{3}\right)$. However, around 50 cubic meters $\left(40-60 \mathrm{~m}^{3}\right)$ both perceived spaciousness and liveability ratings cluster with similar results. In all room shape examples perceived spaciousness has a positive relationship to room size. However, room shape determined the rate of increase suggesting that optimum KEY: solutions can be achieved through optimising room shape and size.

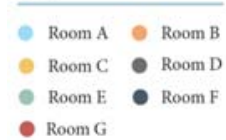

- Room A Room B Room E Room F - Room G

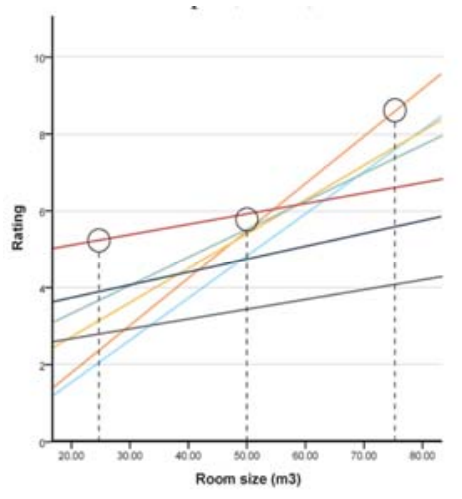

Figure 10: As room size increases perceived liveability also increases at varied rates of room shape.

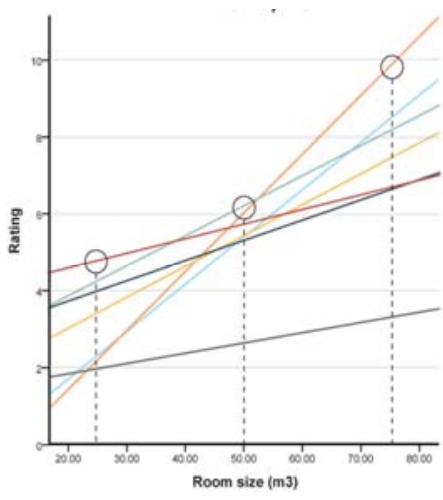

Figure 11: As room size increases perceived spaciousness also increases at varied rates of room shape.

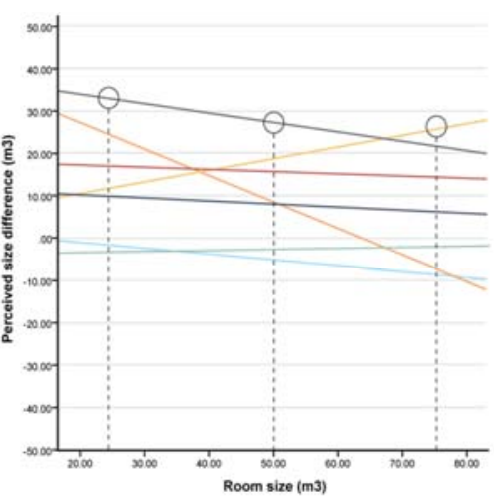

Figure 12: The rate of subjective size increase over objective size typically decreases as size increases. 
Figure 113 - IMAGE COURTESY OF ASA

INTERNATION CONFERENCE

(Griffiths L, 2017b)

\subsection{Discussion}

This study used VR to measure the effect of room shape and volume on perceived space. Overall, room spaciousness was correlated with average width, suggesting that people base judgements of spaciousness on room width. These results support research by Hayward and Franklin (1974), who found that room depth and perceived openness had a positive correlation. However, perceived room size was only weakly correlated with ceiling height, suggesting that other parameters could be contributing also. The correlation, though weak, is supportive of research by Piaget (1976), who found that conservation of space was generally restricted to one dimension of an object which was typically height. Alternatively, the increased ceiling height simply increases the difficulty to accurately perceive a room's size. This interpretation is supported by Figure 8 showing that as room size increases perceived room size accuracy decreases. Research by Sadalla and Oxley (1984), contrary to the results suggesting ceiling height influences perceived size, state that a greater length over width ratio forms a larger perceived space. Room D, which was the largest perceived space, had the smallest length/width ratio. The method used could influence the results produced by Sadalla and Oxley (1984) through a purely two dimensional investigation using perspective lines to gage perceived size. This possibly influenced the results leading to room height as an insignificant contributing factor. Their process differs from a VR experiment in that the perceived space is three dimensional and participants have the opportunity to look up and around.

A negative relationship between perceived size accuracy and actual room size suggests that psychological space is more impactful at smaller volumes. However, as room size increases accuracy decreases (figure 8). This would indicate that as the room increases in size the data associated in perceived size becomes less reliable. Therefore any trends taken from Figure 12 would need to be confirmed by further research. Though Room D met requirement (1) the room did not meet requirement (2) suggesting that an optimum room needs to utilise multiple parameters to meet both requirements. Due to multiple parameters contributing towards forming an ideal room further research is needed to investigate the optimum relationships between them. It is suggested that there are thresholds in parameters which cause significant change in perceived space. It is essential to establish parameter thresholds which vary responses of perceived livability, spacious and size as larger rates. This has been suggested in Room D which, compared to the other rooms, had a comparatively lower average room width resulting in a significantly reduced perceived spaciousness and liveability. Likewise, in Room D with comparatively larger ceiling height produced a significantly larger perceived size. Establishing the crucial thresholds and understanding how they relate is fundamental to developing accurate and useful optimum design parameters. Currently the research illustrates that the height and width of a room influence perceived liveability, spacious and size. With this knowledge the perceived space in high density architecture can be optimised. However, due to the abstract nature of the virtual rooms further studies are needed to determine any additional parameters in more complex environments.

\section{Conclusion}

Overall, the method achieved the desired output of basic optimum design parameters. The data suggests that ceiling height is a contributing parameter to perceived room size accuracy and that average room width contributes to perceived spaciousness ratings. However, perceived size and perceived spaciousness are attributed to different parameters and did not directly correlate. Further research is required to establish the parameter relationships to form optimum room requirements (1) 
Figure 114 - IMAGE COURTESY OF ASA

INTERNATION CONFERENCE

(Griffiths L, 2017b)

and (2). This research acts as a foundation for future research which will expand and refine parameters and their relationships to produce optimum design strategies. A subsequent experiment would investigate what proportions of a room shape produces the optimum perceived room increase and optimum perceived spaciousness and livability. High density design can be optimized with this method to find the optimum efficiency of a volume. This research produces foundational parameters of height and width to form architectural strategies which could optimize spatial design. Further research would refine the parameters and method to form a full optimization of high density architecture.

\section{References}

Baldassare, M. (1979) Residential crowding in urban America, ed., Univ of California Press.

Booth, A. and Cowell, J. (1976) Crowding and health, Journal of Health and Social Behavior, 204-220.

Bosselmann, P. (2012) Urban transformation: Understanding city form and design, ed., Island Press.

Cohen, S., Evans, G. W., Stokols, D. and Krantz, D. S. (2013) Behavior, health, and environmental stress, ed., Springer Science \& Business Media.

Cox, W. (2015) Demographia world urban areas, 11th Annual Edition ed. St. Louis: Demographia. Available: http://www. demographia. com/db-worldua. pdf. Date of access, 30, 2015.

Evans, G. W. and McCoy, J. M. (1998) When buildings don't work: the role of architecture in human health, Journal of Environmental psychology, 18(1), 85-94.

Evans, G. W., Wells, N. M. and Moch, A. (2003) Housing and mental health: a review of the evidence and a methodological and conceptual critique, Journal of social issues, 59(3), 475-500.

Gilchrist, A. L. (1979) The perception of surface blacks and whites, ed., WH Freeman.

Hayward, S. C. and Franklin, S. S. (1974) Perceived openness-enclosure of architectural space, Environment and Behavior, 6(1), 37-52.

Judd, D. B. (1940) Hue saturation and lightness of surface colors with chromatic illumination, JOSA, 30(1), 2-32.

Kopec, D. A. (2006) Environmental psychology for design, ed., Fairchild New York.

Manav, B. and Yener, C. (1999) Effects of different lighting arrangements on space perception, Architectural Science Review, 42(1), 43-47.

Nations, U. (2014) World Urbanization Prospects: The 2014 Revision, Highlights. Department of Economic and Social Affairs, Population Division, United Nations.

Ojose, B. (2008) Applying Piaget's theory of cognitive development to mathematics instruction, The Mathematics Educator, 18(1).

Piaget, J. (1976) Piaget's theory, Handbook of child psychology, 1.

Sadalla, E. K. and Oxley, D. (1984) The Perception of Room Size The Rectangularity Illusion, Environment and Behavior, 16(3), 394-405.

Schnabel, M. A. and Kvan, T. (2003) Spatial understanding in immersive virtual environments, International Journal of Architectural Computing, 1(4), 435-448.

Seltman, H. J. (2012) Experimental design and analysis, Pittsburgh: Carnegie Mellon University, 428.

Siegler, R. S., DeLoache, J. S. and Eisenberg, N. (2003) How children develop, ed., Macmillan.

Solari, C. D. and Mare, R. D. (2012) Housing crowding effects on children's wellbeing, Social science research, 41(2), 464-476.

Stokols, D. (1976) The experience of crowding in primary and secondary environments, Environment and Behavior, 8(1), 49-86.

Stokols, D., Rall, M., Pinner, B. and Schopler, J. (1973) Physical, social, and personal determinants of the perception of crowding, Environment and Behavior, 5(1), 87.

Wong, S.-K., Lai, L. W.-C., Ho, D. C.-W., Chau, K.-W., Lam, C. L.-K. and Ng, C. H.-F. (2009) Sick building syndrome and perceived indoor environmental quality: A survey of apartment buildings in Hong Kong, Habitat International, 33(4), 463-471.

Worchel, S. (1978) Reducing crowding without increasing space: Some applications of an attributional theory of crowding, Population \& Environment, 1(3), 216-230. 